\title{
Multifamily Tool for Energy Audits (MulTEA) Engineering Manual (Version 1)
}

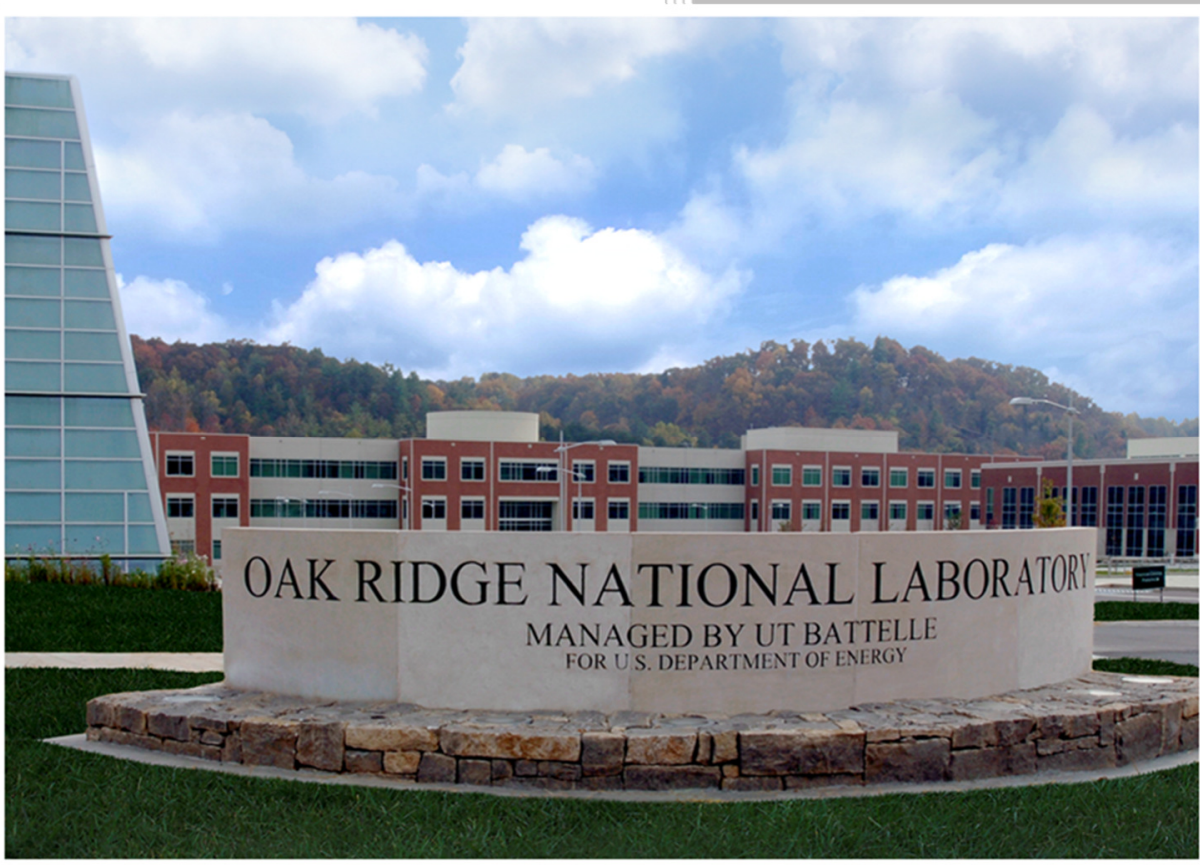

Mini Malhotra, $\mathrm{PhD}$ Piljae Im, PhD Gina Accawi Mark Ternes Mike MacDonald

August 2018 


\section{DOCUMENT AVAILABILITY}

Reports produced after January 1, 1996, are generally available free via US Department of Energy (DOE) SciTech Connect.

Website www.osti.gov

Reports produced before January 1,1996, may be purchased by members of the public from the following source:

National Technical Information Service

5285 Port Royal Road

Springfield, VA 22161

Telephone 703-605-6000 (1-800-553-6847)

TDD 703-487-4639

Fax 703-605-6900

E-mailinfo@ntis.gov

Website http://classic.ntis.gov/

Reports are available to DOE employees, DOE contractors, Energy Technology Data Exchange representatives, and International Nuclear Information System representatives from the following source:

Office of Scientific and Technical Information

PO Box 62

Oak Ridge, TN 37831

Telephone 865-576-8401

Fax 865-576-5728

E-mail reports@osti.gov

Website http://www.osti.gov/contact.html

This report was prepared as an account of work sponsored by an agency of the United States Government. Neither the United States Government nor any agency thereof, nor any of their employees, makes any warranty, express or implied, or assumes any legal liability or responsibility for the accuracy, completeness, or usefulness of any information, apparatus, product, or process disclosed, or represents that its use would not infringe privately owned rights. Reference herein to any specific commercial product, process, or service by trade name, trademark, manufacturer, or otherwise, does not necessarily constitute or imply its endorsement, recommendation, or favoring by the United States Government or any agency thereof. The views and opinions of authors expressed herein do not necessarily state or reflect those of the United States Government or any agency thereof. 
Energy and Transportation Science Division

MULTIFAMILY TOOL FOR ENERGY AUDITS (MULTEA) ENGINEERING MANUAL (VERSION 1)

\author{
Mini Malhotra, $\mathrm{PhD}$ \\ Piljae Im, PhD \\ Gina Accawi \\ Mark Ternes \\ Mike MacDonald
}

Date Published: August 2018

\author{
Prepared by \\ OAK RIDGE NATIONAL LABORATORY \\ Oak Ridge, TN 37831-6283 \\ managed by \\ UT-BATTELLE, LLC \\ for the \\ U.S. DEPARTMENT OF ENERGY \\ under contract DE-AC05-00OR22725
}





\section{TABLE OF CONTENTS}

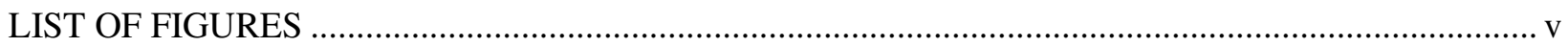

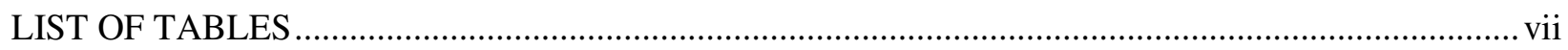

ABBREVIATIONS, ACRONYMS, AND INITIALISMS ….................................................... ix

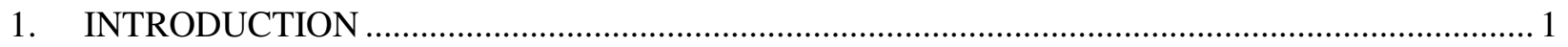

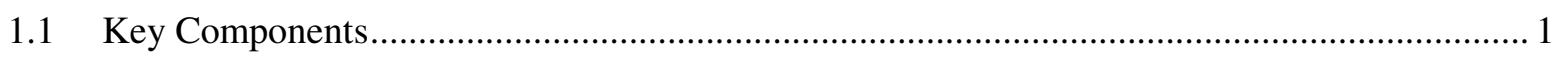

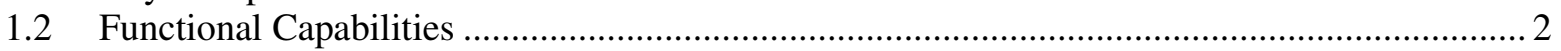

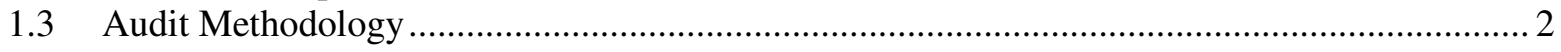

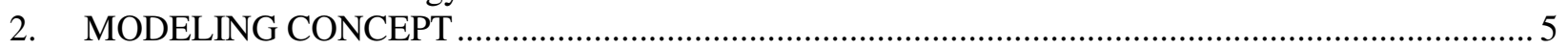

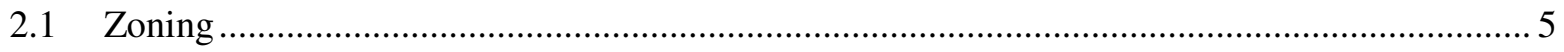

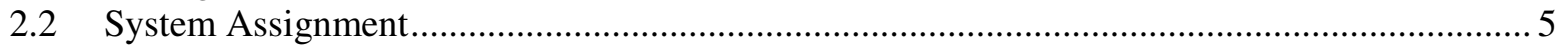

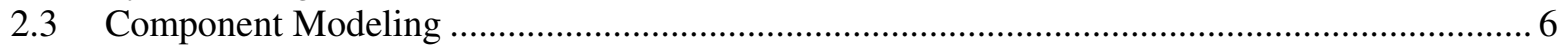

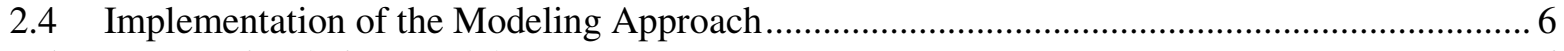

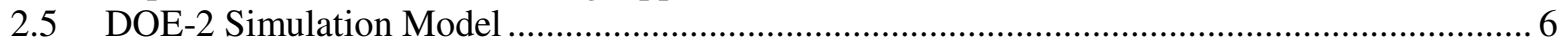

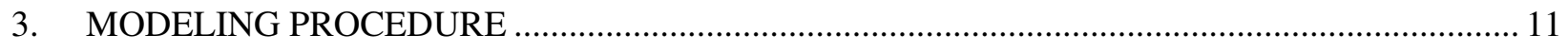

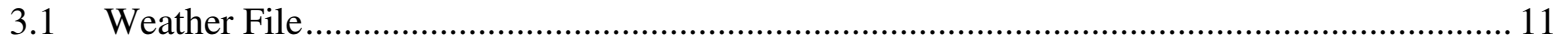

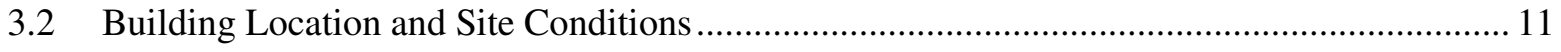

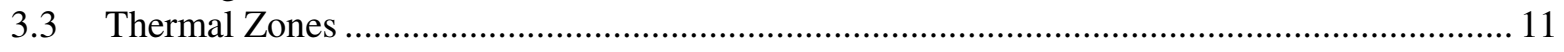

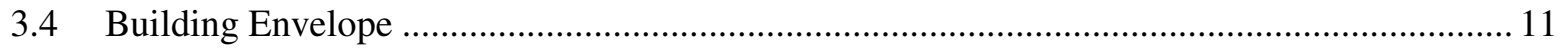

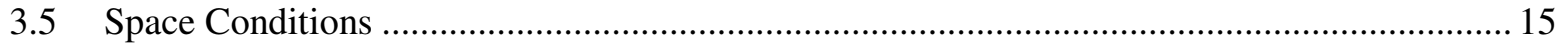

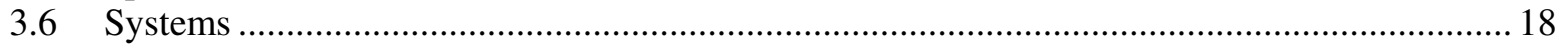

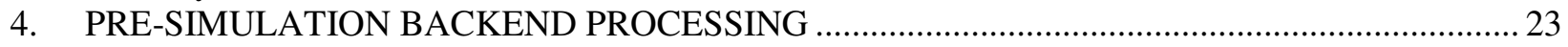

4.1 Determining Existance of Space, Zone and Shell Objects.................................................. 23

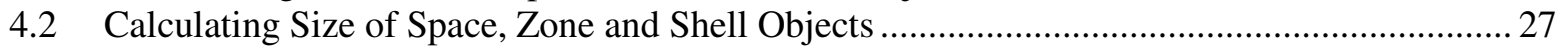

4.3 Determining Properties of Opaque Construction Layers ........................................................... 33

4.4 Calculating Air Leakage Reduction from Window and Door Retrofits.................................. 43

4.5 Calculating Reduced Lighting Power Density and Wattage for Lighting Retrofits.................. 44

4.6 Calculating Reduced Appliance Power Density for Refrigerator Replacement ...................... 45

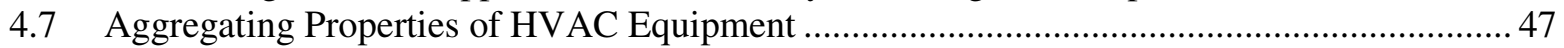

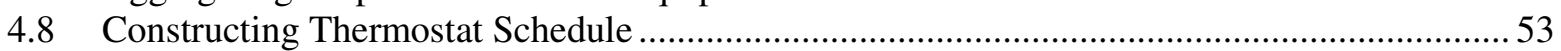

4.9 Calculating Equivalent EF and RE for Water Heater Tank Insulation and Pipe Insulation ......54

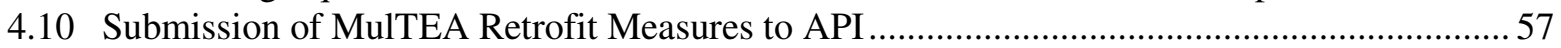

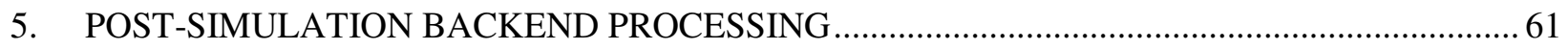

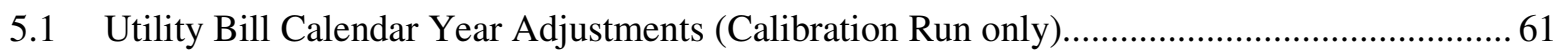

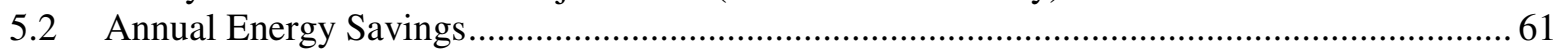

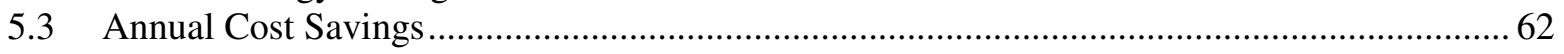

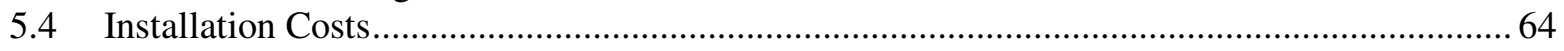

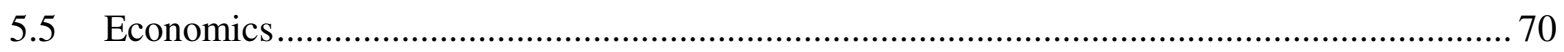

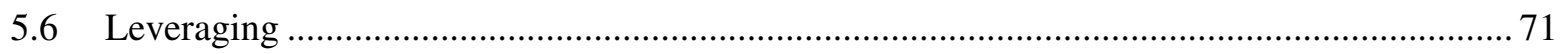

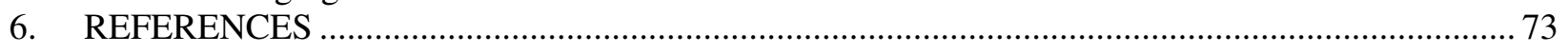

APPENDIX A. LOOKUP TABLES AND ASSUMPTIONS …....................................................

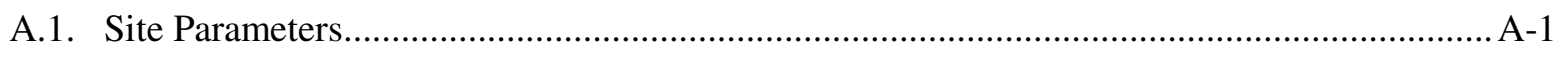

A.2. Properties of Materials for Wall, Roof and Floor .......................................................... A-1

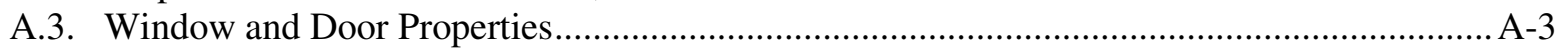

A.4. Shipment Weighted Equipment Efficiencies ................................................................. A-6

A.5. Storage Type Natural Gas Water Heaters Listed in 2012 AHRI Directory ........................... A-9

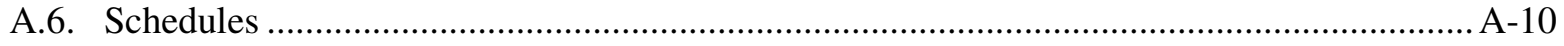

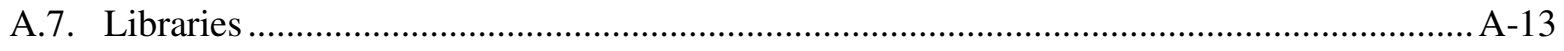

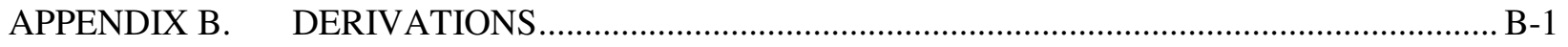


B.1. Modified Zone Method for Metal Stud Walls with Insulated Cavities................................. B-1

B.2. Perimeter Conduction Factor for Ground-Coupled Surfaces ............................................. B-2

B.3. Width of Wall Segments, Windows and Doors …............................................................... B-8

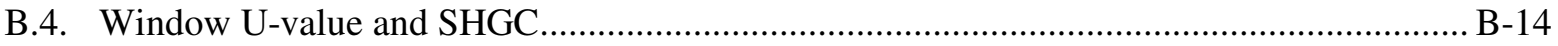

B.5. Slope and Coefficients for R-value Modifier to Account for Storm Doors and Windows ... B-16

B.6. Equivalent RE and EF for Water Heater Tank Insulation and Pipe Insulation.................... B-17

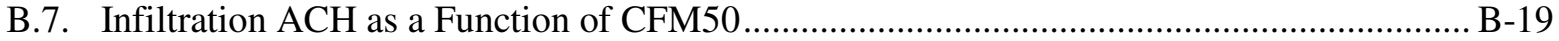




\section{LIST OF FIGURES}

Figure 1.1. Key components of MulTEA.

Figure 2.1. Examples of multifamily building configurations addressed by the proposed zoning scheme.

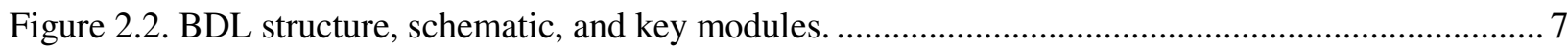

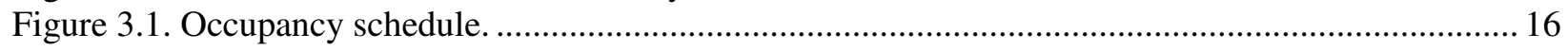

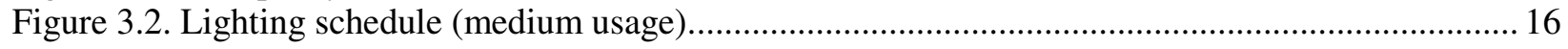

Figure 3.3. Appliance usage schedule (medium usage) ....................................................................... 17

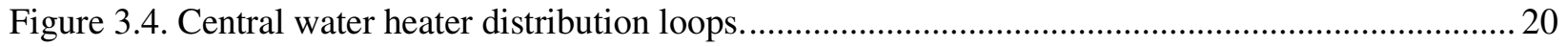

Figure A.5.1. Statistics of natural gas storage domestic water heaters listed in AHRI directory. ............ A-9

Figure A.5.2. Curve-fit between water heater EF and RE. ............................................................... A-9

Figure B.1.1. Modified Zone Method for calculating R-value of metal stud walls with insulated

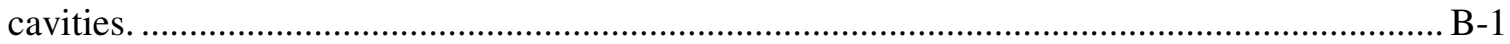

Figure B.1.2. Curve-fit for coefficients of $z_{f}$ as a function of stud size. ……................................ B-2

Figure B.2.1. Typical slab-on-grade floor insulation locations .......................................................... B-3

Figure B.2.2. Method for determining $F 2$ for slab-on-grade floor as a function of carpet fraction,

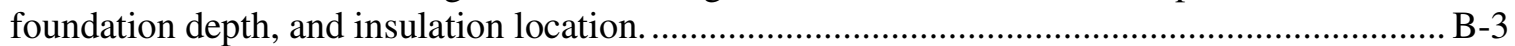

Figure B.2.3. Typical basement wall insulation configurations..................................................... B-4

Figure B.2.4. Method for determining $F 2$ for basement wall as a function of underground wall

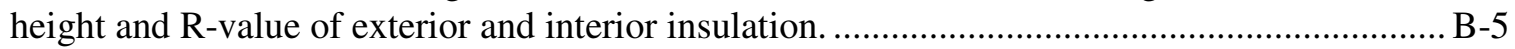

Figure B.2.5. Typical crawlspace wall insulation configurations ...................................................... B-6

Figure B.2.6. Method for determining $F 2$ for crawlspace wall as a function of crawlspace wall

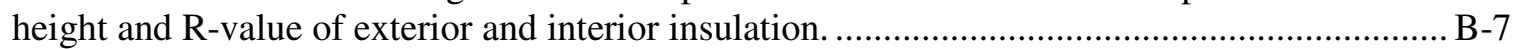

Figure B.5.1. Curve-fit for window R-value with a storm window............................................ B-16

Figure B.5.2. Curve-fit for door R-value with a storm door.......................................................... B-17 



\section{LIST OF TABLES}

Table 3.1. Determining individual water heater name plate information .............................................. 21

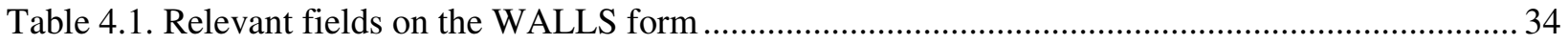

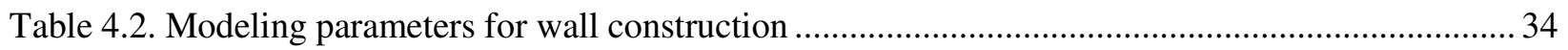

Table 4.3. Coefficients for calculating perimeter conduction factor for underground wall...................... 35

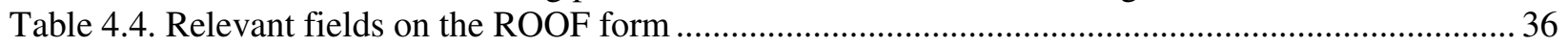

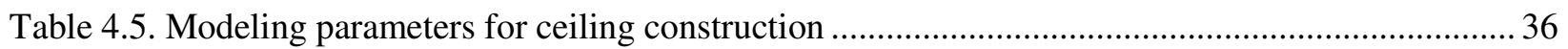

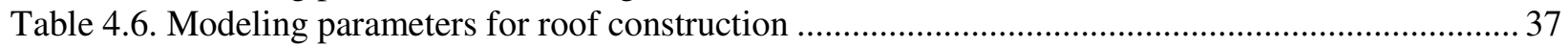

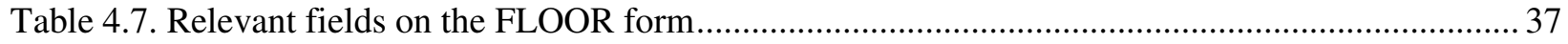

Table 4.8. Modeling parameters for floor construction ....................................................................... 38

Table 4.9. Coefficients for calculating perimeter conduction factor for slab-on-grade floor ..................... 39

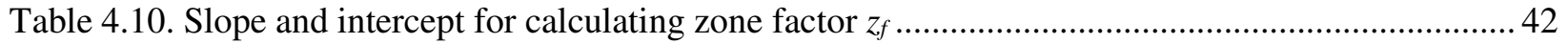

Table 4.11. Calculating zone infiltration CFM reduction from window and door leakage reduction ........ 43

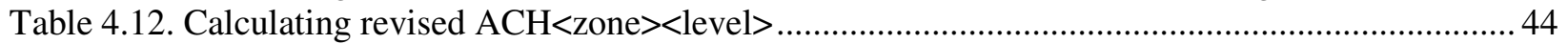

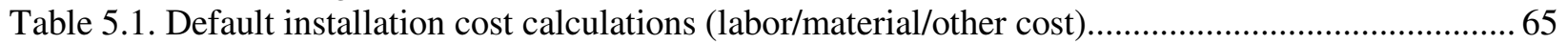

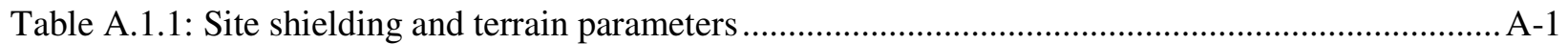

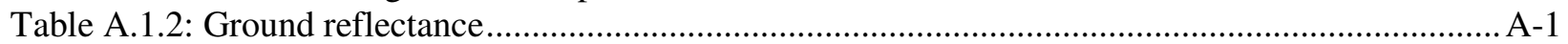

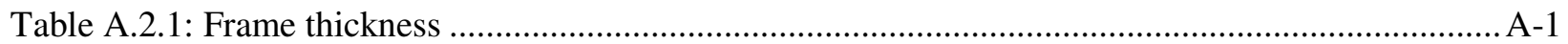

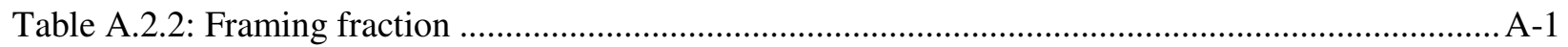

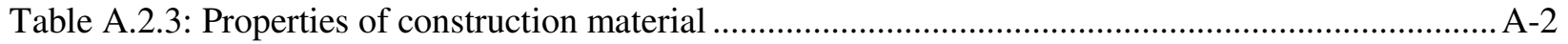

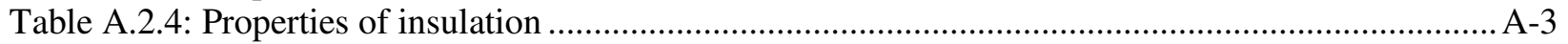

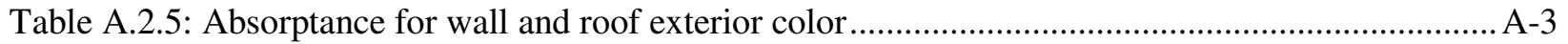

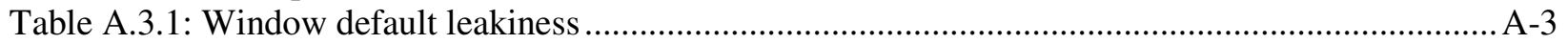

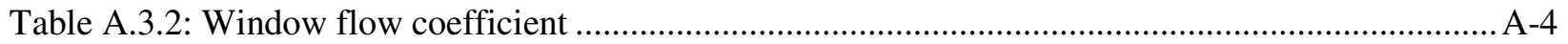

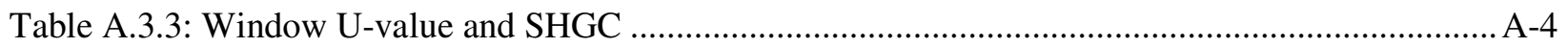

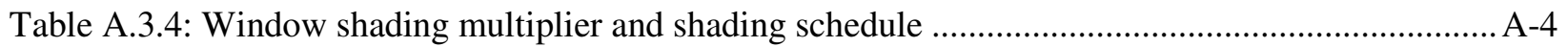

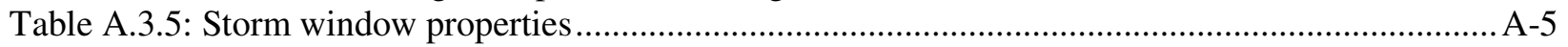

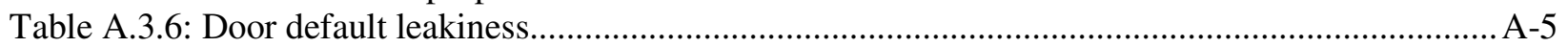

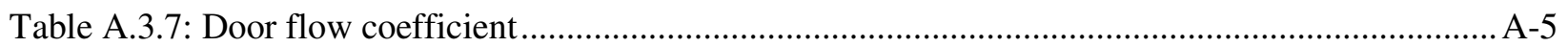

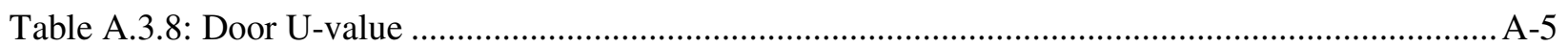

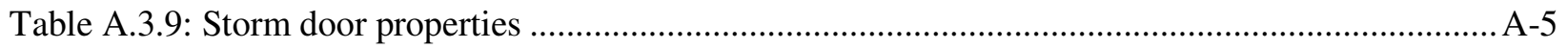

Table A.4.1: Shipment weighted heating and cooling equipment efficiency ..................................... A-6

Table A.4.2: Shipment weighted energy factor (SWEF) for storage water heaters ................................ A-7

Table A.4.3: Shipment weighted efficiency factor (SWEF) for refrigerators..................................... A-8

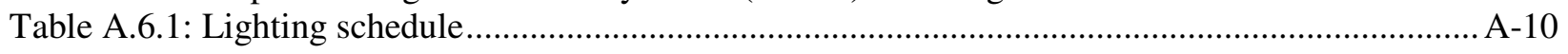

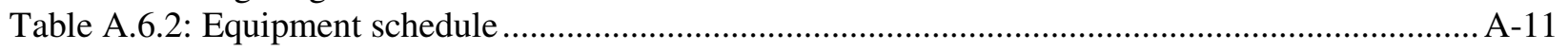

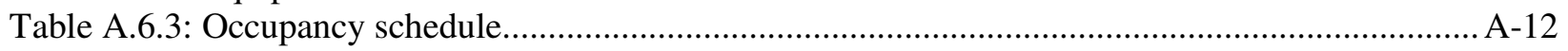

Table A.7.1: Measure lifetimes .................................................................................................. A-13

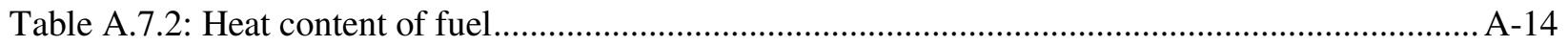

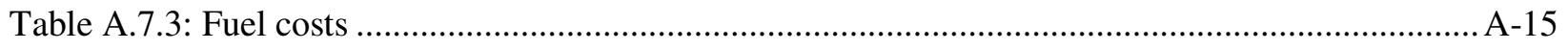

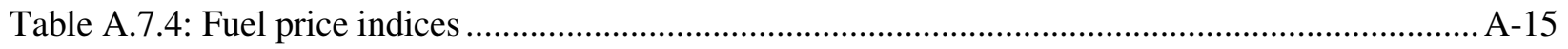

Table B.1.1: Coefficients of $z_{f}$ for different metal stud sizes ......................................................... B-2

Table B.1.2: Curve-fit for coefficients of $x^{n}$ for metal-frame wall ................................................. B-2

Table B.2.1: Perimeter conduction factor $(F 2)$ for selected slab-on-grade floor configurations .............. B-3

Table B.2.2: Curve-fit for $F 2$ as a function of carpet fraction for slab-on-grade floor ........................... B-4

Table B.2.3: Curve-fit for $m_{H}$ and $n_{H}$ as a function of foundation depth ............................................ B-4

Table B.2.4: Perimeter conduction factor $(F 2)$ for selected basement wall configurations..................... B-5

Table B.2.5: Curve-fit for $F 2$ for basement wall as a function of underground wall depth..................... B-5

Table B.2.6: Curve-fit for $m_{\text {Rext }}$ and $n_{\text {Rext }}$ as a function of exterior insulation R-value ........................... B-6 
Table B.2.7: Perimeter conduction factor $(F 2)$ for selected crawlspace wall configurations

Table B.2.8: Curve-fit for $F 2$ for crawlspace wall as a function of crawlspace wall height.................... B-7

Table B.2.9: Curve-fit for $m_{\text {Rext }}$ and $n_{\text {Rext }}$ as a function of exterior insulation R-value........................... B-8

Table B.3.1. GUI inputs versus modeling parameters for vertical surfaces........................................... B-9

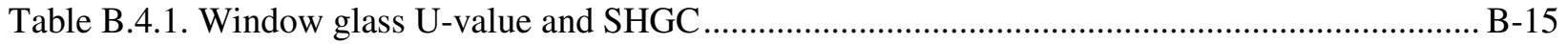

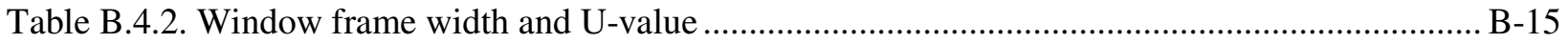

Table B.5.1. Window R-value without and with a storm window ..................................................... B-16

Table B.5.2. Window transmittance without and with a storm window ............................................ B-16

Table B.5.3. Door U-value without and with a storm door............................................................. B-16 


\section{ABBREVIATIONS, ACRONYMS, AND INITIALISMS}

$\mathrm{ACH} \quad$ air changes per hour

AHRI Air-conditioning, Heating and Refrigeration Institute

AMY actual meteorological year

API application programming interface

BDL Building Description Language

CAC central air conditioning

CFM50 cubic feet per minute at $50 \mathrm{~Pa}$ pressure difference

CFR Code of Federal Regulations

DHW domestic hot water

DOE US Department of Energy

DOE-2 DOE-2 Building Energy Analysis Program

EF energy factor

GUI graphical user interface

HESpro Home Energy Saver-Professional Tool

HP heat pump

HPWH heat pump water heater

HVAC heating, ventilation, and air conditioning

IID intermittent ignition device

LBNL Lawrence Berkeley National Laboratory

MulTEA Multifamily Tool for Energy Audits

NFRC National Fenestration Rating Council

ORNL Oak Ridge National Laboratory

RE recovery efficiency

SHGC solar heat gain coefficient

SPP simple payback period

SIR savings-to-investment ratio

SPP simple payback period

SWEF shipment-weighted energy factors or shipment weighted efficiency

TMY3 typical meteorological year 3

UPV uniform present value

WHAM Water Heater Analysis Model 



\section{INTRODUCTION}

The Multifamily Tool for Energy Audits (MulTEA) is an energy audit tool designed to provide auditors with an improved energy simulation tool for multifamily buildings and an improved tool for identifying cost-effective energy-efficiency retrofit measures for multifamily buildings. MulTEA is designed specifically to help states and local weatherization agencies implement the Department of Energy (DOE) Weatherization Assistance Program. MulTEA was developed jointly by the Oak Ridge National Laboratory (ORNL) and the Lawrence Berkeley National Laboratory (LBNL).

MulTEA is part of ORNL's web-based Weatherization Assistant suite of audit tools (https://weatherization.ornl.gov/softwaredescription/). The energy calculation engine including the DOE2 simulation model and supplementary calculation modules is shared by MulTEA and LBNL's Home Energy Saver pro (HESpro) (http://hespro.lbl.gov/pro/). On the ORNL side, the energy calculation engine is coupled with a user interface and output reporting capabilities based on Weatherization Assistance Program regulations and guidelines pertinent to MulTEA. On the LBNL side, the same engine will be used in HESpro to expand it to handle multifamily buildings.

MulTEA is designed to address small and large multifamily buildings with decentralized and centralized heating, ventilation, and air-conditioning (HVAC) and domestic hot water (DHW) systems. Version 1 of MulTEA addresses small multifamily buildings with decentralized HVAC systems, and decentralized or centralized DHW systems. The capability to model large buildings and centralized HVAC systems will be incorporated in Version 2.

MulTEA evaluates each building individually after considering the local weather conditions, retrofit measure costs, fuel costs, and specific construction and operation details of the building. After the envelope components, heating and cooling systems, and base load equipment (e.g., water heaters, lighting and equipment) are described, the energy consumption of the existing building can be estimated and calibrated to actual energy consumption (i.e., utility bills). After an auditor defines and selects the retrofit measures to be analyzed, MulTEA produces a prioritized list of the weatherization measures for the building being evaluated. The output includes estimates of the energy savings, dollar savings, installation cost, and savings-to-investment ratio (SIR) for each recommended measure and for the package of recommended measures to be installed. A method of determining the amount of leveraged funds needed to make the DOE Weatherization Assistance Program investment cost effective for each selected measure is also provided.

\subsection{KEY COMPONENTS}

MulTEA comprises three key components, as shown in Figure 1.1. The graphical user interface (GUI) and backend reside on the ORNL side. On the LBNL side, the application programming interface (API) hosts the energy calculation capabilities of MulTEA. The following sections describe the functions of these components.

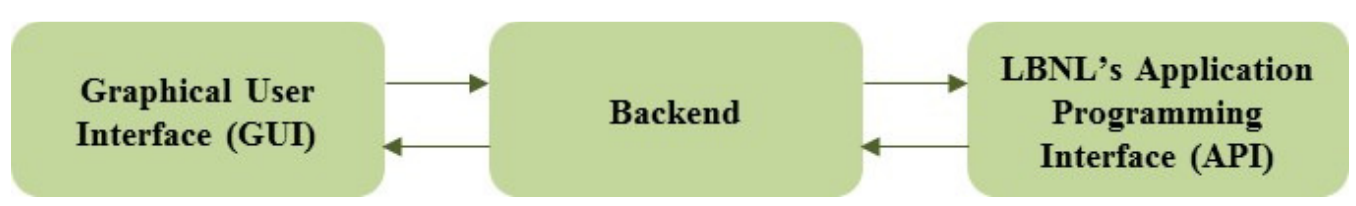

Figure 1.1. Key components of MulTEA. 


\subsubsection{Graphical User Interface}

MulTEA's GUI consists of data input forms (to enter audit details, describe the building and retrofit measures, and enter utility bills), library forms (to enter measure costs, fuel costs, and economic parameters that are used for calculating the SIR of retrofit measures), buttons to perform audit runs, and output forms and reports that provide results.

\subsubsection{Backend}

MulTEA's backend consists of a database that stores the user input data and lookup tables. The backend also contains algorithms for performing pre-simulation calculations (e.g., converting GUI inputs to parameters needed by LBNL's API for performing simulations, performing utility bills adjustments); submitting base case, individual retrofits, and retrofit packages to LBNL's API; and performing postsimulation calculations (e.g., to convert energy use results from the simulation output to energy savings, cost savings, and SIRs).

\subsubsection{LBNL's Application Programming Interface}

MulTEA uses the DOE-2 energy simulation engine with weather files to estimate the energy consumption of analyzed buildings. The DOE-2 Building Description Language (BDL) file describes the building and systems to simulate heating and cooling energy use through the DOE-2 simulation engine. The DOE-2 engine, weather files, and BDL reside on LBNL's API. The weather files include actual meteorological year (AMY) weather data for building energy model calibration and typical meteorological year (TMY3) weather data for 1,020 US weather stations for retrofit analysis.

LBNL's API also includes supplementary modules, such as the "Domestic Hot Water Model" based on the Water Heater Analysis Model (WHAM) (Lutz 1998) that calculates hot water loads and water heating energy use, and algorithms to convert ORNL submissions to BDL inputs and inputs to the supplementary modules.

\subsection{FUNCTIONAL CAPABILITIES}

MulTEA provides five primary functional capabilities:

1. Predicting the energy use of the existing/base case building

2. Reconciling the predicted energy use of the existing/base case building to utility bills

3. Determining the energy savings of retrofit measures

4. Estimating the installation costs of retrofit measures

5. Performing economic calculations to estimate the cost effectiveness of retrofit measures

\subsection{AUDIT METHODOLOGY}

To perform an energy audit, MulTEA requires users to conduct three runs:

1. The Calibration Run analyzes the existing/base case building and provides yearly and monthly estimates of building energy consumption by end use (heating, cooling, water heating, lighting, and appliances) and fuel type (electricity and fossil fuel).

2. The Retrofit Measures run estimates the energy savings of each retrofit measure activated and described by the user on the GUI forms as if it were applied individually to the existing/base case building (i.e., as if it were the only measure applied to the building). This usually provides the 
maximum possible savings for each measure, since there is only one retrofit being applied to the building at a time and thus no measure interactions.

3. The Retrofit Package Run applies each selected measure to the building in decreasing order of its SIR when applied individually to the building. New SIRs are calculated for each measure that reflect measure interaction and are usually less than the initial SIRs. A package SIR is also calculated. 



\section{MODELING CONCEPT}

This section describes the concept of a multizone, flexible DOE 2.1e simulation model formulated to provide detailed modeling capability with a simplified user interface. It describes how the building and its spaces are set up, surfaces are attached to spaces, internal heat gains are modeled, and systems are assigned to zones.

Energy simulation is a very powerful approach, and its benefits are often enticing. However, an excessive focus on detailed modeling may provide only marginal benefits and compromise the usability of the tool. At the same time, oversimplification of audit inputs may undermine the benefits of simulation. Therefore, optimal levels of modeling detail and audit input simplifications are needed. The following discussion presents general criteria that guided the modeling approach for MulTEA.

\subsection{ZONING}

Multifamily buildings typically have dwelling units facing different orientations and may have dissimilar floors, common areas (open or enclosed, conditioned or unconditioned), and vertically connected spaces (e.g., stairwells and shafts). Multiple thermal zones are required to adequately model the impact of the energy interactions of a zone with the outdoors and with attached dissimilar zones, and to evaluate zone-specific retrofit measures. Modeling the energy interactions of a zone with the outdoors requires separate zones for corner units and embedded units facing different orientations. Modeling a zone's energy interactions with attached dissimilar zones requires separate zones for common areas.

Dividing the building into too many zones may increase modeling errors. Therefore, for Version 1 of MulTEA to have a reasonable number of zones, only four typical floor types (i.e., top floor, intermediate floor with a floor-multiplier, first floor, and below-ground floor) are modeled. On each floor, multiple thermal zones for dwelling units having dissimilar exposures are modeled with zone multipliers. In addition, one thermal zone for each of the following is modeled on each floor: enclosed hallway (conditioned or unconditioned), other conditioned spaces (aggregated), and other unconditioned spaces (aggregated). Zones for an attic space and a crawlspace are also incorporated in the model. Figure 2.1 shows examples of multifamily building configurations addressed by the proposed zoning scheme and highlights typical floors and dwelling unit zones required for modeling different building configurations.

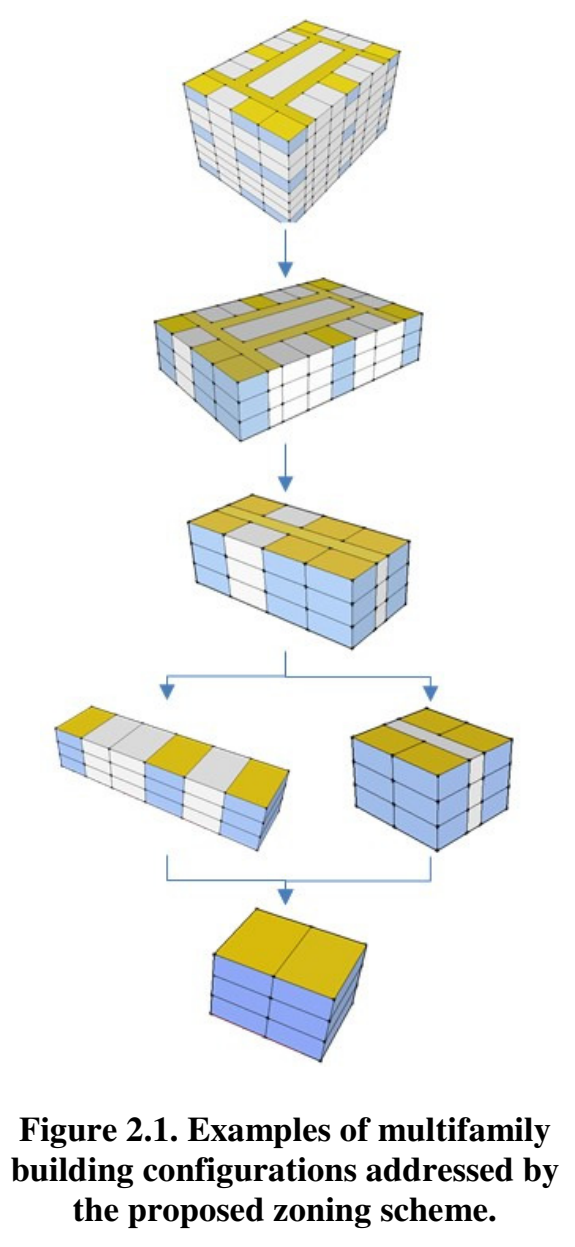

\subsection{SYSTEM ASSIGNMENT}

HVAC and DHW systems in multifamily buildings may be centralized, decentralized, or a combination of both. The characteristics, loads seen by the system, operation and efficiency under part-load conditions, and retrofit measures are all quite different for centralized versus decentralized systems. Therefore, modeling systems and assigning them to zones to reasonably represent the installed configuration is important. The model is developed to handle decentralized systems in all the thermal zones described, a 
centralized system serving a whole building (to be implemented in Version 2, with the exception of centralized DHW, which is implemented in Version 1), or a combination of decentralized systems serving dwelling units and a centralized system serving common areas of the building (to be implemented in Version 2).

\subsection{COMPONENT MODELING}

Building components and associated retrofit measures that impact heating or cooling energy use directly or indirectly (e.g., shell, HVAC system, indoor lighting, and appliances) must be analyzed as part of the whole-building energy simulation. However, some of these components and measures are hard to model accurately within DOE-2. For these components and measures, side calculations estimate effective component performance (e.g., effective R-value for roof or ceiling with radiant barrier in the attic, effective U-value for storm door and windows, appliance power density adjustment to account for refrigerator replacement), or user input is required for evidence-based component performance estimates (such as efficiency improvement for an HVAC system tune up, air changes per hour for infiltration), which are run through DOE-2. Components and measures that have non-interactive energy impacts (e.g., exterior lighting, DHW system) are handled outside DOE-2.

The level of analysis and modeling detail is determined by considering the role and treatment of a component in the building energy audit process. In general, the Weatherization Assistance Program allows retrofit measures that involve materials listed in Appendix A of 10 CFR Part 440 (US GPO 2005) or that are approved by DOE on a case-by-case basis. Analysis of these measures requires detailed modeling of components that are candidates for retrofit. Other components may be analyzed using aggregated or averaged inputs without compromising the modeling benefits.

Variations among dwelling units in terms of characteristics of the shell component, indoor conditions, systems, occupancy, and schedules are handled through aggregated or averaged modeling input. Thus, all dwelling units are modeled as identical zones in all respects except for variations in exposure, which are handled well through the zoning scheme described previously. Aggregated or averaged modeling inputs are also used to combine multiple common areas existing on a floor into one thermal zone.

\subsection{IMPLEMENTATION OF THE MODELING APPROACH}

The modeling approach is implemented at two levels: MulTEA's GUI and the DOE-2.1e simulation model (or BDL). These are connected through algorithms that convert GUI input to BDL input. These key components collectively ensure that the desired modeling capabilities are addressed in the BDL without complicating the data input process in the GUI. The algorithms also prepare input for the supplementary analysis modules (such as WHAM) outside DOE-2.

\subsection{DOE-2 SIMULATION MODEL}

\subsubsection{Structure and Schematic of the BDL}

Figure 2.2 shows the structure and schematic of the BDL. The BDL is structured strategically to create a flexible, multizone model of a multifamily building, which can handle a wide range of possible building scenarios. This is accomplished through DOE-2 macro commands: include macros (\#\#include), definition macros (\#\#def), and conditional macros (\#\#if) (Winkelmann et al. 1993). 


\section{Key BDL Modules}

\section{Assembled in the specified order (1 through 10) to create a complete building model for a simulation run}

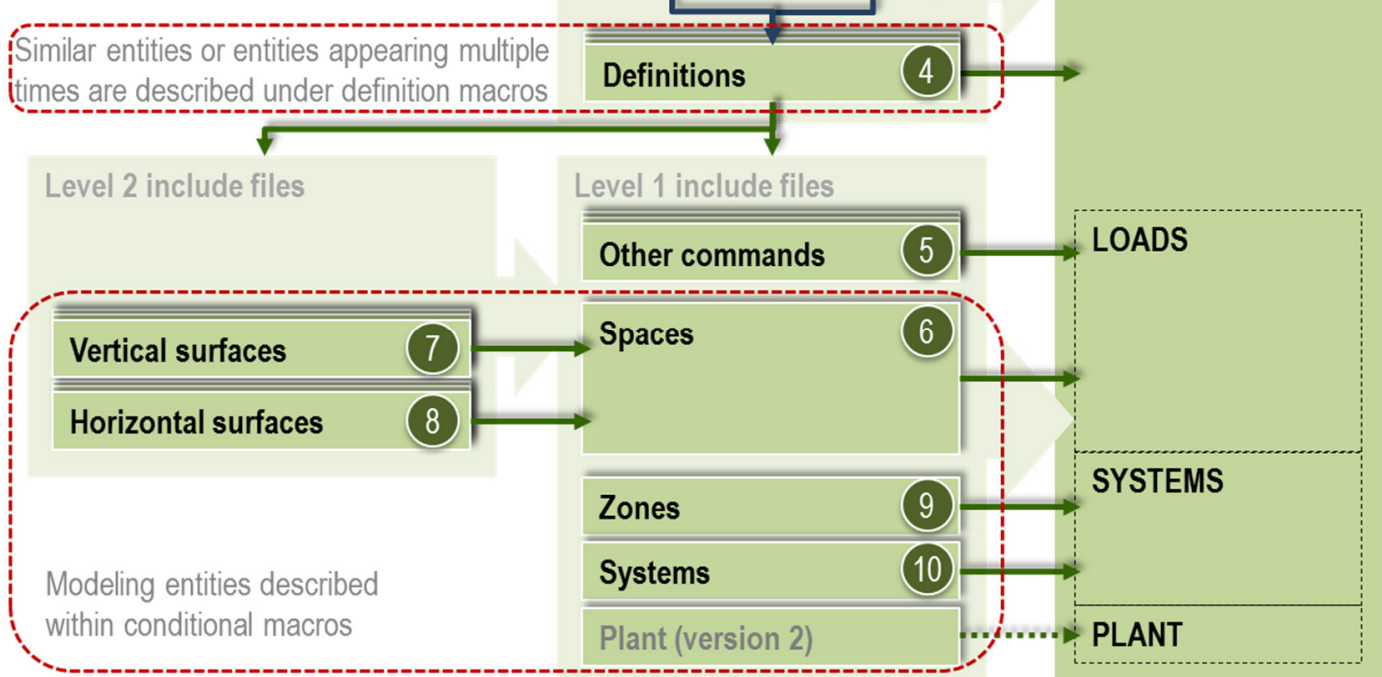

Figure 2.2. BDL structure, schematic, and key modules.

The BDL is developed in segments (i.e., include-files) that are pulled together in the BDL input stream by a parent input file. This file calls all level 1 include-files, some of which call level 2 include-files (e.g., inclusion of a level 2 zone-specific surface description in a level 1 space description). Blocks of inputs for similar commands and for commands that appear multiple times are defined collectively using definition macros. The definition macros optionally use arguments (i.e., variables that can be assigned values at the time the definitions are referenced in the BDL). Conditional macros are extensively used to include or exclude portions of codes based on the existence and types of building and system components inferred from the GUI inputs. Structuring the BDL in this manner offers many advantages in terms of its development and testing:

1. Development of the BDL as a set of include-files, once it is created, allows parallel development of its individual parts, which can be tested with the remaining parts seamlessly.

2. Use of definition macros with arguments for repetitive blocks of inputs makes the BDL more concise, minimizing modeling errors. Errors, if introduced, are easy to identify and fix.

3. Defining macros collectively for similar commands allows faster development of the BDL and prevents omission, duplication, or other modeling errors.

4. New modeling entities (e.g., zones and surfaces) can be defined and added easily.

5. Conditional macros allow the BDL to be flexible yet precise enough to address any number of floors, any arrangement of dwelling units, and the existence of common spaces in the building. 


\subsubsection{Key Modules of the BDL}

The following files collectively build a complete building model of a multifamily building. Figure 2.2 shows how these files are assembled to form the DOE-2 BDL.

\subsubsection{1 main.inp}

This is the main BDL input file that pulls together all level 1 include-files, including those required under LOADS and SYSTEMS subprograms. ${ }^{1}$ All other files described below (*.inc) are include-files.

\subsubsection{2 userInput.inc}

This level 1 include-file defines all macros required to receive GUI inputs and preprocessed values derived from GUI inputs and passes them downstream. Examples of GUI inputs include general building inputs such as area of spaces, number of floors, and number of dwelling units. Examples of preprocessed modeling inputs include material properties derived from descriptive user inputs for construction.

\subsubsection{3 preCalc.inc}

The userInput.inc include-file contains a limited number of macros that are collected as GUI input or preprocessed values. preCalc.inc, a level 1 include-file, defines additional macros required by the BDL based on those already defined in userInput.inc.

\subsubsection{4 def<entity >.inc}

These level 1 include-files contain macro definitions of construction layers, surface components, spaces, zones, and systems, which are referenced multiple times in the BDL. For example, all dwelling units that face a specific orientation have identical walls, windows, and doors; and all dwelling units on a specific floor have identical floors, roofs, and ceilings. These identical shell components are modeled in multiple zones simply by referring to macro definitions rather than using expanded commands. Furthermore, all walls, roofs, ceilings, and floors are assumed to have up to a five-layer construction assembly. Using a five-argument macro definition, all constructions are modeled simply by referring to the same macro definition and assigning materials to the five arguments.

\subsubsection{5 <entity $>$.inc}

These level 1 include-files are used for describing schedules, materials, layers, construction, glass types, and space conditions. These include-files use expanded commands or refer to macro definitions provided previously in various def<entity $>$.inc include-files.

\subsubsection{SPACE.inc}

This level 1 include-file is the core of the LOADS subprogram that is coded to be flexible by using conditional macros to include or exclude floor levels, zones, surfaces, and sub-surfaces. Figure 2.2 indicates how this include-file can generate multiple building configurations by using the flexible modeling scheme. These include-files use macro definitions of spaces defined in defSPACE.inc. The key points of this scheme, in parallel with the key points of the GUI, are as follows:

\footnotetext{
${ }^{1}$ PLANT inputs will be expanded in Version 2 of MulTEA.
} 
1. Only typical floors are modeled, which include a top floor, an intermediate floor with floor multipliers, a first floor, and a below-grade floor.

2. Six enclosed zone-types are modeled: dwelling unit, enclosed hallway, other conditioned space, other unconditioned space, attic, and crawlspace. ${ }^{2}$ All zone types except attic and crawlspace can exist on all floor levels. Among these, dwelling units having dissimilar exposures are modeled as separate zones, and dwelling units with identical exposures are modeled using multipliers.

3. Under each zone, a set of orientation-specific include-files are called for modeling walls, windows, and doors; and floor level-specific include-files are called for modeling floors and ceilings/roofs.

4. The zones are assumed to be rectangular in plan. This allows the coordinates of shell components to be derived easily using the dimensions of the enclosing surface components.

\subsubsection{7 $<$ Vsurf $><$ zone $><$ orientation $>$.inc and $<$ Hsurf $><$ zone $><$ level $>$.inc}

These level 2 include-files define multiple walls, windows, and doors (i.e., vertical surfaces and subsurfaces), and multiple floors, ceilings, and roofs (i.e., horizontal surfaces) under conditional macros, which include or exclude multiple instances of these surfaces based on the user inputs. These include-files use macro definitions of surfaces and sub-surfaces defined in various def<entity $>$.inc include-files.

\subsubsection{ZONE.inc and SYSTEM.inc}

These level 1 include-files are the core of the SYSTEMS subprogram. They use the same conditional macros as described in SPACE.inc for including or excluding zones and assigning systems to these zones. These include-files use macro definitions of zones and systems defined in defZONE.inc and defSYSTEM.inc.

\footnotetext{
${ }^{2}$ Other conditioned spaces and other unconditioned spaces combine all common spaces that are part of the building. More spaces can be added (e.g., modeled as separate zone types, as needed, provided such a change is made at all levels: defining areas, surfaces, internal loads, and systems).
} 



\section{MODELING PROCEDURE}

\subsection{WEATHER FILE}

The weather file used for the audit is selected based on the user input for the weather station on the AUDIT form and start and end dates associated with the utility bills on the UTILITY BILLS form. If utility bills are entered, a Calibration Run is performed using the actual weather for the weather station selected on the AUDIT form and the time period for which the utility bills are entered. Otherwise, the Calibration Run is performed with TMY3 weather data for the weather station selected on the AUDIT form. The Measures Run and Package Run are always performed with TMY3 weather data.

\subsection{BUILDING LOCATION AND SITE CONDITIONS}

The building location is characterized by altitude, azimuth, shielding coefficient, and terrain parameters. Altitude is obtained from various fields on the BUILDING form, including the Elevation of First Floor Above Grade field and the Depth of Building Below Grade field. Azimuth is based on the Orientation of Building field on the BUILDING form. The shielding coefficient and terrain parameters are look-up values (from Table A.1.1) based on the user input for the Site Shielding and Terrain field on the BUILDING form. In addition, user input for Ground Surface, combined with the look up values from Table A.1.2, is used for modeling the reflected part of solar radiation on to the walls.

\subsection{THERMAL ZONES}

The overall building configuration is described on the BUILDING form, which includes the number of floors, presence of conditioned and unconditioned spaces, floor areas of spaces, and number and orientation of dwelling units in the building. MulTEA's backend uses this information to determine the overall skeleton of the building consisting of thermal zones on different floors. See Sections 4.1 and 4.2 for the procedure for determining the existence and size of thermal zones under which the building envelope components, space conditions, and systems are submitted.

\subsection{BUILDING ENVELOPE}

The building envelope comprises walls, windows, doors, roofs, and floors. These components are typically described by the user on respective forms by specifying the construction and area or dimensions. The construction-related user inputs are used along with the DOE-2 material library to determine the thermal properties of construction components. The thermal mass of walls, roofs, and floors is based on the characteristics of the components entered by the user (e.g., concrete versus wood frame wall construction). Using the DOE-2 material library, the conductivity, density, and specific heat of the layers of construction components are determined and transferred to DOE-2. DOE-2 uses these thermal massrelated characteristics in performing energy simulations.

\subsubsection{Walls}

Existing walls are described on the WALLS form by entering the wall construction, insulation, exterior finish, area, and exposed perimeter (for underground walls, only). Up to eight heat transfer walls can be described. These include four exterior walls, two underground walls and two interior walls (i.e., partition walls between a conditioned and an unconditioned space). The area and exposed perimeter are entered by space (i.e., unit, hallway, other conditioned space, other unconditioned space, and crawlspace) and orientation (if an exterior or underground wall) or attached unconditioned space (if an interior wall). 
Walls are modeled in DOE-2 by specifying the width and height of the wall segments and the thermal properties of the wall layers. MulTEA's backend uses pre-simulation calculations to convert GUI inputs to parameters that are needed for modeling a wall in DOE-2. MulTEA then submits the values to the API for DOE-2 simulation. The following calculations are performed by MulTEA's backend:

1. The existence and size of a wall segment are determined using the procedure described in Sections 4.1 and 4.2, respectively. For the size of a wall segment, an equivalent wall width is calculated for each orientation for each floor in each zone from the user inputs for wall area (see Section 4.2.5).

2. The thermal properties (i.e., conductivity, specific heat, density, and thickness; or R-value and thickness) for each layer of a wall assembly are calculated using user inputs for the wall construction, insulation, and exterior; a database of material properties (Appendix A.2); and procedures described in Section 4.3. For an underground basement or crawlspace wall, a fictitious layer with an R-value calculated using procedures, described in Appendix B.2.2 and B.2.3, is modeled to simulate the impact of ground next to the underground basement or crawlspace wall.

Wall retrofit measures that can be analyzed as applicable to the wall type include Add Cavity Insulation, Add Exterior Insulation, and Add Interior Insulation. Retrofit measures are modeled by replacing the parameter values representing the existing wall with those representing the retrofit measure.

\subsubsection{Windows}

Existing windows are described on the WINDOWS form by entering the window width and height, National Fenestration Rating Council (NFRC) ratings (i.e., U-value and solar heat gain coefficient or SHGC) or construction description (i.e., glass assembly, glass type, and frame type), installed leakiness ${ }^{3}$, presence of storm windows, interior and exterior shading, dimensions of an existing overhang/awning (if applicable), and number of windows. The number of windows is entered by parent exterior wall, space and orientation. Up to eight window types can be described.

Windows are modeled in DOE-2 by specifying the window width and height, thermal properties (i.e., Uvalue and SHGC), shading characteristics, and shading schedule. MulTEA's backend uses pre-simulation calculations to convert GUI inputs to parameters that are needed for modeling windows in DOE-2. MulTEA then submits the values to the API for DOE-2 simulation. The following calculations are performed by MulTEA's backend:

1. The existence and size of a window are determined using the procedure described in Sections 4.1 and 4.2, respectively. For the size of a window, an equivalent window width is calculated for each exterior wall in each zone using the user inputs for the number of windows and window dimensions (see Section 4.2.5).

2. If a window is described using NFRC ratings, those values are used directly. If a window is described by entering window assembly details, a lookup table is used to determine the window U-value and SHGC (see Table A.3.3).

3. To account for the presence of a storm window, the window U-value and SHGC are modified using the following equations to calculate the window effective U-value and window effective SHGC:

\footnotetext{
${ }^{3}$ The installed leakiness only provides a baseline for the Replace Windows and Add Storm Window measures. Window default leakiness (see Table A.3.1) is provided as a guide for the user to select the installed leakiness for a given window type.
} 


$$
\begin{aligned}
& \text { Window Effective Uvalue }=\frac{1}{\mathrm{c}+\frac{\mathrm{m}}{\text { Window Uvalue }}}, \\
& \text { Window Effective SHGC }=\mathrm{n} * \text { Window SHGC, }
\end{aligned}
$$

where $c$ (Coefficient of Window R-value Modifier), $m$ (Slope for Window Rvalue Modifier), and $n$ (Multiplier for Window SHGC modifier) are obtained from Table A.3.5.

4. To account for internal and/or exterior shading, a shading schedule is determined from Table A.3.4: Window shading multiplier and shading schedule (assumed). In addition, the window SHGC (or effective window SHGC) is modified using the following equation to calculate the modified window SHGC:

$$
\text { Modified Window SHGC }=\text { Window SHGC } * \text { Shading Multiplier, }
$$

where Shading Multiplier is obtained from Table A.3.4: Window shading multiplier and shading schedule (assumed).

Window retrofit measures that can be analyzed include Replace Windows, Add Storm Windows, Add Shading, and Add Awning. Retrofit measures are modeled by replacing the parameter values representing the existing windows with those representing the retrofit measure. For the Replace Windows and Add Storm Windows measures, the resulting air leakage reduction is also calculated and used to modify the air infiltration parameter value in the parent zones. Section 4.4 describes the calculations for determining the air leakage reduction associated with these window retrofits.

\subsubsection{Doors}

Existing doors are described on the DOOR form by entering the door width and height, U-value or construction description (i.e., construction material, glass area, and glass type), installed leakiness ${ }^{4}$, presence of a storm door, and number of doors. The number of doors is entered by parent exterior wall, space and orientation. Up to four door types can be described.

Doors are modeled in DOE-2 by specifying the width and height of the door and the U-value. The presence of a storm door is modeled by modifying the door U-value. MulTEA's backend uses presimulation calculations to convert GUI inputs to parameters that are needed for modeling doors in DOE-2. MulTEA then submits values to the API for DOE-2 simulation. The following calculations are performed by MulTEA's backend:

1. The existence and size of a door are determined using the procedure described in Sections 4.1 and 4.2, respectively. For the size of a door, an equivalent door width is calculated for each exterior wall in each zone using the user inputs for the number of doors and door dimensions (see Section 4.2.5).

2. If a door is described using U-value, it is used directly. If a door is described by entering construction details, lookup tables are used for determining the door U-value and glass U-value (see Table A.3.8). Then the door overall $U$-value is calculated using the following equation:

\footnotetext{
${ }^{4}$ The installed leakiness only provides a baseline for the Replace Door and Add Storm Door measures. Door default leakiness (Table A.3.6) is provided as a guide for the user to select the installed leakiness for a given door type.
} 


$$
\begin{aligned}
& \text { Door Overall Uvalue } \\
& \qquad=(1-\text { Glass Fraction }) * \text { Door Uvalue }+ \text { Glass Fraction } * \text { Glass Uvalue. }
\end{aligned}
$$

3. To account for the presence of a storm door, the door U-value (or overall U-value) is modified using the following equation to calculate the effective door U-value:

$$
\text { Door Effective Uvalue }=\frac{1}{\mathrm{c}+\frac{\mathrm{m}}{\text { Door Overall Uvalue }}},
$$

where $c$ (Coefficient of Door R-value Modifier) and $m$ (Slope for Door R-value modifier) are obtained from Table A.3.9.

Door retrofit measures that can be analyzed include Replace Door and Add Storm Door. Retrofit measures are modeled by replacing the parameter values representing the existing door with those representing the retrofit measure. In addition, the resulting air leakage reduction from these measures is calculated and used to modify the air infiltration parameter value in the parent zones. Section 4.4 describes the calculations for determining the air leakage reduction associated with these door retrofits.

\subsubsection{Roofs}

Existing roof segments are described on the ROOF form by entering the roof construction, insulation, roofing details, area, and geometry (i.e., slope and height for an attic roof and slope for a cathedral roof). Up to eight roof segments can be described. These include four attic roofs, two cathedral roofs, and two flat roofs. The roof area is entered by space and floor.

Roofs are modeled in DOE-2 by specifying the width, height and slope of the roof segments and the thermal properties of the roof layers. In addition, an attic zone is modeled if an attic roof is described. MulTEA's backend uses pre-simulation calculations to convert GUI inputs to parameters that are needed for modeling a roof in DOE-2. MulTEA then submits the values to the API for DOE-2 simulation. The following calculations are performed by MulTEA's backend:

1. The existence and size of roof and ceiling segment are determined using the procedure described in Sections 4.1 and 4.2, respectively. In general, the roof area and slope in each zone are submitted directly to the API. Macros for calculating the width and height of the roof segments are programmed in the BDL.

2. If an attic roof is described for one or more zones on a floor, ceiling segments are modeled for those zones separating them from the attic, and roof segments are modeled for the attic zone above that floor. The area, volume and equivalent height of the attic zone are calculated using the procedure described in Section 4.2.2.

3. The thermal properties (i.e., equivalent conductivity, specific heat, density, and thickness, or Rvalue and thickness) for each layer of a roof assembly are calculated using user inputs for the roof construction, insulation, and radiant barrier; a database of material properties (Appendix A.3); and procedures described in Section 4.3. For a radiant barrier, an equivalent insulation layer is modeled on the underside of the roof or above the ceiling to simulate its impact.

Roof retrofit measures that can be analyzed as applicable to the roof type include Add Ceiling Insulation, Add Roof Insulation, Add Radiant Barrier, and White Roof Coating. Retrofit measures are modeled by replacing the parameter values representing the existing roof with those representing the retrofit measure. 


\subsubsection{Floors}

Existing floor segments are described on the FLOOR form by entering the floor construction, insulation, floor covering, area, and exposed perimeter. Up to eight floor segments can be described. These include two underground floors, two exposed floors, two interior floors (i.e., partition floors between a conditioned and an unconditioned space), and two above-crawlspace floors. The floor area is entered by space and floor.

Floors are modeled in DOE-2 by specifying the width and height of the floor segments and the thermal properties of the floor layers. In addition, a crawlspace zone is modeled if an above-crawlspace floor is described. MulTEA's backend uses pre-simulation calculations to convert GUI inputs to parameters that are needed for modeling the floor in DOE-2. MulTEA then submits the values to the API for DOE-2 simulation. The following calculations are performed by MulTEA's backend:

1. The existence and size of a floor segment are determined using the procedure described in Sections 4.1 and 4.2, respectively. In general, the floor area in each zone is submitted directly to the API. Macros for calculating the width and height of the floor segments are programmed in the BDL.

2. If an above-crawlspace floor is described for one or more zones on the first floor, interior floor segments are modeled for those zones separating them from the crawlspace, and the ground is modeled for a crawlspace zone below that floor.

3. The thermal properties (i.e., equivalent conductivity, specific heat, density and thickness, or Rvalue and thickness) for each layer of the floor assembly are calculated using user inputs for the floor construction, insulation, and floor; a database of material properties (Table A.2.1, Table A.2.3 and Table A.2.5); and procedures described in Section 4.3. For an underground floor, a fictitious layer with an R-value calculated using the procedures, described in Appendix B.2.1, is modeled to simulate the impact of ground next to the floor.

Floor retrofit measures that can be analyzed as applicable to the floor type include Add Slab Insulation, Add Exterior Insulation, and Add Sill Box Insulation. Retrofit measures are modeled by replacing the parameter values representing the existing floor with those representing the retrofit measure.

\subsection{SPACE CONDITIONS}

\subsubsection{Occupants}

Occupancy is described on the BUILDING form as the number of occupants in the building during the daytime and nighttime. The maximum of the two is used for modeling occupants in the building. Occupancy is modeled in DOE-2 for each thermal zone by specifying the number of occupants, occupancy schedule, and sensible and latent heat gains (i.e., $230 \mathrm{Btu} / \mathrm{h}$ per person and $190 \mathrm{Btu} / \mathrm{h}$ per person, respectively) to simulate the impact of internal heat gains due to occupants on heating and cooling energy use.

MulTEA's backend uses the total building occupancy divided by the number of dwelling units to determine the average number of occupants per dwelling unit. Peak occupancy for common spaces is $15 \%$ of the building occupancy for hallways and $5 \%$ for other conditioned spaces and other unconditioned spaces. The occupancy schedules (i.e., the fraction of peak occupancy during each hour of the day) are space-specific to represent typical occupancy levels throughout the day (see Figure 3.1 and Table A.6.3). Attics and crawlspaces are assumed to be unoccupied. 


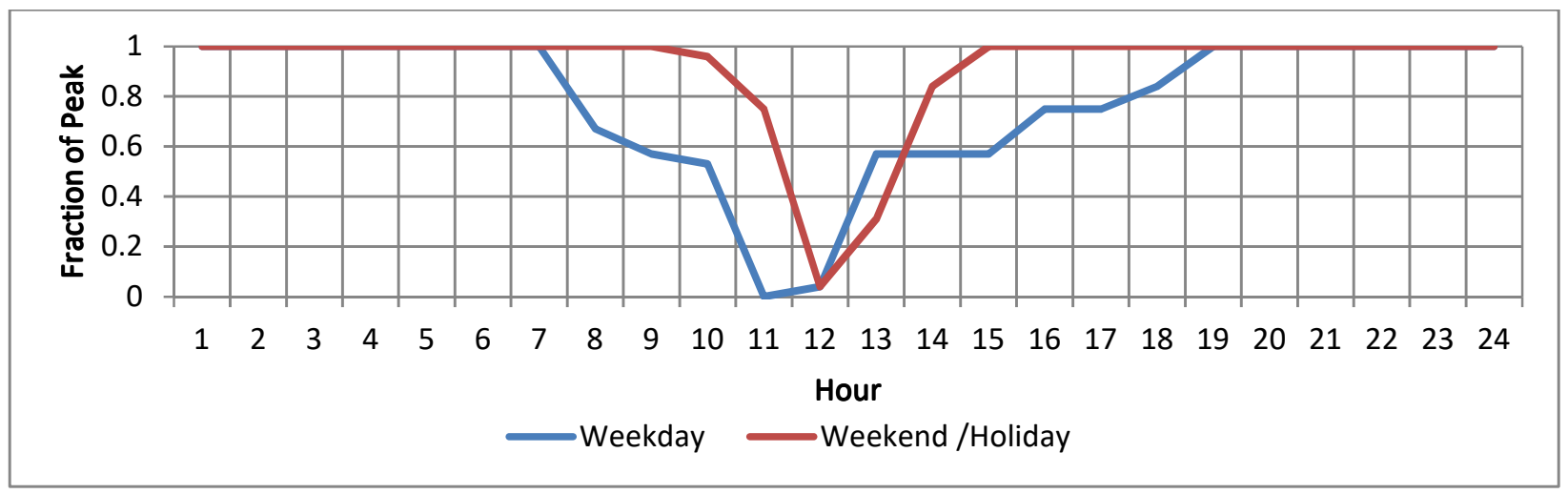

Figure 3.1. Occupancy schedule.

\subsubsection{Lighting}

Interior lighting is described on the LIGHTING form by power density (i.e., installed wattage per floor area, $\mathrm{W} / \mathrm{ft}^{2}$ ) and usage schedule (i.e., the fraction of installed wattage that is used each hour of the day) that are applied to the dwelling units. The power density and usage schedule represent the mix of lighting and their usages in a multifamily building. The lighting power density can be entered by space or for the whole building. If a whole-building power density is entered, it is applied to all the spaces. A user can select low, medium, or high for the lighting usage schedule based on a consideration of the occupancy characteristics in the building. ${ }^{5}$ Exterior lighting for outdoors is described as installed wattage (W).

Lighting is modeled in DOE-2 for each thermal zone as a lighting power density and usage schedule to simulate the electricity use by lighting and the impact of internal heat gains due to lighting on heating and cooling energy use.

MulTEA's backend sends the lighting power density by zone directly to the API. Lighting usage schedules are space-specific (see Figure 3.2 and Table A.6.1) and represent medium usage (i.e., usage in multifamily buildings at normal or typical occupancy levels). High usage is $20 \%$ greater than medium, and low usage is $20 \%$ less than medium. These are implemented by increasing or decreasing the power density by $20 \%$, respectively, because the usage fraction cannot be greater than 1. Exterior lighting is modeled using the installed lighting wattage and assuming 12-hour per day operation.

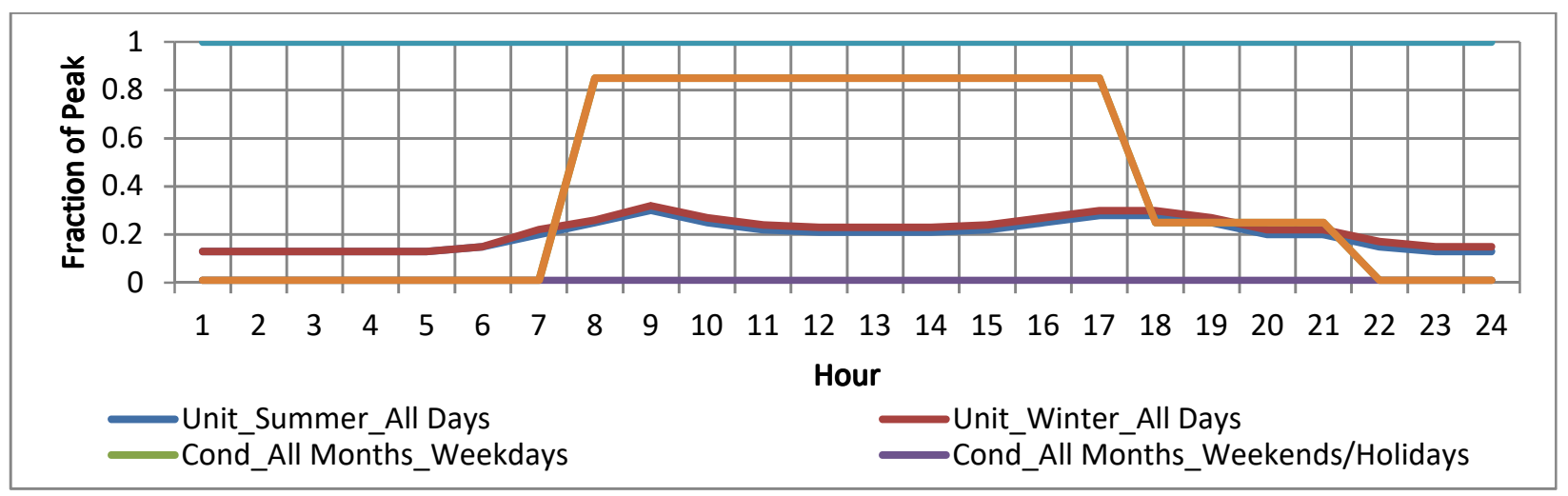

Figure 3.2. Lighting schedule (medium usage).

\footnotetext{
${ }^{5}$ For model calibration, a different lighting schedule could be selected if there is uncertainty about the occupancy. In general, though, the primary adjustment would be made by adjusting the power densities.
} 
Energy savings from lighting retrofits result from reduced lighting electricity use and reduced internal heat gains due to lighting. For a lighting retrofit, characteristics of the existing and replacement lighting system are described on the LIGHTING form. These characteristics include the lamp type; hours of use; wattage; number of lamps; and, if applicable, the number of new ballasts, sensors, or controls. For a lighting retrofit in an interior space, a side calculation is performed in MulTEA's backend to calculate the reduced lighting power density due to the retrofit (see Section 4.5 for the calculation procedure), which is then run through the building energy model to simulate the reduced electricity use for lighting and the impact of reduced internal heat gains on the heating and cooling energy use. For an outdoor lighting retrofit, electricity savings are calculated directly.

\subsubsection{Appliances}

Appliances are described on the APPLIANCES form by the power density (i.e., installed wattage per floor area, $\mathrm{W} / \mathrm{ft}^{2}$ ) and usage schedule (i.e., the fraction of installed wattage that is used each hour of the day) that are applied to the dwelling units., The power density and usage schedule represent the mix of appliances and their usages in a multifamily building. The appliance power density can be entered by space or for the whole building. If a whole-building power density is entered, it is applied to all the spaces. A user can select low, medium, or high for the appliance usage schedule based on a consideration of the occupancy characteristics in the building. ${ }^{6}$

Appliances are modeled in DOE-2 for each thermal zone as an appliance power density and usage schedule to simulate the electricity use by appliances and the impact of internal heat gains due to appliances on heating and cooling energy use.

MulTEA's backend sends the appliance power density by zone directly to the API. Appliance usage schedules are space-specific (see Figure 3.3 and Table A.6.2) and represent medium usage (i.e., usage in multifamily buildings at normal or typical occupancy levels). High usage is $20 \%$ greater than medium, and low usage is $20 \%$ less than medium. These are implemented by increasing or decreasing the power density by $20 \%$, respectively, because the usage fraction cannot be greater than 1 .

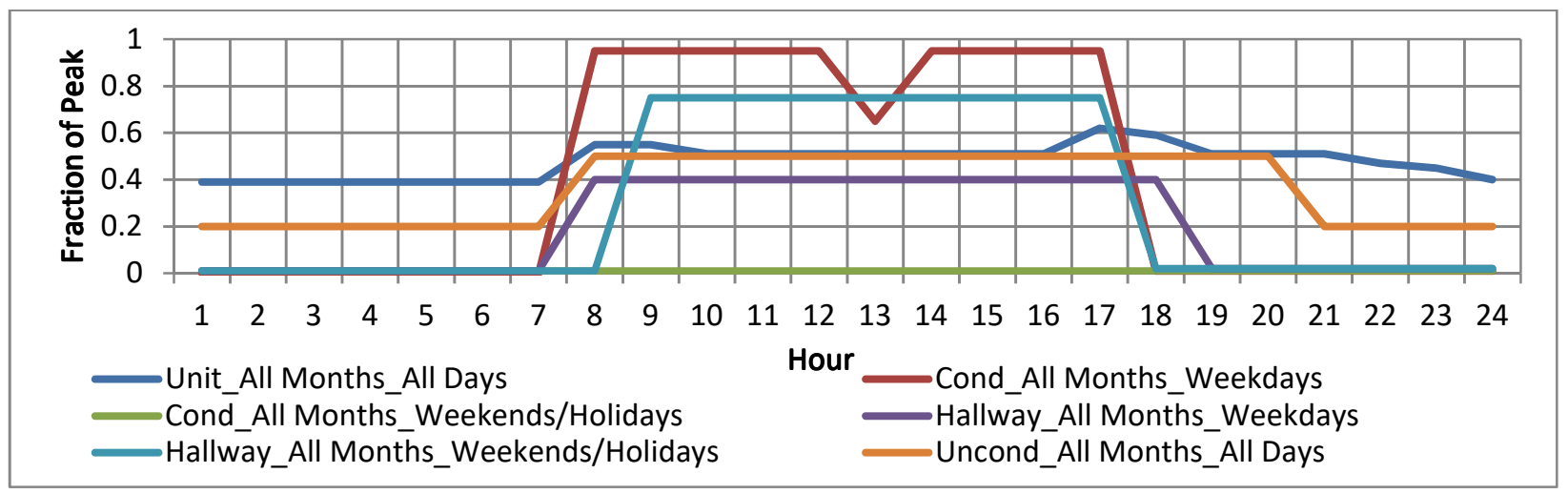

Figure 3.3. Appliance usage schedule (medium usage).

Refrigerator replacement is the only appliance retrofit measure. It is described on the REFRIGERATORS form. Energy savings for a refrigerator replacement are due to reduced appliance electricity use and reduced internal heat gains. For a refrigerator replacement, characteristics of the existing and replacement refrigerator are described on the REFRIGERATORS form. A side calculation is performed in MulTEA's

\footnotetext{
${ }^{6}$ For model calibration, a different appliance schedule could be selected if there is uncertainty about the appliance use. In general, though, the primary adjustment would be made by adjusting the power densities.
} 
backend to calculate the reduced appliance power density due to the retrofit (see Section 4.6 for the calculation procedure), which is then run through the building energy model to simulate the reduced electricity use of the refrigerator retrofit and the impact of reduced internal heat gains on the heating and cooling energy use.

\subsubsection{Infiltration}

Infiltration can be entered on the INFILTRATION form by space or for the whole building. It can be described in terms of natural air changes per hour $(\mathrm{ACH})$ or, for a whole building entry, a blower door reading (CFM50). If a whole-building infiltration $\mathrm{ACH}$ number is entered, it is applied to all the spaces; if a whole-building infiltration CFM50 number is entered, it is applied to all the spaces after being converted to an $\mathrm{ACH}$ value.

Infiltration is modeled in DOE-2 in each space as a design infiltration rate (in units of natural ACH) and infiltration schedule. The design infiltration rates for an attic and a crawlspace are fixed at $3 \mathrm{ACH}$ and $10 \mathrm{ACH}$, respectively. The infiltration schedule (i.e., the fraction of the design infiltration rate for each hour of the day) modifies the design infiltration rate. It is 0.5 for all zones and 1 for the attic and crawlspace.

MulTEA's backend sends the infiltration rate entered for each space directly to the API in units of ACH. When a whole-building CFM50 number is entered on the INFILTRATION form, MulTEA's backend converts it to $\mathrm{ACH}$ using the following equation (see Appendix B.7 for derivation of the equation) before assigning it to all the spaces:

$$
\begin{aligned}
& \mathrm{ACH}= 1000 \frac{\frac{0.055}{144} \mathrm{Q}_{50 \mathrm{~Pa}}}{\mathrm{~A}_{\text {floor }}}\left[\frac{\mathrm{H}}{8.2}\right]^{0.4} \text { wsf } \\
& \text { where } \\
& \\
& \mathrm{Q}_{50 \mathrm{~Pa}}=\text { airflow at } 50 \text { Pascals pressure difference, } \mathrm{cfm} \\
& \text { wsf = weather and shielding factor, from Normative Appendix B of ASHRAE Standard } \\
& \quad 62.2-2013 \text { (ASHRAE 2013b) } \\
& \mathrm{A}_{\text {floor }}=\text { floor area of the building, } \mathrm{ft}^{2} \\
& \mathrm{H}=\text { vertical distance between the lowest and highest above grade points within the } \\
& \quad \text { pressure boundary = number of above grade floors * average floor height, } \mathrm{ft}
\end{aligned}
$$

The only infiltration retrofit measure analyzed directly by MulTEA is a planned reduction in the design infiltration rates of the spaces. The infiltration retrofit measure is modeled by replacing the existing design infiltration rates with those representing the retrofit measure. Replacement windows and doors and the installation of storm windows and doors are credited with a reduction in air leakage. This is calculated by modifying the infiltration rates of the spaces with which they are associated using the procedure described in Section 4.4.

\subsection{SYSTEMS}

\subsubsection{HVAC Systems}

Space heating and cooling systems serving the dwelling units, conditioned hallways, and other conditioned spaces are described on the HVAC form by entering the locations and number of same systems, equipment type, fuel (for space heating systems only), efficiency, and capacity. Additional characteristics entered on the form are the outside air ventilation rate and the presence of a pilot light or 
intermittent ignition device (IID) (for natural gas or propane space heating systems only). The system being described can be heating equipment only, cooling equipment only, or both (i.e., combined). Systems in different spaces are described on different HVAC forms. More than one system can be described for a given space type. Up to six HVAC system types can be described. However, if multiple space heating systems are described, the fossil fuel type should be the same for all.

In DOE-2, one HVAC system is modeled in each zone by specifying the type, efficiency, and capacity of the equipment.

1. MulTEA's backend uses pre-simulation calculations to convert GUI inputs to parameters that are needed for modeling an HVAC system in DOE-2. MulTEA then submits the values to the API for DOE-2 simulation. The following calculations are performed by MulTEA's backend: If the year manufactured is entered because the system efficiency is unknown, a lookup table is used for determining the year-based shipment-weighted efficiency (see Table A.4.1).

2. If there are multiple heating and cooling systems serving a zone, an aggregated capacity and capacity weighted efficiency are calculated for an equivalent HVAC system for each zone (see Section 4.7).

HVAC retrofit measures that can be analyzed as applicable to the system type include Change Ventilation Rate, Replace the System, Tune Up, and Pilot Light. Retrofit measures are modeled by replacing the parameter values representing the existing HVAC system with those representing the retrofit measure.

\subsubsection{Thermostat Settings}

Default thermostat settings for heating and cooling are modeled in each conditioned zone (i.e., units, conditioned hallways, and other conditioned spaces, unless a custom thermostat schedule is described on the THERMOSTAT form for each of these zones. The default heating thermostat setting is $68^{\circ} \mathrm{F}, 24$ hours per day for the entire year, and the default cooling thermostat setting is $76^{\circ} \mathrm{F}, 24$ hours per day for the entire year. A custom thermostat schedule is generated based on the inputs for heating and cooling for Hour To, Hour From, Daytime Temperature, and Nighttime Temperature. Section 4.8 describes the procedure by which MulTEA's backend develops a thermostat schedule for DOE-2 simulation using these custom thermostat inputs.

The only thermostat retrofit measure that can be analyzed is New Thermostat Schedule, which can be described in the same manner as the existing custom thermostat schedule. The thermostat retrofit measure is modeled by replacing the parameter values representing the existing default or custom thermostat schedule with those representing the new thermostat schedule.

\subsubsection{Water Heater}

Domestic water heating systems serving the dwelling units are described on the WATER HEATING form. MulTEA allows modeling of either individual water heaters serving individual dwelling units or a central water heater serving all dwelling units in the building. Up to four types of individual water heaters or one central water heater can be described.

For modeling an individual water heater, MulTEA requires the equipment type (i.e., storage, heat pump, or tankless coil); installation characteristics, including location (i.e., conditioned space, semi-conditioned space, unconditioned space, or outdoors), number of same systems, set point temperature, fuel, water heater wrap R-value, and insulated pipe length; and nameplate-type information, including tank size, rated input, and efficiency. 
For a central water heating system, MulTEA can model only a commercial storage tank-type unit that provides hot water only for domestic hot water use (not for space heating). For modeling the central water heater, MulTEA requires installation characteristics including location (i.e., conditioned space, semi-conditioned space, unconditioned space, or outdoors), number of same water heaters, set point temperature, and fuel; nameplate-type information, including tank size, rated input, steady

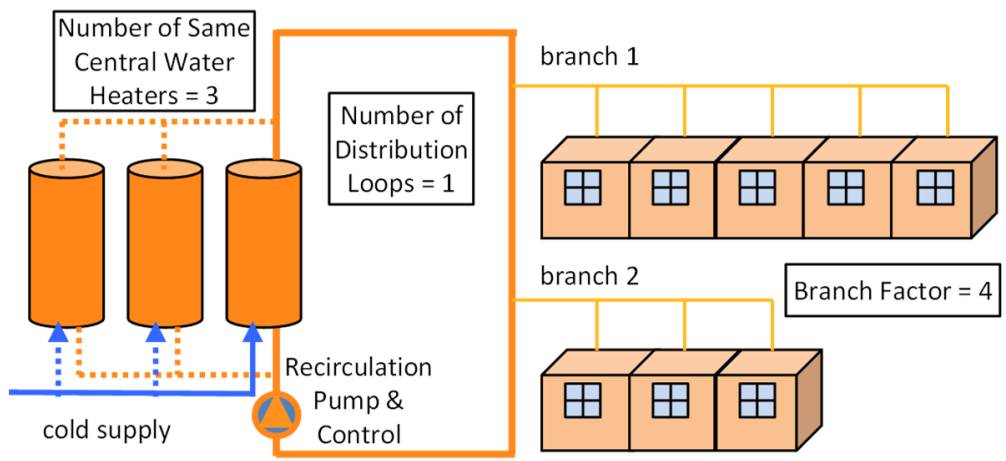

Figure 3.4. Central water heater distribution loops. state efficiency (in units of percent) and standby loss (in units of either Btu/h or \% per h); and distribution system data, including the number of distribution loops (currently set to 1), branch factor (i.e., average number of units per branch), pipe location (i.e., conditioned space, semi-conditioned space, buried, or outdoors), pipe insulation thickness, recirculation control type (i.e., continuous or demand), pump power, flow rate, and pump motor efficiency. Figure 3.4 is provided to help clarify these inputs. It shows a central water heating system with three water heaters, one distribution loop, and two branches, with five apartment units on one branch and three units on a second branch. In this case, the Branch Factor would be four.

A domestic water heating system is modeled using a supplementary "Domestic Hot Water Model" developed by LBNL that resides on LBNL's API (LBNL n.d.). This model contains modules for calculating hot water use, distribution system losses (for a central water heating system), and domestic water heating energy use. MulTEA's backend uses pre-simulation calculations to convert GUI inputs to parameters that are needed to model a water heating system in "Domestic Hot Water Model" and submits those parameter values to the API.

1. For an individual water heater, based on the equipment type, the efficiency information requires user input or is determined by MulTEA based on the criteria shown in Table 3.1.

a. For a storage water heater, if the system efficiency is unknown, the year manufactured can be entered. MulTEA uses a lookup table (Table A.4.2) to determine the year-based shipment-weighted energy factor (SWEF). In that case, MulTEA assigns the recovery efficiency (RE) as 0.98 if the fuel is electricity and $(0.38 * \text { energy factor }+0.54)^{7}$ if the fuel is a fossil fuel.

b. For a heat pump water heater, only the energy factor (EF) must be entered. MulTEA assigns the RE as $2.42 .8,9$

c. For a tankless water heater, only the EF must be entered. MulTEA assigns the RE to be the same as the EF to allow the Domestic Hot Water Model to result in zero standby loss.

\footnotetext{
${ }^{7}$ Derived from curve-fit between the EF and recovery efficiency of storage-type natural gas water heaters listed in the AHRI Directory of Certified Product Performance (AHRI 2012) for domestic water heaters. See Appendix A.5. ${ }^{8}$ Recovery efficiency for heat pump water heating mode is set to 2.42 based on Section 7-C.2.3 of DOE (2009).

${ }^{9}$ The 2012 AHRI directory (AHRI 2012) listed 34 heat pump water heaters with EFs ranging between 1.92 and 2.4 . However, the 2016 AHRI directory listed 185 heat pump water heaters with EFs ranging between 2.08 and 3.50. This will require MulTEA to reconsider the value assigned for RE for HPWH so that new models can be analyzed.
} 
d. For a tankless water heater, MulTEA assigns the tank size to be 35 gallons to allow the Domestic Hot Water Model in LBNL's API to calculate the domestic hot water use based on HES legacy calculations (LBNL n.d.). The updated domestic hot water use calculations in LBNL's API are based on Parker and Lutz (2014) and Parker et al. (2015).

Table 3.1. Determining individual water heater name plate information

\begin{tabular}{|l|c|c|c|c|c|c|}
\hline $\begin{array}{c}\text { Equipment } \\
\text { type }\end{array}$ & Tank size & $\begin{array}{c}\text { Efficiency } \\
\text { input method }\end{array}$ & $\begin{array}{c}\text { Year } \\
\text { manufactured }\end{array}$ & Energy factor & Fuel & $\begin{array}{c}\text { Recovery } \\
\text { efficiency }\end{array}$ \\
\hline Storage & <user input $>$ & $\begin{array}{c}\text { Name plate } \\
\text { efficiency }\end{array}$ & - & $<$ user input $>$ & - & $<$ user input> \\
\cline { 3 - 7 } & & $\begin{array}{c}\text { Year } \\
\text { manufactured }\end{array}$ & $<$ user input $>$ & $\begin{array}{c}<\text { lookup value } \\
\text { from Table A.4.2> }>\end{array}$ & Electricity & 0.98 \\
\cline { 3 - 7 } & & - & - & $<$ Other & $0.38^{*} \mathrm{EF}+0.54$ \\
\hline Heat pump & $<$ user input $>$ & - & - & $<$ user input $>$ & - & 2.42 \\
\hline
\end{tabular}

2. For an individual water heating system, the Domestic Hot Water Model does not account for the reduction in heat losses and resulting reduction in hot water energy use due to a water heater tank wrap and pipe insulation. Therefore, the MulTEA backend uses pre-simulation calculations to calculate an equivalent EF and RE (see Section 4.9) and submits those values to the API instead of the actual EF and RE. With the equivalent EF and RE, the Domestic Hot Water Model would result in domestic water heating energy use reduced by the amount equal to that reduced by the water heater tank wrap and pipe insulation. The equations for equivalent $\mathrm{EF}$ and RE are derived in Appendix B.6.

3. For the central water heater, if standby loss is entered in units of $\%$ per hour on the GUI, the MulTEA backend converts it to Btu/h using the following equation (ANSI Z21.10.3-1998 §2.10, referenced in $10 \mathrm{CFR} \S 431.106)$ and submits to the API:

Standby loss in BTU per hour $=\frac{\text { Standby loss in \% per hour }}{100} * 8.25 * 70 *$ tank size in gallon

4. If there are multiple individual water heating systems, the Domestic Hot Water Model calculates water heating energy use for each individual water heating system and sums the results to determine the total domestic water heating energy use in the building.

Water heating system retrofit measures that can be analyzed for individual water heaters include Replace the System, Change Set-Point Temperature, Install Water Heater Wrap, and Add Insulation on Water Heater Pipes. Retrofit measures for the central water heater include Replace the System, Change Set-Point Temperature, Add Insulation on Distribution Pipes, and Replace Circulation Pump. Retrofit measures are modeled by replacing the parameter values representing the existing water heating system with those representing the retrofit measure. 



\section{PRE-SIMULATION BACKEND PROCESSING}

\subsection{DETERMINING EXISTANCE OF SPACE, ZONE AND SHELL OBJECTS}

\subsubsection{Relevant GUI Fields}

\section{BUILDING form}

- Num[AG]: number of floors above grade

- Num[BG]: number of floors below grade

- Ht[AVG]: average floor height

- $Z[A G]:$ elevation of first floor above grade

- $\mathrm{Z}[\mathrm{BG}]$ : depth of building below grade

- GradeChange[ ]: site grade changes (YES or NO)

- $\mathrm{Z}[\mathrm{BG}$, side $]=\left\{\begin{array}{c}\text { user input, if GradeChange[ ] = YES } \\ \mathrm{Z}[\mathrm{BG}], \text { if GradeChange[ }]=\mathrm{NO}\end{array} ; \mathrm{MAX}(\mathrm{Z}[\mathrm{BG}, \text { side }])_{\text {all sides }}=\mathrm{Z}[\mathrm{BG}]\right.$

- NumUnit[level,sideconfig]: number of units on a level with exposure on one or more sides

- Area[zone,level]: area of a zone on a level

where lowercase text in brackets [ ] are attributes that can have the following values:

level=B2: second floor below grade

B1: first floor below grade

A1: first floor

A2: typical floor (i.e., between A1 and A3)

A3: top floor

zone=UNIT: dwelling unit

HALL: hallway (conditioned or unconditioned)

COND: other conditioned space

UNCD: other unconditioned space

side $=\mathrm{B}:$ back

R: right

F: front

L: left

sideconfig=B,R,F,L,BR,BF,BL,FR,FL,RL,BRF,BFL,BRL,FRL,BRFL

\section{WALLS form: Exterior Wall tabs}

- AreaWall[WallID,zone,side]

where

WallID $=1,2,3,4$

zone $=$ UNIT,HALL,COND,UNCD,CRAWL,ATTIC

side $=\mathrm{B}, \mathrm{R}, \mathrm{F}, \mathrm{L}$

WALLS form: Underground Wall tabs

- AreaWall[WallID,zone,side]

where

$\mathrm{WallID}=5,6$ 
zone $=$ UNIT,HALL,COND,UNCD,CRAWL

side $=\mathrm{B}, \mathrm{R}, \mathrm{F}, \mathrm{L}$

WALLS form: Interior Wall tabs

- AreaWall[WallID,zone,attachedzone]

where

WallID $=7,8$

zone $=$ UNIT,HALL(if conditioned),COND

attachedzone=HALL(if unconditioned),UNCD,CRAWL,ATTIC

\section{WINDOWS form}

- WdWindow[windowID]

- NumWin[windowID,WallID,zone,side]

where

WindowID $=1,2,3,4,5,6,7,8$

WallID $=1,2,3,4$

zone $=$ UNIT,HALL,COND,UNCD

side $=\mathrm{B}, \mathrm{R}, \mathrm{F}, \mathrm{L}$

\section{DOORS form}

- WdDoor[doorID]

- NumDoor[doorID,WallID,zone,side]

where

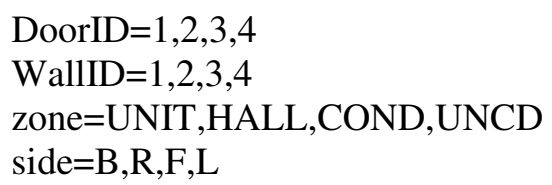

ROOF form: Attic Roof tabs

- AreaRoof[RoofID,zone,level]

- SlopeRoof[RoofID]

- HtAttic[RoofID]

where

RoofID $=1,2,3,4$

level $=\mathrm{A} 1, \mathrm{~A} 2, \mathrm{~A} 3, \mathrm{~A} 4$

zone=UNIT,HALL,COND,UNCD,ATTIC

ROOF form: Cathedral Roof tabs

- AreaRoof[RoofID,zone,level]

- SlopeRoof[RoofID] 
where

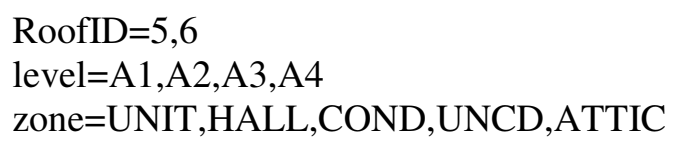

ROOF form: Flat Roof tabs

- AreaRoof[RoofID,zone,level]

where

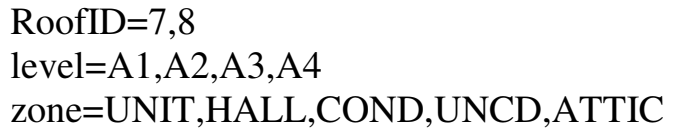

FLOOR form: Underground Floor tabs

- AreaFloor[FloorID,zone,level]

where

FloorID $=1,2$

level=B2,B1,A1,A2,A3

zone $=$ UNIT,HALL,COND,UNCD

\section{FLOOR form: Exposed Floor tabs}

- AreaFloor[FloorID,zone,level]

where

FloorID $=3,4$

level=A1,A2,A3

zone $=$ UNIT,HALL,COND,UNCD

\section{FLOOR form: Interior Floor tabs}

- AreaFloor[FloorID,zone,attachedzonebelow]

where

FloorID $=5,6$

zone $=\mathrm{UNIT}, \mathrm{HALL}, \mathrm{COND}, \mathrm{UNCD}$

attachedzonebelow=UNIT,HALL,COND,UNCD

\section{FLOOR form: AboveCrawlspace Floor tabs}

- AreaFloor[FloorID,zone,level]

where

FloorID $=7,8$

level $=\mathrm{A} 1$

zone $=\mathrm{UNIT}, \mathrm{HALL}, \mathrm{COND}, \mathrm{UNCD}$ 


\subsubsection{Determining Existence of Space, Zone and Shell Objects}

The following general rules govern the existence of space, zone and shell objects that must be submitted to the API. Specifications for submitting zone and shell objects for each space type are provided further below.

1. The API submission for a building comprises of level-specific space objects.

2. For each level in a building, one or more spaces must be submitted.

3. For each space, one or more zones must be submitted.

4. For each zone, multiple walls, roof and floor components may be submitted.

5. For each exterior wall, multiple windows and doors may be submitted.

6. For an attic zone, only roof components must be submitted.

7. For a crawlspace zone, only exterior walls with no window and door must be submitted.

For space $=$ UNIT, HALL, COND, UNCD

On the BUILDING form, if Area[zone, level] > 0, submit space[space, level].

\section{If zone $=$ HALL, COND, UNCD}

Submit zone[zone, level, sideconfig=BRFL].

\section{Elseif zone=UNIT}

On the BUILDING form, if NumUNIT[level, sideconfig] > 0, submit zone[zone=UNIT, level, sideconfig].

\section{Endif}

On the WALLS form, if AreaWall[wallID, zone, side or attachedzone] > 0, submit zone_wall[zone, level, side or attachedzone].

On the WINDOWS form, if NumWin[windowID, wallID, zone, side] $>0$, submit zone_window[windowID, wallID, zone, level, side].

On the DOORS form, if NumDoor[doorID, wallID, zone, side] $>0$, submit zone_door[doorID, wallID, zone, level, side].

On the ROOF form, if AreaRoof[roofID, zone, level] > 0, submit zone_roof[zone, level].

On the FLOOR form, if AreaFloor[floorID, zone, level] > 0, submit zone_floor[zone, level].

\section{For space $=$ ATTIC}

On the ROOF forms, if $\sum \sum$ AreaRoof[roofID, zone, level] over roofID=1 thru 4 and zone=UNIT, HALL, COND, UNCD for a level $>0$, submit space[space=ATTIC, level=levelabove].

Submit zone[zone=ATTIC, level=levelabove, sideconfig=BRFL].

Submit zone_roof[zone=ATTIC, level=levelabove]. 


\section{For space $=$ CRAWL}

On the FLOOR forms, if $\sum \sum$ AreaFloor[floorID, zone, level] over floorID=7and8 and zone=UNIT, HALL, COND, UNCD for level=A1 >0, submit space[space=CRAWL, level=B1].

Submit zone[zone=CRAWL, level=B1, sideconfig=BRFL].

On WALLS form, if AreaWall[wallID, zone=CRAWL, side] $>0$, submit zone_wall[zone=CRAWL, level=B1, side].

\subsection{CALCULATING SIZE OF SPACE, ZONE AND SHELL OBJECTS}

\subsubsection{Determining Floor Multiplier (Num[level]) and Height of Floors (Ht[level])}

- $\quad \operatorname{Num}[\mathrm{B} 2]=\mathrm{Max}(0, \mathrm{Num}[\mathrm{BG}]-1)$

- $\quad$ Num[B1] =Num[BG]-Num[B2]

- $\operatorname{Num}[\mathrm{A} 1]=\operatorname{Min}(1, \mathrm{Num}[\mathrm{AG}])$

- $\operatorname{Num}[A 2]=\operatorname{Max}(0, N u m[A G]-2)$

- $\quad$ Num[A3] =Num[AG]-Num[A1]-Num[A2]

- $\mathrm{Ht}[\mathrm{B} 2]=((\mathrm{Z}[\mathrm{AG}]+\mathrm{Z}[\mathrm{BG}]-\mathrm{Ht}[\mathrm{AVG}])) \mathrm{Num}[\mathrm{B} 2]$, if $\mathrm{Num}[\mathrm{B} 2]>0$

- $\quad \mathrm{Ht}[\mathrm{B} 1]=\left\{\begin{array}{c}\mathrm{Ht}[\mathrm{AVG}], \text { if Num[BG] }>1 \\ \mathrm{Z}[\mathrm{AG}]+\mathrm{Z}[\mathrm{BG}], \text { if } \mathrm{Num}[\mathrm{BG}]=1\end{array}\right.$

- $\mathrm{Ht}[\mathrm{A} 1]=\mathrm{Ht}[\mathrm{AVG}]$, if $\mathrm{Num}[\mathrm{A} 1]>0$

- $\mathrm{Ht}[\mathrm{A} 2]=\mathrm{Ht}[\mathrm{AVG}]$, if $\mathrm{Num}[\mathrm{A} 2]>0$

- $\mathrm{Ht}[\mathrm{A} 3]=\mathrm{Ht}[\mathrm{AVG}]$, if Num[A3]>0

\subsubsection{Determining Height of Space Objects}

For space $=$ UNIT, HALL, COND, UNCD

- $\mathrm{Ht}[$ space, level $]=\mathrm{Ht}[$ level $]$

For space $=$ ATTIC

- $\mathrm{Ht}[$ space=ATTIC, level=levelabove $]=\mathrm{HtAttic}[$ level], as determined below

Step 1: From each ATTIC tab, obtain:

- AreaRoof[roofID,zone,level]; directly submit to API under zone_roof

- SlopeRoof[roofID]; convert to degrees to submit to API under zone_roof

- HtAttic[roofID]

Step 2: Calculate attic area for each ATTIC tab:

AreaAttic[roofID, zone, level] = AreaRoof[roofID, zone, levelbelow $]$

$$
\text { AreaAttic[roofID, level } \left.]=\sum_{\text {zone=UNIT,HALL,COND,UNCD }} \text { AreaAttic[roofID, zone, level }\right]
$$




$$
\text { AreaAttic[rooflD } \left.]=\sum_{\text {level }=\mathrm{A} 2, \mathrm{~A} 3, \mathrm{~A} 4} \text { AreaAttic[roofID, level }\right]
$$

Step 3: Calculate attic volume for each ATTIC tab to be displayed on ATTIC form:

$$
\text { VolumeAttic[roofID] }=\left(\frac{1}{6}\right) * \operatorname{AreaAttic}[\text { roofID }] * \operatorname{HtAttic}[\operatorname{roofID}] *\left(3-\frac{\mathrm{M}}{\mathrm{M}_{\max }}\right)
$$

where

$$
\begin{gathered}
\mathrm{M}_{\max }=\frac{\text { AreaAttic[roofID] }}{\left(\frac{2 * \text { HtAttic[roofID] }}{\text { SlopeRoof[rooflD] } / 12}\right)^{2}} \\
\mathrm{M}=\left\{\begin{array}{c}
1.0, \text { if } 1.0 \leq \mathrm{M}_{\max } \\
0.5, \text { if } 0.5 \leq \mathrm{M}_{\max }<1.0 \\
0.25, \text { if } 0.25 \leq \mathrm{M}_{\max }<0.5 \\
0, \text { if } 0 \leq \mathrm{M}_{\max }<0.25
\end{array}\right.
\end{gathered}
$$

This ensures that:

$$
\begin{aligned}
& \left(3-\frac{M}{M_{\max }}\right) \geq 2 \text {, and } \\
& \text { Volume }=\frac{1}{3} * \mathrm{~A} * \mathrm{H} \text { (i.e., the volume of a pyramidal attic) }
\end{aligned}
$$

The above approach is based on the following assumptions:

1. The attic has an equal slope for all sloping surfaces.

2. The attic configuration can be simplified to or represented by one of the following four options where sloping surfaces of the attic face:
a. all four directions (hipped roof): $\mathrm{M}=1.0$
b. three directions: $\mathrm{M}=0.5$
c. two adjacent directions: $\mathrm{M}=0.25$
d. two opposite directions (gable roof) OR one direction (shed roof): $M=0$

In this approach, if the user-specified A, H, and Slope combination cannot form a hipped roof, then the backend explores subsequent attic shapes. If the roof is actually a gable or shed roof but the hipped roof formation is possible for the given $\mathrm{A}, \mathrm{H}$ and Slope, then the calculated volume will be smaller.

Step 4: Distribute attic volume on A2, A3, and A4 for each ATTIC tab:

$$
\text { VolumeAttic[roofID, level }]=\text { VolumeAttic[roofID }] \times \frac{\text { AreaAttic[roofID, level }]}{\text { AreaAttic[roofID }]}
$$

Step 5: Calculate attic area and height on A2, A3, and A4 combining all ATTIC tabs:

$$
\text { AreaAttic[level }]=\sum_{\text {roofID }=1,2,3,4} \text { AreaAttic[roofID, level]; submit to API under SPACE }
$$




$$
\begin{aligned}
& \text { VolumeAttic[level] }=\sum_{\text {rooflD }=1,2,3,4} \text { VolumeAttic[roofID, level] } \\
& \text { HtAttic[level }]=\frac{3 \times \text { VolumeAttic[level] }}{\text { AreaAttic[level] }} ; \text { submit to API under SPACE }
\end{aligned}
$$

\section{For space $=$ CRAWL}

- $\quad \mathrm{Ht}[$ space, level $]=\mathrm{Ht}[\mathrm{B} 1]$

\subsubsection{Determining Area of Zone Objects}

For space $=$ HALL, COND, UNCD

Area[zone, level, sideconfig=BRFL] = Area[zone, level $]$

For space $=$ UNIT

$$
\text { Area[zone }=\text { UNIT, level, sideconfig }]=\frac{\text { Area[zone, level] }}{\sum_{\text {sideconfig } \text { NumUnit[level, sideconfig] }}}
$$

For space $=$ ATTIC

Area[zone, level $=$ levelabove, sideconfig $=$ BRFL $]$

$$
=\sum_{\text {roofID=1,2,3,4 zone=UNIT,HALL,COND,UNCD }} \text { Area[roofID, zone, level] }
$$

For space $=$ CRAWL

$$
\begin{gathered}
\text { Area }\left[\text { zone }=\text { CRAWL, level }=\sum_{\text {floorID }=7,8 \text { zone }=\text { UNIT,HALL,COND,UNCD }} \sum_{\text {AreaFloor[floorID, zone, level }=\mathrm{A} 1]}\right.
\end{gathered}
$$

\subsubsection{Determining Area of Roof and Floor}

\section{For space $=$ HALL, COND, UNCD}

AreaRoof[roofID,zone,level] is obtained from GUI inputs

AreaFloor[floorID,zone,level] is obtained from GUI inputs

For space $=$ UNIT

$$
\begin{aligned}
& \text { AreaRoof[roofID, zone, level] }=\frac{\text { AreaRoof[roofID, zone, level] }}{\sum_{\text {sideconfig NumUNIT[level, sideconfig] }}} \\
& \text { AreaFloor[floorID, zone, level] }=\frac{\text { AreaFloor[floorID, zone, level] }}{\sum_{\text {sideconfig NumUNIT[level, sideconfig] }}}
\end{aligned}
$$


For space $=$ ATTIC

$$
\begin{gathered}
\text { AreaRoof [roofID, zone }=\text { ATTIC, level }=\text { levelabove }] \\
=\sum_{\text {zone }=\text { UNIT,HALL,COND,UNCD }}^{\text {AreaRoof[roofID, zone, level }]}
\end{gathered}
$$

\subsubsection{Determining Width of Walls, Windows and Doors ${ }^{10}$}

\section{Step 1: Calculate HtWall[level,side]and HtWall[level]}

$$
\begin{aligned}
& \text { HtUgWall[B2, side] }=\mathrm{HtUgWall}[\mathrm{B} 2]=\mathrm{Ht}[\mathrm{B} 2] \text {, if } \mathrm{Num}[\mathrm{B} 2]>0 \\
& {\left[\begin{array}{c}
\text { HtExtWall[B1, side }]=\mathrm{Z}[\mathrm{AG}]+\mathrm{Z}[\mathrm{BG}]-\mathrm{Z}[\mathrm{BG}, \text { side }] \\
\text { HtExtWall[B1] }=\text { Min }(\mathrm{HtExtWall}[\mathrm{B} 1 \text {, side }])_{4 \text { sides }}=\mathrm{Z}[\mathrm{AG}] \\
\text { HtUgWall[B1, side }]=\mathrm{Ht}[\mathrm{B} 1]-\mathrm{HtExtWall}[\mathrm{B} 1 \text {, side }] \\
\text { HtUgWall[B1] }=\operatorname{Max}(\mathrm{HtUgWall}[\mathrm{B} 1 \text {, side }])_{4 \text { sides }}=\mathrm{Ht}[\mathrm{B} 1]-\mathrm{Z}[\mathrm{AG}]
\end{array}\right] \text {, if Num[B1]>0}} \\
& \text { HtExtWall[A1, side] }=\mathrm{HtExtWall[A1]}=\mathrm{Ht}[\mathrm{AVG}] \text {, if Num[A1] }>0 \\
& \text { HtExtWall[A2, side] }=\mathrm{HtExtWall[A2]}=\mathrm{Ht}[\mathrm{AVG}] \text {, if Num[A2] }>0 \\
& \text { HtExtWall[A3, side }]=\mathrm{HtExtWall}[\mathrm{A} 3]=\mathrm{Ht}[\mathrm{AVG}] \text {, if Num[A3] }>0 \\
& \text { HtIntWall[level }]=\mathrm{Ht}[\text { level }] \text {, if Num[level }]>0
\end{aligned}
$$

\section{Step 2: Calculate Distribution Factors (DF) for Walls, Windows and Doors}

For zone $=\mathrm{HALL}, \mathrm{COND}, \mathrm{UNCD}$, which can exist on B2, B1, A1, A2, and A3

$$
\begin{aligned}
& \mathrm{DF}_{\text {window or door }}[\text { zone, level }]=\frac{\text { Area[zone, level }]}{\left.\sum_{\text {level }=\mathrm{B} 1, \mathrm{~A} 1, \mathrm{~A} 2, \mathrm{~A} 3}(\mathrm{Num}[\text { level }] \times \text { Area[zone, level }]\right)} \\
& \mathrm{DF}_{\text {ExtWall }}[\text { zone, level, side }]=\frac{\mathrm{DF}_{\text {ExtWall }}^{\prime}[\text { zone, level] }}{1-\mathrm{DF}^{\prime}{ }_{\text {ExtWall }}\left[\text { zone, B1] } \times \frac{\mathrm{HtUgWall[B1, \text {side } ]}}{\mathrm{Ht}[\mathrm{B} 1]}\right.} \times \frac{\mathrm{HtExtWall[level]}}{\mathrm{Ht}[\text { level }]}
\end{aligned}
$$

where

$$
\begin{aligned}
& \mathrm{DF}_{\text {ExtWall }}^{\prime}[\text { zone, level }]=\frac{\text { Area[zone, level }]}{\sum_{\text {level=B1,A1,A2,A3 }(\text { Num[level }] \times \text { Area[zone, level }])}} \\
& \mathrm{DF}_{\text {UgWall }}[\text { zone, level, side }]=\frac{\mathrm{DF}_{\text {UgWall }}^{\prime}[\text { zone, level] }}{1-\mathrm{DF}_{\text {UgWall }}^{\prime}\left[\text { zone, B1] } \times \frac{\mathrm{HtExtWall[B1, \text {side } ]}}{\mathrm{Ht}[\mathrm{B} 1]}\right.} \times \frac{\mathrm{HtUgWall[level]}}{\mathrm{Ht}[\text { level] }}
\end{aligned}
$$

where

$$
\mathrm{DF}_{\text {UgWall }}^{\prime}[\text { zone, level }]=\frac{\text { Area[zone, level }]}{\left.\sum_{\text {level }=\mathrm{B} 1, \mathrm{~B} 2}(\text { Num[level }] \times \text { Area[zone, level] }\right)}
$$

$\mathrm{DF}_{\text {IntWall }}[$ zone, level, attachedzone] $=$

\footnotetext{
${ }^{10}$ Derivation of material in this section is provided in Appendix B.3.
} 
Area[attachedzone, level]

$\overline{\sum_{\text {level=B2,B1,A1,A2,A3 where Area[zone,level] }>0 \text { and Area[attachedzone,level] }>0}(\text { Num[level] } \times \text { Area[attachedzone, level] })}$

$\underline{\text { For zone }=\mathrm{UNIT} \text {, which exists only on B1, A1, A2, and A3 }}$

$\mathrm{DF}_{\text {window or door }}[$ zone $=$ UNIT, level, side $]$

$$
=\frac{1}{\sum_{\text {level }=\mathrm{B} 1, \mathrm{~A} 1, \mathrm{~A} 2, \mathrm{~A} 3}\left(\mathrm{Num}[\text { level }] \times \text { NumUnit}\left[\text { level, side }{ }^{*}\right]\right)}
$$

where NumUnit[level, side $\left.{ }^{*}\right]=\sum_{8}$ sideconfig NumUnit[level, sideconfig] is number of units on a level having at least one wall facing a specific side. ${ }^{11}$

$\mathrm{DF}_{\text {ExtWall }}[$ zone $=$ UNIT, level, side $]$

$$
=\frac{\text { HtExtWall[level, side] }}{\left.\sum_{\text {level=B1,A1,A2,A3 }}\left(\text { Num[level] } \times \text { NumUnit[level, side }{ }^{*}\right] \times \text { HtExtWall[level, side] }\right)}
$$

$\mathrm{DF}_{\mathrm{UgWall}}[$ zone $=$ UNIT, level, side]

$$
=\frac{\text { HtUgWall[level, side }]}{\left.\left.\left.\sum_{\text {level=B1 }}(\text { Num[level }] \times \text { NumUnit[level, } \text { side }^{*}\right] \times \text { HtUgWall[level, side }\right]\right)}
$$

$\mathrm{DF}_{\text {IntWall }}[$ zone $=$ UNIT, level, attachedzone $]=$

Area[attachedzone, level]

$\overline{\sum_{\text {level=B1,A1,A2,A3 where Area[attachedzone,level] }>0}(\mathrm{Num}[\text { level }] \times \text { NumUnit[level] } \times \text { Area[attachedzone, level] })}$

where NumUnit[level] $=\sum_{15}$ sideconfig NumUnit[level, sideconfig] is total number of units on a level.

$\underline{\text { For zone }=\text { CRAWL, which exists only on B1 }}$

$\mathrm{DF}_{\text {ExtWall }}[$ zone, level $=\mathrm{B} 1$, side $]=1$

$\mathrm{DF}_{\mathrm{UgWall}}[$ zone, level $=\mathrm{B} 1$, side $]=1$

\section{Step 3: Calculate Width of Wall, Window and Door Objects for API Submission}

$\underline{\text { Width of Exterior Wall }}$

$$
\begin{aligned}
& \text { WdExtWall[WallID, zone, level, side] } \\
& \qquad=\frac{\text { AreaExtWall[WallID, zone, side] }}{\text { HtExtWall[level] }} \times \mathrm{DF}_{\text {ExtWall }}[\text { zone, level, side] }
\end{aligned}
$$

where

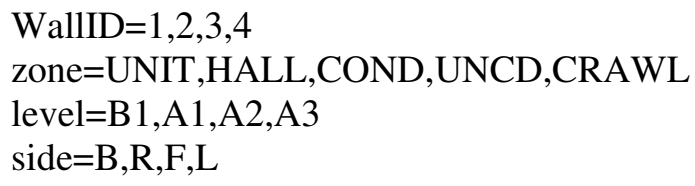

WallID $=1,2,3,4$

zone $=$ UNIT,HALL,COND,UNCD,CRAWL

level=B1,A1,A2,A3

side $=\mathrm{B}, \mathrm{R}, \mathrm{F}, \mathrm{L}$

\footnotetext{
${ }^{11}$ Out of 15 possible 'sideconfig' of units (namely, B, R, F, L, BR, BF, BL, FR, FL, RL, BRF, BFL, BRL, FRL, and BRFL), 8 have at least one wall facing a specific 'side'. For example, B, BR, BF, BL, BRF, BFL, BRL, and BRFL have at least one wall facing B.
} 
Invalid combinations:

[CRAWL,A1,side]

[CRAWL,A2,side]

[CRAWL,A3,side]

Width of Underground Wall

$$
\begin{aligned}
& \text { WdUgWall[WallID, zone, level, side] } \\
& \qquad=\frac{\text { AreaUgWall[WallID, zone, side }]}{\text { HtUgWall[level] }} \times \mathrm{DF}_{\text {UgWall }}[\text { zone, level, side }]
\end{aligned}
$$

where

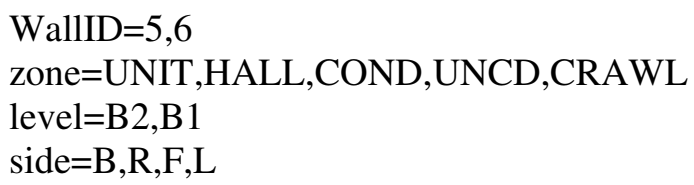

Invalid combinations:

[UNIT,B2,side]

[CRAWL,B2,side]

$\underline{\text { Width of Interior Wall }}$

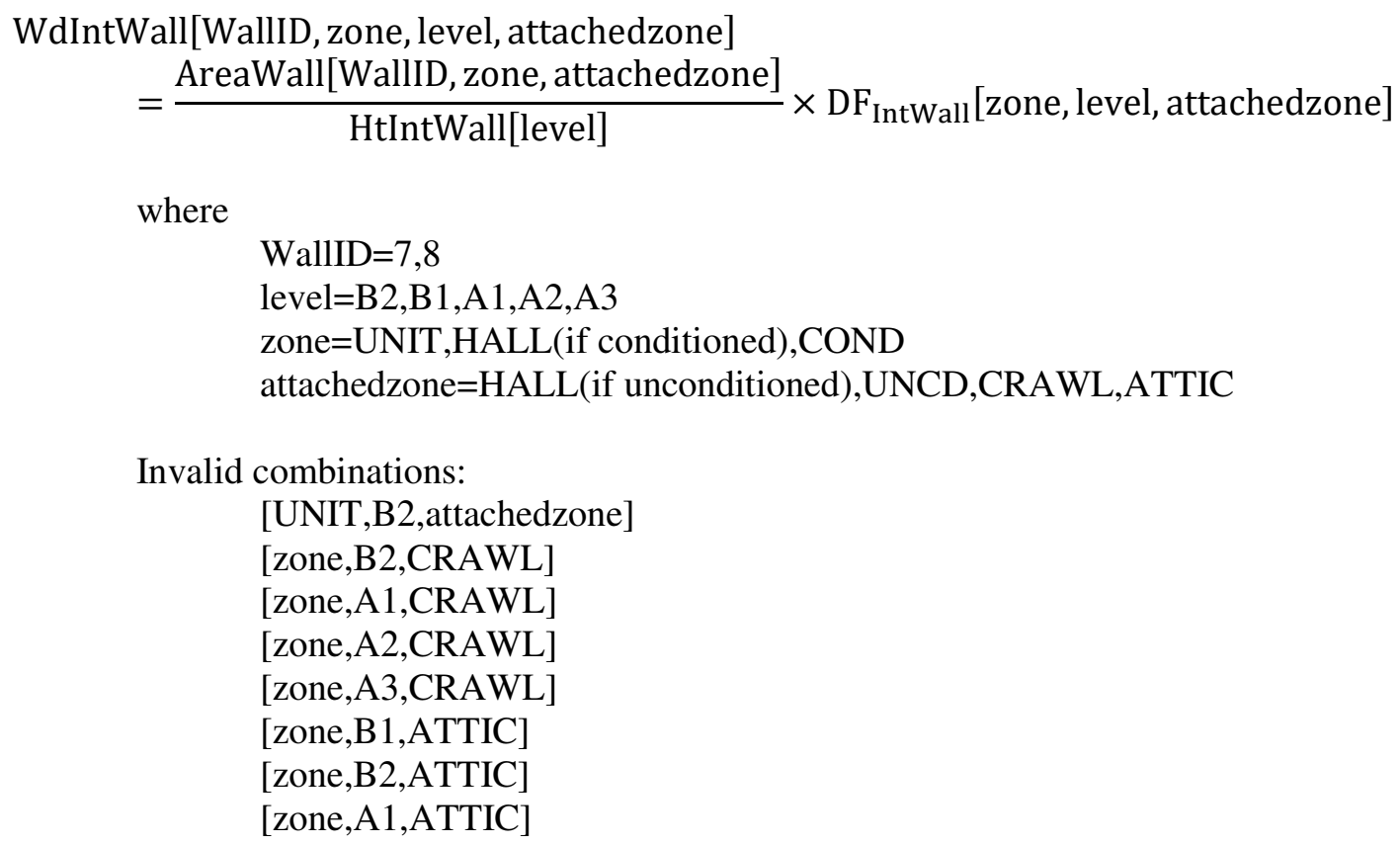

$\underline{\text { Width of Windows }}$

WdWindow[windowID, WallID, zone, level, side]

$=$ WdWindow [windowID] $\times$ NumWin[windowID, WallID, zone, side]

$\times \mathrm{DF}_{\text {window or door }}[$ zone, level, side]

where

WindowID $=1,2,3,4,5,6,7,8$ 


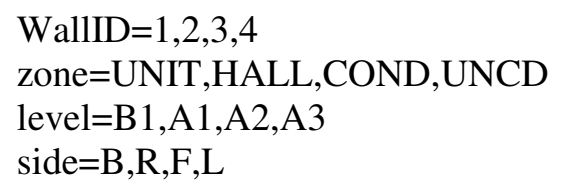

Width of Doors

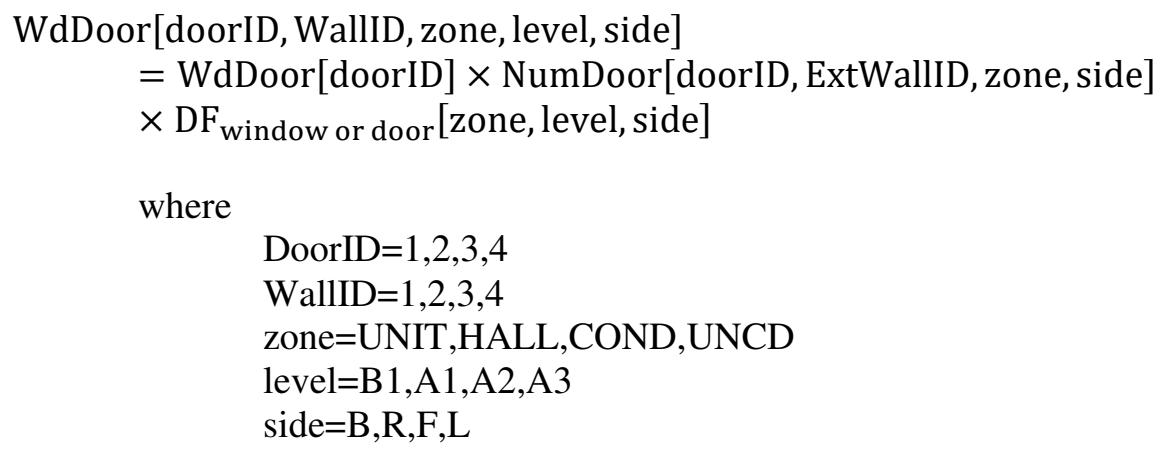

\subsection{DETERMINING PROPERTIES OF OPAQUE CONSTRUCTION LAYERS}

Each wall, roof and ceiling, and floor is modeled as an assembly of up to five layers based on the user input on the WALLS form (Table 4.1), ROOF form (Table 4.4), and FLOOR form (Table 4.7), respectively. These five layers include:

Layer 1: Outer most layer

Layer 2: Exterior insulation

Layer 3: Core layer

Layer 4: Interior insulation

Layer 5: Interior finish

Each layer is submitted to the API as one of the following two sets of attributes, as per Table 4.2 for walls, Table 4.5 for ceiling, Table 4.6 for roof, and Table 4.8 for floor.

\section{Layer attributes set option 1}

COND[ ]: conductivity

DENS[ ]: density

SH[ ]: specific-heat

$\mathrm{TH}[\mathrm{]}$ : thickness

MAT[ ]: material

\section{Layer attributes set option 2}

RES[ ]: resistance $=\mathrm{TH}[\mathrm{]} / \mathrm{COND}[\mathrm{]}$

MAT[ ]: material

The layer attributes are determined using the properties of the materials, which form the layer. If the layer consists of a single material, the attributes are determined using lookup values for material properties (see Appendix A.2). If the layer consists of more than one material in series (i.e., existing insulation and added insulation) or parallel (i.e., insulation or air layer and frame) to the direction of heat transfer, the attributes are determined by calculating equivalent properties of the composite material, as described in Sections 4.3.4 and 4.3.5, respectively. 


\subsubsection{Wall Layers}

Table 4.1. Relevant fields on the WALLS form

\begin{tabular}{|l|l|c|c|c|}
\hline \multirow{2}{*}{ GUI fields } & & \multicolumn{2}{c|}{ Wall tab } \\
\cline { 3 - 5 } & & Exterior & Underground & Interior \\
\hline WallType & Type & $\mathrm{x}$ & $\mathrm{x}$ \\
\hline WallConstruction & Construction & $\mathrm{x}$ & $\mathrm{x}$ \\
\hline WallStudSize & Stud Size & $\mathrm{x}$ & $\mathrm{x}$ \\
\hline WallStudSpacing & Stud Spacing & $\mathrm{x}$ & $\mathrm{x}$ \\
\hline WallMaterial[cavIns] & Material: Cavity Insulation & $\mathrm{x}$ & $\mathrm{x}$ \\
\hline WallRTh[cavIns] & Insulation Thickness: Cavity Insulation & $\mathrm{x}$ & $\mathrm{x}$ \\
\hline WallRval[cavIns] & R-value: Cavity Insulation & $\mathrm{x}$ & $\mathrm{x}$ \\
\hline WallMaterial[extIns] & Material: Exterior Insulation & $\mathrm{x}$ & $\mathrm{x}$ \\
\hline WallRTh[extIns] & Insulation Thickness: Exterior Insulation & $\mathrm{x}$ & $\mathrm{x}$ \\
\hline WallRval[extIns] & R-value: Exterior Insulation & $\mathrm{x}$ & $\mathrm{x}$ \\
\hline WallMaterial[intIns] & Material: Interior Insulation & $\mathrm{x}$ & $\mathrm{x}$ \\
\hline WallRTh[intIns] & Insulation Thickness: Interior Insulation & $\mathrm{x}$ & $\mathrm{x}$ & $\mathrm{x}$ \\
\hline WallRval[intIns] & R-value: Interior Insulation & $\mathrm{x}$ & $\mathrm{x}$ & $\mathrm{x}$ \\
\hline WallMaterial[extFin] & Material: Exterior Finish & $\mathrm{x}$ & $\mathrm{x}$ & $\mathrm{x}$ \\
\hline WallColor & Color & & & \\
\hline WallExposedPerimeter & Exposed Perimeter & & \\
\hline
\end{tabular}

Table 4.2. Modeling parameters for wall construction

\begin{tabular}{|c|c|c|c|c|c|c|}
\hline Material & & \multicolumn{2}{|c|}{ CONDDENS } & SH & TH & RES \\
\hline \multicolumn{7}{|l|}{ Exterior wall } \\
\hline Layer 1: Exterior Finish & Look up for WallMaterial[extFin] & $\mathrm{x}$ & $\mathrm{x}$ & $\mathrm{x}$ & $\mathrm{x}$ & - \\
\hline Layer 2: Exterior Insulation & Calculate for WallMaterial[extIns] & $\mathrm{x}$ & $\mathrm{x}$ & $\mathrm{x}$ & $\mathrm{x}$ & - \\
\hline Layer 3: Core Layer & Calculate for WallConstruction and WallMaterial[cavIns] & $\mathrm{x}$ & $\mathrm{x}$ & $\mathrm{x}$ & $\mathrm{x}$ & - \\
\hline Layer 4: Interior Insulation & Calculate for WallMaterial[intIns] & $\mathrm{x}$ & $\mathrm{x}$ & $\mathrm{x}$ & $\mathrm{x}$ & - \\
\hline Layer 5: Interior Finish & Look up for Drywall & $\mathrm{x}$ & $\mathrm{x}$ & $\mathrm{x}$ & $\mathrm{x}$ & - \\
\hline \multicolumn{7}{|l|}{ Underground wall } \\
\hline Layer 1: Fictitious Layer & Calculate for Fictitious layer (as described below the table) & - & - & - & - & $\mathrm{x}$ \\
\hline Hardcoded (1 ft. Soil) & Look up for Soil & $\mathrm{x}$ & $\mathrm{x}$ & $\mathrm{x}$ & $\mathrm{x}$ & - \\
\hline Layer 2: Exterior Insulation & Calculate for WallMaterial[extIns] & $\mathrm{x}$ & $\mathrm{x}$ & $\mathrm{x}$ & $\mathrm{x}$ & - \\
\hline Layer 3: Core layer & Look up for WallConstruction & $\mathrm{x}$ & $\mathrm{x}$ & $\mathrm{x}$ & $\mathrm{x}$ & - \\
\hline Layer 4: Interior Insulation & Calculate for WallMaterial[intIns] & $\mathrm{x}$ & $\mathrm{x}$ & $\mathrm{x}$ & $\mathrm{x}$ & - \\
\hline Layer 5: Interior Finish & Look up for Drywall & $\mathrm{x}$ & $\mathrm{x}$ & $\mathrm{x}$ & $\mathrm{x}$ & - \\
\hline \multicolumn{7}{|l|}{ Interior wall } \\
\hline Layer 1: Exterior Finish & Look up for Drywall & $\mathrm{x}$ & $\mathrm{x}$ & $\mathrm{x}$ & $\mathrm{x}$ & - \\
\hline Layer 2: Exterior Insulation & Calculate for WallMaterial[extIns] & $\mathrm{x}$ & $\mathrm{x}$ & $\mathrm{x}$ & $\mathrm{x}$ & - \\
\hline Layer 3: Core layer & Calculate for WallConstruction and WallMaterial[cavIns] & $\mathrm{x}$ & $\mathrm{x}$ & $\mathrm{x}$ & $\mathrm{x}$ & - \\
\hline Layer 4: Interior Insulation & Calculate for WallMaterial[intIns] & $\mathrm{x}$ & $\mathrm{x}$ & $\mathrm{x}$ & $\mathrm{x}$ & - \\
\hline Layer 5: Interior Finish & Look up for Drywall & $\mathrm{x}$ & $\mathrm{x}$ & $\mathrm{x}$ & $\mathrm{x}$ & - \\
\hline
\end{tabular}


Calculations for underground wall layer 1 (i.e., a fictitious layer) are performed based on Winkelmann (2002), as follows:

Step 1: Calculate perimeter conduction factor for underground wall:

$$
\mathrm{F} 2=\sum_{\mathrm{i}=0}^{4}\left(\mathrm{~m}_{\mathrm{i}} \mathrm{H}+\mathrm{n}_{\mathrm{i}}\right) \cdot \mathrm{R}^{\mathrm{i}}
$$

where

$$
\mathrm{H}=\text { height of underground wall }
$$

$\mathrm{R}=\left(\mathrm{R}_{\text {extins }}+\mathrm{R}_{\text {eqvintins }}\right) / 100$

$\mathrm{R}_{\text {extins }}=$ Wall exterior insulation $\mathrm{R}$-value

$\mathrm{R}_{\text {eqvintins }}=\mathrm{a} \cdot \mathrm{R}_{\text {intins }} \cdot \mathrm{H}+\mathrm{b} \cdot \mathrm{R}_{\text {intins }}+\mathrm{c} \cdot \mathrm{H}+\mathrm{d}$

$\mathrm{R}_{\text {intins }}=$ Wall interior insulation $\mathrm{R}$-value

Coefficients $m_{i}, n_{i}, a, b, c$, and $d$ are provided in Table 4.3 for crawlspace and basement.

Table 4.3. Coefficients for calculating perimeter conduction factor for underground wall

\begin{tabular}{|c|c|c|}
\hline Multiplier & Crawlspace & Basement \\
\hline $\mathrm{m}_{4}$ & 177.92 & 133.33 \\
\hline $\mathrm{m}_{3}$ & -121.99 & -80 \\
\hline $\mathrm{m}_{2}$ & 30.184 & 17.167 \\
\hline $\mathrm{m}_{1}$ & -3.3265 & -1.825 \\
\hline $\mathrm{m}_{0}$ & -0.005 & 0.0825 \\
\hline $\mathrm{n}_{4}$ & 1421.6 & 2400 \\
\hline $\mathrm{n}_{3}$ & -658.72 & -1186.7 \\
\hline $\mathrm{n}_{2}$ & 103.93 & 218 \\
\hline $\mathrm{n}_{1}$ & -6.7274 & -18.033 \\
\hline $\mathrm{n}_{0}$ & 1.3 & 1.28 \\
\hline $\mathrm{a}$ & 0.0036 & 0 \\
\hline $\mathrm{b}$ & -0.0454 & 0 \\
\hline $\mathrm{c}$ & -0.032 & 0.0425 \\
\hline $\mathrm{d}$ & 1.029 & 0.55 \\
\hline
\end{tabular}

The equation for perimeter conduction factor in Step 1 is derived in Appendix B.2.2 for basement wall and Appendix B.2.3 for crawlspace wall.

Step 2: Calculate effective R-value of underground wall:

$$
\mathrm{R}_{\text {effective }}=\frac{\text { Area }}{\mathrm{P}_{\mathrm{exp}} \cdot \mathrm{F} 2}
$$

where

$$
\begin{aligned}
& \text { Area }=\text { underground wall area } \\
& \text { Pexp }=\text { exposed perimeter }(\mathrm{ft})
\end{aligned}
$$


Step 3: Calculate R-value of fictitious underground wall layer:

$\mathrm{R}_{\text {fictitious }}=\mathrm{R}_{\text {effective }}-\mathrm{R}_{\mathrm{us}}-1$

where

$\mathrm{R}_{\mathrm{us}}=$ underground wall resistance
$\quad=\mathrm{R}_{\text {extins }}+\mathrm{R}_{\text {core }}+\mathrm{R}_{\text {intins }}+\mathrm{R}_{\text {intfin }}+0.68$

$\mathrm{R}_{\text {extins }}, \mathrm{R}_{\text {core }}, \mathrm{R}_{\text {intins }}$, and $\mathrm{R}_{\text {intfin }}$ are $\mathrm{R}$-values of layers $2,3,4$, and 5 , respectively, of the underground wall

0.68 is the interior air-film resistance (in $\mathrm{hr}_{\mathrm{ft}} \mathrm{ft}^{2}{ }^{\circ} \mathrm{F} / \mathrm{Btu}$ ) for a vertical surface

\subsubsection{Roof Layers}

Table 4.4. Relevant fields on the ROOF form

\begin{tabular}{|l|l|c|c|c|}
\hline \multirow{2}{*}{ GUI fields } & & \multicolumn{2}{c|}{ Roof tab } \\
\cline { 3 - 5 } & & Attic & Cathedral & Flat \\
\hline RoofType & Type & $\mathrm{x}$ & $\mathrm{x}$ \\
\hline RoofConstruction & Construction & $\mathrm{x}$ & $\mathrm{x}$ & $\mathrm{x}$ \\
\hline RoofJoistSize & Joist Size & $\mathrm{x}$ & $\mathrm{x}$ & $\mathrm{x}$ \\
\hline RoofJoistSpacing & Joist Spacing & $\mathrm{x}$ & $\mathrm{x}$ \\
\hline RoofMaterial[ceilIns] & Material: Ceiling Insulation & $\mathrm{x}$ & $\mathrm{x}$ \\
\hline RoofRTh[ceilIns] & Insulation Thickness: Ceiling Insulation & $\mathrm{x}$ & $\mathrm{x}$ \\
\hline RoofRval[ceilIns] & R-value: Ceiling Insulation & $\mathrm{x}$ & $\mathrm{x}$ \\
\hline RoofMaterial[roofIns] & Material: Roof Insulation & $\mathrm{x}$ & $\mathrm{x}$ & $\mathrm{x}$ \\
\hline RoofRTh[roofIns] & Insulation Thickness: Roof Insulation & $\mathrm{x}$ & $\mathrm{x}$ \\
\hline RoofRval[roofIns] & R-value: Roof Insulation & $\mathrm{x}$ & $\mathrm{x}$ & $\mathrm{x}$ \\
\hline RoofLocRB[] & Location of Radiant Barrier & $\mathrm{x}$ & $\mathrm{x}$ & $\mathrm{x}$ \\
\hline RoofMaterial[extFin] & Material: Exterior Finish & $\mathrm{x}$ & $\mathrm{x}$ \\
\hline RoofColor & Color & $\mathrm{x}$ & $\mathrm{x}$ \\
\hline
\end{tabular}

Table 4.5. Modeling parameters for ceiling construction

\begin{tabular}{|l|l|c|c|c|c|c|}
\hline \multicolumn{1}{|c|}{ Material } & & COND & DENS & SH & TH & RES \\
\hline Attic roof & & & & & & \\
\hline Layer 1: Radiant Barrier, if any & Lookup for Radiant Barrier & $\mathrm{x}$ & $\mathrm{x}$ & $\mathrm{x}$ & $\mathrm{x}$ & - \\
\hline Layer 2: Exterior Insulation & Calculate for CeilMaterial[extIns] & $\mathrm{x}$ & $\mathrm{x}$ & $\mathrm{x}$ & $\mathrm{x}$ & - \\
\hline Layer 3: Core Layer & $\begin{array}{l}\text { Calculate for CeilConstruction and } \\
\text { CeilMaterial[cavIns] }\end{array}$ & $\mathrm{x}$ & $\mathrm{x}$ & $\mathrm{x}$ & $\mathrm{x}$ & - \\
\hline Layer 4: Interior Insulation & Calculate for CeilMaterial[intIns] & $\mathrm{x}$ & $\mathrm{x}$ & $\mathrm{x}$ & $\mathrm{x}$ & - \\
\hline Layer 5: Interior Finish & Lookup for Drywall & $\mathrm{x}$ & $\mathrm{x}$ & $\mathrm{x}$ & $\mathrm{x}$ & - \\
\hline
\end{tabular}


Table 4.6. Modeling parameters for roof construction

\begin{tabular}{|c|c|c|c|c|c|c|}
\hline Material & & COND & DENS & SH & TH & RES \\
\hline \multicolumn{7}{|l|}{ Attic roof } \\
\hline Layer 1: Roofing & Look up for RoofMaterial[extFin] & $\mathrm{x}$ & $\mathrm{x}$ & $\mathrm{x}$ & $\mathrm{x}$ & - \\
\hline Layer 2: Insulation Above Core & Calculate for RoofMaterial[extIns] & $\mathrm{x}$ & $\mathrm{x}$ & $\mathrm{x}$ & $\mathrm{x}$ & - \\
\hline Layer 3: Core Layer & $\begin{array}{l}\text { Calculate for RoofConstruction and } \\
\text { RoofMaterial[cavIns] }\end{array}$ & $\mathrm{x}$ & $\mathrm{x}$ & $\mathrm{x}$ & $\mathrm{x}$ & - \\
\hline Layer 4: Insulation Below Core & Calculate for RoofMaterial[intIns] & $\mathrm{x}$ & $\mathrm{x}$ & $\mathrm{x}$ & $\mathrm{x}$ & - \\
\hline Layer 5: Radiant Barrier, if any & Look up for Radiant Barrier & $\mathrm{x}$ & $\mathrm{x}$ & $\mathrm{x}$ & $\mathrm{x}$ & - \\
\hline \multicolumn{7}{|l|}{ Cathedral roof } \\
\hline Layer 1: Roofing & Look up for RoofMaterial[extFin] & - & - & - & - & $\mathrm{x}$ \\
\hline Layer 2: Insulation Above Core & Calculate for RoofMaterial[extIns] & $\mathrm{x}$ & $\mathrm{x}$ & $\mathrm{x}$ & $\mathrm{x}$ & - \\
\hline Layer 3: Core layer & Look up for RoofConstruction & $\mathrm{x}$ & $\mathrm{x}$ & $\mathrm{x}$ & $\mathrm{x}$ & - \\
\hline Layer 4: Insulation Below Core & Calculate for RoofMaterial[intIns] & $\mathrm{x}$ & $\mathrm{x}$ & $\mathrm{x}$ & $\mathrm{x}$ & - \\
\hline Layer 5: Interior Finish & Look up for Drywall & $\mathrm{x}$ & $\mathrm{x}$ & $\mathrm{x}$ & $\mathrm{x}$ & - \\
\hline \multicolumn{7}{|l|}{ Flat roof } \\
\hline Layer 1: Roofing & Look up for RoofMaterial[extFin] & $\mathrm{x}$ & $\mathrm{x}$ & $\mathrm{x}$ & $\mathrm{x}$ & - \\
\hline Layer 2: Insulation Above Core & Calculate for RoofMaterial[extIns] & $\mathrm{x}$ & $\mathrm{x}$ & $\mathrm{x}$ & $\mathrm{x}$ & - \\
\hline Layer 3: Core layer & $\begin{array}{l}\text { Calculate for RoofConstruction and } \\
\text { RoofMaterial[cavIns] }\end{array}$ & $\mathrm{x}$ & $\mathrm{x}$ & $\mathrm{x}$ & $\mathrm{x}$ & - \\
\hline Layer 4: Insulation Below Core & Calculate for RoofMaterial[intIns] & $\mathrm{x}$ & $\mathrm{x}$ & $\mathrm{x}$ & $\mathrm{x}$ & - \\
\hline Layer 5: Interior Finish & Look up for Drywall & $\mathrm{x}$ & $\mathrm{x}$ & $\mathrm{x}$ & $\mathrm{x}$ & - \\
\hline
\end{tabular}

\subsubsection{Floor Layers}

Table 4.7. Relevant fields on the FLOOR form

\begin{tabular}{|l|l|c|c|c|c|}
\hline \multirow{2}{*}{ GUI fields } & & \multicolumn{3}{c|}{ Floor tab } \\
\cline { 3 - 6 } & & Underground & Exposed & Interior & Above-crawlspace \\
\hline FloorType & Type & $\mathrm{x}$ & $\mathrm{x}$ & $\mathrm{x}$ & $\mathrm{x}$ \\
\hline FloorConstruction & Construction & & $\mathrm{x}$ & $\mathrm{x}$ & $\mathrm{x}$ \\
\hline FloorJoistSize & Joist Size & & $\mathrm{x}$ & $\mathrm{x}$ & $\mathrm{x}$ \\
\hline FloorJoistSpacing & Joist Spacing & $\mathrm{x}$ & $\mathrm{x}$ & \\
\hline FloorMaterial[slabIns] & Material: Slab Insulation & & & \\
\hline FloorRTh[slabIns] & Insulation Thickness: Slab Insulation & $\mathrm{x}$ & & \\
\hline FloorRval[slabIns] & R-value: Slab Insulation & & & & \\
\hline FloorMaterial[extIns] & Material: Exterior Insulation & & $\mathrm{x}$ & $\mathrm{x}$ & \\
\hline FloorRTh[extIns] & Insulation Thickness: Exterior Insulation & & $\mathrm{x}$ & $\mathrm{x}$ \\
\hline FloorRval[extIns] & R-value: Exterior Insulation & & $\mathrm{x}$ & $\mathrm{x}$ & $\mathrm{x}$ \\
\hline FloorMaterial[intIns] & Material: Interior Insulation & & $\mathrm{x}$ & $\mathrm{x}$ & \\
\hline FloorRTh[intIns] & Insulation Thickness: Interior Insulation & & $\mathrm{x}$ & $\mathrm{x}$ & $\mathrm{x}$ \\
\hline FloorRval[intIns] & R-value: Interior Insulation & & $\mathrm{x}$ & $\mathrm{x}$ & $\mathrm{x}$ \\
\hline FloorMaterial[sillIns] & Material: Sill Insulation & & $\mathrm{x}$ & $\mathrm{x}$ \\
\hline FloorRTh[sillIns] & Insulation Thickness: Sill Insulation & & & $\mathrm{x}$ & $\mathrm{x}$ \\
\hline FloorRval[sillIns] & R-value: Sill Insulation & & $\mathrm{x}$ & $\mathrm{x}$ \\
\hline FloorCarpetFrac & Carpet Fraction & & $\mathrm{x}$ & $\mathrm{x}$ \\
\hline FloorExposedPerimeter & Exposed Perimeter & & $\mathrm{x}$ \\
\hline
\end{tabular}


Table 4.8. Modeling parameters for floor construction

\begin{tabular}{|c|c|c|c|c|c|c|}
\hline Material & & COND & DENS & SH & TH & RES \\
\hline \multicolumn{7}{|l|}{ Underground floor } \\
\hline Layer 1: Fictitious Layer & $\begin{array}{l}\text { Calculate for Fictitious Layer (as described } \\
\text { below the table) }\end{array}$ & - & - & - & - & $\mathrm{x}$ \\
\hline Hardcoded (1 ft. Soil) & Look up for Soil & $\mathrm{x}$ & $\mathrm{x}$ & $\mathrm{x}$ & $\mathrm{x}$ & - \\
\hline Layer 2: Insulation Below Core & NA & $\mathrm{x}$ & $\mathrm{x}$ & $\mathrm{x}$ & $\mathrm{x}$ & - \\
\hline Layer 3: Core Layer & Look up for FloorConstruction & $\mathrm{x}$ & $\mathrm{x}$ & $\mathrm{x}$ & $\mathrm{x}$ & - \\
\hline Layer 4: Insulation Above Core & NA & $\mathrm{x}$ & $\mathrm{x}$ & $\mathrm{x}$ & $\mathrm{x}$ & - \\
\hline Layer 5: Floor Finish & Look up for FloorMaterial[intFinish] & $\mathrm{x}$ & $\mathrm{x}$ & $\mathrm{x}$ & $\mathrm{x}$ & - \\
\hline \multicolumn{7}{|l|}{ Exposed floor } \\
\hline Layer 1: Exterior Finish & Look up for Drywall & - & - & - & - & $\mathrm{x}$ \\
\hline Layer 2: Insulation Below Core & Calculate for FloorMaterial[extIns] & $\mathrm{x}$ & $\mathrm{x}$ & $\mathrm{x}$ & $\mathrm{x}$ & - \\
\hline Layer 3: Core layer & $\begin{array}{l}\text { Look up for FloorConstruction and } \\
\text { FloorMaterial[cavIns] }\end{array}$ & $\mathrm{x}$ & $\mathrm{x}$ & $\mathrm{x}$ & $\mathrm{x}$ & - \\
\hline Layer 4: Insulation Above Core & Calculate for FloorMaterial[intIns] & $\mathrm{x}$ & $\mathrm{x}$ & $\mathrm{x}$ & $\mathrm{x}$ & - \\
\hline Layer 5: Floor Finish & Look up for FloorMaterial[intFinish] & $\mathrm{x}$ & $\mathrm{x}$ & $\mathrm{x}$ & $\mathrm{x}$ & - \\
\hline \multicolumn{7}{|l|}{ Interior floor } \\
\hline Layer 1: Drywall & Look up for Drywall & $\mathrm{x}$ & $\mathrm{x}$ & $\mathrm{x}$ & $\mathrm{x}$ & - \\
\hline Layer 2: Insulation Below Core & Calculate for FloorMaterial[extIns] & $\mathrm{x}$ & $\mathrm{x}$ & $\mathrm{x}$ & $\mathrm{x}$ & - \\
\hline Layer 3: Core layer & $\begin{array}{l}\text { Look up for FloorConstruction and } \\
\text { FloorMaterial[cavIns] }\end{array}$ & $\mathrm{x}$ & $\mathrm{x}$ & $\mathrm{x}$ & $\mathrm{x}$ & - \\
\hline Layer 4: Insulation Above Core & Calculate for FloorMaterial[intIns] & $\mathrm{x}$ & $\mathrm{x}$ & $\mathrm{x}$ & $\mathrm{x}$ & - \\
\hline Layer 5: Interior Finish & Look up for FloorMaterial[intFinish] & $\mathrm{x}$ & $\mathrm{x}$ & $\mathrm{x}$ & $\mathrm{x}$ & - \\
\hline \multicolumn{7}{|l|}{ Above-crawlspace floor } \\
\hline Layer 1: Exterior Finish & NA & & & & & \\
\hline Layer 2: Insulation Below Core & Calculate for FloorMaterial[extIns] & & & & & \\
\hline Layer 3: Core layer & $\begin{array}{l}\text { Look up for FloorConstruction and } \\
\text { FloorMaterial[cavIns] }\end{array}$ & & & & & \\
\hline Layer 4: Insulation Above Core & NA & & & & & \\
\hline Layer 5: Floor Finish & Look up for FloorMaterial[intFinish] & $\mathrm{x}$ & $\mathrm{x}$ & $\mathrm{x}$ & $\mathrm{x}$ & - \\
\hline
\end{tabular}

Calculations for underground floor layer 1 (i.e., a fictitious layer) are performed based on Winkelmann (2002), as follows:

Step 1: Calculate perimeter conduction factor for slab-on-grade floor:

$\mathrm{F} 2=\mathrm{a} \cdot \mathrm{C}_{\mathrm{f}} \cdot \mathrm{H}+\mathrm{b} \cdot \mathrm{C}_{\mathrm{f}}+\mathrm{c} \cdot \mathrm{H}+\mathrm{d}$

where

$\mathrm{H}=\mathrm{Slab}$ insulation depth/width (ft)

$\mathrm{C}_{\mathrm{f}}=$ carpet fraction

Coefficients a, b, c, and d are given in Table 4.9 for different slab insulation location 
Table 4.9. Coefficients for calculating perimeter conduction factor for slab-on-grade floor

\begin{tabular}{|l|c|c|c|c|}
\hline \multicolumn{1}{|c|}{ Slab insulation location } & a & b & c & d \\
\hline None & 0 & -0.33 & 0 & 1.1 \\
\hline Exterior & 0.02 & -0.23 & -0.06 & 0.85 \\
\hline Interior & 0.015 & -0.21 & -0.06 & 0.87 \\
\hline Perimeter & 0.02 & -0.22 & -0.05 & 0.88 \\
\hline Horizontal & 0.01 & -0.19 & -0.035 & 0.72 \\
\hline
\end{tabular}

The equation for perimeter conduction factor in Step 1 is derived in Appendix B.2.1.

Step 2: Calculate effective R-value of underground floor:

$$
\mathrm{R}_{\text {effective }}=\frac{\text { Area }}{\mathrm{P}_{\mathrm{exp}} \cdot \mathrm{F} 2}
$$

where

$$
\begin{aligned}
& \text { Area = underground floor area } \\
& \mathrm{P}_{\text {exp }}=\text { exposed perimeter }(\mathrm{ft})
\end{aligned}
$$

Step 3: Calculate R-value of fictitious underground floor layer 1:

$$
\begin{aligned}
& \mathrm{R}_{\text {fictitious }}=\mathrm{R}_{\text {effective }}-\mathrm{R}_{\mathrm{us}}-1 \\
& \text { where } \\
& \qquad \begin{aligned}
& \mathrm{R}_{\mathrm{us}}=\text { underground floor resistance }=\mathrm{R}_{\text {ugfloor }}+0.77 \\
& \mathrm{R}_{\text {ugfloor }}=\text { underground slab resistance }=\frac{1}{\frac{1-\mathrm{C}_{\mathrm{f}}}{\mathrm{R}_{\text {slab }}}+\frac{\mathrm{C}_{\mathrm{f}}}{\mathrm{R}_{\text {slab }}+\mathrm{R}_{\text {carpet }}}} \\
&=\frac{\mathrm{R}_{\text {slab }} *\left(\mathrm{R}_{\text {slab }}+\mathrm{R}_{\text {carpet }}\right)}{\left(\mathrm{R}_{\text {slab }}+\mathrm{R}_{\text {carpet }}\right)-\mathrm{C}_{\mathrm{f}} * \mathrm{R}_{\text {carpet }}}=\frac{0.44 *(0.44+2.08)}{(0.44+2.08)-\mathrm{C}_{\mathrm{f}} * 2.08} \\
&=\frac{1.1088}{2.52-\mathrm{C}_{\mathrm{f}} * 2.08}
\end{aligned}
\end{aligned}
$$

0.77 is the average interior air-film resistance (in $\mathrm{hr}_{\mathrm{ft}}{ }^{2} .{ }^{\circ} \mathrm{F} / \mathrm{Btu}$ ) for heat flow up

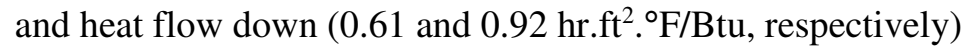

\subsubsection{Composite Layer Consisting of $\boldsymbol{n}$ Layers in Series (e.g., Existing and Added Insulation)}

\section{Known:}

COND[n], DENS[n], SH[n], TH[n]

\section{Calculate:}

$$
\operatorname{FRAC}[\mathrm{n}]=\frac{\mathrm{TH}[\mathrm{n}]}{\sum \mathrm{TH}[\mathrm{n}]}
$$


If layers are in series,

$$
\operatorname{COND}[\mathrm{eqv}]=\frac{\sum \mathrm{TH}[\mathrm{n}]}{\sum \frac{\mathrm{TH}[\mathrm{n}]}{\operatorname{COND}[\mathrm{n}]}}
$$

Elseif layers are in parallel,

$$
\operatorname{COND}[\mathrm{eqv}]=\sum \operatorname{COND}[\mathrm{n}] \cdot \operatorname{FRAC}[\mathrm{n}]
$$

Endif

$$
\begin{aligned}
& \text { DENS[eqv] }=\sum \text { DENS[n] } \operatorname{FRAC}[\mathrm{n}] \\
& \mathrm{SH}\left[\text { eqv] }=\frac{\sum \mathrm{SH}[\mathrm{n}] \cdot \operatorname{DENS}[\mathrm{n}] \cdot \operatorname{FRAC}[\mathrm{n}]}{\sum \mathrm{DENS}[\mathrm{n}]}\right. \\
& \mathrm{TH}[\mathrm{eqv}]=\sum \mathrm{TH}[\mathrm{n}] \\
& \text { MAT }[\text { eqv }]=\left\{\begin{array}{c}
\text { MAT }[\text { eqv }], \text { if TH[eqv] }>0 \\
\text { NONE, otherwise }
\end{array}\right.
\end{aligned}
$$

\subsubsection{Composite Core Layer Consisting of Frame and Insulation in Parallel}

The following procedure is based on Modified Zone Method for Metal Stud Walls with Insulated Cavities (ASHRAE 2013a, p.27.5). This procedure is employed for both wood and metal stud walls. For wood stud walls, the method reduces to the traditional parallel path method.

\section{Known:}

- $\quad$ COND[cavIns], DENS[cavIns], SH[cavIns], TH[cavIns], RES[cavIns]

- COND[frame], DENS[frame], SH[frame], TH[frame]

- $\quad$ DENS[airlayer] $=0.076, \mathrm{SH}$ [airlayer] $=0.24, \operatorname{RES}[$ airlayer $]=0.80$

- FrameFrac[ ]

- $\quad \mathrm{COND}[1], \mathrm{TH}[1]$

- COND[2], TH[2]

- $\operatorname{COND}[4], \mathrm{TH}[4]$

- COND[5], TH[5]

\section{Calculate:}

$\underline{\text { Adjustments if insulation thickness }<\text { frame thickness }}$

$$
\begin{aligned}
& \text { IsTH }[\text { cavIns }<\text { frame }]=\text { Is }(\text { TH [cavIns }]<\text { TH[frame }]) \\
& \text { IsMAT[no4no5] = FALSE } \\
& \text { IsTH[frameAdj] = AND (IsTH[cavIns }<\text { frame] = TRUE, IsMAT[no4no5] = TRUE) }
\end{aligned}
$$


$\operatorname{IsRES}[\operatorname{cavInsAdj}]=\operatorname{AND}(\operatorname{IsTH}[\operatorname{cavIns}<$ frame $]=$ TRUE, IsMAT[no4no5] $=$ FALSE $)$

$\mathrm{TH}\left[\right.$ frameAdj] $=\left\{\begin{array}{c}\mathrm{TH}[\mathrm{cavIns}], \text { if IsTH[frameAdj] }=\text { TRUE (i. e. , cavity is partially filled) } \\ \mathrm{TH}[\text { frame }], \text { otherwise (i. e. , if cavity is completely filled) }\end{array}\right.$

$\operatorname{RES}[$ cavInsAdj $]=\left\{\begin{array}{c}\text { RES[cavIns] }+ \text { RES[airlayer], if IsRES[cavInsAdj] }=\text { TRUE } \\ \text { RES[cavIns], otherwise }\end{array}\right.$

$\operatorname{COND}[$ cavInsAdj $]=\frac{\mathrm{TH}[\text { frameAdj }]}{\operatorname{RES}[\text { cavInsAdj }]}$

Frac $[$ cavIns $]=\operatorname{Th}[\operatorname{cavIns}] / \operatorname{Th}[$ frameAdj $]$

DENS[cavInsAdj] $=$ DENS[cavIns $] *$ Frac[cavIns $]+$ DENS[airlayer $] *(1-$ Frac[cavIns $])$

$\mathrm{SH}[\operatorname{cavInsAdj}]=$

SH[cavIns] $*$ DENS[cavIns] $*$ Frac[cavIns] + SH[airlayer] $*$ DENS[airlayer] $*(1-$ Frac[cavIns] $)$

DENS[cavInsAdj]

$\underline{\text { Intermediate calculations }}$

$\mathrm{l}=$ frame width or stud flange size $=\left\{\begin{array}{c}1.5^{\prime \prime}, \text { if WallConstruction }=\text { wood } \\ 1.625 ", \text { if WallConstruction }=\text { metal }\end{array}\right.$

$\mathrm{d}_{2}=$ frame web thickness $=\left\{\begin{array}{c}l, \text { if WallConstruction }=\text { wood } \\ 0.125 ", \text { if WallConstruction }=\text { metal }\end{array}\right.$

$\mathrm{d}_{2 \mathrm{a}}=$ flange 1 thickness

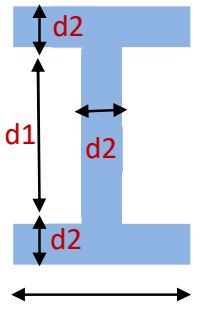

Frame Width, I

ROOF or FLOOR
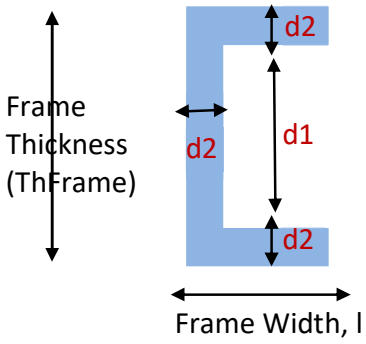

WALL $=\operatorname{MIN}\left[\mathrm{d}_{2}, \mathrm{TH}[\right.$ frameAdj $\left.] * 12\right]$

$\mathrm{d}_{2 \mathrm{~b}}=$ flange 2 thickness $=\left\{\begin{array}{c}0, \text { if IsTH[frameAdj }]=\text { TRUE } \\ \operatorname{MIN}\left[\mathrm{d}_{2}, \mathrm{TH}[\text { frameAdj }] * 12 \text {, otherwise }\right.\end{array}\right.$

$\mathrm{d}_{1}=$ frame web depth $=\mathrm{TH}[$ frameAdj $] * 12-\mathrm{d}_{2 \mathrm{a}}-\mathrm{d}_{2 \mathrm{~b}}$

$\mathrm{s}=$ theoretical frame spacing $=\frac{\mathrm{l}}{\text { FrameFrac[ ] }}$

FrameFrac[actual $]=$ FrameFrac $[\quad] * \frac{\mathrm{d}_{2 \mathrm{a}} * \mathrm{l}+\mathrm{d}_{2 \mathrm{~b}} * \mathrm{l}+\mathrm{d}_{1} * \mathrm{~d}_{2}}{\left(\mathrm{~d}_{1}+\mathrm{d}_{2 \mathrm{a}}+\mathrm{d}_{2 \mathrm{~b}}\right) * \mathrm{l}}$

$\operatorname{COND}[$ extSh $]=\left\{\begin{array}{c}\mathrm{COND}[2], \text { if } \\ \operatorname{COND}[1], \text { otherwise }\end{array}\right.$

$\operatorname{COND}[$ intSh $]=\left\{\begin{array}{c}\operatorname{COND}[4], \text { if } \\ \operatorname{COND}[5], \text { otherwise }\end{array}\right.$

$\operatorname{COND}[\operatorname{avgSh}]=\operatorname{AVG}(\operatorname{COND}[$ extSh $], \operatorname{COND}[$ intSh $])$ 
FCOND $[\quad]=$ ratio of conducticities of cavity insulation and sheathing $=\frac{\operatorname{COND}[\text { cavIns }]}{\operatorname{COND}[\operatorname{avgSh}]}$

$\mathrm{TH}[\mathrm{extSh}]=\mathrm{TH}[1]+\mathrm{TH}[2]$

$\mathrm{TH}[\mathrm{intSh}]=\mathrm{TH}[4]+\mathrm{TH}[5]$

$\mathrm{z}_{\mathrm{f}}=$ zone factor

$=\left(\mathrm{m}_{0} * \mathrm{TH}[\right.$ frameAdj $\left.] * 12+\mathrm{c}_{0}\right)+\left(\mathrm{m}_{1} * \mathrm{TH}[\right.$ frameAdj $\left.] * 12+\mathrm{c}_{1}\right) * \mathrm{FCOND}[\quad]$

$+\left(\mathrm{m}_{2} * \mathrm{TH}[\right.$ frameAdj $\left.] * 12+\mathrm{c}_{2}\right) * \mathrm{FCOND}[]^{2}$,

where $m_{0}, m_{1}, m_{2}, c_{0}, c_{1}$, and $c_{2}$ are obtained from Table 4.10.

Table 4.10. Slope and intercept for calculating zone factor $z_{f}$

\begin{tabular}{|c|c|c|c|}
\hline \multicolumn{2}{|c|}{ Slope, $\mathbf{m}$} & \multicolumn{2}{c|}{ Intercept, $\mathbf{c}$} \\
\hline $\mathrm{m} 2$ & -0.0112 & $\mathrm{c} 2$ & -0.0733 \\
\hline $\mathrm{m} 1$ & 0.0915 & $\mathrm{c} 1$ & 0.4107 \\
\hline $\mathrm{m} 0$ & 0.1331 & $\mathrm{c} 0$ & 0.4683 \\
\hline
\end{tabular}

The equation for $z_{f}$ is derived in Appendix B.1 from ASHRAE (2013a), Figure 6, p. 27.5.

$$
\begin{aligned}
& \mathrm{w}=\mathrm{l}+\mathrm{z}_{\mathrm{f}} \cdot \operatorname{MAX}(\mathrm{TH}[\text { extSh], TH[intSh] }) \cdot 12 \\
& \operatorname{COND}\left[\text { web] }=\left(1-\frac{\mathrm{d}_{2}}{\mathrm{w}}\right) \cdot \operatorname{COND}\left[\text { cavInsAdj] }+\frac{\mathrm{d}_{2}}{\mathrm{w}} \cdot \operatorname{COND}[\text { frame }]\right.\right. \\
& \operatorname{COND}[\text { flange }]=\left(1-\frac{\mathrm{l}}{\mathrm{w}}\right) \cdot \operatorname{COND}[\text { cavInsAdj }]+\frac{\mathrm{l}}{\mathrm{w}} \cdot \operatorname{COND}[\text { frame }] \\
& \operatorname{COND}\left[\text { framAdj] }=\frac{1}{\frac{\mathrm{d}_{1} / 12}{\mathrm{TH}[\text { frameAdj]/COND }[\mathrm{web}]}+\frac{\left(\mathrm{d}_{2 \mathrm{a}}+\mathrm{d}_{2 \mathrm{~b}}\right) / 12}{\mathrm{TH}[\text { frameAdj]/COND[flange }]}}\right. \\
& \operatorname{COND}[\text { cavity }]=\operatorname{COND}[\text { cavInsAdj] }
\end{aligned}
$$

$\underline{\text { Final calculations }}$

$\operatorname{COND}[$ composite $]=\left(1-\frac{\mathrm{w}}{\mathrm{s}}\right) \cdot \operatorname{COND}[$ cavity $]+\frac{\mathrm{w}}{\mathrm{s}} \cdot \operatorname{COND}[$ frameAdj $]$

DENS[composite]

$$
=\text { DENS[frame] } * \text { FrameFrac[actual }]+ \text { DENS[cavInsAdj] } *(1-\text { FrameFrac[actual] })
$$

$\mathrm{SH}[$ composite $]=$

SH[frame] $\cdot$ DENS[frame] $\cdot$ FrameFrac[actual] + SH[cavInsAdj] $\cdot$ DENS[cavInsAdj] $\cdot(1-$ FrameFrac[actual] $)$

$$
\text { DENS[frame] + DENS[cavInsAdj] }
$$

$\mathrm{TH}[$ composite $]=\mathrm{TH}[$ frameAdj $]$ 


\subsection{CALCULATING AIR LEAKAGE REDUCTION FROM WINDOW AND DOOR RETROFITS}

Step 1: For each WINDOW and DOOR tab, collect the following from the GUI and perform calculations outlined in Table 4.11:

- Width (ft), Height (ft)

- InstalledLeakiness = VERYTIGHT/TIGHT/MEDIUM/LOOSE/VERYLOOSE

- Replacement $=$ CHECKED/UNCHECKED

- $\quad$ AddStorm $=$ CHECKED/UNCHECKED

Table 4.11. Calculating zone infiltration CFM reduction from window and door leakage reduction

\begin{tabular}{|c|c|c|c|c|}
\hline \multirow{2}{*}{\multicolumn{2}{|c|}{ Parameter }} & \multicolumn{3}{|c|}{ Value assignment } \\
\hline & & Baseline & Retrofit $=$ Replacement & Retrofit $=$ AddStorm \\
\hline 1 & Leakiness $=$ & InstalledLeakiness & $\begin{array}{l}\text { VERYTIGHT if } \\
\text { InstalledLeakiness = } \\
\text { VERYTIGHT; else } \\
\text { TIGHT }\end{array}$ & InstalledLeakiness \\
\hline 2 & StormPresent $=$ & 0 & 0 & 1 \\
\hline 3 & InstalledFlowCoefficient $=$ & \multicolumn{3}{|c|}{$\begin{array}{l}\text { From Table A.3.2: Window flow coefficient (Gettings 2003, pp. } 2.2-19 \text {, Table } \\
\text { 2.2.1) or Table A.3.7 for Leakiness }\end{array}$} \\
\hline \multirow[b]{2}{*}{4} & & \multirow[b]{2}{*}{$\begin{array}{l}\text { InstalledFlow } \\
\text { Coefficient }\end{array}$} & \multirow[b]{2}{*}{$\begin{array}{l}\text { InstalledFlow } \\
\text { Coefficient }\end{array}$} & 1 \\
\hline & FlowCoefficient $=$ & & & {$\left[\left(\frac{1}{\text { InstalledFlowCoefficient }}\right)^{\frac{1}{0.8}}+\left(\frac{1}{0.03}\right)^{\frac{1}{0.8}}\right]^{0.8}$} \\
\hline 5 & $\begin{array}{l}\text { DeltaCFMperRetrofitComponent } \\
=\end{array}$ & - & \multicolumn{2}{|c|}{$\begin{array}{l}\text { (InstalledFlowCoefficient } \text { baseline } \\
\left.\quad-\text { InstalledFlowCoefficient }_{\text {retrofit }}\right) * 0.1 * 10^{1.6} * 2 \\
\quad * \text { (Width + Height })\end{array}$} \\
\hline
\end{tabular}

Step 2: From the INFILTRATION tab, collect:

- Baseline $\mathrm{ACH}<$ space $>$

Step 3: From the BUILDING tab and backend, collect:

- Area<space $>$

- Height $<$ level $>$

Step 4: For each space (e.g., A1Units) in EchoBasecase, collect:

- All multiplier<zone>

- All width<zone_window/door $>$

- All height<zone_window/door $>$

Step 5: For each retrofit window or door type, calculate the total number of windows or doors in that space and the resulting DeltaCFM using the following equations:

$$
\begin{aligned}
& \text { Number }=\frac{\sum\left[\text { multiplier }<\text { zone }>* \sum\{\text { width }<\text { zone_window } / \text { door }>* \text { height }<\text { zone_window } / \text { door }>\}\right]}{\text { Width } * \text { Height }} \\
& \text { DeltaCFM }=\text { DeltaCFMperRetrofitComponent } * \text { Number }
\end{aligned}
$$

Step 6: For each zone-level combination, calculate RevisedACH $<$ zone $><$ level $>$ using the equations outlined in Table 4.12 and submit it to the API. 
Table 4.12. Calculating revised ACH<zone $><$ level $>$

\begin{tabular}{|l|l|l|l|}
\hline \multicolumn{2}{|c|}{} & $\begin{array}{l}\text { If RUN2 (i.e., one measure at a } \\
\text { time) }\end{array}$ & $\begin{array}{c}\text { If RUN3, calculate for each submission when a } \\
\text { Replacement or Add Storm measure added to the } \\
\text { package }\end{array}$ \\
\hline 6 & $\begin{array}{l}\text { RevisedDeltaCFM<spa } \\
\text { ce }>=\end{array}$ & DeltaCFM & $\begin{array}{l}\text { SUM[DeltaCFM] over all Replacement and AddStorm } \\
\text { measures across all window and door tabs that have already } \\
\text { been added to the package }\end{array}$ \\
\hline 7 & $\begin{array}{l}\text { RevisedDeltaACH<spa } \\
\text { ce }>=\end{array}$ & $\begin{array}{l}\text { RevisedDeltaCFM<space }>* \\
60 /(\text { Area }<\text { space }>* \\
\text { Height }<\text { level }>)\end{array}$ & $\begin{array}{l}\text { RevisedDeltaCFM }<\text { space }>* 60 /(\text { Area }<\text { space }>* \\
\text { Height }<\text { level }>)\end{array}$ \\
\hline 8 & RevisedACH $<$ space $>=$ & $\begin{array}{l}\text { BaselineACH }<\text { space }>- \\
\text { RevisedDeltaACH }<\text { space }>\end{array}$ & LastACH<space $>-$ RevisedDeltaACH $<$ space $>$ \\
\hline
\end{tabular}

\subsection{CALCULATING REDUCED LIGHTING POWER DENSITY AND WATTAGE FOR LIGHTING RETROFITS}

For outdoors,

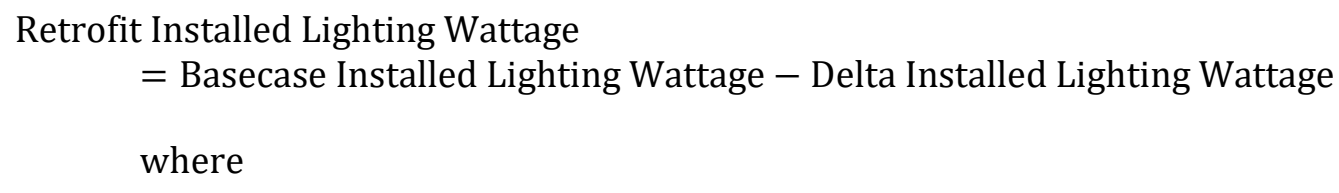

Delta Installed Lighting Wattage

$$
=\text { Lighting } \mathrm{kWh} \text { per year Savings } \times \frac{1000 \mathrm{~W} / \mathrm{kW}}{\text { Operating hours per year }}
$$

For other spaces,

$$
\begin{aligned}
& \text { Retrofit Lighting W/sqft }=\text { Basecase Lighting W/sqft }- \text { Delta Lighting W/sqft } \\
& \text { where } \\
& \text { Delta Lighting W/sqft } \\
& =\text { Lighting WH per day Savings } \times \frac{365 \text { days per year }}{\text { Lighting operating hours per year }} \times \frac{1}{\text { Area }} \\
& \text { Lighting Wh per day Savings } \\
& =[\text { Quantity } \times \text { Wattage } \times \text { BallastFactor } \times \text { Usage }]_{\text {existing }} \\
& -[\text { Quantity } \times \text { Wattage } \times \text { BallastFactor } \times \text { Usage }]_{\text {retrofit }} \\
& \text { BallastFactor } 12= \\
& \left\{\begin{array}{c}
1.2, \text { if fluorescent lamps with an existing ballast(assuming magnetic ballast) } \\
0.9, \text { if fluorescent lamps with a new ballast(assuming electronic ballast) } \\
1, \text { otherwise }
\end{array}\right.
\end{aligned}
$$

\footnotetext{
${ }^{12}$ The ballast factors were obtained from ASHRAE (2005), Table 2, Typical Non-incandescent Light Fixtures, in Chapter 30, Nonresidential Cooling and Heating Load Calculations (Special Allowance Factors for 2-T12 ES lamp with Mgn-Std ballast and with electronic ballast).
} 
Lighting operating hours per year

$$
=\left\{\begin{array}{c}
1,793.8 \text { in units with medium lighting use } \\
2,446.32 \text { in other conditioned spaces } \\
8,760 \text { in hallways } \\
4,775 \text { (or 3,504) in other unconditioned spaces } \\
4,380 \text { for outdoors }
\end{array}\right.
$$

\subsection{CALCULATING REDUCED APPLIANCE POWER DENSITY FOR REFRIGERATOR REPLACEMENT}

Retrofit Appliance W/sqft $=$ Basecase Appliance W/sqft - Delta Appliance W/sqft

where

Delta Appliance $\mathrm{W} / \mathrm{sqft}=$

Appliance $\mathrm{kWh}$ per year Savings $\times \frac{1000 \mathrm{~W} / \mathrm{kW}}{\text { Appliance operatinghours per year }} \times \frac{1}{\text { Area }}$

- Appliance $\mathrm{kWh}$ per year Savings $=$ Refrigerator $\mathrm{kWh}$ per year Savings $=$ Number of Refrigerator $\times\left([\text { Calculated Current kWh per year }]_{\text {Existing }}-\right.$ [Adjusted kWh per year $]_{\text {Replacement }}$ )

- Appliance operating hours per year $=$ 4,182.9 in units with medium appliance use

$\{$ 4,052.6 in units with low appliance use

4,313.21 in units with high appliance use

2,363.21 in other conditioned spaces

- [Calculated Current kWh per year $]_{\text {Existing }}$ is calculated based on the InputMethod according the following table:

\begin{tabular}{|c|c|}
\hline If InputMethod = & {$[\text { Calculated Current kWh per Year }]_{\text {Existing }}=$} \\
\hline EnterMeteredData & Metered kWh per year $\times(1+$ OccupancyFactor $)$ \\
\hline PickFromDatabase & $\begin{array}{l}\text { Database kWh per year } \\
\quad \times(1+\text { OccupancyFactor }+ \text { AgeFactor } \\
\quad+\text { DoorSealFactor })\end{array}$ \\
\hline EnterLabel kWh per year & $\begin{array}{l}\text { Label kWh per year } \\
\quad \times(1+\text { OccupancyFactor }+ \text { AgeFactor } \\
\quad+\text { DoorSealFactor })\end{array}$ \\
\hline EnterGeneralConditions & $\begin{array}{l}\text { SWEF kWh per year } \\
\quad \times(1+\text { OccupancyFactor }+ \text { AgeFactor } \\
\quad+\text { DoorSealFactor })\end{array}$ \\
\hline
\end{tabular}

- $\quad[\text { Adjusted } \mathrm{kWh} \text { per Year }]_{\text {Replacement }}=\mathrm{OR}\left\{\begin{array}{l}\text { Database } \mathrm{kWh} \text { per year } \\ \text { Label kWh per year }\end{array} \times\right.$ $(1+$ OccupancyFactor $)$ 
where

Metered kWh per Year $=$

$\frac{(\text { MeteredWh }- \text { DefrostCycleWh }) / 1000}{(\text { MeteredMinutes }- \text { DefrostCycleMinutes }) / 60} \times 8760 \times$ AdjustmentForDefrost

- MeteredWh and MeteredMinutes from UserInput

- $\quad$ DefrostCycleWh $=$ $\left\{\begin{array}{c}80, \text { if } \operatorname{AND}\left(\begin{array}{c}\text { DefrostCycleDuringMetering }=\text { AutomaticOccured } \\ \text { MeteredMinutes }<1440 \\ \text { 0, otherwise }\end{array}\right.\end{array}\right.$

- DefrostCycleMinutes $=$ $\left\{\begin{array}{c}12, \text { if } \operatorname{AND}\left(\begin{array}{c}\text { DefrostCycleDuringMetering }=\text { AutomaticOccured } \\ \text { MeteredMinutes }<1440 \\ \text { 0, otherwise }\end{array}\right.\end{array}\right.$

- $\quad$ AdjustmentForDefrost $=$ $\left\{\begin{array}{c}1.08, \text { if AND }\left(\begin{array}{r}\text { DefrostCycleDuringMetering }=\text { OR }\left(\begin{array}{c}\text { AutomaticOccured } \\ \text { AutomaticNotOccured }\end{array}\right. \\ \text { MeteredMinutes }<1440\end{array}\right. \\ 1.0 \text { otherwise }\end{array}\right.$

Database $\mathrm{kWh}$ per year $=$ function[Manufaturer, Model $]^{13}$

Label kWh per year $=[$ numericInput $]$

SWEF kWh per year $=\frac{365 \times \text { AdjustedVolume }}{\text { ShipmentWeightedEF }}$

- $\quad$ AdjustedVolume $=$ Size $\times[$ FreshFoodFraction $+1.63 \times(1-$ FreshFoodFraction)]

Size in cu. ft. $=$ [numericInput $]$

FreshFoodFraction $=\left\{\begin{array}{l}0.60 \text { if Style }=\text { SideBySide } \\ 0.66 \text { otherwise }\end{array}\right.$

- ShipmentWeightedEF = function[Style, DefrostType, YearMade], obtained from Table A.4.3

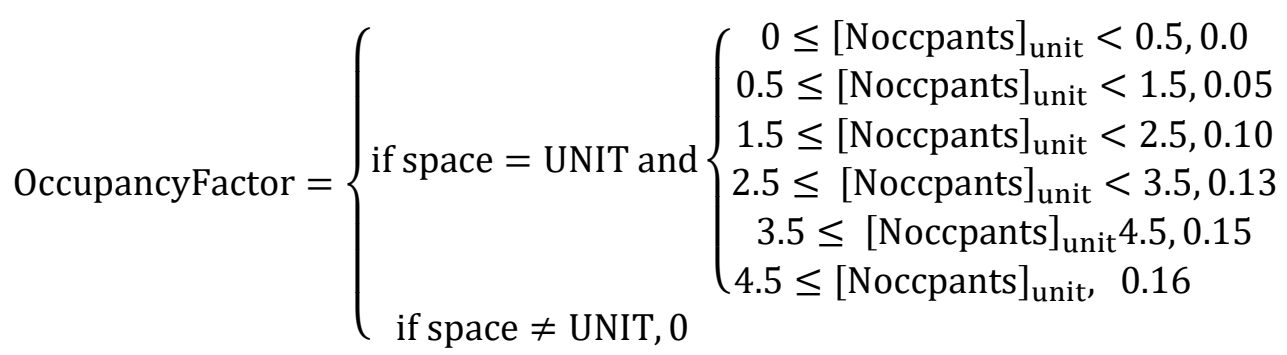

${ }^{13}$ AHAM table can be obtained from the NEAT database (Gettings 2003, p.4.4 - 16). 


$$
\begin{gathered}
\text { DoorSealFactor }=\left\{\begin{array}{l}
0.0 \text { if DoorSealCondition }=\text { Good } \\
0.05 \text { if DoorSealCondition }=\text { Fair } \\
0.15 \text { if DoorSealCondition }=\text { Poor }
\end{array}\right. \\
\text { AgeFactor }=\left\{\begin{aligned}
0.0 \text { if } 0 \leq(\text { CurrentYear }- \text { YearMade })<5 \\
0.05 \text { if } 5 \leq(\text { CurrentYear }- \text { YearMade })<10 \\
0.10 \text { if } 10 \leq(\text { CurrentYear }- \text { YearMade })<15 \\
0.15 \text { if } 15 \leq(\text { CurrentYear }- \text { YearMade })
\end{aligned}\right.
\end{gathered}
$$

\subsection{AGGREGATING PROPERTIES OF HVAC EQUIPMENT}

\subsubsection{HVAC System Submittal}

Overall submission approach for $<$ space $>$ and $<$ zone $>$

1. <space> is identified by "type" and "story" (such as UNITA1, UNITA2, HALLA1, HALLA2).

2. <zone> under a < space> is identified by "orientation" (such as UNITA1_F, UNITA2_BR, HALLA1_BRFL).

3. Under $<$ space "type $=$ unit" $>$, multiple $<$ zone $>$ facing different "orientation" can be submitted per "story". But, under all other <space "type">, one and only one <zone > can be submitted per "story" with "orientation = all_sides".

$\underline{\text { Submission approach for }<\text { hvac }>\text { system and }<\text { hvac_equipment }>}$

1. Each $<$ zone $>$ under a $<$ space "conditioned $=1$ " $>$ will be submitted with one $<$ hvac $>$ system.

2. Under each $<$ hvac $>$ system, up to two unique $<$ hvac_equipment $>$ will be submitted, one with "category = heating" and the other with "category = cooling".

3. $\quad$ For $<$ space "type = unit," "conditioned = always 1" $>$, an identical $<$ hvac $>$ system will be submitted irrespective of "story" and "orientation".

4. For $<$ space "type $=$ hall and other," "conditioned $=1$ " $>$, each "story" will have a unique $<$ hvac $>$ system. This unique $<$ hvac $>$ system will have the same $<$ hvac_equipment $>$ and $<$ hvac_property $>$ attribute values EXCEPT that $<$ hvac_equipment "type=capacity" $>$ will be different per "story."

5. Determine which $<$ zone $>$ should be submitted with an $<$ hvac $>$ system and which $<$ hvac_equipment $>$ should be submitted under $<$ hvac $>$ system:

a. All <zone > in all "orientations" under a <space "type=Location (unit)" $>$ on all "story" will be submitted with an $<$ hvac $>$ system. Under that $<$ hvac $>$ system:

i. One <hvac_equipment "category $=$ cooling"> will be submitted, if at least one System tab with [Location $=$ Dwelling unit $]$ has System Configuration $=$ Cooling Only or Combined.

ii. One <hvac_equipment "category = heating" $>$ will be submitted, if at least one System tab has System Configuration $=$ Heating Only or Combined. 
b. All <zone $>$ under < space "type=Location (hall or other)" "conditioned = 1" "story=Floor with non-zero systems in that Location"> will be submitted with an $<$ hvac $>$ system. Under that <hvac> system:

i. One <hvac_equipment "category = cooling"> will be submitted, if at least one System tab with non-zero systems in that Location-Floor combination has System Configuration $=$ Cooling Only or Combined .

ii. One <hvac_equipment "category = heating" $>$ will be submitted, if at least one System tab with non-zero systems in that Location-Floor combination has System Configuration $=$ Heating Only or Combined .

\subsubsection{Cooling Equipment Submittals and Averaging}

Perform the following steps to determine the values for $<$ hvac_equipment "category $=$ cooling" $>$ :

1. Convert cooling capacities and efficiencies to consistent units:

a. Convert all cooling capacities (Btu/h, kBtu/h and Ton) to $\mathrm{kBtu} / \mathrm{h}$ using:

$$
\begin{aligned}
& \mathrm{kBtu} / \mathrm{h}=\mathrm{Btu} / \mathrm{h} / 1000 \\
& \mathrm{kBtu} / \mathrm{h}=\text { Ton } \times 12
\end{aligned}
$$

b. Convert all cooling efficiencies (nameplate/looked up SEER and EER) to EER using:

$$
\mathrm{EER}=0.875 \times \mathrm{SEER}
$$

2. Determine "type" for $<$ hvac_equipment $>$ :

a. If all the equipment in the Location is Central (either Central Air Conditioner or Central Heat Pump), then <hvac_equipment "type $=$ split_dx" $>$ for the Location.

b. If all the equipment in the Location is Room/Wall—either Room (Wall) Air Conditioner or Room (Wall) Heat Pump—-then $<$ hvac_equipment "type = packaged_dx" $>$ for the Location.

c. If there is a mix of Central and Room/Wall equipment in the Location, then do the following:

i. Calculate the total capacity of the Central equipment in the Location:

$\sum_{\mathrm{i}=1}^{\mathrm{n}}$ (Total Number of System i combining all floors $\mathrm{X}$ Capacity of Equipment i)

where $n$ is the number of system tabs where that Location is selected and equipment is Central.

ii. Calculate the total capacity of the Room/Wall equipment in the Location:

$\sum_{\mathrm{i}=1}^{\mathrm{n}}$ (Total Number of System i combining all floors $\mathrm{X}$

Capacity of Equipment i) 
where $n$ is the number of system tabs where that Location is selected and equipment is Room (Wall).

iii. Select the equipment type that has the greatest total capacity:

If Central, then use <hvac_equipment "type $=$ split_dx" $>$.

If Room/Wall, then use <hvac_equipment "type = packaged_dx" $>$.

d. Assign this $<$ hvac_equipment "type" $>$ for all <zones $>$ under the $<$ space "type" $>$ that corresponds to GUI's Location.

3. Calculate "value" for <hvac_property "type = capacity" $>$ :

a. For <space "type = unit" >, same capacity for all "story" and "orientation":

$=\frac{\sum_{\mathrm{i}=1}^{\mathrm{n}}(\text { Total Number of System } \mathrm{i} \text { combining all floors } \times \text { Capacity of Equipment } \mathrm{i})}{\text { Total Number of Dwelling Units in the building }}$

where $n$ is the number of different system tabs where the Location is Dwelling Unit.

b. $\quad$ For $<$ space "type $=$ hall" "conditioned $=1$ " $>$, unique capacity for each "story" (B2, B1, $\mathrm{A} 1, \mathrm{~A} 2$, and $\mathrm{A} 3$ ) that has a cooling system in the hallway:

$\underline{\sum_{\mathrm{i}=1}^{\mathrm{n}} \text { (Total Number of System i on a floor } \times \text { Capacity of Equipment i) }}$

Floor Multiplier of the floor

where $n$ is the number of different system tabs where the Location is Hallway.

c. For $<$ space "type $=$ other" "conditioned $=1$ " $>$, unique capacity for each "story" (B2, B1, $\mathrm{A} 1, \mathrm{~A} 2$, and A3) that has a cooling system in the other conditioned space:

$\underline{\sum_{\mathrm{i}=1}^{\mathrm{n}} \text { (Total Number of System i on a floor } \times \text { Capacity of Equipment i) }}$

Floor Multiplier of the floor

where $n$ is the number of different system tabs where the Location is Other Conditioned Space.

4. Calculate "value" for $<$ hvac_property "type = efficiency" $>$ :

a. For <space "type = unit" >, average EER for all "story" and "orientation":

$\underline{\sum_{\mathrm{i}=1}^{\mathrm{n}} \text { (Total Number of System i combining all floors } \times \text { Capacity of System i } \times \text { efficiency of Equipment } \mathrm{i} \text { ) }}$ $\sum_{\mathrm{i}=1}^{\mathrm{n}}$ (Total Number of System i combining all floors $\times$ Capacity of System i)

where $n$ is the number of different system tabs where the Location is Dwelling Unit.

b. For $<$ space "type $=$ hall" "conditioned $=1$ " $>$, average EER for all "story" and "orientation":

$\underline{\sum_{\mathrm{i}=1}^{\mathrm{n}} \text { (Total Number of System i combining all floors } \times \text { Capacity of System ixefficiency of Equipment } \mathrm{i} \text { ) }}$ $\sum_{\mathrm{i}=1}^{\mathrm{n}}$ (Total Number of System i combining all floors $\times$ Capacity of System $\mathrm{i}$ ) 
where $n$ is the number of different system tabs where the Location is Hallway.

c. For $<$ space "type $=$ other" "conditioned $=1$ " $>$, average EER for all "story" and "orientation": $\frac{\sum_{\mathrm{i}=1}^{\mathrm{n}}(\text { Total Number of System } \mathrm{i} \text { combining all floors } \times \text { Capacity of System i } \times \text { efficiency of Equipment } \mathrm{i})}{\sum_{\mathrm{i}=1}^{\mathrm{n}} \text { (Total Number of System } \mathrm{i} \text { combining all floors } \times \text { Capacity of System i) }}$

where $n$ is the number of different system tabs where the Location is Other Conditioned Space.

d. If <hvac_equipment "type" $>$ determined in step 2 is:

i. packaged_dx, submit $<$ hvac_property "type $=$ efficiency" "value $=$ average EER">.

ii. split_dx, submit $<$ hvac_property "type $=$ efficiency" "value $=$ average EER/0.875">.

5. Calculate "value" for $<$ hvac_property "type = outdoor_air" $>$ :

a. For <space "type = unit">, same value for all "story" and "orientation":

$\sum_{\mathrm{i}=1}^{\mathrm{n}}$ (Total Number of System i combining all floors $\times$ Outdoor Air for Equipment $\mathrm{i}$ )

Total Number of dwelling units in the building

where $n$ is the number of different system tabs where the Location is Dwelling Unit.

b. For <space "type = hall" "conditioned =1" >, same value for all "story" and "orientation":

$\underline{\sum_{\mathrm{i}=1}^{\mathrm{n}} \text { (Total Number of System i combining all floors } \times \text { Outdoor Air for Equipment i) }}$ Total Number of floors having a system in hallway

where $n$ is the number of different system tabs where the Location is Hallway.

c. For <space "type $=$ other" "conditioned $=1$ ">, same value for all "story" and "orientation":

$\underline{\sum_{\mathrm{i}=1}^{\mathrm{n}} \text { (Total Number of System i combining all floors } \times \text { Outdoor Air for Equipment } \mathrm{i} \text { ) }}$

Total Number of floors having a system in other conditioned space

where $n$ is the number of different system tabs where the Location is Other Conditioned Space.

\subsubsection{Heating Equipment Submittals and Averaging}

Perform the following steps to determine the values for $<$ hvac_equipment "category $=$ heating" $>$ :

1. Convert heating capacities and efficiencies to consistent units:

a. Convert all heating capacities (Btu/h, $\mathrm{kBtu} / \mathrm{h}$, gal $/ \mathrm{h}$, and $\mathrm{kW}$ ) to $\mathrm{kBtu} / \mathrm{h}$ using: 


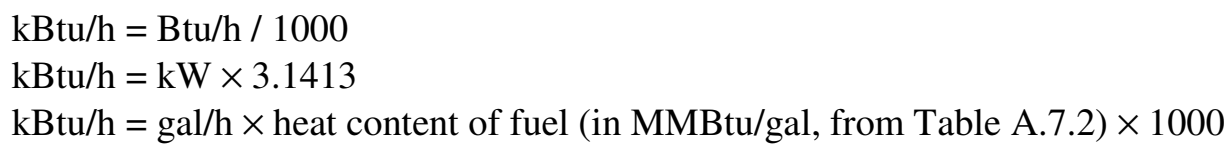

b. Convert all heating efficiencies (AFUE, COP, HSPF, and SSE\%) to Steady State Efficiency fraction using:

$$
\begin{aligned}
& \text { SSEf }=\text { AFUE } \\
& \text { SSEf }=\text { COP } \\
& \text { SSEf }=\text { HSPF } / 2.079 \\
& \text { SSEf }=\text { SSE } \% / 100
\end{aligned}
$$

2. Determine "type" for $<$ hvac_equipment $>$ :

a. If all the equipment in the Location is the same, then assign <hvac_equipment "type"> for all <zones> under the <space "type"> that corresponds to GUI's Location.

b. If there is a mix of equipment in the Location, then:

i. Calculate the total capacity of each item of equipment $i$ in the Location:

$\sum_{\mathrm{i}=1}^{\mathrm{n}}$ (Total Number of System i combining all floors $\times$

Capacity of Equipment i)

where $n$ is the number of system tabs where that Location is selected and equipment is $i$.

ii. Select the equipment type that has the greatest total capacity.

iii. Assign this $<$ hvac_equipment "type" $>$ for all $<$ zones $>$ under the $<$ space "type" $>$ that correspond to GUI's Location.

3. Calculate "value" for $\langle$ hvac_property "type = capacity" $>$ :

a. For <space "type = unit">, same capacity for all "story" and "orientation":

$\underline{\sum_{\mathrm{i}=1}^{\mathrm{n}} \text { (Total Number of System i combining all floors } \times \text { Capacity of Equipment i) }}$

Total Number of Dwelling Units in the building

where $n$ is the number of different system tabs where the Location is Dwelling Unit.

b. $\quad$ For $<$ space "type $=$ hall" "conditioned = 1" $>$, unique capacity for each "story" (B2, B1, $\mathrm{A} 1, \mathrm{~A} 2$, and A3) that has a heating system in the hallway:

$\underline{\left.\sum_{i=1}^{\mathrm{n}} \text { (Total Number of System i on a floor } \times \text { Capacity of Equipment } \mathrm{i}\right)}$

Floor Multiplier of the floor

where $n$ is the number of different system tabs where the Location is Hallway.

c. For $<$ space "type $=$ other" "conditioned $=1$ " $>$, unique capacity for each "story" (B2, B1, $\mathrm{A} 1, \mathrm{~A} 2$, and $\mathrm{A} 3$ ) that has a heating system in the other conditioned space: 
$\underline{\sum_{\mathrm{i}=1}^{\mathrm{n}} \text { (Total Number of System i on a floor } \times \text { Capacity of Equipment i) }}$

Floor Multiplier of the floor

where $n$ is the number of different system tabs where the Location is Other Conditioned Space.

4. Calculate "value" for <hvac_property "type = efficiency" $>$ :

a. For <space "type = unit" >, average SSEf for all "story" and "orientation":

$\frac{\sum_{\mathrm{i}=1}^{\mathrm{n}} \text { (Total Number of System } \mathrm{i} \text { combining all floors } \times \text { Capacity of System i } \times \text { efficiency of Equipment } \mathrm{i} \text { ) }}{\sum_{\mathrm{i}=1}(\text { Totan }}$ $\sum_{\mathrm{i}=1}^{\mathrm{n}}$ (Total Number of System i combining all floors $\times$ Capacity of System i)

where $n$ is the number of different system tabs where the Location is Dwelling unit.

b. For $<$ space "type = hall" "conditioned $=1$ " $>$, average SSEf for all "story" and "orientation":

$\frac{\sum_{\mathrm{i}=1}^{\mathrm{n}}(\text { Total Number of System i combining all floors } \times \text { Capacity of System i } \times \text { efficiency of Equipment } \mathrm{i})}{\sum_{\mathrm{i}=1}^{\mathrm{n}}(\text { Total Number of System i combining all floors } \times \text { Capacity of System } \mathrm{i})}$

where $n$ is the number of different system tabs where the Location is Hallway.

c. For $<$ space "type $=$ other" "conditioned $=1$ " $>$, average SSEf for all "story" and "orientation":

$\underline{\sum_{\mathrm{i}=1}^{\mathrm{n}} \text { (Total Number of System i combining all floors } \times \text { Capacity of System i } \times \text { efficiency of Equipment } \mathrm{i} \text { ) }}$ $\sum_{\mathrm{i}=1}^{\mathrm{n}}$ (Total Number of System i combining all floors $\times$ Capacity of System i)

where $n$ is the number of different system tabs where the Location is Other Conditioned Space.

d. If <hvac_equipment "type" $>$ determined in step 2 is:

i. heat_pump, submit $<$ hvac_property "type $=$ efficiency" "value $=$ average SSEf*2.079">.

ii. forced_air_furnace or boiler or baseboard, submit $<$ hvac_property "type $=$ efficiency" "value = average SSEf">.

5. Calculate "value" for <hvac_property "type = outdoor_air" $>$ :

a. For <space "type = unit" >, same value for all "story" and "orientation":

$\underline{\sum_{i=1}^{n} \text { (Total Number of System i combining all floors } \times \text { Outdoor Air for Equipment i) }}$

Total Number of dwelling units in the building

where $n$ is the number of different system tabs where the Location is Dwelling Unit.

b. $\quad$ For $<$ space "type $=$ hall" "conditioned $=1$ " $>$, same value for all "story" and "orientation": 
$\underline{\sum_{\mathrm{i}=1}^{\mathrm{n}} \text { (Total Number of System i combining all floors } \times \text { Outdoor Air for Equipment } \mathrm{i} \text { ) }}$

Total Number of floors having a system in hallway

where $n$ is the number of different system tabs where the Location is Hallway.

c. For <space "type = other" "conditioned =1">, same value for all "story" and

"orientation":

$\underline{\sum_{i=1}^{n} \text { (Total Number of System i combining all floors } \times \text { Outdoor Air for Equipment } \mathrm{i} \text { ) }}$

Total Number of floors having a system in other conditioned space

where $n$ is the number of different system tabs where the Location is Other Conditioned Space.

6. Calculate "value" for $<$ hvac_property "type = pilot" $>$ :

a. For <space "type = unit">, same value for all "story" and "orientation":

$\underline{\sum_{\mathrm{i}=1}^{\mathrm{n}}(\text { Total Number of System i combining all floors } \times \text { PilotLight\# } \mathrm{i}(1 \text { or } 0))}$

Total Number of dwelling units in the building

where $n$ is the number of different system tabs where the Location is Dwelling Unit; and PilotLight\# $i=1$ if Equipment $i$ has Pilot Light, else 0.

b. For <space "type = hall" "conditioned =1">, same value for all "story" and "orientation":

$\underline{\sum_{\mathrm{i}=1}^{\mathrm{n}}(\text { Total Number of System i combining all floors } \times \text { PilotLight } \# \mathrm{i}(1 \text { or } 0))}$

Total Number of floors having a system in hallway

where $n$ is the number of different system tabs where the Location is Hallway; and PilotLight\# $i=1$ if Equipment $i$ has Pilot Light, else 0.

c. For <space "type = other" "conditioned $=1$ " >, same value for all "story" and "orientation":

$\frac{\sum_{\mathrm{i}=1}^{\mathrm{n}}(\text { Total Number of System i combining all floors } \times \text { PilotLight\# } \mathrm{i}(1 \text { or } 0) \text { ) }}{\text { Total Number of floors having a system in other conditioned space }}$

where $n$ is the number of different system tabs where the Location is Other Conditioned Space; and PilotLight\# $i=1$ if Equipment $i$ has Pilot Light, else 0.

\subsection{CONSTRUCTING THERMOSTAT SCHEDULE}

The equations provided in this section show how the thermostat schedules are constructed using the four GUI inputs: From, To, Daytime Temperature, and Nighttime Temperature. The MulTEA backend uses a modified logic that creates the same thermostat schedule. These equations assume that the GUI time selections 1 am to midnight are translated to a numerical hour number as 1 to 24 . They also show how to handle different scenarios when the 'From' time is equal to, less than, and greater than the 'To' time.

With most normal GUI inputs (e.g., From 8:00 am and To 5:00 pm), a 3-row schedule is needed. But there are conditions when only a 1-row or 2-row schedule is needed to describe the schedule (e.g., if 'From' equals 'To', if 'To' is midnight, or if 'From' is midnight). 


\section{$\underline{\text { Case 1: } \text { HourFrom }=\text { HourTo }}$}

value $=\mathrm{T} \_$day

begin_hour $=1$

end_hour $=24$
Case 2: HourFrom < HourTo

value $=$ T_night

begin_hour $=1$

end_hour $=$ HourFrom

value $=\mathrm{T} \_$day

begin_hour $=$ HourFrom +1

end_hour $=$ HourTo

if $[$ HourTo < 24]

value $=\mathrm{T}$ _night

begin_hour $=$ HourTo+1

end_hour $=24$

endif
Case 3: HourFrom > HourTo

value $=\mathrm{T} \_$day

begin_hour $=1$

end_hour $=$ HourTo

value $=$ T_night

begin_hour $=$ HourTo+1

end_hour $=$ HourFrom

if $[$ HourFrom $<24]$

value $=\mathrm{T} \_$day

begin $\_$hour $=$HourFrom +1

end_hour $=24$

endif

\subsection{CALCULATING EQUIVALENT EF AND RE FOR WATER HEATER TANK INSULATION AND PIPE INSULATION}

To simulate the existing or retrofit water heater tank insulation and pipe insulation, the EF and RE for the water heater, entered on the GUI, are replaced with an equivalent EF (EF') and equivalent RE (RE') and then submitted to the API. Equations for calculating EF' and RE' shown in Step 4 below are derived in Appendix B.6.

\section{GUI inputs:}

- Fuel: Primary Fuel [Electricity, Natural Gas, Propane, Oil]

- EF: Energy Factor [fraction]

- RE: Recovery Efficiency [fraction]

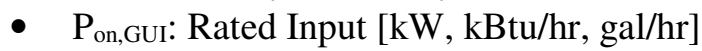

- TankSize: Tank Size [gallons]

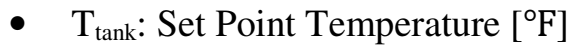

- Location: Location [Conditioned, Semi-conditioned, Unconditioned, Outdoors]

- Station: Weather Station [dropdown list]

- $\mathrm{R}_{\mathrm{wrap}_{\text {existing }}}:\left\{\begin{array}{l}\text { Existing Water Heater Wrap R value, if Basecase Run } \\ 0, \text { if Install Water Heater Wrap Retrofit Run } \\ 0, \text { if Replace the System Retrofit Run }\end{array}\right.$

- $\mathrm{R}_{\mathrm{wrap}_{\text {added }}}:\left\{\begin{array}{l}0 \text {, if Basecase Run } \\ \text { Added Water Heater Wrap R value, if Install Water Heater Wrap Retrofit Run) }\end{array}\right.$

- $\quad t_{\text {pipeinsulation }}:\left\{\begin{array}{l}\text { If Basecase Run, assume } 0.5 \\ \text { If Pipe Insulation Retrofit Run, Insulation Thickness }\end{array} \quad\right.$ [inch]

- L: $\{$ If Basecase Run, Insulated Pipe Length

L: $\{$ If Pipe Insulation Retrofit Run, Length of Pipe to Insulate 


\section{Calculations:}

Step 1: Calculate $\Delta \mathrm{T}$ :

$$
\begin{aligned}
& \mathrm{T}_{\mathrm{amb}}=\left\{\begin{array}{l}
\frac{67.5, \text { if Location }=\text { Conditioned Space }}{67.5+\text { Average Station Temperature }} \\
\left.\frac{2}{2} \text { if Location }=\text { Semiconditioned }{ }^{\circ} \mathrm{F}\right] \\
\text { Average Station Temperature, if Location }=\text { Unconditioned } \\
\text { Average Station Temperature, if Location }=\text { Outdoors }
\end{array}\right. \\
& \Delta \mathrm{T}=\mathrm{T}_{\mathrm{tank}}-\mathrm{T}_{\mathrm{amb}}\left[{ }^{\circ} \mathrm{F}\right]
\end{aligned}
$$

Step 2: Calculate $\Delta \mathrm{Q}_{\text {pipe }}$ (Gettings 2003, pp. $4.4-21$ ):

If $L=0$, then $\Delta Q_{\text {pipe }}=0$

Else Assume

$$
\begin{aligned}
& \left.\mathrm{r}_{1} \text { (radius of water pipe }\right)=0.035[\mathrm{ft}] \\
& \mathrm{k}_{\text {pipeinsulation }}(\text { conductivity of pipe insulation })=0.0225\left[\frac{\mathrm{Btu}}{\mathrm{h} \cdot \mathrm{ft} \cdot{ }^{\circ} \mathrm{F}}\right] \\
& \mathrm{h}_{\mathrm{o}}(\text { exterior film coefficient of insulated pipe })=1.35\left[\frac{\mathrm{Btu}}{\mathrm{h} \cdot \mathrm{ft}^{2} \cdot{ }^{\circ} \mathrm{F}}\right] \\
& \sigma(\text { Stefan }- \text { Boltzmann Constant })=0.1714 \times 10^{-8}\left[\frac{\mathrm{Btu}}{\mathrm{h} \cdot \mathrm{ft}^{2} \cdot \mathrm{R}^{4}}\right] \\
& \epsilon(\text { Emittance of pipe })=0.8
\end{aligned}
$$

Calculate

$$
\begin{aligned}
& \overline{\mathrm{T}}=\frac{\mathrm{T}_{\text {tank }}+\mathrm{T}_{\mathrm{amb}}}{2}[\mathrm{~F}] \\
& \mathrm{T}_{\mathrm{i}}=\mathrm{T}_{\text {tank }}+460[\mathrm{R}] \\
& \mathrm{T}_{\mathrm{o}}=\mathrm{T}_{\mathrm{amb}}+460[\mathrm{R}] \\
& \mathrm{k}_{\mathrm{air}}=2.059 \times 10^{-5} \overline{\mathrm{T}}+0.01334\left[\frac{\mathrm{Btu}}{\mathrm{h} \cdot \mathrm{ft} \cdot{ }^{\circ} \mathrm{F}}\right] \\
& \mathrm{r}_{2}=\mathrm{r}_{1}+\frac{\mathrm{t}_{\text {pipeinsulation }}}{12}[\mathrm{ft}] \\
& \mathrm{h}_{\mathrm{c}}(\text { exterior film coefficient of uninsulated pipe }) \\
& \quad=23.1 \mathrm{k}_{\text {air }}\left(\frac{\Delta \mathrm{T}}{\mathrm{L}} \mathrm{e}^{-8.698 \times 10^{-3} \overline{\mathrm{T}}}\right)^{1 / 4}\left[\frac{\mathrm{Btu}}{\mathrm{h} \cdot \mathrm{ft}^{2} \cdot{ }^{\circ} \mathrm{F}}\right]
\end{aligned}
$$




$$
\begin{aligned}
& \mathrm{Q}_{\text {convective per } \mathrm{L}}=2 \pi \mathrm{r}_{1} \mathrm{~h}_{\mathrm{c}} \Delta \mathrm{T}\left[\frac{\mathrm{Btu}}{\mathrm{h}} \cdot \mathrm{ft}\right] \\
& \mathrm{Q}_{\text {radiative per } \mathrm{L}}=2 \pi \mathrm{r}_{1} \sigma \epsilon\left(\mathrm{T}_{\mathrm{i}}{ }^{4}-\mathrm{T}_{\mathrm{o}}{ }^{4}\right)\left[\frac{\mathrm{Btu}}{\mathrm{h}} \cdot \mathrm{ft}\right] \\
& \mathrm{Q}_{\text {insulation per } \mathrm{L}}=\frac{2 \pi \Delta \mathrm{T}}{\frac{\ln \left(\mathrm{r}_{2} / \mathrm{r}_{1}\right)}{\mathrm{k}_{\text {pipeinsulation }}}+\frac{1}{\mathrm{r}_{2} \mathrm{~h}_{\mathrm{o}}}}\left[\frac{\mathrm{Btu}}{\mathrm{h}} \cdot \mathrm{ft}\right] \\
& \Delta \mathrm{Q}_{\text {pipe per } \mathrm{L}} \\
& \quad=\mathrm{Q}_{\text {convective per } \mathrm{L}}+\mathrm{Q}_{\text {radiative per } \mathrm{L}}-\mathrm{Q}_{\text {insulation per } \mathrm{L}}\left[\frac{\mathrm{Btu}}{\mathrm{h}} \cdot \mathrm{ft}\right] \\
& \Delta \mathrm{Q}_{\text {pipe }}=\frac{\Delta \mathrm{Q}_{\text {pipe per } \mathrm{L}} \times \mathrm{L}}{\mathrm{EF}}\left[\frac{\mathrm{Btu}}{\mathrm{h}}\right]
\end{aligned}
$$

Endif

Step 3: Calculate $\Delta \mathrm{Q}_{\mathrm{wrap}}$ :

$$
\begin{aligned}
& \mathrm{R}_{\text {wrap }}=\mathrm{R}_{\text {wrap }_{\text {existing }}}+\mathrm{R}_{\mathrm{wrap}_{\text {added }}} \\
& \text { If } \mathrm{R}_{\mathrm{wrap}}=0 \text {, then } \Delta \mathrm{Q}_{\mathrm{tank}}=0 \\
& \text { Else } \\
& \begin{array}{l}
\mathrm{R}_{\operatorname{tank}}= \\
\left\{\begin{array}{l}
860.41 * \mathrm{EF}^{2}-1355.1 * \mathrm{EF}+537.12, \text { if } \mathrm{EF}>0.78 \\
3.615, \text { if } \mathrm{EF} \leq 0.78 \\
583.78 * \mathrm{EF}^{2}-553.57 * \mathrm{EF}+134.76, \text { if } 0.46<\mathrm{EF}<0.62 \\
15.952, \text { if } \mathrm{EF} \geq 0.62 \\
3.646, \text { if } \mathrm{EF} \leq 0.46
\end{array}\right\}, \text { if Fuel } \neq \text { Electric }
\end{array} \\
& \mathrm{U}_{\mathrm{tank}}=\frac{1}{\mathrm{R}_{\operatorname{tank}}+0.66} \\
& \mathrm{U}_{\text {tank }}^{\prime}=\frac{1}{\mathrm{R}_{\text {tank }}+\mathrm{R}_{\mathrm{wrap}}+0.66} \\
& A=\left\{\begin{array}{l}
3.92+0.274 * \text { TankSize, if Fuel } \neq \text { Electric } \\
5.08+0.2975 * \text { TankSize, if Fuel }=\text { Electric }
\end{array}\left[\mathrm{ft}^{2}\right]\right. \\
& \Delta \mathrm{Q}_{\text {tank }}=\frac{\mathrm{U}_{\text {tank }} \mathrm{A} \Delta \mathrm{T}}{\mathrm{EF}}-\frac{\mathrm{U}_{\text {tank }}{ }^{\mathrm{A} \Delta} \mathrm{T}}{\mathrm{EF}^{\prime}} \approx \frac{\left(\mathrm{U}_{\text {tank }}-\mathrm{U}_{\text {tank }}{ }\right) \mathrm{A} \Delta \mathrm{T}}{\mathrm{EF}}\left[\frac{\mathrm{Btu}}{\mathrm{h}}\right]
\end{aligned}
$$

Endif

Step 4: Calculate $\mathrm{RE}^{\prime}$ and $\mathrm{EF}^{\prime}$ : 


$$
\begin{aligned}
& \mathrm{P}_{\mathrm{on}}=\left\{\begin{array}{l}
\mathrm{P}_{\mathrm{on}_{\mathrm{GUI}}} * 3413, \text { if Fuel }=\text { Electric } \\
\mathrm{P}_{\mathrm{on}_{\mathrm{GUI}}} * 1000, \text { if Fuel }=\text { Natural Gas or Propane }\left[\frac{\mathrm{Btu}}{\mathrm{h}}\right] \\
\mathrm{P}_{\mathrm{on}_{\mathrm{GUI}}} * 139000, \text { if Fuel }=\text { Oil }
\end{array}\right. \\
& \mathrm{UA}=\frac{\frac{1}{\mathrm{EF}}-\frac{1}{\mathrm{RE}}}{67.5\left(\frac{24}{41094}-\frac{1}{\mathrm{RE} * \mathrm{P}_{\mathrm{on}}}\right)} \\
& \mathrm{U}^{\prime} \mathrm{A}=\mathrm{UA}-\frac{\Delta \mathrm{Q}_{\mathrm{tank}}+\Delta \mathrm{Q}_{\mathrm{pipe}}}{\Delta \mathrm{T}} \\
& \mathrm{RE}^{\prime}=\mathrm{RE} \cdot\left[1+\frac{\Delta \mathrm{Q}_{\mathrm{tank}}+\Delta \mathrm{Q}_{\mathrm{pipe}}}{\mathrm{P}_{\mathrm{on}}-\mathrm{UA} * \Delta \mathrm{T}}\right] \\
& \mathrm{EF}^{\prime}=\frac{1}{\frac{1}{\mathrm{RE}^{\prime}}+67.5 * \mathrm{U}^{\prime} \mathrm{A}\left(\frac{24}{41094}-\frac{1}{\mathrm{RE}^{\prime} \cdot \mathrm{P}_{\mathrm{on}}}\right)}
\end{aligned}
$$

Step 5: Submit EF' and RE'instead of EF and RE to the API, respectively.

\subsection{SUBMISSION OF MULTEA RETROFIT MEASURES TO API}

\section{WALLS (8 tabs)}

1. Add Cavity Insulation: multiple opaque_construction[name $=\langle\mathrm{ID}\rangle$, opaque_construction_layer[layer_type $=$ custom, order $=3$, thickness, conductivity, density, specific_heat]]

2. Add Exterior Insulation: multiple opaque_construction[name $=\langle\mathrm{ID}\rangle$, opaque_construction_layer[layer_type $=$ custom, order $=2$, thickness, conductivity, density, specific_heat]]

3. Add Interior Insulation: multiple opaque_construction[name $=\langle\mathrm{ID}\rangle$, opaque_construction_layer[layer_type $=$ custom, order $=4$, thickness, conductivity, density, specific_heat]]

\section{WINDOWS (8 tabs)}

1. Replace Window: multiple glazing_construction[name $=\langle\mathrm{ID}\rangle$, num_panes, u_value, shgc], multiple space[name $=\langle\mathrm{ID}\rangle$, infiltration_rate]

2. Add Storm Window: multiple glazing_construction[name $=\langle\mathrm{ID}\rangle, \mathrm{u}$ _value, shgc], multiple space[name $=<\mathrm{ID}>$, infiltration_rate]

3. Add Shading: multiple schedule[name $=<\mathrm{ID}\rangle$, schedule_week[schedule_day[schedule_value[value, begin_hour, end_hour]]] $]^{14}$

\footnotetext{
${ }^{14}$ To make the retrofit submission this simple, the schedule for None needs to have three identical schedule_week blocks, all with values of 1 . Otherwise, submission of a complete schedule block will be required for retrofit.
} 
4. Add Awning: multiple zone_window[name $=\langle\mathrm{ID}\rangle$, zone_attached_shade[name $=\langle\mathrm{ID}\rangle$, type, height_above_window, depth]] OR multiple zone_attached_shade[name $=\langle\mathrm{ID}\rangle$, type, height_above_window, depth] ${ }^{15}$

\section{DOORS (4 tabs)}

1. Replace Door: multiple zone_door[name $=\langle\mathrm{ID}\rangle$, u_value], multiple space [name $=\langle\mathrm{ID}\rangle$, infiltration_rate]

2. Add Storm Door: multiple zone_door[name $=\langle\mathrm{ID}\rangle$, u_value], multiple space[name $=\langle\mathrm{ID}\rangle$, infiltration_rate]

\section{ROOF (8 tabs)}

1. Add Ceiling Insulation: multiple opaque_construction[name $=\langle\mathrm{ID}\rangle$, multiple opaque_construction_layer[layer_type = custom, order, thickness, conductivity, density, specific_heat]]

2. Add Roof Insulation: multiple opaque_construction[name $=\langle\mathrm{ID}\rangle$, multiple opaque_construction_layer[layer_type = custom, order, thickness, conductivity, density, specific_heat]]

3. Add Radiant Barrier: multiple opaque_construction[name $=\langle\mathrm{ID}\rangle$, opaque_construction_layer[layer_type = custom, order, thickness, conductivity, density, specific_heat]]

4. White Roof Coating: multiple opaque_construction[name $=<\mathrm{ID}>$, absorptance]

\section{FLOOR (8 tabs)}

1. Add Slab Insulation: multiple opaque_construction[name $=\langle\mathrm{ID}\rangle$, opaque_construction_layer[layer_type $=$ custom, order $=1$, thickness, conductivity, density, specific_heat]]

2. Add Exterior Insulation: multiple opaque_construction[name $=\langle\mathrm{ID}\rangle$, multiple opaque_construction_layer[layer_type $=$ custom, order $=2$ and 3 , thickness, conductivity, density, specific_heat]]

3. Add Sill Box Insulation: multiple opaque_construction[name $=\langle\mathrm{ID}\rangle$, opaque_construction_layer[layer_type $=$ custom, order $=4$, thickness, conductivity, density, specific_heat]]

\section{HVAC - SYSTEM (6 tabs)}

1. Replacement: multiple hvac_equipment[name $=\langle\mathrm{ID}\rangle$, category, type, fuel_primary, multiple hvac_property[type, value]]

2. Tune Up: multiple hvac_equipment[name $=<\mathrm{ID}>$, hvac_property[type $=$ efficiency, value]]

\footnotetext{
${ }^{15}$ Second option is suggested only if windows are always submitted with an overhang of 0 depth (i.e., if zoneattached-shade name exists in the base case for use as a component name reference).
} 
3. Replace Pilot Light with IID - multiple hvac_equipment[name $=<\mathrm{ID}\rangle$, hvac_property[type $=$ pilot, value]]

4. Eliminate the Equipment: multiple hvac_equipment[name $=\langle\mathrm{ID}\rangle$, multiple hvac_property[type $=$ capacity, value $=0]$ ]

5. Change Ventilation Rate: multiple hvac_equipment[name $=<\mathrm{ID}\rangle$, hvac_property[type $=$ outdoor_air, value]]

\section{HVAC - THERMOSTAT ( 3 tabs)}

New Thermostat Schedule: multiple schedule[name $=\langle\mathrm{ID}\rangle$,

schedule_week[schedule_day[day_type, schedule_value[value, begin_hour, end_hour]]]]

\section{INFILTRATION/VENTILATION}

Air Sealing Measures Planned: multiple space[name $=<\mathrm{ID}>$, infiltration_rate]

\section{WATER HEATING - INDIVIDUAL (4 tabs)}

1. System Replacement: multiple dhw_water_heater[name $=\langle\mathrm{ID}\rangle$, multiple dhw_water_heater_property[type, value]]

2. Change Set-Point Temperature: multiple dhw_water_heater[name $=<\mathrm{ID}>$, set_point_temp]

3. Install Water Heater Wrap: multiple dhw_water_heater[name $=\langle\mathrm{ID}\rangle$, multiple dhw_water_heater_property[type, value]]

4. Add Insulation on Water Heater Pipes: multiple dhw_water_heater[name $=<\mathrm{ID}>$, multiple dhw_water_heater_property[type, value]]

5. Eliminate the System: multiple dhw_water_heater[name $=\langle\mathrm{ID}\rangle$, multiple dhw_water_heater_property[type = rated_input, value $=0]$ ]

\section{WATER HEATING - CENTRAL (1 tab)}

1. System Replacement: dhw_water_heater[name $=\langle\mathrm{ID}\rangle$, multiple dhw_water_heater_property[type, value]]

2. Change Set-Point Temperature: dhw_water_heater[name $=<\mathrm{ID}\rangle$, set_point_temp]

3. Add Insulation on Distribution Pipes: dhw_water_heater[name $=\langle\mathrm{ID}\rangle$, dhw_distribution[dhw_pipe[name $=<\mathrm{ID}>$, insulation_level]

4. Replace Circulation Pump: pump[name $=<\mathrm{ID}>$, power, flow_rate, motor_efficiency]

5. Eliminate the System: dhw_water_heater[name $=\langle\mathrm{ID}\rangle$, multiple dhw_water_heater_property[type $=$ rated_input, value $=0]$ ]

\section{LIGHTING}

Any measure: multiple space[name $=<\mathrm{ID}>$, lighting[lighting_power_density]] 


\section{APPLIANCES/EQUIPMENT}

No retrofits (currently, the retrofit under Refrigerator is the only appliances/equipment retrofit)

\section{REFRIGERATOR (8 tabs)}

Replacement Refrigerator: multiple appliance_unit[name $=<\mathrm{ID}>$, appliance_property[value]] OR multiple space[name $=<\mathrm{ID}>$, appliance[appliance_unit[appliance_property[value]] 


\section{POST-SIMULATION BACKEND PROCESSING}

\subsection{UTILITY BILL CALENDAR YEAR ADJUSTMENTS (CALIBRATION RUN ONLY)}

A composite month bill is split into 2 months in proportion to the number of days, and is added to calendar months as follows:

$$
\mathrm{E}_{\mathrm{m}}=\mathrm{E}_{\mathrm{m}-1, \mathrm{~m}} *\left(\frac{\text { BilledDays }_{\mathrm{m} 1}}{\text { BilledDays }_{\mathrm{m}-1, \mathrm{~m}}}\right)+\mathrm{E}_{\mathrm{m}, \mathrm{m}+1} *\left(\frac{\text { BilledDays }_{\mathrm{m} 2}}{\text { BilledDays }_{\mathrm{m}, \mathrm{m}+1}}\right)
$$

Example: From the billed energy use $\mathrm{E}_{\mathrm{JanFeb2014}}$ and $\mathrm{E}_{\mathrm{FebMar2014}}$, we can calculate $\mathrm{E}_{\mathrm{Feb2014}}$ (energy use for February 2014) as follows:

$$
\mathrm{E}_{\mathrm{Feb2014}}=\mathrm{E}_{\mathrm{JanFeb2014}} *\left(\frac{\text { BilledDays }_{\mathrm{FebA2014}}}{\text { BilledDays }_{\mathrm{JanFeb2014}}}\right)+\mathrm{E}_{\mathrm{FebMar2014}} *\left(\frac{\text { BilledDays }_{\mathrm{FebB2014}}}{\text { BilledDays }_{\mathrm{FebMar2014}}}\right)
$$

- FebA is the part of the February month that belongs to the JanFeb billing period

- FebB is the remaining part of the February month that belongs to the FebMar billing period

- Billed days are calculated from the billing dates directly

Note: In MulTEA, months with partial billed days are discarded. Extrapolation is not conducted for calendar months with partial billed days.

\subsection{ANNUAL ENERGY SAVINGS}

\subsubsection{Measure Run}

The annual energy savings predicted for each measure $m$ are calculated with reference to the existing building as the base case. The savings are reported for electricity and a fossil fuel by end use $u$ (heating, cooling, water heating, appliances and equipment, and lighting) and for all end uses combined (i.e., a total).

$$
\begin{aligned}
& \text { Predicted Annual Electricity Savings } \mathrm{m}_{\mathrm{m}, \mathrm{u}}(\mathrm{kWh})=\text { Elecricity Use }_{\mathrm{m}, \mathrm{u}}-{\text { Electricity } \text { Use }_{0, \mathrm{u}}} \\
& \text { Predicted Annual Fossil Fuel Savings } \mathrm{m}_{\mathrm{m}, \mathrm{u}}(\mathrm{MMBtu})=\text { Fossil Fuel Use }_{\mathrm{m}, \mathrm{u}}-\text { Fossil Fuel Use }_{0, \mathrm{u}} \\
& \text { Predicted Annual Electricity Savings } \mathrm{m}_{\mathrm{m}, \mathrm{all}} \text { end uses }(\mathrm{kWh}) \\
& \qquad=\sum_{\mathrm{u}} \text { Predicted Annual Electricity Savings } \mathrm{m}_{\mathrm{m}, \mathrm{u}} \\
& \text { Predicted Annual Fossil Fuel Savings } \mathrm{m}_{\mathrm{m}, \mathrm{all}} \text { end uses }(\mathrm{MMBtu}) \\
& \quad=\sum_{\mathrm{u}} \text { Predicted Annual Fossil Fuel Savings } \mathrm{s}_{\mathrm{m}, \mathrm{u}}
\end{aligned}
$$

\subsubsection{Package Run}

The annual energy savings predicted for each measure $m$ in the package are calculated with reference to a modified base case (i.e., after measures 1 through $m-1$ have been applied to the existing building). The savings are reported for each measure and for the package for electricity and a fossil fuel by end use $u$ 
(heating, cooling, water heating, appliances and equipment, and lighting) and for all end uses combined (i.e., a total).

For each measure $m$ in the package:

Predicted Annual Incremental Electricity Savings $\mathrm{m}_{\mathrm{m}, \mathrm{u}}(\mathrm{kWh})$

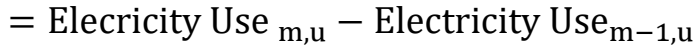

Predicted Annual Incremental Fossil Fuel Savings $s_{m, u}(M M B t u)$

$=$ Fossil Fuel Use $_{\mathrm{m}, \mathrm{u}}-$ Fossil Fuel Use $_{\mathrm{m}-1, \mathrm{u}}$

Predicted Annual Incremental Electricity Savings $\mathrm{m}_{\mathrm{m} \text {,all end uses }}(\mathrm{kWh})$

$=\sum_{\mathrm{u}}$ Predicted Annual Incremental Electricity Savings $\mathrm{m}_{\mathrm{m}, \mathrm{u}}$

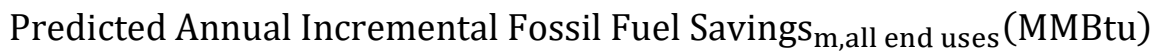

$=\sum_{\mathrm{u}}$ Predicted Annual Incremental Fossil Fuel Savings $\mathrm{m}_{\mathrm{u}} \mathrm{u}$

For the package:

Predicted Annual Electricity Savings package,u $(\mathrm{kWh})$

$=\sum_{\mathrm{m}}$ Predicted Annual Incremental Electricity Savings $\mathrm{m}_{\mathrm{m}, \mathrm{u}}$

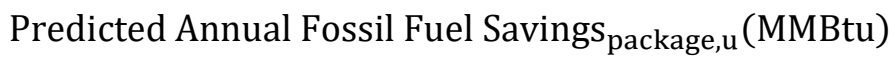

$=\sum_{\mathrm{m}}$ Predicted Annual Incremental Fossil Fuel Savings $\mathrm{m}_{\mathrm{m}, \mathrm{u}}$

Predicted Annual Electricity Savings package,all end uses $(\mathrm{kWh})$

$=\sum_{\mathrm{u}}$ Predicted Annual Electricity Savings package,u $_{\mathrm{u}}(\mathrm{kWh})$

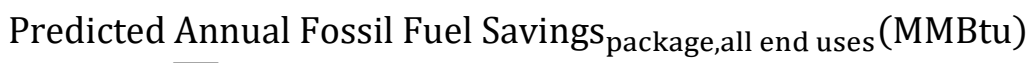

$=\sum_{\mathrm{u}}$ Predicted Annual Fossil Fuel Savings package, $\mathrm{u}$ (MMBtu)

\subsection{ANNUAL COST SAVINGS}

\subsubsection{Measure Run}

Annual cost savings are reported for each measure $m$ by end use $u$ (heating, cooling, water heating, appliances and equipment, and lighting) and for all end uses combined (i.e., a total). These savings are with reference to the existing building as the base case. 


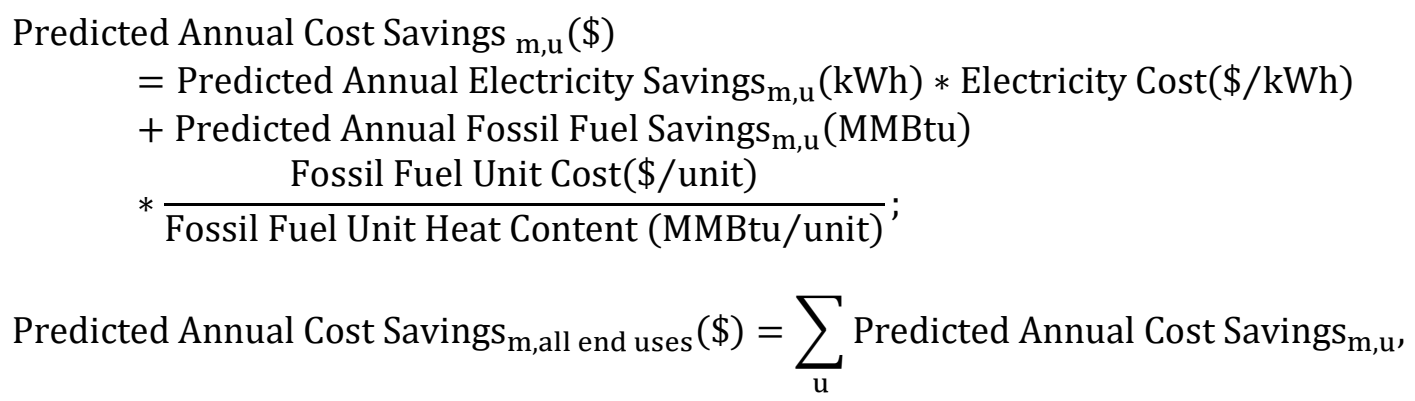

where

Predicted Annual Electricity Savings and Predicted Annual Fossil Fuel Savings are calculated as outlined in Section 5.2.

Electricity costs and fossil fuel unit costs are obtained from the fuel cost library selected for the audit. Fuel cost libraries can be created by the user to reflect local prices for electricity, natural gas, propane, oil, kerosene, coal, and wood. Fuel cost libraries that reflect the average residential cost for these fuels in the United States are also available to the user and are updated annually. Table A.7.3 shows 2015 average US residential fuel costs for all fuel types as an example.

The unit heat content of fuels is also obtained from the fuel cost library selected for the audit. Table A.7.2 shows the default unit heat content for all fuel types (including electricity, natural gas, propane, oil, kerosene, coal, wood, and other). Users may overwrite these values when they create their own fuel cost libraries.

\subsubsection{Package Run}

Annual cost savings are reported for each measure $m$ in the package and for the package by end use $u$ (heating, cooling, water heating, appliances and equipment, and lighting) and for all end uses combined (i.e., a total). For a measure $m$, the savings are with reference to a modified base case (i.e., after measures 1 through $\mathrm{m}-1$ have been applied to the existing building).

For each measure $m$ in the package:

Predicted Annual Incremental Cost Savings $\mathrm{m}_{\mathrm{m}, \mathrm{u}}(\$)$

$=$ Predicted Annual Incremental Electricity Savings $_{\mathrm{m}, \mathrm{u}}(\mathrm{kWh})$

* Electricity Cost $(\$ / \mathrm{kWh})$

+ Predicted Annual Incremental Fossil Fuel Savings $\mathrm{m}_{\mathrm{m}, \mathrm{u}}$ (MMBtu)

$* \frac{\text { Fossil Fuel Unit Cost(\$/unit) }}{\text { Fossil Fuel Unit Heat Content (MMBtu/unit) }}$

Predicted Annual Incremental Cost Savings m,all end uses $_{(\$)}$

$=\sum_{\mathrm{u}}$ Predicted Annual Incremental Cost Savings $\mathrm{s}_{\mathrm{m}, \mathrm{u}}$,

where

Predicted Annual Incremental Electricity Savings and Predicted Annual Incremental Fossil Fuel Savings are calculated as outlined in Section 5.2. 
See Section 5.3.1 for a discussion of the fuel costs and unit heat contents used in these equations.

For the package:

$$
\begin{aligned}
& \text { Predicted Annual Cost Savings Package,u }(\$) \\
& =\sum_{\mathrm{m}} \text { Predicted Annual Incremental Cost Savings } \mathrm{m,u} \\
& \text { Predicted Annual Cost Savings Package,all end uses }(\$) \\
& =\sum_{\mathrm{u}} \text { Predicted Annual Incremental Cost Savings } \text { package, } \mathrm{u}
\end{aligned}
$$

\subsection{INSTALLATION COSTS}

A default installation cost is calculated according to Table 5.1 for each measure $m$ on the Measure Results $>$ Installation Costs tab if the user selects a unit cost from the Measure Cost library. An adjustment cost can be entered for each measure $m$ that reflects either an adjustment to the default cost or the total cost of the measure if a default cost was not calculated. The final installation cost is the sum of the default and adjustment costs. The final installation cost is reported on the Measure Results $>$ Installation and Economics tabs and Package Results $>$ Economics and Leveraging tabs. Also, for the package run, the final installation cost for the package is calculated and reported on the Package Results $>$ Economics and Leveraging tabs.

Estimated (Final) Installation $\operatorname{Cost}_{\mathrm{m}}(\$)=$ Default Installation Cost $_{\mathrm{m}}(\$)+\operatorname{Adjustment}_{\mathrm{m}}( \pm, \$)$

$$
\text { Default Installation Cost }_{\mathrm{m}}(\$)=\sum_{\mathrm{n}=\text { Labor,Material,Other }}\left(\text { Cost per Unit }_{\mathrm{m}, \mathrm{n}} * \text { Unit Quantity }_{\mathrm{c}}\right. \text { ) }
$$

Cost per Unit ${ }_{m, n}$ is obtained from the Measure Costs library $>$ RETROFIT MEASURE COST DETAILS form for measure $m$.

Unit Quantity ${ }_{m}$ is calculated from the user inputs on the building description form for the component to which measure $m$ is applied.

Adjustment $_{m}( \pm, \$)$ is obtained from the user input on the Measure Results > Installation Costs tab.

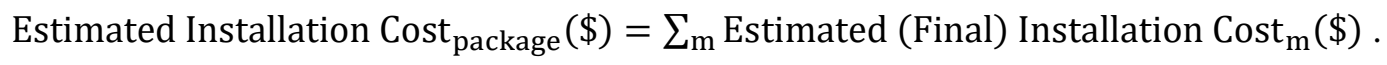


Table 5.1. Default installation cost calculations (labor/material/other cost)

\begin{tabular}{|c|c|c|c|c|}
\hline $\begin{array}{c}\text { Component } \\
\text { type }\end{array}$ & $\begin{array}{l}\text { Component } \\
\text { subtype }\end{array}$ & Retrofit measure & “Per unit" options & Default installation cost for labor, material, and other \\
\hline \multirow[t]{27}{*}{ Walls } & \multirow[t]{12}{*}{ Exterior } & \multirow[t]{4}{*}{ Add Cavity Insulation } & Each & $\$$ \\
\hline & & & Square Foot & $\$ \times$ Total Net Area $(\mathrm{sqft})^{16}$ \\
\hline & & & Square Foot per R-value & $\$ \times$ Total Net Area $($ sqft $) \times$ R-value \\
\hline & & & Square Foot per inch thickness & $\$ \times$ Total Net Area $($ sqft $) \times$ Thickness (in.) \\
\hline & & \multirow[t]{4}{*}{ Add Exterior Insulation } & Each & $\$$ \\
\hline & & & Square Foot & $\$ \times$ Total Net Area $(\mathrm{sqft})$ \\
\hline & & & Square Foot per R-value & $\$ \times$ Total Net Area $($ sqft $) \times$ R-value \\
\hline & & & Square Foot per inch thickness & $\$ \times$ Total Net Area $(\mathrm{sqft}) \times$ Thickness (in.) \\
\hline & & \multirow[t]{4}{*}{ Add Interior Insulation } & Each & $\$$ \\
\hline & & & Square Foot & $\$ \times$ Total Net Area $(\mathrm{sqft})$ \\
\hline & & & Square Foot per R-value & $\$ \times$ Total Net Area $($ sqft $) \times$ R-value \\
\hline & & & Square Foot per inch thickness & $\$ \times$ Total Net Area (sqft) $\times$ Thickness (in.) \\
\hline & \multirow[t]{11}{*}{ Underground } & \multirow[t]{7}{*}{ Add Exterior Insulation } & Each & $\$$ \\
\hline & & & Square Foot & $\$ \times$ Total Net Area $(\mathrm{sqft})$ \\
\hline & & & Square Foot per R-value & $\$ \times$ Total Net Area $($ sqft $) \times$ R-value \\
\hline & & & Square Foot per inch thickness & $\$ \times$ Total Net Area $($ sqft $) \times$ Thickness (in.) \\
\hline & & & Linear Foot & $\$ \times$ Total Exposed Perimeter $(\mathrm{ft})$ \\
\hline & & & Linear Foot per R-value & $\$ \times$ Total Exposed Perimeter $(\mathrm{ft}) \times \mathrm{R}$-value \\
\hline & & & Linear Foot per inch thickness & $\$ \times$ Total Exposed Perimeter $(\mathrm{ft}) \times$ Thickness (in.) \\
\hline & & \multirow[t]{4}{*}{ Add Interior Insulation } & Each & $\$$ \\
\hline & & & Square Foot & $\$ \times$ Total Net Area (sqft) \\
\hline & & & Square Foot per R-value & $\$ \times$ Total Net Area $(\mathrm{sqft}) \times \mathrm{R}$-value \\
\hline & & & Square Foot per inch thickness & $\$ \times$ Total Net Area $(\mathrm{sqft}) \times$ Thickness (in.) \\
\hline & \multirow[t]{4}{*}{ Interior } & \multirow[t]{4}{*}{ Add Cavity Insulation } & Each & $\$$ \\
\hline & & & Square Foot & $\$ \times$ Total Net Area (sqft) \\
\hline & & & Square Foot per R-value & $\$ \times$ Total Net Area $($ sqft $) \times$ R-value \\
\hline & & & Square Foot per inch thickness & $\$ \times$ Total Net Area $($ sqft $) \times$ Thickness (in.) \\
\hline
\end{tabular}

${ }^{16}$ Total Net Area $(\mathrm{sqft})_{\text {wall1 }}=$ Total Gross Area $(\mathrm{sqft})_{\text {wall1 }}-\Sigma[\text { Number of Windows } \times \text { Width (in) } \times \text { Height (in) } / 144]_{\text {sum over all windows on wall1 }}-\Sigma[$ Number of Doors $\times$ Width (in.) $\times$ Height (in.) / 144] $]_{\text {sum over all doors on wall } 1}$ 
Table 5.1. Default installation cost calculations (labor/material/other cost) (continued)

\begin{tabular}{|c|c|c|c|c|}
\hline \multirow[t]{20}{*}{$\begin{array}{c}\text { Component } \\
\text { type }\end{array}$} & $\begin{array}{c}\text { Component } \\
\text { subtype }\end{array}$ & Retrofit measure & "Per unit" options & Default installation cost for labor, material, and other \\
\hline & & \multirow[t]{4}{*}{ Add Exterior Insulation } & Each & $\$$ \\
\hline & & & Square Foot & $\$ \times$ Total Net Area $(\mathrm{sqft})$ \\
\hline & & & Square Foot per R-value & $\$ \times$ Total Net Area $($ sqft $) \times$ R-value \\
\hline & & & Square Foot per inch thickness & $\$ \times$ Total Net Area $($ sqft $) \times$ Thickness (in.) \\
\hline & & \multirow[t]{4}{*}{ Add Interior Insulation } & Each & $\$$ \\
\hline & & & Square Foot & $\$ \times$ Total Net Area $(\mathrm{sqft})$ \\
\hline & & & Square Foot per R-value & $\$ \times$ Total Net Area $($ sqft $) \times$ R-value \\
\hline & & & Square Foot per inch thickness & $\$ \times$ Total Net Area $($ sqft $) \times$ Thickness (in.) \\
\hline & \multirow[t]{11}{*}{ Exterior } & \multirow[t]{3}{*}{ Replace Window } & Each & $\$ \times$ Total Number of Windows \\
\hline & & & Square Foot & $\$ \times$ Total Number of Windows $\times[$ Width (in.) $\times$ Height (in.) $] / 144$ \\
\hline & & & United Inch & $\$ \times$ Total Number of Windows $\times[$ Width (in.) + Height (in.) $]$ \\
\hline & & \multirow[t]{3}{*}{ Add Storm Window } & Each & $\$ \times$ Total Number of Windows \\
\hline & & & Square Foot & $\$ \times$ Total Number of Windows $\times[$ Width (in.) $\times$ Height (in.) $] / 144$ \\
\hline & & & United Inch & $\$ \times$ Total Number of Windows $\times[$ Width $($ in. $)+$ Height $($ in. $)]$ \\
\hline & & \multirow[t]{3}{*}{ Add Shading } & Each & $\$ \times$ Total Number of Windows \\
\hline & & & Square Foot & $\$ \times[$ Width (in.) $\times$ Height (in.) $] / 144$ \\
\hline & & & United Inch & $\$ \times[$ Width (in.) + Height (in.) $]$ \\
\hline & & \multirow[t]{2}{*}{ Add Awning } & Each & $\$ \times$ Total Number of Windows \\
\hline & & & Linear Foot & $\$ \times$ Total Number of Windows $\times$ Width (in.) $/ 12$ \\
\hline Doors & \multirow[t]{2}{*}{ Exterior } & Replace Door & Each & $\$ \times$ Total Number of Doors \\
\hline & & Add Storm Door & Each & $\$ \times$ Total Number of Doors \\
\hline \multirow[t]{8}{*}{ Roof } & \multirow[t]{8}{*}{ Attic } & \multirow[t]{4}{*}{ Add Ceiling Insulation } & Each & $\$$ \\
\hline & & & Square Foot & $\$ \times$ Total Area (sqft) \\
\hline & & & Square Foot per R-value & $\$ \times$ Total Area $($ sqft $) \times$ R-value \\
\hline & & & Square Foot per inch thickness & $\$ \times$ Total Area $($ sqft $) \times$ Thickness (in.) \\
\hline & & \multirow[t]{4}{*}{ Add Roof Insulation } & Each & $\$$ \\
\hline & & & Square Foot & $\$ \times$ Total Area $($ sqft $) \times \operatorname{sqrt}\left[1+(\text { roof slope } / 12)^{\wedge} 2\right]$ \\
\hline & & & Square Foot per R-value & $\$ \times$ Total Area $($ sqft $) \times \operatorname{sqrt}\left[1+(\text { roof slope } / 12)^{\wedge} 2\right] \times$ R-value \\
\hline & & & Square Foot per inch thickness & $\$ \times$ Total Area $($ sqft $) \times \operatorname{sqrt}\left[1+(\text { roof slope } / 12)^{\wedge} 2\right] \times$ Thickness (in.) \\
\hline
\end{tabular}


Table 5.1. Default installation cost calculations (labor/material/other cost) (continued)

\begin{tabular}{|c|c|c|c|c|}
\hline $\begin{array}{c}\text { Component } \\
\text { type }\end{array}$ & $\begin{array}{c}\text { Component } \\
\text { subtype }\end{array}$ & Retrofit measure & "Per unit" options & Default installation cost for labor, material, and other \\
\hline & & \multirow[t]{3}{*}{ Add Radiant Barrier } & Each & $\$$ \\
\hline & & & Square Foot & $\$ \times$ Total Area $(\mathrm{sqft})$ \\
\hline & & & & $\$ \times$ Total Area $($ sqft $) \times \operatorname{sqrt}\left[1+(\text { roof slope } / 12)^{\wedge} 2\right]$ \\
\hline & & \multirow[t]{2}{*}{ White Roof Coating } & Each & $\$$ \\
\hline & & & Square Foot & $\$ \times$ Total Area $($ sqft $) \times \operatorname{sqrt}\left[1+(\text { roof slope } / 12)^{\wedge} 2\right]$ \\
\hline & \multirow[t]{6}{*}{ Cathedral } & \multirow[t]{4}{*}{ Add Roof Insulation } & Each & $\$$ \\
\hline & & & Square Foot & $\$ \times$ Total Area $(\mathrm{sqft})$ \\
\hline & & & Square Foot per R-value & $\$ \times$ Total Area $($ sqft $) \times$ R-value \\
\hline & & & Square Foot per inch thickness & $\$ \times$ Total Area $($ sqft $) \times$ Thickness (in.) \\
\hline & & \multirow[t]{2}{*}{ White Roof Coating } & Each & $\$$ \\
\hline & & & Square Foot & $\$ \times$ Total Area $($ sqft $) \times \operatorname{sqrt}\left[1+(\text { roof slope } / 12)^{\wedge} 2\right]$ \\
\hline & \multirow[t]{10}{*}{ Flat } & \multirow[t]{4}{*}{ Add Ceiling Insulation } & Each & $\$$ \\
\hline & & & Square Foot & $\$ \times$ Total Area (sqft) \\
\hline & & & Square Foot per R-value & $\$ \times$ Total Area $(\mathrm{sqft}) \times \mathrm{R}$-value \\
\hline & & & Square Foot per inch thickness & $\$ \times$ Total Area (sqft) $\times$ Thickness (in.) \\
\hline & & \multirow[t]{4}{*}{ Add Roof Insulation } & Each & $\$$ \\
\hline & & & Square Foot & $\$ \times$ Total Area $($ sqft $)$ \\
\hline & & & Square Foot per R-value & $\$ \times$ Total Area $($ sqft $) \times$ R-value \\
\hline & & & Square Foot per inch thickness & $\$ \times$ Total Area $($ sqft $) \times$ Thickness (in.) \\
\hline & & \multirow[t]{2}{*}{ White Roof Coating } & Each & $\$$ \\
\hline & & & Square Foot & $\$ \times$ Total Area $($ sqft) \\
\hline \multirow[t]{8}{*}{ Floor } & \multirow{7}{*}{$\begin{array}{l}\text { Underground } \\
\text { (Slab) }\end{array}$} & \multirow[t]{7}{*}{ Add Slab Insulation } & Each & $\$$ \\
\hline & & & \begin{tabular}{|l|} 
Square Foot \\
\end{tabular} & $\$ \times$ Total Area $($ sqft $)$ \\
\hline & & & Square Foot per R-value & $\$ \times$ Total Area $($ sqft $) \times$ R-value \\
\hline & & & Square Foot per inch thickness & $\$ \times$ Total Area $($ sqft $) \times$ Thickness (in.) \\
\hline & & & Linear Foot & $\$ \times$ Total Exposed Perimeter $(\mathrm{ft})$ \\
\hline & & & Linear Foot per R-value & $\$ \times$ Total Exposed Perimeter $(\mathrm{ft}) \times \mathrm{R}$-value \\
\hline & & & Linear Foot per inch thickness & $\$ \times$ Total Exposed Perimeter $(\mathrm{ft}) \times$ Thickness (in.) \\
\hline & Exposed & Add Exterior Insulation & Each & $\$$ \\
\hline
\end{tabular}


Table 5.1. Default installation cost calculations (labor/material/other cost) (continued)

\begin{tabular}{|c|c|c|c|c|}
\hline $\begin{array}{c}\text { Component } \\
\text { type }\end{array}$ & $\begin{array}{c}\text { Component } \\
\text { subtype }\end{array}$ & Retrofit measure & "Per unit" options & Default installation cost for labor, material, and other \\
\hline & & & Square Foot & $\$ \times$ Total Area (sqft) \\
\hline & & & Square Foot per R-value & $\$ \times$ Total Area $($ sqft $) \times$ R-value \\
\hline & & & Square Foot per inch thickness & $\$ \times$ Total Area $($ sqft $) \times$ Thickness (in.) \\
\hline & Interior & Add Exterior Insulation & Each & $\$$ \\
\hline & & & Square Foot & $\$$ Total Area (sqft) \\
\hline & & & Square Foot per R-value & $\$ \times$ Total Area $($ sqft $) \times$ R-value \\
\hline & & & Square Foot per inch thickness & $\$ \times$ Total Area $($ sqft $) \times$ Thickness (in.) \\
\hline & & Add Sill Box Insulation & Each & $\$$ \\
\hline & & & Square Foot & $\$ \times$ Total Exposed Perimeter $(\mathrm{ft}) \times[$ Joist Depth $($ in. $) / 12]$ \\
\hline & & & Square Foot per R-value & $\$ \times$ Total Exposed Perimeter $(\mathrm{ft}) \times[$ Joist Depth (in.) $/ 12] \times$ R-value \\
\hline & & & Square Foot per inch thickness & $\$ \times$ Total Exposed Perimeter $(\mathrm{ft}) \times[$ Joist Depth (in.) $/ 12] \times$ Thickness (in.) \\
\hline & & & Linear Foot & $\$ \times$ Total Exposed Perimeter $(\mathrm{ft})$ \\
\hline & & & Linear Foot per R-value & $\$ \times$ Total Exposed Perimeter $(\mathrm{ft}) \times \mathrm{R}$-value \\
\hline & & & Linear Foot per inch thickness & $\$ \times$ Total Exposed Perimeter $(\mathrm{ft}) \times$ Thickness (in.) \\
\hline & Above & Add Exterior Insulation & Each & $\$$ \\
\hline & & & Square Foot & $\$ \times$ Total Area $(\mathrm{sqft})$ \\
\hline & & & Square Foot per R-value & $\$ \times$ Total Area $($ sqft $) \times$ R-value \\
\hline & & & Square Foot per inch thickness & $\$ \times$ Total Area $($ sqft $) \times$ Thickness (in.) \\
\hline & & Add Sill Box Insulation & Each & 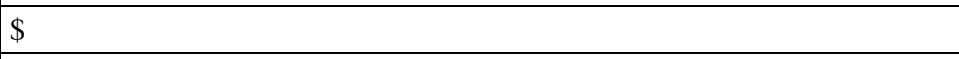 \\
\hline & & & Square Foot & $\$ \times$ Total Exposed Perimeter $(\mathrm{ft}) \times[$ Joist Depth (in.) $/ 12]$ \\
\hline & & & Square Foot per R-value & $\$ \times$ Total Exposed Perimeter $(\mathrm{ft}) \times[$ Joist Depth $($ in. $) / 12] \times \mathrm{R}$-value \\
\hline & & & Square Foot per inch thickness & $\$ \times$ Total Exposed Perimeter $(\mathrm{ft}) \times[$ Joist Depth (in.) $/ 12] \times$ Thickness (in.) \\
\hline & & & Linear Foot & $\$ \times$ Total Exposed Perimeter $(\mathrm{ft})$ \\
\hline & & & Linear Foot per R-value & $\$ \times$ Total Exposed Perimeter $(\mathrm{ft}) \times \mathrm{R}$-value \\
\hline & & & Linear Foot per inch thickness & $\$ \times$ Total Exposed Perimeter $(\mathrm{ft}) \times$ Thickness (in.) \\
\hline HVAC & System & Change Ventilation Rate & Each & $\$ \times \Sigma$ Number of Same Systems \\
\hline & & Replace the System & Each & $\$ \times \Sigma$ Number of Same Systems \\
\hline & & Tune-Up & Each & $\$ \times \Sigma$ Number of Same Systems \\
\hline & & Replace Pilot Light with IID & Each & $\$ \times \Sigma$ Number of Same Systems \\
\hline
\end{tabular}


Table 5.1. Default installation cost calculations (labor/material/other cost) (continued)

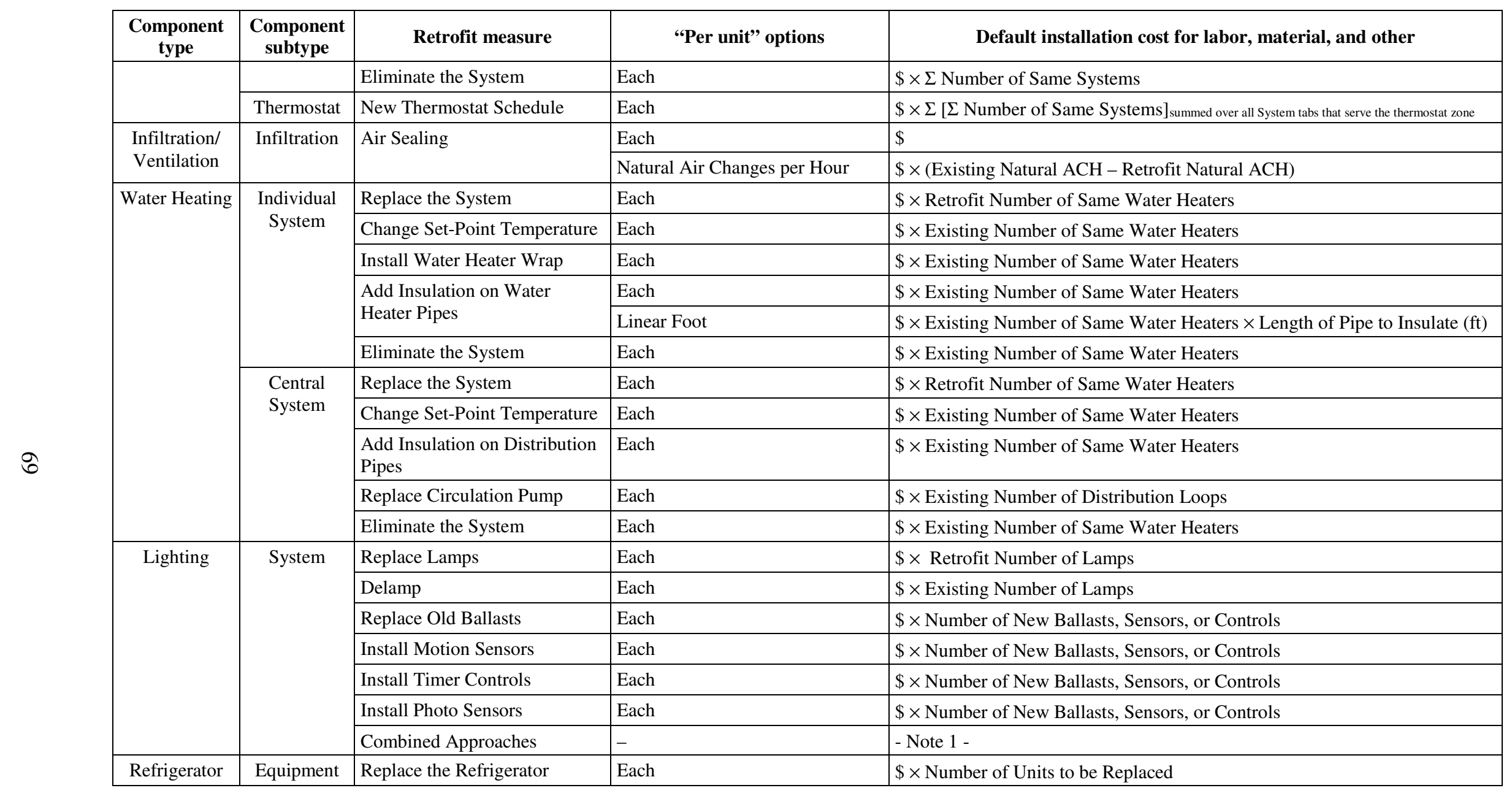

Note 1: No default cost is calculated for the combined approaches lighting measure. The installation cost for this measure is entered in the Adjustment column on the Measure Results > Installation Costs tab. 


\subsection{ECONOMICS}

\subsubsection{Measure Run}

The SIR and simple payback period (SPP) for the measure run are calculated for each measure $m$ with reference to the existing building as the base case.

$$
\begin{aligned}
& \operatorname{SIR}_{\mathrm{m}}=\frac{\text { Present Value of Energy Cost Savings }_{\mathrm{m}}}{\text { Estimated (Final) Installation Cost }} \\
& \text { Present Value of Energy Cost Savings }{ }_{m}(\$) \\
& =\text { Predicted Annual Electricity Savings }{ }_{\mathrm{m}}(\mathrm{kWh}) * \text { Electricity Cost }(\$ / \mathrm{kWh}) \\
& * \mathrm{UPV}_{\text {elec, } \mathrm{L}_{\mathrm{m}}}+\text { Predicted Annual Fossil Fuel Savings } \mathrm{m}_{\mathrm{m}} \text { (MMBtu) } \\
& * \frac{\text { Fossil Fuel Unit Cost }\left(\frac{\$}{\text { unit }}\right)}{\text { Unit Heat Content }\left(\frac{\text { MMBtu }}{\text { unit }}\right)} * U V_{\text {fossil fuel, } \mathrm{L}_{\mathrm{m}}}
\end{aligned}
$$

$\mathrm{UPV}_{\text {fuel, } \mathrm{L}_{\mathrm{m}}}=$ Modified uniform present value (UPV) for a fuel (electricity and a fossil fuel), obtained from the Economics Parameters library selected by the user.

The UPV factors are automatically calculated in the Economics Parameters library for each fuel and year using the fuel price indices for the fuel and real discount rate as:

$$
\sum_{i=1}^{L_{m}} \frac{\text { Fuel Price Index }}{i}
$$

Table A.7.4 shows the 2015 fuel price indices for 30 years for all fuel types (including natural gas, oil, electricity, propane, wood, coal, kerosene, and other). A new Economics Parameter library will be created each year as fuel prices indices are updated annually.

$\mathrm{L}_{\mathrm{m}}=$ Life of measure $m$ in years, obtained from the Measure Costs library selected by the user on the RETROFIT MEASURE COST DETAILS form for measure $m$. Table A.7.1 lists default lifetimes of measures that appear on the RETROFIT MEASURE COST DETAILS form. Users may overwrite the default lifetimes when they create their own Measure Costs libraries.

$$
\mathrm{SPP}_{\mathrm{m}}(\text { years })=\frac{\text { Estimated (Final) Installation } \text { Cost }_{\mathrm{m}}}{\text { Predicted Annual Cost Savings }}
$$

\subsubsection{Package Run}

For each measure $m$ in the package:

$$
\mathrm{SIR}_{\mathrm{m}}{ }^{\prime}=\frac{\text { Present Value of Incremental Energy Cost Savings }}{\mathrm{m}}
$$




$$
\begin{aligned}
& \text { Present Value of Incremental Energy Cost Savings }{ }_{m}(\$) \\
& =\text { Predicted Annual Incremental Electricity Savings }{ }_{\mathrm{m}}(\mathrm{kWh}) \\
& \text { * Electricity } \operatorname{Cost}(\$ / \mathrm{kWh}) * \mathrm{UPV}_{\text {elec }, \mathrm{L}_{\mathrm{m}}} \\
& \text { + Predicted Annual Incremental Fossil Fuel Savings }{ }_{m} \text { (MMBtu) } \\
& * \frac{\text { Fossil Fuel Unit Cost }(\$ / \text { unit })}{\text { Unit Heat Content (MMBtu/unit) }} * \mathrm{UPV}_{\text {fossil fuel, } \mathrm{L}_{\mathrm{m}}} \\
& \mathrm{SPP}_{\mathrm{m}}{ }^{\prime} \text { (years) }=\frac{\text { Estimated (Final)Installation } \text { Cost }_{\mathrm{m}}}{\text { Predicted Annual Incremental Cost Savings }{ }_{\mathrm{m}, \text { total }}\left(\frac{\$}{\text { year }}\right)}
\end{aligned}
$$

For the package:

$$
\begin{aligned}
& \operatorname{SIR}_{\text {package }}=\frac{\sum_{\mathrm{m}} \text { Present Value of Energy Cost Savings }}{\text { Estimated Installation Cost }} \\
& \text { Present Value of Incremental Energy Cost Savings }{ }_{m}(\$) \\
& =\text { Predicted Annual Incremental Electricity Savings } \mathrm{m}_{\mathrm{m}}(\mathrm{kWh}) \\
& * \text { Electricity } \operatorname{Cost}(\$ / \mathrm{kWh}) * \mathrm{UPV}_{\text {elec }, \mathrm{L}_{\mathrm{m}}} \\
& + \text { Predicted Annual Incremental Fossil Fuel Savings }{ }_{m} \text { (MMBtu) } \\
& * \frac{\text { Fossil Fuel Unit Cost }\left(\frac{\$}{\text { unit }}\right)}{\text { Unit Heat Content }\left(\frac{\text { MMBtu }}{\text { unit }}\right)} * \operatorname{UPV}_{\text {fossil fuel, } \mathrm{L}_{\mathrm{m}}} \\
& \mathrm{SPP}_{\text {package }}(\text { years })=\frac{\text { Estimated Installation Cost }}{\text { package }_{\mathrm{m}}} \frac{\text { Predicted Annual Incremental Cost Savings }_{\mathrm{m}, \text { all end uses }}\left(\frac{\$}{\text { year }}\right)}{\sum_{\mathrm{m}}}
\end{aligned}
$$

\subsection{LEVERAGING}

As part of the package run, calculations are performed on the LEVERAGING form to account for any leveraged funding sources (e.g., building owner contribution). For each measure $m$ in the package, the buydown amount needed to achieve an SIR $=1.0$, from the perspective of the weatherization program (i.e., using only the installation cost that the weatherization program will pay rather than the total installation cost), is calculated to provide guidance to the user. Based on the user input for the actual buydown for each measure $m$, a program installation cost and program SIR are calculated. Finally, the actual buydowns and estimated program installation costs for each measure are totaled for the package, and a program SIR is calculated for the package.

$\underline{\text { For each measure } m \text { in the package: }}$

$$
\begin{aligned}
& \begin{array}{l}
\text { (Buydown for SIR to be } 1.0)_{\mathrm{m}}=\text { Estimated (Final) Installation } \text { Cost }_{\mathrm{m}} \\
\quad-\text { Present Value of Incremental Energy Cost Savings } \\
\mathrm{m}
\end{array} \\
& \text { Estimated Program Installation Cost } \\
& \quad=\text { Estimated (Final) Installation Cost } \\
& \mathrm{m}
\end{aligned}
$$


For the package:

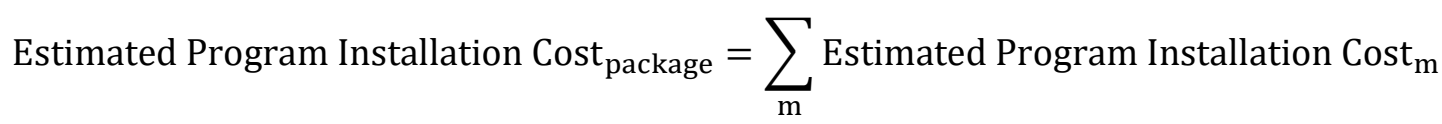
Program SIR package $=\operatorname{SIR}_{\text {package }} * \frac{\text { Estimated Installation Cost }}{\text { package }}$ 


\section{REFERENCES}

Abraham, M.M., H.A. McLain, J.M. MacDonald. 1995. Impact Evaluation of the Energy Retrofits Installed in the Margolis High-Rise Apartment Building, Chelsea Housing Authority. ORNL/CON413. Oak Ridge, TN: Oak Ridge National Laboratory. March 1995.

https://digital.library.unt.edu/ark:/67531/metadc664289/m2/1/high_res_d/188596.pdf. Accessed July 2018.

AHAM (Association of Home Appliance Manufacturers). 1996. Energy Efficiency and Consumption Trends. var. products. June-October. http://www.aham.org/mfrs/stats/. Updated information accessed July 1998.

AHAM (Association of Home Appliance Manufacturers). 2003. AHAM Fact Book 2003.

AHRI (Air-conditioning, Heating, and Refrigeration Institute). 2012. AHRI Directory of Certified

Product Performance. https://www.ahridirectory.org/Search/SearchHome?ReturnUrl=\%2f (Updated URL). Accessed September 2012.

ASHRAE. 1977. 1977 ASHRAE Handbook: Fundamentals. Atlanta: ASHRAE.

ASHRAE. 2001. 2001 ASHRAE Handbook: Fundamentals. Atlanta: ASHRAE.

ASHRAE. 2003. ASHRAE Handbook: HVAC Applications. Atlanta: ASHRAE.

ASHRAE. 2005. 2005 ASHRAE Handbook: Fundamentals. Atlanta: ASHRAE.

ASHRAE. 2006. ASHRAE Standard 136-1993 (R2006), A Method of Determining Air Change Rates in Detached Dwellings. Atlanta: ASHRAE.

ASHRAE. 2013a. 2013 ASHRAE Handbook: Fundamentals. Atlanta: ASHRAE.

ASHRAE. 2013b. ASHRAE Standard 62.2-2013, Ventilation and Acceptable Indoor Air Quality in LowRise Residential Buildings. Atlanta: ASHRAE.

DOE (Department of Energy). 2009. Notice of Proposed Rulemaking Technical Support Document Energy Conservation Program for Consumer Products: Energy Conservation Standards for Residential Water Heaters, Direct Heating Equipment, and Pool Heaters. EE-2006-STD-0129 COMMENT 56.10. November 23, 2009.

EIA (Energy Information Administration). n.d. Heating Fuel Comparison Calculator. Energy Information Administration. www.eia.gov/neic/experts/heatcalc.xls (Outdated URL).

EIA (Energy Information Administration). 2018a. https://www.eia.gov. Accessed July 2018.

EIA (Energy Information Administration). 2018b. Monthly Energy Review, Appendices. https://www.eia.gov/totalenergy/data/monthly/index.php\#appendices. Accessed July 2018.

Gettings, M.B. 2003. The National Energy Audit Tool (NEAT) Engineering Manual (Version 7). ORNL/CON-469/R1. September 2003. Oak Ridge, TN: Oak Ridge National Laboratory. https://weatherization.ornl.gov/wp-content/uploads/2018/05/NEATEngineering.pdf. Accessed July 2018. 
GPO (Government Publishing Office). 2005. 10 CFR Appendix A to Part 440 - Standards for Weatherization Materials. Washington, DC: US Government Publishing Office. https://www.gpo.gov/fdsys/granule/CFR-2011-title10-vol3/CFR-2011-title10-vol3-part440-appA. Accessed July 2018.

Hiller, C.C. 2000. Determining Equipment Service Life. ASHRAE Journal (August): 48-53.

InterNACHI. 2018. InterNACHI's Standard Estimated Life Expectancy Chart for Homes. www.nachi.org/life-expectancy.htm. Accessed July 2018.

Lavappa, P.D. and J.D. Kneifel. 2015. NISTIR 85-3273-30, Energy Price Indices and Discount Factors for Life-Cycle Cost Analysis-2015, Annual Supplement to NIST Handbook 135; (updated annually). Washington, DC: National Institute of Standards and Technology, US Department of Commerce. https://nvlpubs.nist.gov/nistpubs/ir/2015/NIST.IR.85-3273-30.pdf. Accessed July 2018.

LBNL. n.d. Home Energy Saver \& Score: Engineering Documentation. https://sites.google.com/a/lbl.gov/hes-public/. Accessed July 2018.

Martin, M.A. and M.B. Gettings. 1998. Review of Water, Lighting, and Cooling Energy-Efficiency Measures for Low-Income Homes Located in Warm Climates. ORNL/CON-437. February 1998. Oak Ridge, TN: Oak Ridge National Laboratory. https://weatherization.ornl.gov/wpcontent/uploads/pdf/1996_2000/ORNL_CON-437.pdf. Accessed July 2018.

NREL (National Renewable Energy Laboratory). n.d. National Residential Efficiency Measures Database. www.nrel.gov/ap/retrofits/group_listing.cfm. Accessed July 2018.

ORNL (Oak Ridge National Laboratory). 2010. MF CHP Level 2 Analysis Tool, Beta 3. https://eber.ed.ornl.gov/MF_CHP/. Accessed July 2018.

Seiders, D., G. Ahluwalia, S. Melman, R. Quint, A. Chaluvadi, M. Liang, A. Silverberg, C. Bechler, and J. Jackson. 2007. Study of Life Expectancy of Home Components by NAHB. February. https://www.interstatebrick.com/library/leed/nahb-study-life-expectancy-home-components. Accessed July 2018.

Skumatz, L.A., M.S. Khwaja, and J. Colby. 2009. Lessons Learned and Next Steps in Energy Efficiency Measurement and Attribution: Energy Savings, Net to Gross, Non-Energy Benefits, and Persistence of Energy Efficiency Behavior. November. https://library.cee1.org/system/files/library/10517/CIEE_Behavior_White_Paper__Skumatz_2009.pdf. Accessed July 2018.

Weitzel, D. and L.A. Skumatz. 2002. Measure Retention Study: Revised Lifetimes for a Residential Weatherization Program. American Council for an Energy-Efficient Economy. http://aceee.org/files/proceedings/2002/data/papers/SS02_Panel10_Paper27.pdf. Accessed July 2018.

Winkelmann F.C., B.E. Birdsall, W.F. Buhl, K.L. Ellington, A.E. Erdem, J.J. Hirsch, and S. Gates. 1993. DOE-2 BDL Summary Version 2.1E. LBL-34946. Berkeley, CA: Lawrence Berkeley Laboratory.

Winkelmann, F. 2002. Underground Surfaces: How to Get a Better Underground Surface Heat Transfer Calculation in DOE-2.1e. Building Energy Simulation User News, Vol. 23, No. 6 (November/December). https://gundog.lbl.gov/dirpubs/un_articles02.pdf. Accessed July 2018. 


\section{APPENDIX A. LOOKUP TABLES AND ASSUMPTIONS}

\section{A.1. SITE PARAMETERS}

Table A.1.1: Site shielding and terrain parameters (Winkelmann et al. 1993)

\begin{tabular}{|l|c|c|c|}
\hline \multicolumn{1}{|c|}{ Site shielding and terrain } & Terrain parameter 1 & Terrain parameter 2 & Shielding coefficient \\
\hline No Obstruction (Water, Desert) & 1.30 & 0.10 & 0.32 \\
Light (Flat Terrain with Few Obstructions) & 1.00 & 0.15 & 0.29 \\
Moderate (Rural Area) & 0.85 & 0.20 & 0.24 \\
Heavy (Urban, Suburban, Forest Area & 0.67 & 0.25 & 0.19 \\
Very Heavy (Downtown) & 0.47 & 0.35 & 0.1 \\
\hline
\end{tabular}

Table A.1.2: Ground reflectance (Winkelmann et al. 1993)

\begin{tabular}{|l|c|}
\hline \multicolumn{1}{|c|}{ Ground surface } & Ground reflectance \\
\hline Dark Soil & 0.08 \\
New Asphalt (Dark) & 0.10 \\
Green Grass & 0.15 \\
Old Asphalt (Light Color) & 0.18 \\
Crushed Rock or Gravel & 0.20 \\
Old Concrete (Dark) & 0.22 \\
Dry or Brown Grass & 0.24 \\
New Concrete (Light Color) & 0.32 \\
\hline
\end{tabular}

\section{A.2. PROPERTIES OF MATERIALS FOR WALL, ROOF AND FLOOR}

Table A.2.1: Frame thickness (Winkelmann et al. 1993)

\begin{tabular}{|l|c|c|c|}
\hline \multirow{2}{*}{ Frame Size } & \multicolumn{3}{|c|}{ Frame thickness (in.) } \\
\cline { 2 - 4 } & Wall & Roof & Floor \\
\hline $2 \times 2$ Wood or Metal & 1.50 & - & - \\
$2 \times 3$ Wood or Metal & 2.50 & - & - \\
$2 \times 4$ Wood or Metal & 3.50 & 3.50 & 3.50 \\
$2 \times 6$ Wood or Metal & 5.50 & 5.50 & 5.50 \\
$2 \times 8$ Wood or Metal & - & 7.50 & 7.50 \\
$2 \times 10$ Wood or Metal & - & 9.50 & 9.50 \\
$2 \times 12$ Wood or Metal & - & 11.50 & 11.50 \\
\hline
\end{tabular}

Table A.2.2: Framing fraction (Winkelmann et al. 1993)

\begin{tabular}{|l|c|c|c|}
\hline \multirow{2}{*}{ Spacing } & \multicolumn{3}{c|}{ Framing fraction } \\
\cline { 2 - 4 } & Wall & Roof & Floor \\
\hline 16 inch on center & 0.25 & 0.10 & 0.10 \\
24 inch on center & 0.22 & 0.07 & 0.07 \\
\hline
\end{tabular}


Table A.2.3: Properties of construction material (Winkelmann et al. 1993)

\begin{tabular}{|c|c|c|c|c|c|}
\hline Material & $\begin{array}{l}\text { Thickness } \\
\text { (in.) }\end{array}$ & $\begin{array}{c}\text { Conductivity } \\
\left(\text { Btu } \cdot \mathbf{f t} / \mathbf{h} \cdot \mathbf{f t}^{2} \cdot{ }^{\circ} \mathbf{F}\right)\end{array}$ & $\begin{array}{c}\text { Density } \\
\left(\mathbf{l b} / \mathbf{f t}^{3}\right)\end{array}$ & \begin{tabular}{|c|}
$\begin{array}{c}\text { Specific heat } \\
\left(\mathrm{Btu} / \mathrm{lb} \cdot{ }^{\circ} \mathbf{F}\right)\end{array}$ \\
\end{tabular} & $\begin{array}{c}\text { R-value } \\
\left(\mathbf{h} \cdot \mathbf{f t}^{2} \cdot{ }^{\circ} \mathbf{F} / \mathbf{B t u}\right)\end{array}$ \\
\hline Wood Frame (Stud, Truss/Joist) & From Table A.2.1 & 0.0667 & 32 & 0.33 & Thickness/12 \\
\hline Steel Frame (Stud, Truss/Joist) & and User Input & 26 & 480 & 0.1 & $\overline{\text { Conductivity }}$ \\
\hline \multicolumn{6}{|l|}{ Wall Construction } \\
\hline 8 in. Concrete (Heavy Weight) & 8 & 0.7576 & 140 & 0.2 & 0.88 \\
\hline 12 in. Concrete (Heavy Weight) & 12 & 0.7576 & 140 & 0.2 & 1.32 \\
\hline 8 in. Concrete Block, Hollow & 8 & 0.606 & 69 & 0.2 & 1.1 \\
\hline 8 Concrete Block, Concrete Filled & 8 & 0.7575 & 140 & 0.2 & 0.88 \\
\hline 8 in. Concrete Block, Integrated Insulation & 8 & 0.2272 & 70 & 0.2 & 2.93 \\
\hline 12 in. Concrete Block, Hollow & 12 & 0.7813 & 76 & 0.2 & 1.28 \\
\hline 12 in. Concrete Block, Concrete Filled & 12 & 0.7575 & 140 & 0.2 & 1.32 \\
\hline 12 in. Concrete Block, Integrated Insulation & 12 & 0.7773 & 98 & 0.2 & 1.29 \\
\hline 8 in. Brick & 8 & 0.4167 & 120 & 0.2 & 1.6 \\
\hline 12 in. Brick & 12 & 0.4167 & 120 & 0.2 & 2.4 \\
\hline 8 in. Stone & 8 & 1.0416 & 140 & 0.2 & 0.64 \\
\hline 12 in. Stone & 12 & 1.0416 & 140 & 0.2 & 0.96 \\
\hline \multicolumn{6}{|l|}{ Wall Exterior Finish } \\
\hline Wood Shingles & 0.7 & 0.0667 & 32 & 0.3 & 0.87 \\
\hline Vinyl Siding & - & - & - & - & 0.05 \\
\hline Aluminum Siding & 0.06 & 26 & 480 & 0.1 & 0 \\
\hline Brick Veneer & 3 & 0.7576 & 130 & 0.22 & 0.33 \\
\hline Stone Veneer & 1 & 1.0416 & 140 & 0.2 & 0.08 \\
\hline Stucco & 1 & 0.4167 & 116 & 0.2 & 0.2 \\
\hline Drywall & 0.5 & 0.0926 & 50 & 0.2 & 0.45 \\
\hline Wood Paneling & 0.75 & 0.0544 & 40 & 0.28 & 1.15 \\
\hline Plaster & 0.75 & 0.133 & 45 & 0.2 & 0.47 \\
\hline Oriented Strand Board & 0.75 & 0.045 & 75 & 0.31 & 1.39 \\
\hline \multicolumn{6}{|l|}{ Roofing } \\
\hline Asphalt Shingles & - & - & - & - & 0.44 \\
\hline Built-up Roofing & 0.38 & 0.0939 & 70 & 0.35 & 0.33 \\
\hline Metal & 0.06 & 26 & 480 & 0.1 & 0 \\
\hline Asbestos Cement & 0.25 & 0.345 & 120 & 0.2 & 0.06 \\
\hline Rubber Tile & - & - & - & - & 0.05 \\
\hline Slate & 0.5 & 0.834 & 100 & 0.35 & 0.05 \\
\hline Tar and Gravel & 1 & 0.834 & 55 & 0.4 & 0.1 \\
\hline Clay Tiles & 3 & 0.3125 & 70 & 0.2 & 0.8 \\
\hline \multicolumn{6}{|l|}{ Floor Finish } \\
\hline Carpet & - & - & - & - & 2.08 \\
\hline Hardwood & 0.75 & 0.0916 & 45 & 0.3 & 0.68 \\
\hline Stone/Terrazzo & 1 & 1.0416 & 140 & 0.2 & 0.08 \\
\hline Tile (Linoleum /Rubber/Vinyl) & - & - & - & - & 0.05 \\
\hline
\end{tabular}


Table A.2.4: Properties of insulation (Winkelmann et al. 1993)

\begin{tabular}{|l|c|c|c|c|c|}
\hline Material & $\begin{array}{c}\text { Thickness } \\
\text { (in.) }\end{array}$ & $\begin{array}{c}\text { Conductivity } \\
\left(\mathbf{B t u} \cdot \mathbf{f t} / \mathbf{h} \cdot \mathbf{f t}^{\mathbf{2}} \cdot{ }^{\circ} \mathbf{F}\right)\end{array}$ & $\begin{array}{c}\text { Density } \\
\left(\mathbf{l b} / \mathbf{f t}^{\mathbf{3}}\right)\end{array}$ & $\begin{array}{c}\text { Specific heat } \\
\left(\mathbf{B t u} / \mathbf{l b} \cdot{ }^{\circ} \mathbf{F}\right)\end{array}$ & $\begin{array}{c}\text { R-value per inch } \\
\left(\mathbf{h} \cdot \mathbf{f t}^{\mathbf{2} \cdot{ }^{\circ}} \mathbf{F} / \mathbf{B t u}^{-i n c h}\right)\end{array}$ \\
\hline Insulation (For Walls, Roof and Floor) & & & & \\
Fiberglass Batt-Normal Density & User Input & 0.0250 & 0.6 & 0.20 & 3.33 \\
Fiberglass Batt-High Density & User Input & 0.0250 & 0.6 & 0.20 & 3.33 \\
Fiberglass Blown & User Input & 0.0270 & 0.6 & 0.20 & 3.09 \\
Rockwool Batt & User Input & 0.0250 & 0.6 & 0.20 & 3.33 \\
Rockwool Blown & User Input & 0.0270 & 0.6 & 0.20 & 3.09 \\
Rockwool Board & User Input & 0.0240 & 15.0 & 0.17 & 3.47 \\
Cellulose Blown-Normal Density & User Input & 0.0225 & 3.0 & 0.33 & 3.70 \\
Cellulose Blown-High Density & User Input & 0.0225 & 3.0 & 0.33 & 3.70 \\
Extruded Polystyrene & User Input & 0.0200 & 1.8 & 0.29 & 4.17 \\
Polyisocyanurate & User Input & 0.0133 & 1.5 & 0.38 & 6.27 \\
Polyurethane Foam (Spray Foam) & User Input & 0.0200 & 0.7 & 0.30 & 4.17 \\
Other (Fiberglass Batt-Normal Density) & User Input & 0.0250 & 0.6 & 0.20 & 3.33 \\
\hline
\end{tabular}

Table A.2.5: Absorptance for wall and roof exterior color

(Winkelmann et al. 1993)

\begin{tabular}{|l|c|}
\hline \multicolumn{1}{|c|}{ Exterior color } & Absorptance \\
\hline Wall & \\
Dark & 0.85 \\
Medium-dark & 0.75 \\
Medium & 0.65 \\
Medium-light & 0.55 \\
Light & 0.45 \\
\hline Roof & \\
Dark & 0.9 \\
Medium-dark & 0.75 \\
Medium & 0.65 \\
Medium-light & 0.5 \\
Light & 0.25 \\
\hline
\end{tabular}

\section{A.3. WINDOW AND DOOR PROPERTIES}

Table A.3.1: Window default leakiness (Gettings 2003, pp. 2.2 - 19, Table 2.2.1)

\begin{tabular}{|l|l|}
\hline \multicolumn{1}{|c|}{ Window type } & \multicolumn{1}{c|}{ Default leakiness } \\
\hline Awning & Tight \\
Casement & Tight \\
Fixed & Very Tight \\
Hinged Glass Door & Medium \\
Horizontal Slider & Medium \\
Jalousie & Loose \\
Skylight & Tight \\
Sliding Door & Medium \\
Vertical Slider & Tight \\
\hline
\end{tabular}


Table A.3.2: Window flow coefficient (Gettings 2003, pp. 2.2 - 19, Table 2.2.1)

\begin{tabular}{|l|c|}
\hline Window installed leakiness & Flow coefficient \\
\hline Very Tight & 0.0035 \\
Tight & 0.012 \\
Medium & 0.046 \\
Loose & 0.1125 \\
Very Loose & 0.24 \\
\hline
\end{tabular}

Table A.3.3: Window U-value and SHGC (derived in Appendix B.4)

\begin{tabular}{|c|c|c|c|c|c|c|c|c|c|}
\hline \multirow{3}{*}{$\begin{array}{l}\text { Glazing } \\
\text { assembly }\end{array}$} & \multirow{3}{*}{ Glass type } & \multicolumn{8}{|c|}{ Frame type } \\
\hline & & \multicolumn{2}{|c|}{ Metal } & \multicolumn{2}{|c|}{$\begin{array}{l}\text { Metal w/ thermal } \\
\text { break }\end{array}$} & \multicolumn{2}{|c|}{ Wood } & \multicolumn{2}{|c|}{ Vinyl } \\
\hline & & U-value & SHGC & U-value & SHGC & U-value & SHGC & U-value & SHGC \\
\hline \multirow[t]{4}{*}{ Single Pane } & Clear & 1.244 & 0.656 & 1.073 & 0.656 & 0.931 & 0.623 & 0.908 & 0.623 \\
\hline & Tinted & 1.244 & 0.494 & 1.073 & 0.494 & 0.931 & 0.469 & 0.908 & 0.469 \\
\hline & Low-e, Low Solar Gains & 0.969 & 0.583 & 0.798 & 0.583 & 0.669 & 0.554 & 0.646 & 0.554 \\
\hline & Low-e, High Solar Gains & 0.969 & 0.583 & 0.798 & 0.583 & 0.669 & 0.554 & 0.646 & 0.554 \\
\hline \multirow[t]{4}{*}{ Double pane } & Clear & 0.759 & 0.615 & 0.587 & 0.615 & 0.469 & 0.585 & 0.446 & 0.585 \\
\hline & Tinted & 0.759 & 0.502 & 0.587 & 0.502 & 0.469 & 0.477 & 0.446 & 0.477 \\
\hline & Low-e, Low Solar Gains & 0.621 & 0.486 & 0.450 & 0.486 & 0.338 & 0.462 & 0.315 & 0.462 \\
\hline & Low-e, High Solar Gains & 0.645 & 0.591 & 0.474 & 0.591 & 0.362 & 0.562 & 0.338 & 0.562 \\
\hline \multirow{4}{*}{$\begin{array}{l}\text { Double pane, } \\
\text { gas-filled }\end{array}$} & Clear & 0.735 & 0.615 & 0.563 & 0.615 & 0.446 & 0.585 & 0.423 & 0.585 \\
\hline & Tinted & 0.735 & 0.502 & 0.563 & 0.502 & 0.446 & 0.477 & 0.423 & 0.477 \\
\hline & Low-e, Low Solar Gains & 0.573 & 0.478 & 0.401 & 0.478 & 0.292 & 0.454 & 0.269 & 0.454 \\
\hline & Low-e, High Solar Gains & 0.605 & 0.599 & 0.433 & 0.599 & 0.323 & 0.569 & 0.300 & 0.569 \\
\hline \multirow[t]{4}{*}{ Triple pane } & Clear & 0.621 & 0.550 & 0.450 & 0.550 & 0.338 & 0.523 & 0.315 & 0.523 \\
\hline & Tinted & 0.621 & 0.421 & 0.450 & 0.421 & 0.338 & 0.400 & 0.315 & 0.400 \\
\hline & Low-e, Low Solar Gains & 0.500 & 0.380 & 0.328 & 0.380 & 0.223 & 0.362 & 0.200 & 0.362 \\
\hline & Low-e, High Solar Gains & 0.548 & 0.469 & 0.377 & 0.469 & 0.269 & 0.446 & 0.246 & 0.446 \\
\hline \multirow{4}{*}{$\begin{array}{l}\text { Triple pane, } \\
\text { gas-filled }\end{array}$} & Clear & 0.597 & 0.656 & 0.425 & 0.550 & 0.315 & 0.523 & 0.292 & 0.523 \\
\hline & Tinted & 0.597 & 0.494 & 0.425 & 0.421 & 0.315 & 0.400 & 0.292 & 0.400 \\
\hline & Low-e, Low Solar Gains & 0.476 & 0.583 & 0.304 & 0.380 & 0.200 & 0.362 & 0.177 & 0.362 \\
\hline & Low-e, High Solar Gains & 0.516 & 0.583 & 0.344 & 0.469 & 0.238 & 0.446 & 0.215 & 0.446 \\
\hline
\end{tabular}

Table A.3.4: Window shading multiplier and shading schedule (assumed)

\begin{tabular}{|l|l|l|}
\hline \multicolumn{2}{|c|}{ Shading type } & \multicolumn{1}{c|}{ Shading multiplier and shading schedule } \\
\hline Exterior Shading & Overhang or Awning & 1.0 \\
& Sun Screen (Full) & 0.3 all year \\
& Sun Screen (Partial) & 0.5 all year \\
& Window Film & 0.7 all year \\
\hline \multirow{2}{*}{ Interior Shading } & Drapes & 0.7 in the winter (January 1 - April 30, October 1 - December 31) \\
& Blinds & 0.25 in the summer (May 1 - September 30) \\
& Shades or Sun Screen & \\
\hline
\end{tabular}


Table A.3.5: Storm window properties (derived in Appendix B.5)

\begin{tabular}{|c|c|c|c|}
\hline Storm window type & $\begin{array}{c}\text { Coefficient for R-value } \\
\text { modifier, }\end{array}$ & $\begin{array}{c}\text { Slope for R-value modifier, } \\
\mathbf{m}\end{array}$ & $\begin{array}{c}\text { Multiplier for SHGC } \\
\text { modifier, } \mathbf{n}\end{array}$ \\
\hline None & 0 & 1 & 1 \\
Metal & 0.36 & 1 & 0.9 \\
Wood & 0.89 & 1 & 0.9 \\
Vinyl & 0.89 & 1 & 0.9 \\
\hline
\end{tabular}

Table A.3.6: Door default leakiness (Assumed based on window leakiness from Gettings 2003, pp. 2.2 - 19, Table 2.2.1)

\begin{tabular}{|c|c|}
\hline Door type & Default leakiness \\
\hline Hinged & Medium \\
Sliding & Medium \\
French & Loose \\
Hatched & Tight \\
\hline
\end{tabular}

Table A.3.7: Door flow coefficient (Based on window leakiness from Gettings 2003, pp. 2.2 - 19, Table 2.2.1)

\begin{tabular}{|c|c|}
\hline Door installed leakiness & Flow coefficient \\
\hline Tight & 0.0035 \\
Medium & 0.012 \\
Loose & 0.046 \\
\hline
\end{tabular}

Table A.3.8: Door U-value (Gettings 2003, pp. 2.2 - 5)

\begin{tabular}{|c|c|c|}
\hline \multicolumn{2}{|c|}{ Door construction } & U-value \\
\hline \multicolumn{2}{|l|}{ Wood, Hollow Core } & 0.46 \\
\hline \multicolumn{2}{|l|}{ Wood, Panel Door } & 0.39 \\
\hline \multicolumn{2}{|l|}{ Wood, Solid Core } & 0.33 \\
\hline \multicolumn{2}{|l|}{ Steel, Hollow Core } & 0.4 \\
\hline \multicolumn{2}{|c|}{ Steel Insulated Core-Mineral Fiber } & 0.19 \\
\hline \multicolumn{2}{|c|}{ Steel, Insulated Core-Urethane Foam Core } & 0.19 \\
\hline \multicolumn{2}{|l|}{ Steel, Polystyrene } & 0.19 \\
\hline $\begin{array}{c}\text { Glass type } \\
\text { (in doors with glass) } \\
\end{array}$ & \multicolumn{2}{|c|}{$\begin{array}{c}\text { Glass U-value (Window Library, } \\
\text { Winkelmann et al. 1993) }\end{array}$} \\
\hline Single pane & \multicolumn{2}{|l|}{1.1} \\
\hline Double pane & \multicolumn{2}{|l|}{0.49} \\
\hline
\end{tabular}

Table A.3.9: Storm door properties (derived in Appendix B.5)

\begin{tabular}{|c|c|c|}
\hline Storm door type & Coefficient for R-value modifier, $\mathbf{c}$ & Slope for R-value modifier, $\mathbf{m}$ \\
\hline None & 0 & 1 \\
Metal & 0.8348 & 1.063 \\
Wood & 1.2246 & 1.019 \\
Vinyl & 1.2246 & 1.019 \\
\hline
\end{tabular}




\section{A.4. SHIPMENT WEIGHTED EQUIPMENT EFFICIENCIES}

Table A.4.1: Shipment weighted heating and cooling equipment efficiency (LBNL, n.d., Heating and Cooling Equipment Efficiencies-Legacy System)

\begin{tabular}{|c|c|c|c|c|c|c|c|c|c|}
\hline \multirow{4}{*}{ Year } & \multicolumn{6}{|c|}{ Heating equipment } & \multicolumn{3}{|c|}{ Cooling equipment } \\
\hline & \multicolumn{4}{|c|}{ Central furnace or room (wall) furnace } & \multirow{2}{*}{$\begin{array}{c}\begin{array}{c}\text { Central or } \\
\text { room heat } \\
\text { pump }(\mathrm{HP})\end{array} \\
\text { Electricity }\end{array}$} & \multirow{2}{*}{$\begin{array}{c}\begin{array}{c}\text { Electric } \\
\text { baseboard }\end{array} \\
\text { Electricity }\end{array}$} & \multirow{2}{*}{\begin{tabular}{|c|}
$\begin{array}{c}\text { Central air } \\
\text { conditioning } \\
\text { (AC) }\end{array}$ \\
Electricity
\end{tabular}} & \multirow{2}{*}{\begin{tabular}{|c|}
$\begin{array}{c}\text { Central heat } \\
\text { pump }\end{array}$ \\
Electricity
\end{tabular}} & \multirow{2}{*}{$\begin{array}{c}\text { Room } \\
\text { AC/HP } \\
\text { Electricity }\end{array}$} \\
\hline & Natural gas & Propane & $\begin{array}{c}\text { Oil/ } \\
\text { kerosene }\end{array}$ & Electricity & & & & & \\
\hline & AFUE & AFUE & AFUE & Percent & HSPF & Percent & SEER & SEER & EER \\
\hline 1970 & 60 & 60 & 70 & 98 & 6.21 & 98 & 6.5 & 5.5 & 5.8 \\
\hline 1971 & 61.4 & 61.4 & 71.8 & 98 & 6.21 & 98 & 6.58 & 5.86 & 5.89 \\
\hline 1972 & 62.7 & 62.7 & 73.6 & 98 & 6.21 & 98 & 6.66 & 6.21 & 5.98 \\
\hline 1973 & 62.7 & 62.7 & 73.6 & 98 & 6.21 & 98 & 6.75 & 6.21 & 6 \\
\hline 1974 & 62.7 & 62.7 & 73.6 & 98 & 6.21 & 98 & 6.85 & 6.21 & 6.1 \\
\hline 1975 & 65.8 & 62.7 & 73.6 & 98 & 6.21 & 98 & 6.97 & 6.21 & 6.2 \\
\hline 1976 & 66.1 & 63 & 74.1 & 98 & 6.21 & 98 & 7.03 & 6.87 & 6.4 \\
\hline 1977 & 66.4 & 63.3 & 74.5 & 98 & 6.21 & 98 & 7.13 & 6.89 & 6.55 \\
\hline 1978 & 66.7 & 63.6 & 75 & 98 & 6.21 & 98 & 7.34 & 7.24 & 6.72 \\
\hline 1979 & 68.7 & 64.8 & 75.5 & 98 & 6.21 & 98 & 7.47 & 7.34 & 6.87 \\
\hline 1980 & 70.6 & 65.9 & 76 & 98 & 6.21 & 98 & 7.55 & 7.51 & 7.02 \\
\hline 1981 & 70.4 & 67.1 & 76.8 & 98 & 6.21 & 98 & 7.78 & 7.7 & 7.06 \\
\hline 1982 & 70.3 & 68.4 & 77.5 & 98 & 6.21 & 98 & 8.31 & 7.79 & 7.14 \\
\hline 1983 & 70.1 & 69.6 & 78.3 & 98 & 6.2 & 98 & 8.43 & 8.23 & 7.29 \\
\hline 1984 & 72.6 & 73 & 78.6 & 98 & 6.36 & 98 & 8.66 & 8.45 & 7.48 \\
\hline 1985 & 72.9 & 73.8 & 78.6 & 98 & 6.39 & 98 & 8.82 & 8.56 & 7.7 \\
\hline 1986 & 73.7 & 74.3 & 79.6 & 98 & 6.55 & 98 & 8.87 & 8.7 & 7.8 \\
\hline 1987 & 74.3 & 75.1 & 79.8 & 98 & 6.71 & 98 & 8.97 & 8.93 & 8.06 \\
\hline 1988 & 74.9 & 75.8 & 80.4 & 98 & 6.88 & 98 & 9.11 & 9.13 & 8.23 \\
\hline 1989 & 74.7 & 75.5 & 80.4 & 98 & 6.92 & 98 & 9.25 & 9.26 & 8.48 \\
\hline 1990 & 76.7 & 75.7 & 80.3 & 98 & 7.03 & 98 & 9.31 & 9.46 & 8.73 \\
\hline 1991 & 77.5 & 76.9 & 80.8 & 98 & 7.06 & 98 & 9.49 & 9.77 & 8.8 \\
\hline 1992 & 82.1 & 83.2 & 80.8 & 98 & 7.1 & 98 & 10.46 & 10.6 & 8.88 \\
\hline 1993 & 82.4 & 83.8 & 80.9 & 98 & 7.1 & 98 & 10.56 & 10.86 & 9.05 \\
\hline 1994 & 82.4 & 83.9 & 80.9 & 98 & 7.1 & 98 & 10.61 & 10.94 & 8.97 \\
\hline 1995 & 82.3 & 84.1 & 80.9 & 98 & 7.1 & 98 & 10.68 & 10.97 & 9.03 \\
\hline 1996 & 82.7 & 84.1 & 80.9 & 98 & 7.4 & 98 & 10.68 & 11 & 9.08 \\
\hline 1997 & 82.9 & 84.1 & 80.9 & 98 & 7.1 & 98 & 10.66 & 10.97 & 9.09 \\
\hline 1998 & 82.6 & 84.1 & 80.9 & 98 & 7.4 & 98 & 10.92 & 11.29 & 9.08 \\
\hline 1999 & 82.6 & 84.1 & 80.9 & 98 & 7.4 & 98 & 10.96 & 11.29 & 9.07 \\
\hline 2000 & 82.6 & 84.1 & 80.9 & 98 & 7.4 & 98 & 10.95 & 11.21 & 9.3 \\
\hline 2001 & 83.1 & 84.1 & 80.9 & 98 & 7.4 & 98 & 11.07 & 11.3 & 9.63 \\
\hline 2002 & 83.1 & 84.1 & 80.9 & 98 & 7.4 & 98 & 11.07 & 11.31 & 9.75 \\
\hline 2003 & 83.5 & 84.1 & 80.9 & 98 & 7.4 & 98 & 11.19 & 11.46 & 9.75 \\
\hline 2004 & 83.6 & 84.1 & 80.9 & 98 & 7.4 & 98 & 11.29 & 11.56 & 9.71 \\
\hline 2005 & 83.9 & 84.1 & 80.9 & 98 & 7.4 & 98 & 11.32 & 11.6 & 9.95 \\
\hline 2006 & 84 & 84.1 & 80.9 & 98 & 7.9 & 98 & 13.17 & 13.17 & 10.02 \\
\hline 2007 & 84.1 & 84.1 & 80.9 & 98 & 7.9 & 98 & 13.66 & 13.66 & 9.81 \\
\hline 2008 & 84.8 & 84.1 & 80.9 & 98 & 7.9 & 98 & 13.76 & 13.76 & 9.93 \\
\hline 2009 & 84.8 & 84.1 & 80.9 & 98 & 7.9 & 98 & 13.76 & 13.76 & 9.93 \\
\hline 2010 & 84.8 & 84.1 & 80.9 & 98 & 7.9 & 98 & 13.76 & 13.76 & 9.93 \\
\hline
\end{tabular}


Notes:

1. Green shaded values did not have data available, so the last available year is copied forward.

2. Yellow shaded values did not have data available, so the first available year is copied backward.

3. New federal central air-conditioning (CAC)/heat pump (HP) standard took effect on January 23, 2006. Standard level is 13 SEER. Because no SWEF data are available since 2003 that split out CAC from HP, both products are set to the average for the combined product class (according to Air Conditioning, Heating and Refrigeration Institute data for DOE rulemaking).

Table A.4.2: Shipment weighted energy factor (SWEF) for storage water heaters (LBNL, n.d., Table 12)

\begin{tabular}{|c|c|c|c|c|}
\hline Year & Electric & Natural gas & LPG & Fuel Oil \\
\hline 1972 & 0.798 & 0.474 & 0.474 & 0.54 \\
\hline 1973 & 0.798 & 0.474 & 0.474 & 0.54 \\
\hline 1974 & 0.798 & 0.474 & 0.474 & 0.54 \\
\hline 1975 & 0.798 & 0.474 & 0.474 & 0.54 \\
\hline 1976 & 0.799 & 0.475 & 0.475 & 0.54 \\
\hline 1977 & 0.799 & 0.475 & 0.475 & 0.54 \\
\hline 1978 & 0.8 & 0.476 & 0.476 & 0.54 \\
\hline 1979 & 0.801 & 0.476 & 0.476 & 0.54 \\
\hline 1980 & 0.802 & 0.477 & 0.477 & 0.54 \\
\hline 1981 & 0.803 & 0.478 & 0.478 & 0.54 \\
\hline 1982 & 0.804 & 0.479 & 0.479 & 0.54 \\
\hline 1983 & 0.806 & 0.48 & 0.48 & 0.54 \\
\hline 1984 & 0.809 & 0.481 & 0.481 & 0.54 \\
\hline 1985 & 0.812 & 0.483 & 0.483 & 0.54 \\
\hline 1986 & 0.815 & 0.484 & 0.484 & 0.54 \\
\hline 1987 & 0.819 & 0.486 & 0.486 & 0.54 \\
\hline 1988 & 0.823 & 0.488 & 0.488 & 0.54 \\
\hline 1989 & 0.828 & 0.49 & 0.49 & 0.54 \\
\hline 1990 & 0.832 & 0.492 & 0.492 & 0.59 \\
\hline 1991 & 0.837 & 0.494 & 0.494 & 0.59 \\
\hline 1992 & 0.842 & 0.496 & 0.496 & 0.59 \\
\hline 1993 & 0.846 & 0.498 & 0.498 & 0.59 \\
\hline 1994 & 0.85 & 0.499 & 0.499 & 0.59 \\
\hline 1995 & 0.854 & 0.5 & 0.5 & 0.59 \\
\hline 1996 & 0.857 & 0.501 & 0.501 & 0.59 \\
\hline 1997 & 0.857 & 0.501 & 0.501 & 0.59 \\
\hline 1998 & 0.857 & 0.501 & 0.501 & 0.59 \\
\hline 1999 & 0.857 & 0.501 & 0.501 & 0.59 \\
\hline 2000 & 0.857 & 0.501 & 0.501 & 0.59 \\
\hline 2001 & 0.857 & 0.501 & 0.501 & 0.59 \\
\hline 2002 & 0.857 & 0.501 & 0.501 & 0.59 \\
\hline 2003 & 0.857 & 0.501 & 0.501 & 0.59 \\
\hline 2004 & 0.9 & 0.55 & 0.55 & 0.59 \\
\hline 2005 & 0.9 & 0.55 & 0.55 & 0.59 \\
\hline
\end{tabular}

Notes:

1. EF for water heaters is percentage efficiency divided by 100 .

2. Yellow cells contain data held constant from previous real data point.

3. In 2004, a new standard for water heaters went into effect (green cells). 
Table A.4.3: Shipment weighted efficiency factor (SWEF) for refrigerators (LBNL, n.d., Table 14)

\begin{tabular}{|c|c|c|c|c|}
\hline Year & $\begin{array}{c}\text { Automatic defrost, } \\
\text { side-by-side }\end{array}$ & $\begin{array}{c}\text { Automatic defrost, top } \\
\text { or bottom freezer }\end{array}$ & Generic & Manual defrost \\
\hline 1972 & 3.57 & 3.56 & 3.84 & 6.69 \\
\hline 1973 & 3.81 & 3.81 & 4.03 & 6.77 \\
\hline 1974 & 4.05 & 4.06 & 4.22 & 6.85 \\
\hline 1975 & 4.29 & 4.31 & 4.41 & 6.93 \\
\hline 1976 & 4.53 & 4.56 & 4.6 & 7.01 \\
\hline 1977 & 4.77 & 4.81 & 4.79 & 7.09 \\
\hline 1978 & 5.02 & 4.75 & 4.96 & 7.18 \\
\hline 1979 & 5.32 & 5.21 & 5.27 & 7.25 \\
\hline 1980 & 5.62 & 5.67 & 5.59 & 7.32 \\
\hline 1981 & 5.93 & 6.12 & 6.09 & 7.39 \\
\hline 1982 & 6.02 & 6.3 & 6.12 & 7.69 \\
\hline 1983 & 6.1 & 6.47 & 6.39 & 7.98 \\
\hline 1984 & 6.12 & 6.75 & 6.57 & 8.19 \\
\hline 1985 & 6.36 & 6.89 & 6.72 & 5.85 \\
\hline 1986 & 6.49 & 6.95 & 6.83 & 6.14 \\
\hline 1987 & 7.28 & 7.66 & 7.45 & 5.45 \\
\hline 1988 & 7.45 & 7.83 & 7.6 & 5.09 \\
\hline 1989 & 7.68 & 8.06 & 7.78 & 4.55 \\
\hline 1990 & 7.78 & 8.51 & 8.15 & 4.84 \\
\hline 1991 & 8.26 & 8.91 & 8.44 & 4.32 \\
\hline 1992 & 8.69 & 9.36 & 8.8 & 3.5 \\
\hline 1993 & 12.18 & 11.39 & 11.13 & 3.89 \\
\hline 1994 & 12.45 & 11.37 & 11.19 & 4.13 \\
\hline 1995 & 12.41 & 11.47 & 11.22 & 3.75 \\
\hline 1996 & 12.08 & 11.48 & 11.22 & 4.21 \\
\hline 1997 & 11.44 & 10.88 & 10.63 & 3.99 \\
\hline 1998 & 11.3 & 10.74 & 10.5 & 3.94 \\
\hline 1999 & 11.2 & 10.64 & 10.4 & 3.9 \\
\hline 2000 & 11.96 & 11.37 & 11.11 & 4.17 \\
\hline 2001 & 14.62 & 13.89 & 13.58 & 5.1 \\
\hline 2002 & 16.33 & 15.52 & 15.17 & 5.69 \\
\hline 2003 & 16.47 & 15.65 & 15.3 & 5.74 \\
\hline 2004 & 16.47 & 15.65 & 15.05 & 5.74 \\
\hline 2005 & 16.47 & 15.65 & 14.60 & 5.74 \\
\hline 2006 & 16.47 & 15.65 & 15.56 & 5.74 \\
\hline 2007 & 16.47 & 15.65 & 15.46 & 5.74 \\
\hline 2008 & 16.47 & 15.65 & 15.50 & 5.74 \\
\hline 2009 & 16.47 & 15.65 & 15.50 & 5.74 \\
\hline 2010 & 16.47 & 15.65 & 15.50 & 5.74 \\
\hline
\end{tabular}

Notes:

1. EF has units of (cubic feet-day/kWh), where cubic feet is adjusted volume.

2. Source: AHAM $(1996,2003)$; the Association for Home Appliance Manufacturers (AHAM) changed the reporting of refrigerator efficiencies after 1996. Annual data are available for the "General" category. Data for the other refrigerator types for years subsequent to 1996 were derived from the "General" refrigerator efficiency by scaling the efficiency for a particular type of refrigerator proportional to the annual change in efficiencies in the "General" refrigerator category.

3. Data have been held at 2003 or 2008 levels for subsequent years, where unavailable. Shaded cells do not have data available, so last available year is simply copied forward. 


\section{A.5. STORAGE TYPE NATURAL GAS WATER HEATERS LISTED IN 2012 AHRI DIRECTORY (AHRI 2012)}
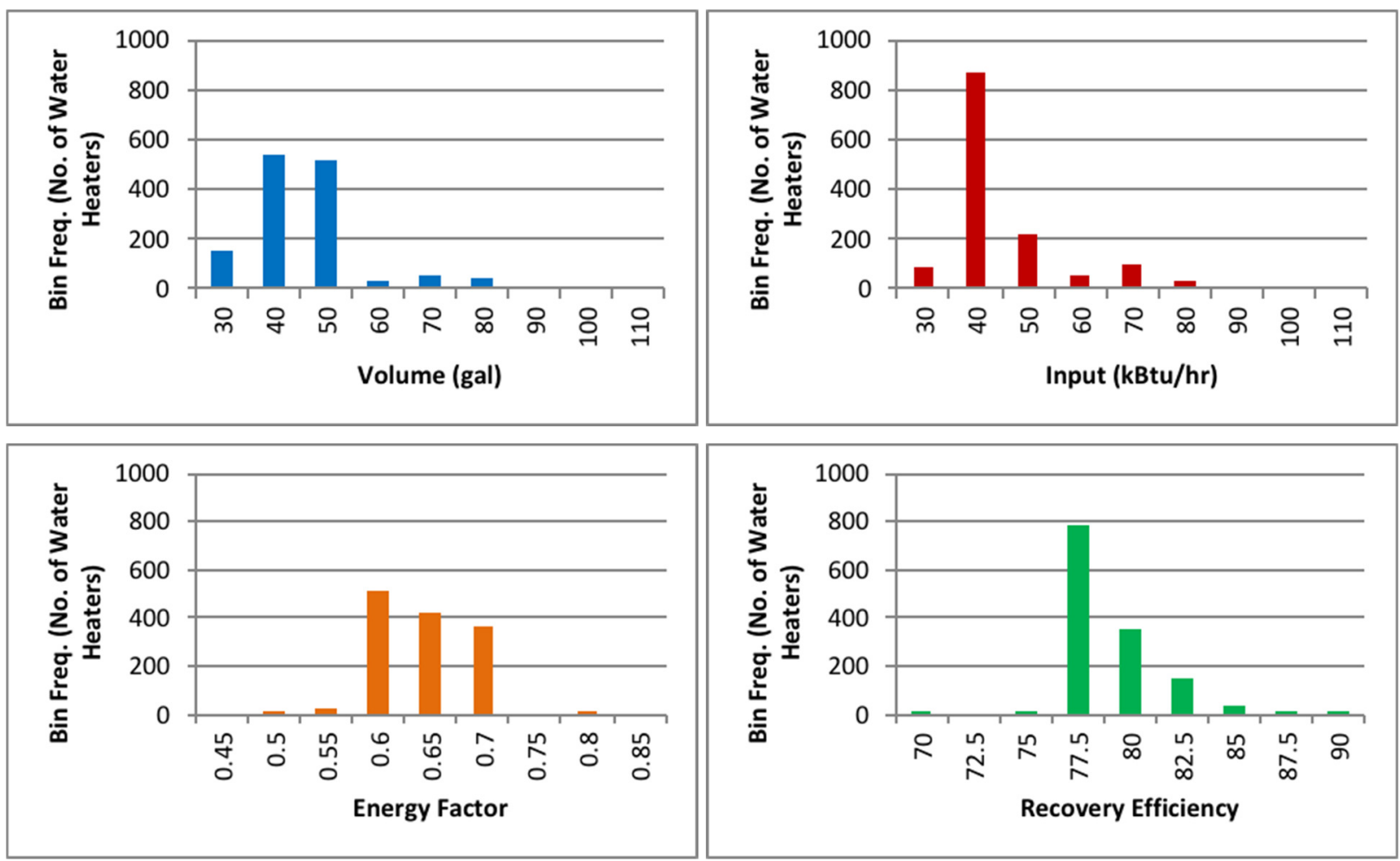

Figure A.5.1. Statistics of natural gas storage domestic water heaters listed in AHRI directory.

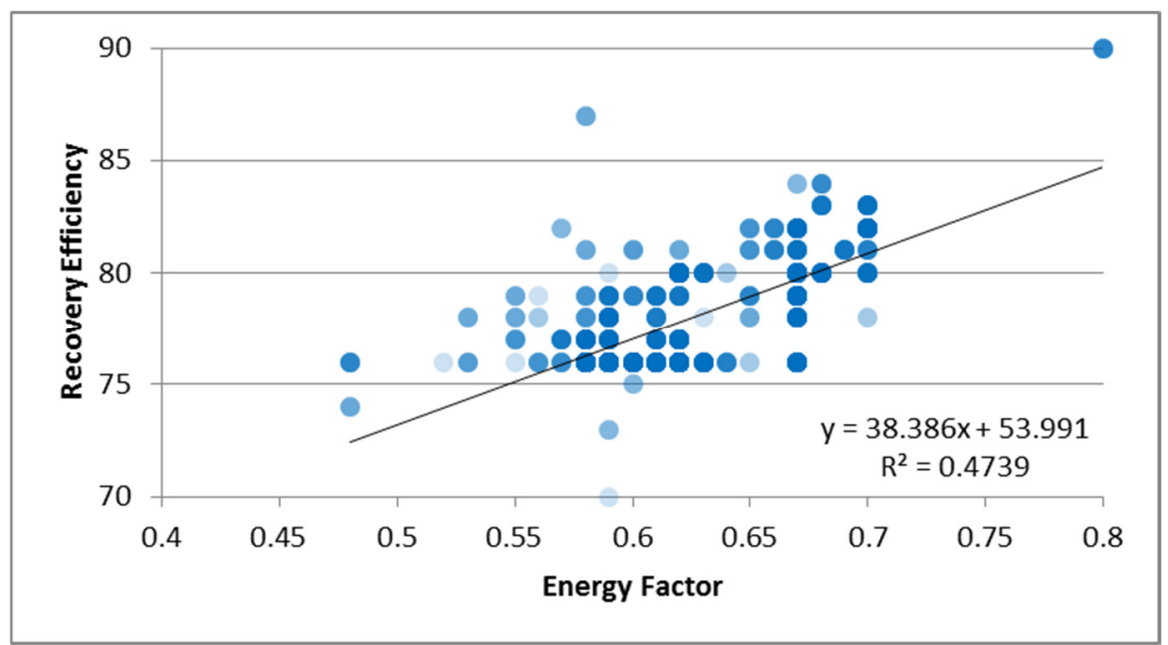

Figure A.5.2. Curve-fit between water heater EF and RE. 


\section{A.6. SCHEDULES}

Table A.6.1: Lighting schedule (Abraham et al. 1995)

\begin{tabular}{|c|c|c|c|c|c|c|}
\hline Variable type & \multicolumn{6}{|c|}{ Fraction of installed wattage used per hour } \\
\hline Space: & \multicolumn{2}{|c|}{ Unit } & \multicolumn{2}{|c|}{ Other conditioned spaces } & \multirow{2}{*}{$\begin{array}{c}\text { Hallway } \\
\text { All } \\
\end{array}$} & \multirow{2}{*}{$\begin{array}{c}\begin{array}{c}\text { Other } \\
\text { unconditionec } \\
\text { spaces }\end{array} \\
\text { All } \\
\end{array}$} \\
\hline Months: & Summer & Winter & \multicolumn{2}{|c|}{ All } & & \\
\hline Day type: & All & All & Weekday & $\begin{array}{c}\text { Weekend/ } \\
\text { holiday }\end{array}$ & All & All \\
\hline 1 & 0.13 & 0.13 & 0.01 & 0.01 & 1 & 0.01 \\
\hline 2 & 0.13 & 0.13 & 0.01 & 0.01 & 1 & 0.01 \\
\hline 3 & 0.13 & 0.13 & 0.01 & 0.01 & 1 & 0.01 \\
\hline 4 & 0.13 & 0.13 & 0.01 & 0.01 & 1 & 0.01 \\
\hline 5 & 0.13 & 0.13 & 0.01 & 0.01 & 1 & 0.01 \\
\hline 6 & 0.15 & 0.15 & 0.01 & 0.01 & 1 & 0.01 \\
\hline 7 & 0.2 & 0.22 & 0.01 & 0.01 & 1 & 0.01 \\
\hline 8 & 0.25 & 0.26 & 0.85 & 0.01 & 1 & 0.85 \\
\hline 9 & 0.30 & 0.32 & 0.85 & 0.01 & 1 & 0.85 \\
\hline 10 & 0.25 & 0.27 & 0.85 & 0.01 & 1 & 0.85 \\
\hline 11 & 0.22 & 0.24 & 0.85 & 0.01 & 1 & 0.85 \\
\hline 12 & 0.21 & 0.23 & 0.85 & 0.01 & 1 & 0.85 \\
\hline 13 & 0.21 & 0.23 & 0.85 & 0.01 & 1 & 0.85 \\
\hline 14 & 0.21 & 0.23 & 0.85 & 0.01 & 1 & 0.85 \\
\hline 15 & 0.22 & 0.24 & 0.85 & 0.01 & 1 & 0.85 \\
\hline 16 & 0.25 & 0.27 & 0.85 & 0.01 & 1 & 0.85 \\
\hline 17 & 0.28 & 0.30 & 0.85 & 0.01 & 1 & 0.85 \\
\hline 18 & 0.28 & 0.30 & 0.25 & 0.01 & 1 & 0.25 \\
\hline 19 & 0.25 & 0.27 & 0.25 & 0.01 & 1 & 0.25 \\
\hline 20 & 0.20 & 0.22 & 0.25 & 0.01 & 1 & 0.25 \\
\hline 21 & 0.20 & 0.22 & 0.25 & 0.01 & 1 & 0.25 \\
\hline 22 & 0.15 & 0.17 & 0.01 & 0.01 & 1 & 0.01 \\
\hline 23 & 0.13 & 0.15 & 0.01 & 0.01 & 1 & 0.01 \\
\hline 24 & 0.13 & 0.15 & 0.01 & 0.01 & 1 & 0.01 \\
\hline Peak & 0.30 & 0.32 & 0.85 & 0.01 & 1 & 0.85 \\
\hline Daily sum & 4.74 & 5.09 & 9.6 & 0.24 & 24 & 9.60 \\
\hline
\end{tabular}


Table A.6.2: Equipment schedule (Abraham et al. 1995)

\begin{tabular}{|c|c|c|c|c|c|c|}
\hline \multirow{2}{*}{$\begin{array}{c}\text { Variable type } \\
\text { Space: }\end{array}$} & \multicolumn{6}{|c|}{ Fraction of installed wattage used per hour } \\
\hline & \multirow{3}{*}{\begin{tabular}{|l|} 
Unit \\
All \\
All
\end{tabular}} & Other cor & hed spaces & \multicolumn{2}{|c|}{ Hallway } & \multirow{3}{*}{$\begin{array}{c}\begin{array}{c}\text { Other } \\
\text { unconditioned } \\
\text { spaces }\end{array} \\
\text { All } \\
\text { All } \\
\end{array}$} \\
\hline Months: & & \multicolumn{2}{|c|}{ All } & \multicolumn{2}{|c|}{ All } & \\
\hline Day type: & & Weekday & $\begin{array}{c}\text { Weekend/ } \\
\text { holiday }\end{array}$ & Weekday & $\begin{array}{l}\text { Weekend/ } \\
\text { holiday }\end{array}$ & \\
\hline 1 & 0.39 & 0 & 0.01 & 0.01 & 0.01 & 0.2 \\
\hline 2 & 0.39 & 0 & 0.01 & 0.01 & 0.01 & 0.2 \\
\hline 3 & 0.39 & 0 & 0.01 & 0.01 & 0.01 & 0.2 \\
\hline 4 & 0.39 & 0 & 0.01 & 0.01 & 0.01 & 0.2 \\
\hline 5 & 0.39 & 0 & 0.01 & 0.01 & 0.01 & 0.2 \\
\hline 6 & 0.39 & 0 & 0.01 & 0.01 & 0.01 & 0.2 \\
\hline 7 & 0.39 & 0 & 0.01 & 0.01 & 0.01 & 0.2 \\
\hline 8 & 0.55 & 0.95 & 0.01 & 0.40 & 0.01 & 0.5 \\
\hline 9 & 0.55 & 0.95 & 0.01 & 0.40 & 0.75 & 0.5 \\
\hline 10 & 0.51 & 0.95 & 0.01 & 0.40 & 0.75 & 0.5 \\
\hline 11 & 0.51 & 0.95 & 0.01 & 0.40 & 0.75 & 0.5 \\
\hline 12 & 0.51 & 0.95 & 0.01 & 0.40 & 0.75 & 0.5 \\
\hline 13 & 0.51 & 0.65 & 0.01 & 0.40 & 0.75 & 0.5 \\
\hline 14 & 0.51 & 0.95 & 0.01 & 0.40 & 0.75 & 0.5 \\
\hline 15 & 0.51 & 0.95 & 0.01 & 0.40 & 0.75 & 0.5 \\
\hline 16 & 0.51 & 0.95 & 0.01 & 0.40 & 0.75 & 0.5 \\
\hline 17 & 0.62 & 0.95 & 0.01 & 0.40 & 0.75 & 0.5 \\
\hline 18 & 0.59 & 0.01 & 0.01 & 0.40 & 0.02 & 0.5 \\
\hline 19 & 0.51 & 0.01 & 0.01 & 0.02 & 0.02 & 0.5 \\
\hline 20 & 0.51 & 0.01 & 0.01 & 0.02 & 0.02 & 0.5 \\
\hline 21 & 0.51 & 0.01 & 0.01 & 0.02 & 0.02 & 0.2 \\
\hline 22 & 0.47 & 0.01 & 0.01 & 0.02 & 0.02 & 0.2 \\
\hline 23 & 0.45 & 0.01 & 0.01 & 0.02 & 0.02 & 0.2 \\
\hline 24 & 0.40 & 0.01 & 0.01 & 0.02 & 0.02 & 0.2 \\
\hline Peak & 0.62 & 0.95 & 0.01 & 0.40 & 0.75 & 0.5 \\
\hline Daily Sum & 11.46 & 9.27 & 0.24 & 4.59 & 6.97 & 8.7 \\
\hline
\end{tabular}


Table A.6.3: Occupancy schedule (ORNL 2010)

\begin{tabular}{|c|c|c|}
\hline Variable type & \multicolumn{2}{|c|}{ Fraction of peak } \\
\hline Space: & \multicolumn{2}{|c|}{$\begin{array}{l}\text { Unit, Other conditioned spaces, Hallway, Othe } \\
\text { unconditioned spaces }\end{array}$} \\
\hline Months: & \multicolumn{2}{|c|}{ All } \\
\hline Day type: & Weekday & Weekend/holiday \\
\hline 1 & 1 & 1 \\
\hline 2 & 1 & 1 \\
\hline 3 & 1 & 1 \\
\hline 4 & 1 & 1 \\
\hline 5 & 1 & 1 \\
\hline 6 & 1 & 1 \\
\hline 7 & 1 & 1 \\
\hline 8 & 0.67 & 1 \\
\hline 9 & 0.57 & 1 \\
\hline 10 & 0.53 & 0.96 \\
\hline 11 & 0 & 0.75 \\
\hline 12 & 0.04 & 0.04 \\
\hline 13 & 0.57 & 0.57 \\
\hline 14 & 0.57 & 0.57 \\
\hline 15 & 0.57 & 0.57 \\
\hline 16 & 0.75 & 0.75 \\
\hline 17 & 0.75 & 0.75 \\
\hline 18 & 0.84 & 0.84 \\
\hline 19 & 1 & 1 \\
\hline 20 & 1 & 1 \\
\hline 21 & 1 & 1 \\
\hline 22 & 1 & 1 \\
\hline 23 & 1 & 1 \\
\hline 24 & 1 & 1 \\
\hline Peak & 1 & 1 \\
\hline Daily Sum & 18.86 & 20.8 \\
\hline
\end{tabular}

Note: Currently, a whole-building occupancy schedule is used for all spaces. Spacespecific occupancy schedules will be considered as a potential update to MulTEA. 


\section{A.7. LIBRARIES}

Table A.7.1: Measure lifetimes (NREL, n.d.; InterNACHI 2018; Skumatz et al. 2009, Table 5.2; Seiders et al. 2007; ASHRAE 2003; Weitzel and Skumatz 2002; Martin and Gettings 1998; Hiller 2000)

\begin{tabular}{|c|c|c|c|}
\hline Component type & Component subtype & Retrofit measure & Default lifetime \\
\hline \multirow[t]{8}{*}{ Walls } & \multirow[t]{3}{*}{ Exterior } & Add Cavity Insulation & 20 \\
\hline & & Add Exterior Insulation & 20 \\
\hline & & Add Interior Insulation & 20 \\
\hline & \multirow[t]{2}{*}{ Underground } & Add Exterior Insulation & 20 \\
\hline & & Add Interior Insulation & 20 \\
\hline & \multirow[t]{3}{*}{ Interior } & Add Cavity Insulation & 20 \\
\hline & & Add Exterior Insulation & 20 \\
\hline & & Add Interior Insulation & 20 \\
\hline \multirow[t]{4}{*}{ Windows } & \multirow[t]{4}{*}{ Exterior } & Replace Window & 20 \\
\hline & & Add Storm Window & 15 \\
\hline & & Add Shading & 10 \\
\hline & & Add Awning & 10 \\
\hline \multirow[t]{2}{*}{ Doors } & \multirow[t]{2}{*}{ Exterior } & Replace Door & 20 \\
\hline & & Add Storm Door & 10 \\
\hline \multirow[t]{9}{*}{ Roofs } & \multirow[t]{4}{*}{ Attic } & Add Ceiling Insulation & 20 \\
\hline & & Add Roof Insulation & 20 \\
\hline & & Add Radiant Barrier & 15 \\
\hline & & White Roof Coating & 7 \\
\hline & \multirow[t]{2}{*}{ Cathedral } & Add Roof Insulation & 20 \\
\hline & & White Roof Coating & 7 \\
\hline & \multirow[t]{3}{*}{ Flat } & Add Ceiling Insulation & 20 \\
\hline & & Add Roof Insulation & 20 \\
\hline & & White Roof Coating & 7 \\
\hline \multirow[t]{6}{*}{ Floors } & Underground & Add Slab Insulation & 20 \\
\hline & Exposed & Add Exterior Insulation & 20 \\
\hline & \multirow[t]{2}{*}{ Interior } & Add Exterior Insulation & 20 \\
\hline & & Add Sill Box Insulation & 20 \\
\hline & \multirow[t]{2}{*}{ Above Crawlspace } & Add Exterior Insulation & 20 \\
\hline & & Add Sill Box Insulation & 20 \\
\hline \multirow[t]{6}{*}{ HVAC } & \multirow[t]{5}{*}{ System } & Change Ventilation Rate & 15 \\
\hline & & Replace the System & 15 \\
\hline & & Tune Up & 3 \\
\hline & & Replace Pilot Light with IID & 10 \\
\hline & & Eliminate the System & 15 \\
\hline & Thermostat & New Thermostat Schedule & 15 \\
\hline Infiltration/Ventilation & Infiltration & Air Sealing & 10 \\
\hline \multirow[t]{5}{*}{ Water Heating } & \multirow[t]{5}{*}{ Individual System } & Replace the System & 13 \\
\hline & & Change Set-Point Temperature & 13 \\
\hline & & Install Water Heater Wrap & 13 \\
\hline & & Add Insulation on Water Heater Pipes & 13 \\
\hline & & Eliminate the System & 13 \\
\hline
\end{tabular}


Table A.7.1: Measure lifetimes (continued) (NREL, n.d.; InterNACHI 2018; Skumatz et al. 2009 Table 5.2; Seiders et al. 2007; ASHRAE 2003; Weitzel and Skumatz 2002; Martin and Gettings 1998; Hiller 2000)

\begin{tabular}{|l|l|l|r|}
\hline Water Heating & Central System & Replace the System & 20 \\
& & Change Set-Point Temperature & 20 \\
& & Add Insulation on Distribution Pipes & 20 \\
& & Replace Circulation Pump & 20 \\
\hline Lighting & System & Eliminate the System & 20 \\
& & Replace Lamps & Calculate using following eqn. \\
& & Delamp & 20 \\
& & Replace Old Ballasts & 12 \\
& & Install Motion Sensors & 12 \\
\hline Refrigerator & Install Timer Controls & NA \\
\hline
\end{tabular}

$$
\text { Lifetime (years) }=\frac{\text { Operational lifetime in hours }}{\text { Usage in } \frac{\text { hours }}{\text { day }} * 365 \frac{\text { days }}{\text { year }}} \text {, }
$$

where operational lifetime is obtained from the following table; usage is obtained from the Retrofit Usage field on the Lighting form.

\begin{tabular}{|l|c|}
\hline Replacement lamp type or ballast & Operational lifetime (hours) \\
\hline Incandescent & 1,000 \\
Halogen & 4,000 \\
Fluorescent & 10,000 \\
Compact fluorescent lamp & 10,000 \\
Ballast & 30,000 \\
\hline
\end{tabular}

Table A.7.2: Heat content of fuel (EIA n.d.; EIA 2018b; ASHRAE 1977, Chapter 14, Tables 7 and 9)

\begin{tabular}{|l|c|c|}
\hline \multicolumn{1}{|c|}{ Fuel } & Heat content (MMBtu) & Per unit \\
\hline Electricity & 0.003413 & kWh \\
\hline Natural Gas & 1.025 & Mcf \\
& 1.0 & MMBtu \\
& 0.1 & therm \\
& 0.1025 & ccf \\
\hline Propane & 0.0915 & Gallon \\
Oil & 0.139 & Gallon \\
Kerosene & 0.135 & Gallon \\
\hline Coal & 21.0 & Ton \\
Wood & 20.0 & Cord \\
Other & 1.0 & MMBtu \\
\hline
\end{tabular}


Table A.7.3: Fuel costs (EIA 2018a)

\begin{tabular}{|l|c|c|}
\hline \multicolumn{1}{|c|}{ Fuel cost name } & Cost $\mathbf{( \$ )}$ & Per unit \\
\hline Average U.S. Residential Electricity Costs-2015 & 0.1235 & $\mathrm{kWh}$ \\
Average U.S. Residential Natural Gas Costs—2015 & 9.27 & $\mathrm{Mcf}$ \\
Average U.S. Residential Propane Costs—2015 & 2.34 & Gallon \\
Average U.S. Residential Oil Costs-2015 & 3.07 & Gallon \\
Average U.S. Residential Kerosene Costs-2015 & 3.65 & Gallon \\
Average U.S. Residential Coal Costs-2015 & 90.51 & Ton \\
Average U.S. Residential Wood Costs-2015 & 250.0 & Cord \\
\hline
\end{tabular}

Table A.7.4: Fuel price indices (Lavappa and Kneifel 2015)

\begin{tabular}{|c|c|c|c|c|c|c|c|c|}
\hline Year & Natural gas & Oil & Electricity & Propane & Wood & Coal & Kerosene & Other \\
\hline 0 & 1 & 1 & 1 & 1 & 1 & 1 & 1 & 1 \\
\hline 1 & 0.98 & 0.97 & 1 & 0.97 & 1 & 0.99 & 0.97 & 1 \\
\hline 2 & 0.97 & 0.97 & 1.01 & 9.94 & 1 & 1.01 & 0.97 & 1 \\
\hline 3 & 1.01 & 0.98 & 1.02 & 0.94 & 1 & 1.02 & 0.98 & 1 \\
\hline 4 & 1.04 & 1 & 1.03 & 0.96 & 1 & 1.02 & 1 & 1 \\
\hline 5 & 1.08 & 1.01 & 1.03 & 0.99 & 1 & 1.04 & 1.01 & 1 \\
\hline 6 & 1.1 & 1.03 & 1.03 & 1.01 & 1 & 1.04 & 1.03 & 1 \\
\hline 7 & 1.12 & 1.04 & 1.03 & 1.02 & 1 & 1.05 & 1.04 & 1 \\
\hline 8 & 1.14 & 1.06 & 1.03 & 1.04 & 1 & 1.06 & 1.06 & 1 \\
\hline 9 & 1.16 & 1.07 & 1.03 & 1.05 & 1 & 1.06 & 1.07 & 1 \\
\hline 10 & 1.18 & 1.09 & 1.03 & 1.06 & 1 & 1.07 & 1.09 & 1 \\
\hline 11 & 1.2 & 1.11 & 1.03 & 1.08 & 1 & 1.08 & 1.11 & 1 \\
\hline 12 & 1.21 & 1.12 & 1.04 & 1.09 & 1 & 1.08 & 1.12 & 1 \\
\hline 13 & 1.22 & 1.14 & 1.04 & 1.1 & 1 & 1.1 & 1.14 & 1 \\
\hline 14 & 1.23 & 1.16 & 1.05 & 1.1 & 1 & 1.1 & 1.16 & 1 \\
\hline 15 & 1.25 & 1.18 & 1.05 & 1.11 & 1 & 1.11 & 1.18 & 1 \\
\hline 16 & 1.26 & 1.19 & 1.05 & 1.12 & 1 & 1.12 & 1.19 & 1 \\
\hline 17 & 1.27 & 1.21 & 1.06 & 1.13 & 1 & 1.14 & 1.21 & 1 \\
\hline 18 & 1.29 & 1.23 & 1.06 & 1.14 & 1 & 1.14 & 1.23 & 1 \\
\hline 19 & 1.31 & 1.24 & 1.06 & 1.14 & 1 & 1.15 & 1.24 & 1 \\
\hline 20 & 1.33 & 1.26 & 1.07 & 1.15 & 1 & 1.16 & 1.26 & 1 \\
\hline 21 & 1.35 & 1.28 & 1.07 & 1.16 & 1 & 1.17 & 1.28 & 1 \\
\hline 22 & 1.39 & 1.3 & 1.08 & 1.17 & 1 & 1.19 & 1.3 & 1 \\
\hline 23 & 1.42 & 1.33 & 1.09 & 1.18 & 1 & 1.2 & 1.33 & 1 \\
\hline 24 & 1.46 & 1.35 & 1.1 & 1.19 & 1 & 1.21 & 1.35 & 1 \\
\hline 25 & 1.5 & 1.37 & 1.11 & 1.21 & 1 & 1.22 & 1.37 & 1 \\
\hline 26 & 1.53 & 1.39 & 1.12 & 1.22 & 1 & 1.24 & 1.39 & 1 \\
\hline 27 & 1.55 & 1.41 & 1.13 & 1.23 & 1 & 1.25 & 1.41 & 1 \\
\hline 28 & 1.58 & 1.44 & 1.14 & 1.24 & 1 & 1.26 & 1.44 & 1 \\
\hline 29 & 1.6 & 1.46 & 1.14 & 1.25 & 1 & 1.27 & 1.46 & 1 \\
\hline 30 & 1.63 & 1.49 & 1.15 & 1.26 & 1 & 1.27 & 1.49 & 1 \\
\hline
\end{tabular}





\section{APPENDIX B. DERIVATIONS}

\section{B.1. MODIFIED ZONE METHOD FOR METAL STUD WALLS WITH INSULATED CAVITIES}

ASHRAE (2013a) describes a Modified Zone Method for Metal Stud Walls with Insulated Cavities. This method is specified as the most accurate simple method for estimating the clear wall R-value of light-gage steel stud walls with insulated cavities. For MulTEA, this method is employed to derive a generalized equation for both wood and metal stud walls; for a wood stud wall, the parameters reduce the equation to the same as the parallel path method.

For MulTEA, curve-fit for the modified zone factor, $z_{f}$ (plotted in ASHRAE 2013a, Figure 6, p.27.5) for different metal stud sizes are derived, as shown in Figure B.1.1, such that

$$
\mathrm{z}_{\mathrm{f}}=\mathrm{a} * \mathrm{x}^{2}+\mathrm{b} * \mathrm{x}+\mathrm{c}
$$

where

$$
\mathrm{x}=\frac{\text { Average Resistivity of Sheathing and Face materials }}{\text { Resistivity of Cavity Insulation }}=\frac{\text { COND[avgSh] }}{\text { COND[cavIns] }}
$$

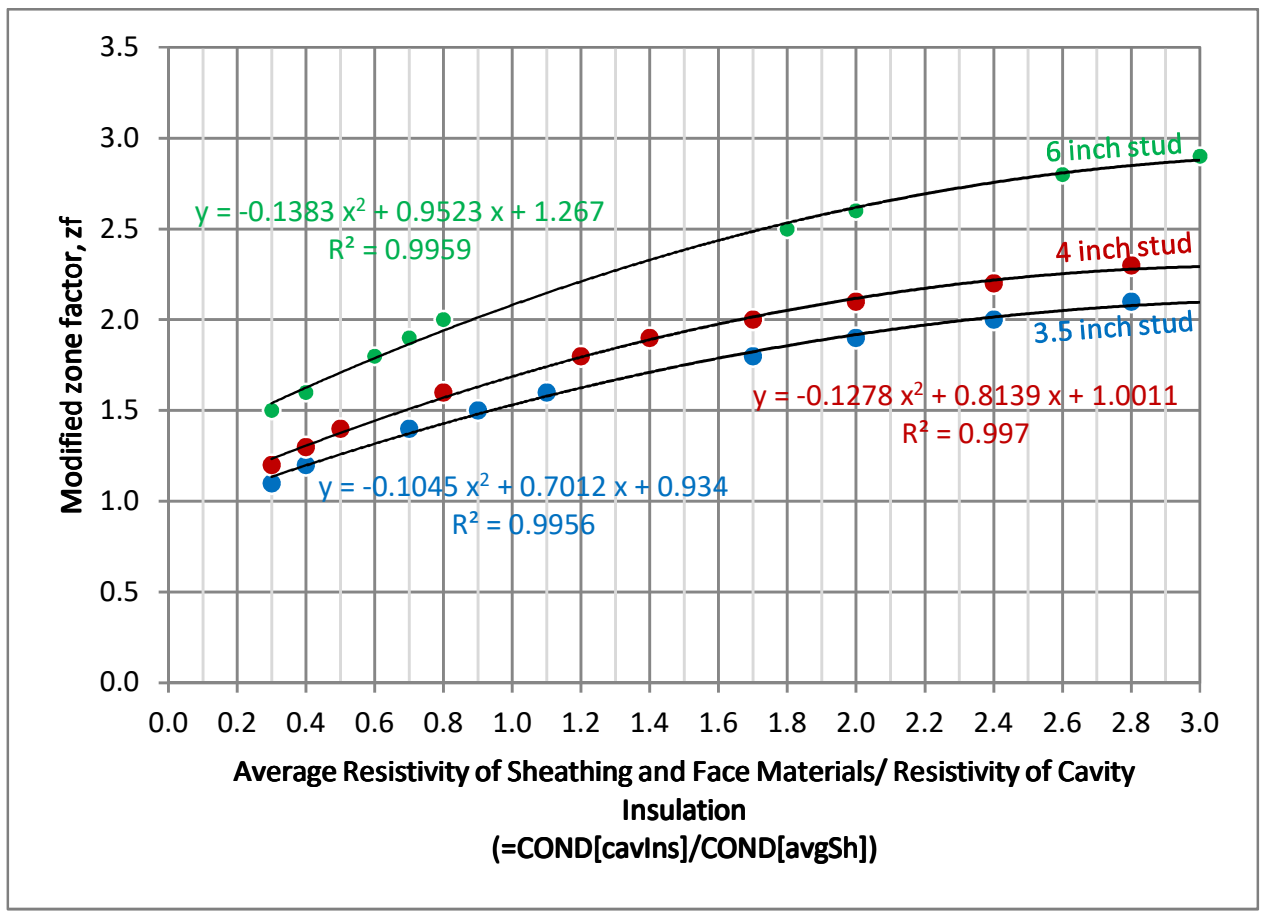

Figure B.1.1. Modified Zone Method for calculating R-value of metal stud walls with insulated cavities.

Then, we derive another set of curve-fits for the coefficients $a, b$, and $c$ of these equations as a function of stud size, as shown in Figure B.1.2, so that

$$
\mathrm{a}=\mathrm{m}_{2} * \text { stud size }+\mathrm{c}_{2}, \mathrm{~b}=\mathrm{m}_{1} * \text { stud size }+\mathrm{c}_{1} \text {, and } \mathrm{c}=\mathrm{m}_{0} * \text { stud size }+\mathrm{c}_{0} .
$$




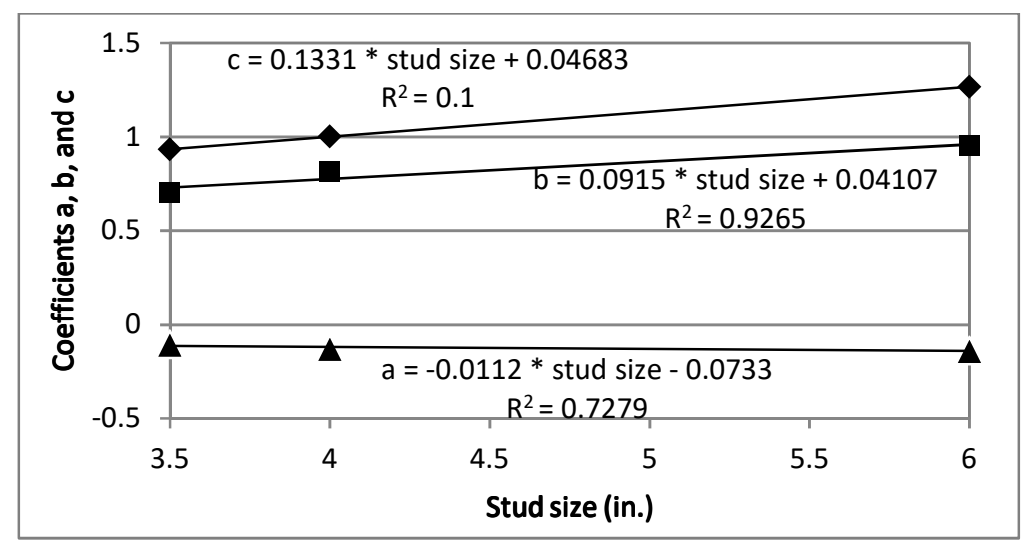

Figure B.1.2. Curve-fit for coefficients of $z_{f}$ as a function of stud size.

Table B.1.1: Coefficients of $z_{f}$ for different metal stud sizes

\begin{tabular}{|c|c|c|c|c|c|}
\hline \multirow{2}{*}{ Coefficients } & \multicolumn{3}{|c|}{ Stud size } & \multicolumn{2}{c|}{ Curve-fit } \\
\cline { 2 - 6 } & $\mathbf{3 . 5}$ in. & $\mathbf{4 . 0}$ in. & $\mathbf{6 . 0}$ in. & Slope, m & Intercept, c \\
\hline a & -0.1045 & -0.1278 & -0.1383 & -0.0112 & -0.0733 \\
b & 0.7012 & 0.8139 & 0.9523 & 0.0915 & 0.4107 \\
c & 0.934 & 1.0011 & 1.267 & 0.1331 & 0.4683 \\
\hline
\end{tabular}

Thus, the zone factor $z_{f}$ can be expressed as a function of $x$ (i.e., conductivity ratio of cavity insulation and sheathing plus face material) and stud size as shown below, where $m_{0}, m_{1}, m_{2}, c_{0}, c_{1}$, and $c_{2}$ are obtained from Table B.1.2.

$$
\mathbf{z}_{\mathbf{f}}=\left(\mathbf{m}_{\mathbf{2}} * \text { stud size }+\mathbf{c}_{2}\right) * \mathbf{x}^{2}+\left(\mathbf{m}_{1} * \text { stud size }+\mathbf{c}_{\mathbf{1}}\right) * \mathbf{x}+\left(\mathbf{m}_{\mathbf{0}} * \text { stud size }+\mathbf{c}_{\mathbf{0}}\right)
$$

Table B.1.2: Curve-fit for coefficients of $x^{n}$ for metal-frame wall

\begin{tabular}{|c|c|c|c|}
\hline \multicolumn{2}{|c|}{ Slope, $\boldsymbol{m}_{\boldsymbol{n}}$} & \multicolumn{2}{c|}{ Intercept, $\boldsymbol{c}_{\boldsymbol{n}}$} \\
\hline $\mathrm{m}_{2}$ & -0.0112 & $\mathrm{c}_{2}$ & -0.0733 \\
$\mathrm{~m}_{1}$ & 0.0915 & $\mathrm{c}_{1}$ & 0.4107 \\
$\mathrm{~m}_{0}$ & 0.1331 & $\mathrm{c}_{0}$ & 0.4683 \\
\hline
\end{tabular}

\section{B.2. PERIMETER CONDUCTION FACTOR FOR GROUND-COUPLED SURFACES}

Winkelmann (2002) provides perimeter conduction factors $(F 2)$ for ground-coupled surfaces including slab-on-grade floor, underground basement wall, and underground crawlspace wall for selected configurations. For MulTEA, we derive $F 2$ as a continuous function of parameters that define these configurations, so that the MulTEA user interface is not limited to the configurations listed in Winkelmann (2002).

\section{B.2.1. Slab-on-grade Floor}

Figure B.2.1 shows typical slab-on-grade floor insulation locations (Winkelman 2002). Table B.2.1 shows perimeter $F 2$ as obtained from Winkelman (2002) for selected slab-on-grade floor configurations (i.e., $2 \mathrm{ft}$ and $4 \mathrm{ft}$ foundation depths, uncarpeted and carpeted, and different insulation locations). 


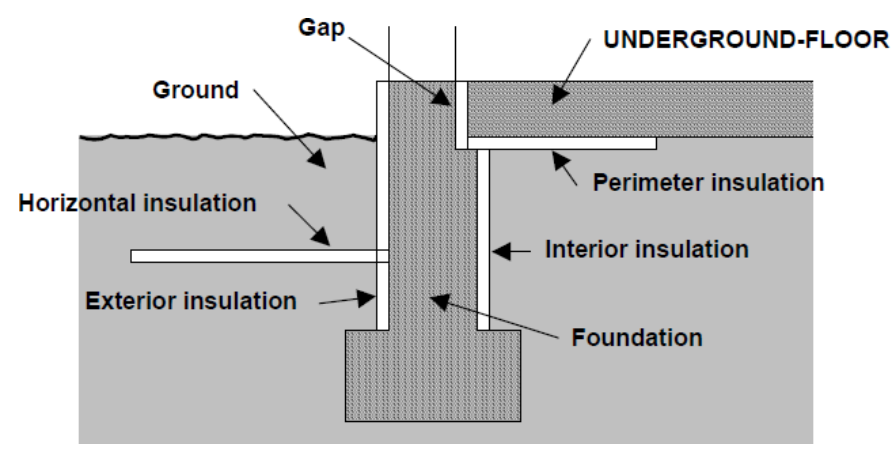

Figure B.2.1. Typical slab-on-grade floor insulation locations (Winkelmann 2002).

Table B.2.1: Perimeter conduction factor (F2) for selected slab-on-grade floor configurations (Winkelmann 2002)

\begin{tabular}{|l|c|c|c|c|}
\hline \multirow{2}{*}{ Insulation configuration } & \multicolumn{2}{|c|}{ 2 ft foundation depth } & \multicolumn{2}{c|}{ 4 ft foundation depth } \\
\cline { 2 - 5 } & Uncarpeted & Carpeted & Uncarpeted & Carpeted \\
\hline None & 1.1 & 0.77 & 1.1 & 0.77 \\
R-5 Exterior & 0.73 & 0.54 & 0.61 & 0.46 \\
R-5 Interior, R-5 Gap & 0.75 & 0.57 & 0.63 & 0.48 \\
R-5 Perimeter, R-5 Gap & 0.78 & 0.6 & 0.68 & 0.54 \\
R-5 16-in Exterior, R-5 2-ft or 4-ft Horizontal & 0.65 & 0.48 & 0.58 & 0.43 \\
\hline
\end{tabular}

For MulTEA, we derive a curve-fit to calculate $F 2$ as a function of the carpet fraction $\left(C_{f}\right)$, foundation depth $(H)$, and insulation location (InsLoc) for a slab-on-grade floor, as shown in Figure B.2.2, so that the MulTEA user interface is not limited to the listed configurations.

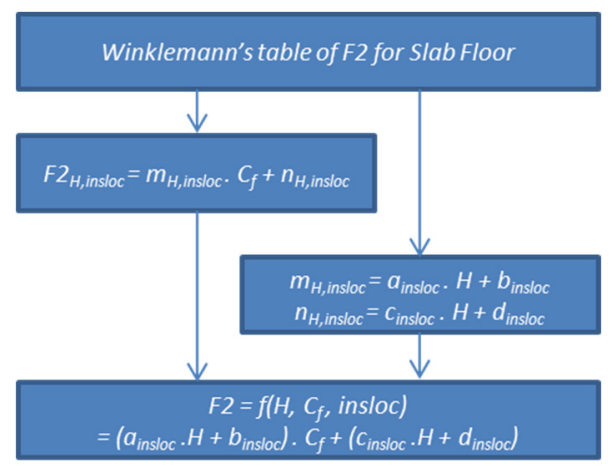

Figure B.2.2. Method for determining $F 2$ for slab-on-grade floor as a function of carpet fraction, foundation depth, and insulation location.

First, based on Table B.2.1, we derive curve-fit for $F 2$ as a function of carpet fraction for the two foundation depths and five slab-on-grade floor insulation locations (as shown in Table B.2.2). 
Table B.2.2: Curve-fit for $F 2$ as a function of carpet fraction for slab-on-grade floor

\begin{tabular}{|l|c|c|}
\hline \multirow{2}{*}{ Insulation configuration } & \multicolumn{2}{|c|}{$\mathbf{F} \mathbf{2}_{\mathbf{H}}=\mathbf{m}_{\mathbf{H}} * \mathbf{C f}+\mathbf{n}_{\mathbf{H}}$} \\
\cline { 2 - 3 } & $\mathbf{H}=\mathbf{2}$ & $\mathbf{H}=\mathbf{4}$ \\
\hline None & $\mathrm{F} 22_{2}=-0.33 * \mathrm{Cf}+1.1$ & $\mathrm{~F} 24=-0.33 * \mathrm{Cf}+1.1$ \\
R-5 Exterior & $\mathrm{F} 2{ }_{2}=-0.19 * \mathrm{Cf}+0.73$ & $\mathrm{~F} 2{ }_{4}=-0.15 * \mathrm{Cf}+0.61$ \\
R-5 Interior, R-5 Gap & $\mathrm{F} 2{ }_{2}=-0.18 * \mathrm{Cf}+0.75$ & $\mathrm{~F} 24=-0.15 * \mathrm{Cf}+0.63$ \\
R-5 Perimeter, R-5 Gap & $\mathrm{F} 2{ }_{2}=-0.18 * \mathrm{Cf}+0.78$ & $\mathrm{~F} 24=-0.14 * \mathrm{Cf}+0.68$ \\
R-5 16-in Exterior, R-5 2-ft or 4-ft Horizontal & $\mathrm{F} 2{ }_{2}=-0.17 * \mathrm{Cf}+0.65$ & $\mathrm{~F} 24=-0.15 * \mathrm{Cf}+0.58$ \\
\hline
\end{tabular}

Next, for each insulation location in Table B.2.2, we derive another set of curve-fits for coefficients $m_{H}$ and $n_{h}$ as a function of foundation depth $H$, as shown in Table B.2.3.

Table B.2.3: Curve-fit for $m_{H}$ and $n_{H}$ as a function of foundation depth

\begin{tabular}{|l|c|c|c|c|}
\hline \multirow{2}{*}{ Insulation configuration } & \multicolumn{2}{|c|}{$\mathbf{m}_{\mathbf{H}}=\mathbf{a}_{\text {InsLoc }} * \mathbf{H}+\mathbf{b}_{\text {InsLoc }}$} & \multicolumn{2}{c|}{$\mathbf{n}_{\mathbf{H}}=\mathbf{c}_{\text {InsLoc }} * \mathbf{H}+\mathbf{d}_{\text {InsLoc }}$} \\
\cline { 2 - 5 } & $\mathbf{a}_{\text {InsLoc }}$ & $\mathbf{b}_{\text {InsLoc }}$ & $\mathbf{c}_{\text {InsLoc }}$ & $\mathbf{d}_{\text {InsLoc }}$ \\
\hline None & 0 & -0.33 & 0 & 1.1 \\
R-5 Exterior & 0.02 & -0.23 & -0.06 & 0.85 \\
R-5 Interior, R-5 Gap & 0.015 & -0.21 & -0.06 & 0.87 \\
R-5 Perimeter, R-5 Gap & 0.02 & -0.22 & -0.05 & 0.88 \\
R-5 16-in Exterior, R-5 2-ft or 4-ft Horizontal & 0.01 & -0.19 & -0.035 & 0.72 \\
\hline
\end{tabular}

In this manner, $F 2$ can be expressed as a function of foundation depth, carpet fraction, and insulation location, as shown below, where coefficients $a_{I n s L o c}, b_{I n s L o c}, c_{I n S L o c}$, and $d_{I n s L o c}$ are obtained from Table B.2.3.

$$
\mathbf{F} 2=\mathbf{f}\left\{\mathbf{H}, \mathbf{C}_{\mathbf{f}}, \text { Insulation Location }\right\}=\left(\mathbf{a}_{\text {InsLoc }} * \mathbf{H}+\mathbf{b}_{\text {InsLoc }}\right) * \mathbf{C}_{\mathbf{f}}+\left(\mathbf{c}_{\text {InsLoc }} * \mathbf{H}+\mathbf{d}_{\text {InsLoc }}\right)
$$

\section{B.2.2. Basement Wall}

Figure B.2.3 shows typical basement wall insulation configurations (Winkelman 2002). Table B.2.4 shows perimeter $F 2$ as obtained from Winkelman (2002) for selected basement wall configurations (i.e., $8 \mathrm{ft}$ and $4 \mathrm{ft}$ underground wall height representing deep and shallow basements, respectively, and different $\mathrm{R}$-values of exterior and interior insulation).
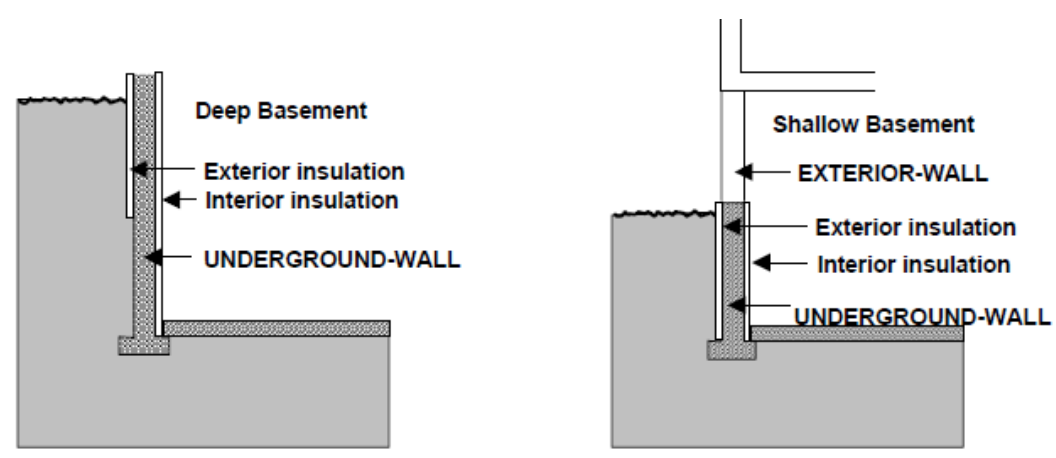

Figure B.2.3. Typical basement wall insulation configurations (Winkelmann 2002). 
Table B.2.4: Perimeter conduction factor $(F 2)$ for selected

basement wall configurations (Winkelmann 2002)

\begin{tabular}{|c|c|c|}
\hline \multirow{2}{*}{$\begin{array}{c}\text { Insulation } \\
\text { Configuration }\end{array}$} & \multicolumn{2}{|c|}{ Underground Wall Height } \\
\hline & $8 \mathrm{ft}$ & $4 \mathrm{ft}$ \\
\hline None & 1.94 & 1.61 \\
\hline R-5 Exterior & 0.99 & 0.89 \\
\hline R-10 Exterior & 0.75 & 0.73 \\
\hline R-15 Exterior & 0.63 & 0.66 \\
\hline R-20 Exterior & 0.56 & 0.65 \\
\hline R-10 Interior & 0.78 & 0.79 \\
\hline
\end{tabular}

For MulTEA, we derive a curve-fit to calculate $F 2$ as a function of underground wall height $(H)$ and Rvalue of exterior and interior insulation $\left(R_{e x t}\right.$ and $\left.R_{i n t}\right)$, as shown in Figure B.2.4, so that the MulTEA user interface is not limited to the listed configurations.

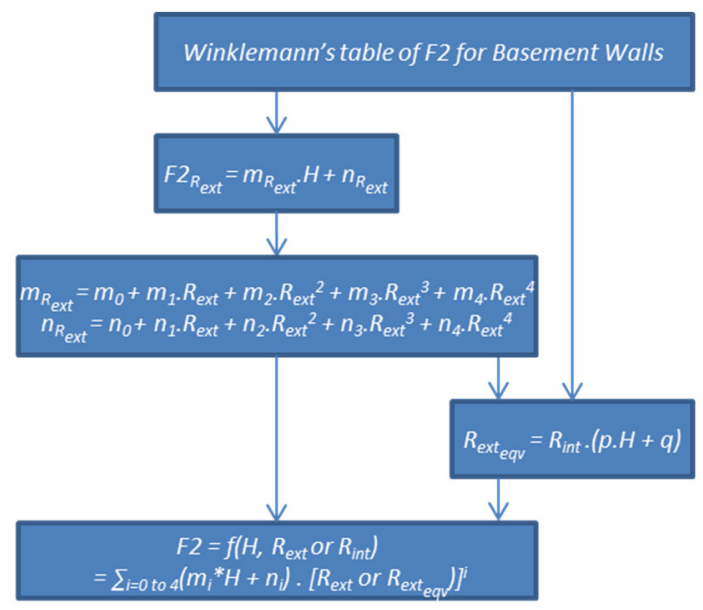

Figure B.2.4. Method for determining $F 2$ for basement wall as a function of underground wall height and $R$-value of exterior and interior insulation.

First, based on Table B.2.4, we derive curve-fit for $F 2$ as a function of underground wall height for each exterior insulation level listed, as shown in Table B.2.5.

Table B.2.5: Curve-fit for $\boldsymbol{F} 2$ for basement wall as a function of underground wall depth

\begin{tabular}{|l|l|}
\hline Exterior insulation, $\mathbf{R}_{\text {ext }}$ & \multicolumn{1}{|c|}{$\mathbf{F}_{2}=\mathbf{m}_{\mathbf{R}_{\text {ins }}} * \mathbf{H}+\mathbf{n}_{\mathbf{R}_{\text {ins }}}$} \\
\hline None & $\mathrm{F} 2_{(\operatorname{Rext}=0)}=0.0825 * \mathrm{H}+1.28$ \\
R-5 Exterior & $\left.\mathrm{F} 2_{(\text {Rext }}=5\right)=0.025 * \mathrm{H}+0.79$ \\
R-10 Exterior & $\mathrm{F} 2_{(\text {Rext }=10)}=-0.005 * \mathrm{H}+0.71$ \\
R-15 Exterior & $\mathrm{F} 2_{(\operatorname{Rext}=15)}=-0.0075 * \mathrm{H}+0.69$ \\
R-20 Exterior & $\mathrm{F} 2_{(\operatorname{Rext}=20)}=-0.0225 * \mathrm{H}+0.74$ \\
\hline
\end{tabular}

Next, based on Table B.2.5, we derive another set of curve-fits for coefficients $m_{R_{\text {ext }}}$ and $n_{R_{\text {ext }}}$ as a function of exterior insulation R-value $\left(R_{e x t}\right)$, as shown in Table B.2.6. 
Table B.2.6: Curve-fit for $m_{\text {Rext }}$ and $n_{\text {Rext }}$ as a function of exterior insulation R-value

\begin{tabular}{|c|c|c|c|}
\hline \multicolumn{2}{|c|}{$\mathbf{m}_{\mathbf{R}_{\text {ext }}}=\sum_{\mathbf{i}=\mathbf{0}}^{\mathbf{4}} \mathbf{m}_{\mathbf{i}} *\left(\frac{\mathbf{R}_{\text {ext }}}{\mathbf{1 0 0}}\right)^{\mathbf{i}}$} & \multicolumn{2}{|c|}{$\mathbf{n}_{\mathbf{R}_{\text {ext }}}=\sum_{\mathbf{i}=\mathbf{0}}^{\mathbf{4}} \mathbf{n}_{\mathbf{i}} *\left(\frac{\mathbf{R}_{\text {ext }}}{\mathbf{1 0 0}}\right)^{\mathbf{i}}$} \\
\hline Coefficient & Derived value & Coefficient & Derived value \\
\hline $\mathrm{m}_{4}$ & 133.33 & $\mathrm{n}_{4}$ & 2400 \\
$\mathrm{~m}_{3}$ & -80 & $\mathrm{n}_{3}$ & -1186.7 \\
$\mathrm{~m}_{2}$ & 17.167 & $\mathrm{n}_{2}$ & 218 \\
$\mathrm{~m}_{1}$ & -1.825 & $\mathrm{n}_{1}$ & -18.033 \\
$\mathrm{~m}_{0}$ & 0.0825 & $\mathrm{n}_{0}$ & 1.28 \\
\hline
\end{tabular}

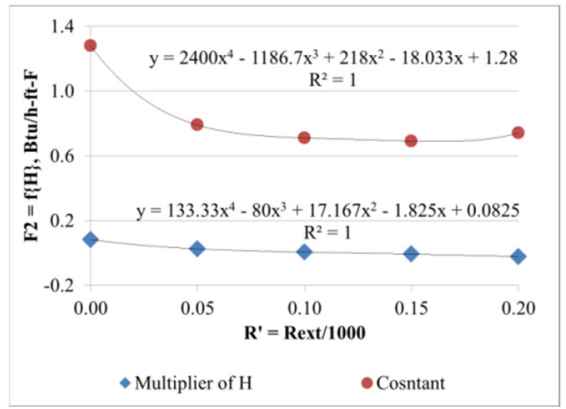

Thus, $F 2$ can be expressed as the following equation:

$$
\mathrm{F} 2=\mathrm{m}_{\mathrm{R}_{\text {ext }}} * \mathrm{H}+\mathrm{n}_{\mathrm{R}_{\mathrm{ext}}}=\sum_{\mathrm{i}=0}^{4}\left[\left(\mathrm{~m}_{\mathrm{i}} * \mathrm{H}+\mathrm{n}_{\mathrm{i}}\right) *\left(\frac{\mathrm{R}_{\mathrm{ext}}}{100}\right)^{\mathrm{i}}\right]
$$

Next, to accommodate the value of $F 2$ for a basement with interior insulation, we derive an equivalency relation between interior insulation R-value and exterior insulation R-value (as shown in the following equation), so that a unit $R_{\text {int }}$ will result in the same value of $F 2$ as an equivalent value of $R_{\text {ext }}$.

$$
\mathrm{R}_{\text {ext }} \text { eqv }=\mathrm{R}_{\text {int }} *(0.0425 * \mathrm{H}+0.55)
$$

In this manner, $F 2$ can be expressed as a function of basement height and $\mathrm{R}$-value of exterior and interior insulation, where $R_{\text {ext }}$ eqv is calculated from the above equation and coefficients $m_{i}$ and $n_{i}$ are obtained from Table B.2.6.

$$
\mathbf{F} 2=\mathbf{f}\left(\mathbf{H}, \mathbf{R}_{\mathrm{ext}} \text { or } \mathbf{R}_{\mathrm{int}}\right)=\sum_{\mathrm{i}=\mathbf{0}}^{4}\left[\left(\mathbf{m}_{\mathrm{i}} * \mathbf{H}+\mathbf{n}_{\mathbf{i}}\right) *\left(\frac{\mathbf{R}_{\mathrm{ext}} \text { or }_{\mathbf{R}_{\text {ext }}}}{\mathbf{1 0 0}}\right)^{\mathrm{i}}\right]
$$

\section{B.2.3. Crawlspace Wall}

Figure B.2.5 shows typical crawlspace wall insulation configurations (Winkelman 2002). Table B.2.7 shows perimeter $F 2$ as obtained from Winkelman (2002) for selected crawlspace configurations (i.e., $2 \mathrm{ft}$ and $4 \mathrm{ft}$ crawlspace wall height, respectively, and different R-values of exterior and interior insulation).

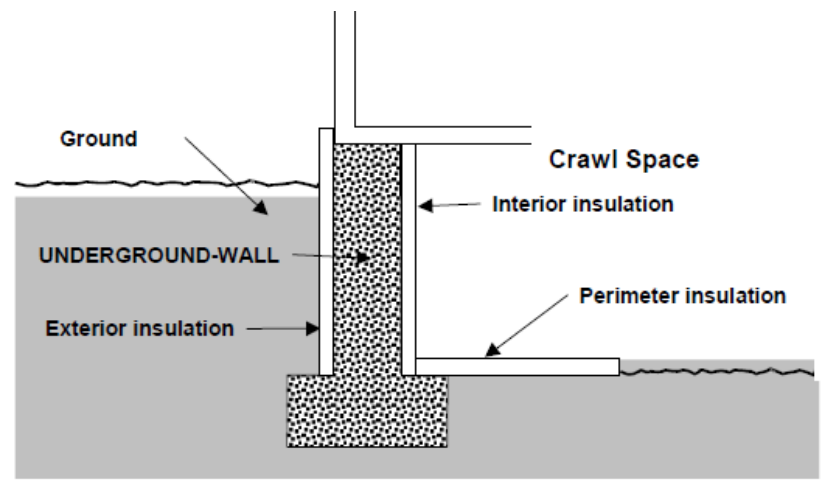

Figure B.2.5. Typical crawlspace wall insulation configurations (Winkelmann 2002). 
Table B.2.7: Perimeter conduction factor $(F 2)$ for selected crawlspace wall configurations (Winkelmann 2002)

\begin{tabular}{|l|c|c|}
\hline \multirow{2}{*}{ Insulation configuration } & \multicolumn{2}{|c|}{ Crawlspace wall height } \\
\cline { 2 - 3 } & $\mathbf{2 ~ f t}$ & $\mathbf{4 ~ f t}$ \\
\hline None & 1.29 & 1.28 \\
R-5 Exterior & 0.93 & 0.71 \\
R-10 Exterior & 0.87 & 0.59 \\
R-15 Exterior & 0.83 (extrapolated) & 0.54 \\
R-20 Exterior & 0.81 (extrapolated) & 0.5 \\
R-5 Interior & 0.97 & 0.79 (extrapolated) \\
R-10 Interior & 0.91 & 0.67 (extrapolated) \\
\hline
\end{tabular}

For MulTEA, we derive a curve-fit to calculate $F 2$ as a function of crawlspace wall height $(H)$ and the Rvalue of the exterior and interior insulation $\left(R_{e x t}\right.$ and $\left.R_{\text {int }}\right)$, as shown in Figure B.2.6, so that the MulTEA user interface is not limited to the listed configurations.

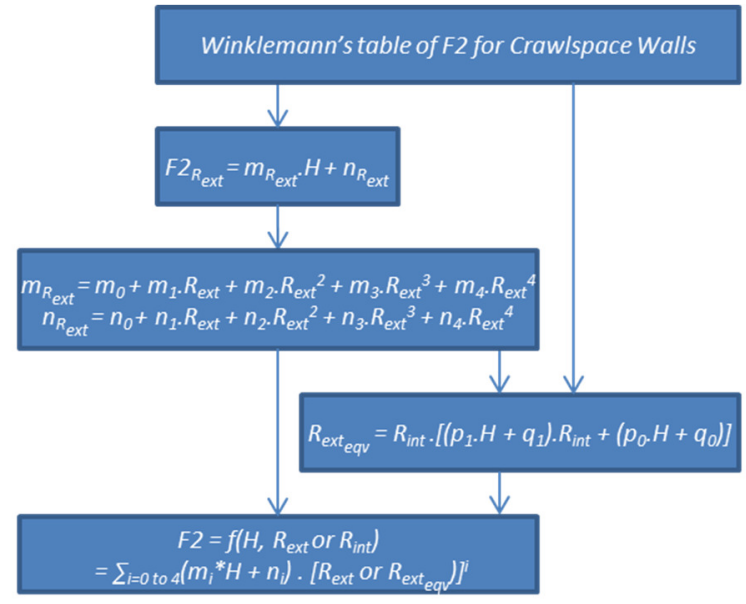

Figure B.2.6. Method for determining $F 2$ for crawlspace wall as a function of crawlspace wall height and Rvalue of exterior and interior insulation.

First, based on Table B.2.7, we derive curve-fit for $F 2$ as a function of crawlspace wall height for each exterior insulation level listed, as shown in Table B.2.8.

Table B.2.8: Curve-fit for $F 2$ for crawlspace wall as a function of crawlspace wall height

\begin{tabular}{|l|l|}
\hline Insulation configuration & \multicolumn{1}{|c|}{$\mathbf{F}_{\mathbf{2}}=\mathbf{m}_{\mathbf{R}_{\text {ins }}} * \mathbf{H}+\mathbf{n}_{\mathbf{R}_{\text {ins }}}$} \\
\hline None & $\left.\mathrm{F} 2_{(\text {Rext }}=0\right)=-0.005 * \mathrm{H}+1.3$ \\
R-5 Exterior & $\left.\mathrm{F} 2_{(\text {Rext }}=5\right)=-0.11 * \mathrm{H}+1.15$ \\
R-10 Exterior & $\left.\mathrm{F} 2_{(\text {Rext }}=10\right)=-0.14 * \mathrm{H}+1.15$ \\
R-15 Exterior & $\left.\mathrm{F} 2_{(\text {Rext }}=15\right)=-0.146 * \mathrm{H}+1.126$ \\
R-20 Exterior & $\left.\mathrm{F} 2_{(\text {Rext }}=20\right)=-0.154 * \mathrm{H}+1.117$ \\
\hline
\end{tabular}


Next, based on Table B.2.8, we derive another set of curve-fits for coefficients $m_{R_{\text {ext }}}$ and $n_{R_{\text {ext }}}$ as a function of exterior insulation R-value $\left(R_{e x t}\right)$, as shown in Table B.2.9.

Table B.2.9: Curve-fit for $m_{\text {Rext }}$ and $n_{\text {Rext }}$ as a function of exterior insulation $\mathbf{R}$-value

\begin{tabular}{|c|c|c|c|}
\hline \multicolumn{2}{|c|}{$\mathbf{m}_{\mathbf{R}_{\text {ext }}}=\sum_{\mathbf{i}=\mathbf{0}}^{\mathbf{4}} \mathbf{m}_{\mathbf{i}} *\left(\frac{\mathbf{R}_{\text {ext }}}{\mathbf{1 0 0}}\right)^{\mathbf{i}}$} & \multicolumn{2}{|c|}{$\mathbf{n}_{\mathbf{R}_{\text {ext }}}=\sum_{\mathrm{i}=\mathbf{0}}^{\mathbf{4}} \mathbf{n}_{\mathbf{i}} *\left(\frac{\mathbf{R}_{\text {ext }}}{\mathbf{1 0 0}}\right)^{\mathbf{i}}$} \\
\hline Coefficient & Derived value & Coefficient & Derived value \\
\hline $\mathrm{m}_{4}$ & 177.92 & $\mathrm{n}_{4}$ & 1421.6 \\
$\mathrm{~m}_{3}$ & -121.99 & $\mathrm{n}_{3}$ & -658.72 \\
$\mathrm{~m}_{2}$ & 30.184 & $\mathrm{n}_{2}$ & 103.93 \\
$\mathrm{~m}_{1}$ & -3.3265 & $\mathrm{n}_{1}$ & -6.7274 \\
$\mathrm{~m}_{0}$ & -0.005 & $\mathrm{n}_{0}$ & 1.3 \\
\hline
\end{tabular}

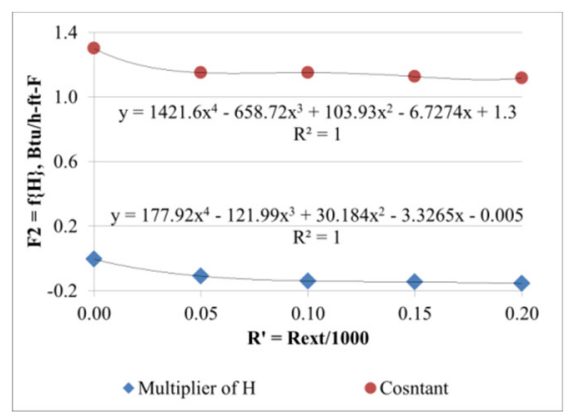

Thus, $F 2$ can be expressed as the following equation:

$$
\mathrm{F}_{2}=\mathrm{m}_{\mathrm{R}_{\mathrm{ext}}} * \mathrm{H}+\mathrm{n}_{\mathrm{R}_{\mathrm{ext}}}=\sum_{\mathrm{i}=0}^{4}\left[\left(\mathrm{~m}_{\mathrm{i}} * \mathrm{H}+\mathrm{n}_{\mathrm{i}}\right) *\left(\frac{\mathrm{R}_{\mathrm{ext}}}{100}\right)^{\mathrm{i}}\right]
$$

Next, to accommodate the value of $F 2$ for a crawlspace with interior insulation, we derive an equivalency relation between interior insulation R-value and exterior insulation R-value (as shown in the following equation), so that a unit $R_{\text {int }}$ will result in the same value of $F 2$ as an equivalent value of $R_{\text {ext }}$.

$$
\mathrm{R}_{\mathrm{ext}_{\mathrm{eqv}}}=\mathrm{R}_{\mathrm{int}} *\left[(0.0036 * \mathrm{H}-0.0454) * \mathrm{R}_{\mathrm{int}}+(-0.032 * \mathrm{H}+1.029)\right]
$$

In this manner, $F 2$ can be expressed as a function of crawlspace wall height and R-value of exterior and interior insulation, where $R_{\text {ext }}$ eqv is calculated from the above equation and coefficients $m_{i}$ and $n_{i}$ are obtained from Table B.2.9.

$$
\mathbf{F} 2=\mathbf{f}\left(\mathbf{H}, \mathbf{R}_{\text {ext }}, \mathbf{R}_{\text {int }}\right)=\sum_{\mathbf{i}=\mathbf{0}}^{4}\left[\left(\mathbf{m}_{\mathbf{i}} * \mathbf{H}+\mathbf{n}_{\mathbf{i}}\right) *\left(\frac{\mathbf{R}_{\text {ext }}+\mathbf{R}_{\text {ext }_{\text {eqv }}}}{\mathbf{1 0 0}}\right)^{\mathbf{i}}\right]
$$

\section{B.3. WIDTH OF WALL SEGMENTS, WINDOWS AND DOORS}

On MulTEA's GUI, to simplify the data input for the size or quantity of vertical surface components (i.e., area of walls and number of windows and doors), the inputs are required by the parent space type but for the entire building, i.e., the totals for all levels. However, for the BDL to model the building as set of zones on different levels, these surface components must be specified by level. This requires backend calculations to convert the GUI inputs for vertical surfaces, which are totals for all levels, into surface segments on different levels, as shown in Table B.3.1. The derivation for converting the GUI inputs for vertical surfaces to level-specific segments is shown further below. 
Table B.3.1. GUI inputs versus modeling parameters for vertical surfaces

\begin{tabular}{|l|l|l|}
\hline \multicolumn{1}{|c|}{ Vertical surface } & \multicolumn{1}{|c|}{ GUI inputs (combining all levels) } & \multicolumn{1}{c|}{ Surface segments for BDL (defined by level) } \\
\hline Exterior Wall & AreaWall[ExtWallID, zone, side] & WdWall[ExtWallID, zone, level, side] \\
Underground Wall & AreaWall[UgWallID, zone, side] & WdWall[UgWallID, zone, level, side] \\
Interior Wall & AreaWall[IntWallID, zone, attachedzone] & WdWall[IntWallID, zone, level, attachedzone] \\
Window & NumWin[windowID, ExtWallID, zone, side] & WdWin[windowID, ExtWallID, zone, level, side] \\
Door & NumDoor[doorID, ExtWallID, zone, side] & WdDoor[doorID, ExtWallID, zone, level, side] \\
\hline
\end{tabular}

\section{Step 1: Determine the existence of vertical surface segments on different levels}

1. Exterior walls, underground walls, windows, and doors, which are orientation-specific surfaces, as characterized by [zone, level, side], would exist on a level if the parent zone exists on that level with exposure to that side.

2. Interior walls, which are not specific to orientation but specific to the attached zone, as characterized by [zone, level, attachedzone], would exist on a level if both the parent zone and the attached zone exist on that level.

\section{Step 2: Define the distribution factor for vertical surface components}

Define the distribution factor (DF) as the ratio of area of a vertical surface component on a level to the total area of that component, as described on the GUI, combing all levels in the building. In lieu of detailed building data, following assumptions are made to determine DFs:

1. The area of exterior walls, underground walls, windows, and doors in a zone is distributed on different levels in the same proportion as the area of that zone on different levels. That is, DF is equal to the ratio of zone area on a level to the total area of that zone in the building.

a. For common spaces, which are modeled as one zone per level, DF for a vertical surface (i.e., exterior wall, underground wall, windows, or doors), i.e., the ratio of vertical surface area on a level in an orientation to the total vertical surface area in that orientation is equal to the ratio of zone area on a level to the total area of that zone in the building:

$$
\mathrm{DF}[\text { zone, level }]=\frac{\text { Area[zone, level }]}{\left.\left.\sum_{\text {level,where Area[zone,level }]>0}(\text { Num[level }] \times \text { Area[zone, level }\right]\right)}
$$

b. For units, which are modeled on a level as exposure-specific (i.e., exposed to one or more orientations) multiple zones of equal area, DF for exterior surfaces will be exposurespecific and can be expressed in terms of exposure-specific number of units. In other words, dividing the numerator and denominator in the previous equation by the area of a unit:

$$
\begin{aligned}
\mathrm{DF}[\text { zone } & =\text { UNIT, level, side }] \\
& =\frac{1}{\left.\left.\sum_{\text {level,where NumUnit[level,side } \left.{ }^{*}\right]>0}(\text { Num[level }] \times \text { NumUnit[level, side }{ }^{*}\right]\right)}
\end{aligned}
$$


where NumUnit[level, side $\left.{ }^{*}\right]=\sum_{8}$ sideconfig NumUnit[level, sideconfig] is number of units on a level having at least one wall facing a specific side. ${ }^{17}$

2. The area of interior walls in a zone is distributed on different levels in the same proportion as the area of the attached zone on different levels.

a. For common spaces, which are modeled as one zone per level, DF for an interior wall, i.e., the ratio of interior wall area on a level attached to a zone to the total interior wall area in the building attached to that zone is equal to the ratio of the area of attached zone on that level to the total area of attached zone in the building:

DF[zone, level, attachedzone]

$$
=\frac{\text { Area[attachedzone, level] }}{\left.\left.\sum_{\text {level,where Area[zone,level }]>0 \text { and Area[attachedzone,level }]>0}(\text { Num[level }] \times \text { Area[attachedzone, level }\right]\right)}
$$

b. For units, which are modeled on a level as multiple zones of equal area, DF for interior walls will be attached zone-specific and the ratio of areas can be expressed in terms of number of units. In other words, dividing the numerator and denominator in the previous equation by the area of a unit:

$\mathrm{DF}[$ zone $=$ UNIT, level, attachedzone $]$

$$
\begin{aligned}
& =\frac{\text { Area[attachedzone, level] }}{\sum_{\text {level,where Area[attachedzone,level] }>0}(\text { Num[level] } \times \text { NumUnit[level] }) \times \text { Area[attachedzone, level] }} \\
& \\
& \begin{array}{l}
\text { where NumUnit[level] } \\
\text { units on a level. }
\end{array}
\end{aligned}
$$

\section{Step 3: Determine the width of the vertical surface segments on different levels as the user input area of the component multiplied by DF}

For exterior wall segments, accounting for:

1. partial exterior wall height on $\mathrm{B} 1$, since the user input exterior wall area will include wall areas on $\mathrm{A} 1, \mathrm{~A} 2, \mathrm{~A} 3$, and the aboveground portion of $\mathrm{B} 1$, and

2. different exterior wall heights on different orientations of B1 (which can occur at a sloping site), since the user input exterior wall area will be based on how much area is exposed on each side,

the ratio of exterior wall area on a level to the total exterior wall area in an orientation for a zone can be expressed as:

$$
\frac{\text { WdWall[ExtWallID, zone, level, side }] \times \mathrm{Ht}[\text { level }]}{\text { AreaWall[ExtWallID, zone, side }]+(\text { WdWall[ExtWallID, zone, B1, side }] \times \text { HtUgWall[B1, side }])}=\mathrm{DF}[\text { zone, level] }
$$

\footnotetext{
${ }^{17}$ Out of 15 possible 'sideconfig' of units (namely, B, R, F, L, BR, BF, BL, FR, FL, RL, BRF, BFL, BRL, FRL, and BRFL), 8 have at least one wall facing a specific 'side'. For example, B, BR, BF, BL, BRF, BFL, BRL, and BRFL have at least one wall facing B.
} 
$\Rightarrow$ WdWall[ExtWallID, zone, level, side]

$=\mathrm{DF}[$ zone, level $]$

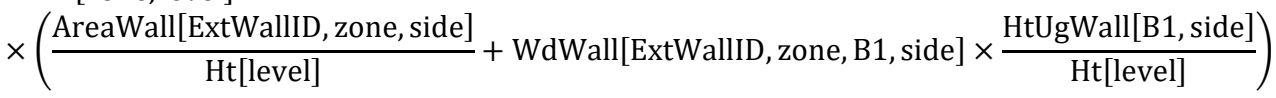

To calculate WdWall[ExtWallID,zone,B1,side] in the above equation, substitute level=B1.

$$
\begin{aligned}
& \Rightarrow \text { WdWall[ExtWallID, zone, B1, side] } \\
& =\mathrm{DF}[\text { zone, } \mathrm{B} 1] \\
& \times\left(\frac{\text { AreaWall[ExtWallID, zone, side] }}{\mathrm{Ht}[\mathrm{B} 1]}+\mathrm{WdWall[ExtWallID} \text {, zone, B1, side] } \times \frac{\mathrm{HtUgWall[B1,} \mathrm{side]}}{\mathrm{Ht}[\mathrm{B} 1]}\right) \\
& \Rightarrow \text { WdWall[ExtWallID, zone, B1, side] } \times\left(1-\mathrm{DF}\left[\text { zone, B1] } \times \frac{\mathrm{HtUgWall[B1,} \mathrm{side]}}{\mathrm{Ht}[\mathrm{B} 1]}\right)\right. \\
& =\mathrm{DF}[\text { zone }, \mathrm{B} 1] \times \frac{\text { AreaWall[ExtWallID, zone, side }]}{\mathrm{Ht}[\mathrm{B} 1]}
\end{aligned}
$$

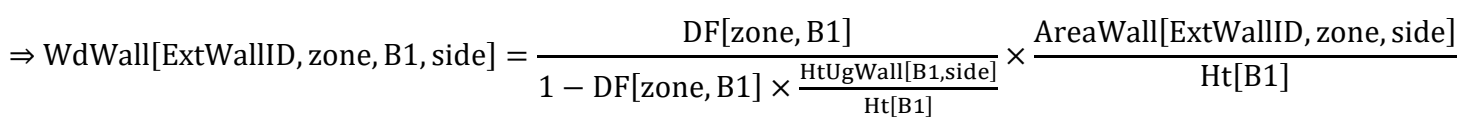

Now, substitute WdWall[ExtWallID,zone,B1,side] in the previous equation.

$$
\begin{aligned}
& \Rightarrow \text { WdWall[ExtWallID, zone, level, side] } \\
& =\mathrm{DF}[\text { zone, level }] \\
& \times\left(\frac{\text { AreaWall[ExtWalliD, zone, side }]}{\mathrm{Ht}[\text { level] }}\right.
\end{aligned}
$$

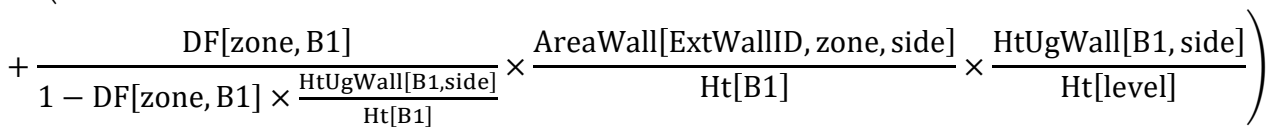

$$
\begin{aligned}
& =\mathrm{DF}[\text { zone, level }] \times \frac{\text { AreaWall[ExtWallID, zone, side }]}{\mathrm{Ht}[\text { level }]} \\
& \times\left(1+\frac{\text { DF[zone, B1] }}{1-\mathrm{DF}\left[\text { zone, B1] } \times \frac{\mathrm{HtUgWall[B1, \text {side } ]}}{\mathrm{Ht}[\mathrm{B} 1]}\right.} \times \frac{\mathrm{HtUgWall[B1, \text {side } ]}}{\mathrm{Ht}[\mathrm{B} 1]}\right) \\
& =\mathrm{DF}[\text { zone, level }] \times \frac{\text { AreaWall[ExtWallID, zone, side }]}{\mathrm{Ht}[\text { level }]} \times \frac{1}{1-\mathrm{DF}\left[\text { zone, B1] } \times \frac{\mathrm{HtUgWall[B1, \text {side } ]}}{\mathrm{Ht}[\mathrm{B} 1]}\right.}
\end{aligned}
$$

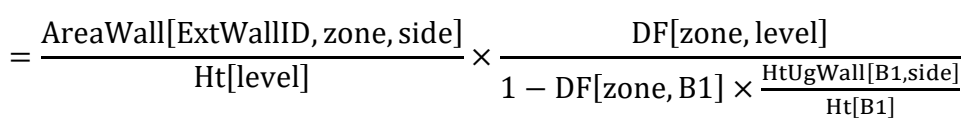

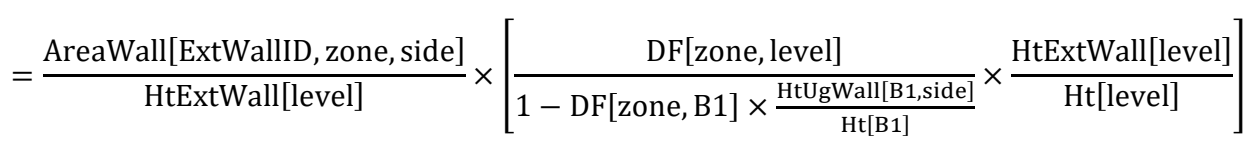

$$
\begin{aligned}
& =\frac{\text { AreaWall[ExtWallID, zone, side }]}{\text { HtExtWall[level] }} \times \mathrm{DF}_{\text {ExtWall }}[\text { zone, level, side }]
\end{aligned}
$$

where 
$\mathrm{DF}_{\text {ExtWall }}[$ zone, level, side $]=\frac{\mathrm{DF}[\text { zone, level }]}{1-\mathrm{DF}[\text { zone, B1 }] \times \frac{\mathrm{HtUgWall[B1, \text {side } ]}}{\mathrm{Ht}[\mathrm{B} 1]}} \times \frac{\mathrm{HtExtWall[level]}}{\mathrm{Ht}[\text { level }]}$

where the second term accounts for partial exterior wall height on B1, and the denominator in the first term accounts for different exterior wall heights on different orientations of $\mathrm{B} 1$ at a sloping site.

For underground wall segments, accounting for:

1. partial underground wall height on B1, since the user input underground wall area will include wall areas on $\mathrm{B} 2$ and the belowground portion of $\mathrm{B} 1$, and

2. different underground wall heights on different orientations of B1 (which can occur at a sloping site), since the user input underground wall area will be based on how much area is groundcoupled on each side,

the ratio of underground wall area on a level to the total underground wall area in an orientation for a zone can be expressed as:

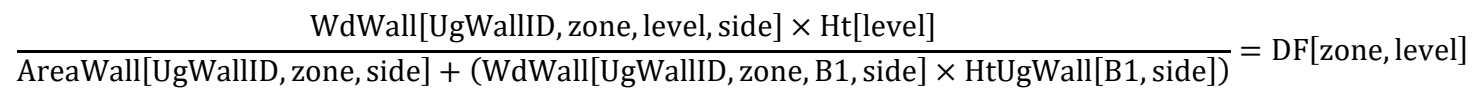

Solving this equation as shown above for the exterior walls,

$$
\text { WdWall[UgWallID, zone, level, side }]=\frac{\text { AreaWall[UgWallID, zone, side }]}{\mathrm{HtUgWall}[\text { level }]} \times \mathrm{DF}_{\mathrm{UgWall}}[\text { zone, level, side }]
$$

where

$$
\mathrm{DF}_{\mathrm{UgWall}}[\text { zone, level, side }]=\frac{\mathrm{DF}[\text { zone, level }]}{1-\mathrm{DF}[\text { zone, } \mathrm{B} 1] \times \frac{\mathrm{HtUgWall}[\mathrm{B} 1, \text { side }]}{\mathrm{Ht}[\mathrm{B} 1]}} \times \frac{\mathrm{HtUgWall[level]}}{\mathrm{Ht}[\text { level }]}
$$

where the second term accounts for partial underground wall height on B1, and the denominator in the first term accounts for different underground wall heights on different orientations of B1 at a sloping site.

For interior wall segments, which are same for aboveground and belowground floors.

$$
\begin{aligned}
& \frac{\text { WdWall[IntWallID, zone, level, attachedzone }] \times \mathrm{Ht}[\text { level] }}{\text { AreaWall[IntWallID, zone, attachedzone] }}=\mathrm{DF}[\text { zone, level, attachedzone }] \\
& \begin{array}{c}
\Rightarrow \text { WdWall[IntWallID, zone, level, attachedzone] } \\
\quad=\frac{\text { AreaWall[IntWallID, zone, attachedzone] }}{\text { HtIntWall[level] }} \times \mathrm{DF}_{\text {IntWall }} \text { [zone, level, attachedzone] }
\end{array}
\end{aligned}
$$

\section{B.3.1. Analytical Check}

$\underline{\text { For WdExtWall in zone }=\text { HALL,COND,UNCD }}$

$\sum_{\text {level }}($ WdWall[ExtWallID, zone, level, side $] \times \mathrm{HtExtWall[level]} \times \mathrm{Num}[$ level $\left.] \times 1\right)$ 


$$
\begin{aligned}
& =\sum_{\text {level }}\left(\frac{\text { AreaWall[ExtWallID, zone, side] }}{\text { HtExtWall[level] }} \times \mathrm{DF}_{\text {ExtWall }}[\text { zone, level, side] } \times \text { HtExtWall[level] } \times \text { Num[level] })\right. \\
& =\text { AreaWall[ExtWallID, zone, side }] \times \sum_{\text {level }}\left(\mathrm{DF}_{\text {ExtWall }}[\text { zone, level, side }] \times \mathrm{Num}[\text { level }]\right) \\
& =\text { AreaWall[ExtWallID, zone, side] } \\
& \times \sum_{\text {level }}\left(\frac{\mathrm{DF}[\text { zone, level }]}{1-\mathrm{DF}\left[\text { zone, B1] } \times \frac{\mathrm{HtUgWall[B1, \text {side } ]}}{\mathrm{Ht}[\mathrm{B} 1]}\right.} \times \frac{\mathrm{HtExtWall[level,} \mathrm{side]}}{\mathrm{Ht}[\text { level }]} \times \mathrm{Num[ \text {level } ]}\right)
\end{aligned}
$$

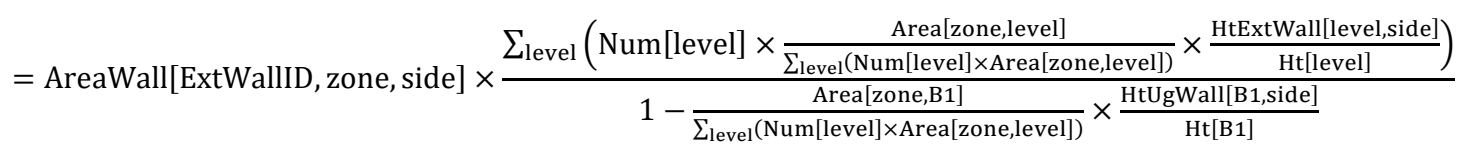

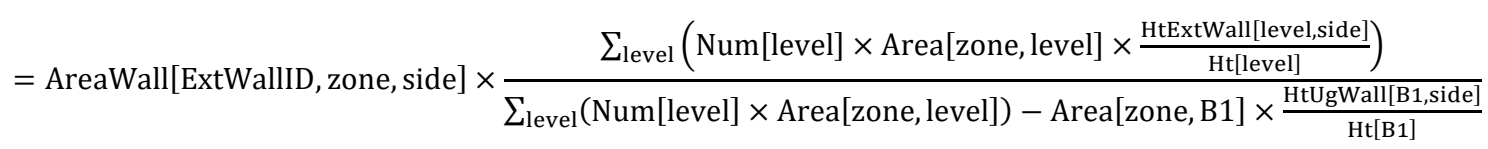

$$
\begin{aligned}
& =\text { AreaWall[ExtWallID, zone, side }] \times
\end{aligned}
$$

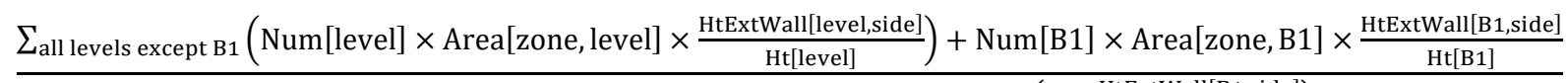

$$
\begin{aligned}
& \sum_{\text {level }}(\text { Num[level] } \times \text { Area[zone, level] })-\text { Area[zone, B1] } \times\left(1-\frac{\text { HtExtWall[B1,side] }}{\mathrm{Ht}[\mathrm{B} 1]}\right) \\
& =\text { AreaWall[ExtWallID, zone, side] } \\
& \times \frac{\sum_{\text {all levels except B1 }}(\text { Num[level] } \times \text { Area[zone, level] } \times 1)+\text { Area[zone, B1] } \times \frac{\text { HtExtWall[B1,side }]}{\mathrm{Ht[B1]}}}{\sum_{\text {level }}(\text { Num[level] } \times \text { Area[zone, level] })-\text { Area[zone, B1] }+ \text { Area[zone, B1] } \times \frac{\text { HtExtWall[B1,side }]}{\mathrm{Ht}[\mathrm{B} 1]}} \\
& =\text { AreaWall[ExtWallID, zone, side] }
\end{aligned}
$$

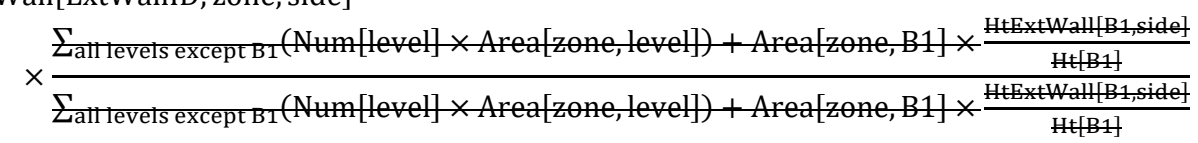

$$
\begin{aligned}
& \text { = AreaWall[ExtWallID, zone, side] }
\end{aligned}
$$

\section{For WdWindow in zone $=$ HALL,COND,UNCD}

$$
\begin{aligned}
& \sum_{\text {level }}\left(\frac{\text { WdWindow[windowID, ExtWallID, zone, level, side }]}{\text { WdWindow[windowID] }} \times \operatorname{Num[level]} \times 1\right) \\
& =\sum_{\text {level }}\left(\frac{\text { WdWindowindowID] }}{\text { NumWin[windowID, ExtWallID, zone, side] } \times \text { DF[zone, level] }} \times \text { Num[level] }\right) \\
& \left.=\text { NumWin[windowID, ExtWallID, zone, side }] \times \sum_{\text {level }}(\text { DF[zone, level }] \times \text { Num[level] }\right) \\
& =\text { NumWin[windowID, ExtWallID, zone, side }] \times \sum_{\text {level }}\left(\frac{\text { Area[zone, level] }}{\left.\left.\sum_{\text {level }}(\text { Num[level }] \times \text { Area[zone, level }\right]\right)} \times \text { Num[level] }\right) \\
& =\text { NumWin[windowID, ExtWallID, zone, side] } \times \frac{\sum_{\text {level }}(\text { Area[zone,level] } \times \text { Num[level] })}{\sum_{\text {level }}(\text { Num[level] } \times \text { Area[zone,level] })}
\end{aligned}
$$


$=$ NumWin[windowID, ExtWallID, zone, side]

\section{For WdExtWall in zone $=$ UNIT}

$$
\begin{aligned}
& \left.\left.\left.\sum_{\text {level }}(\text { WdWall[ExtWallID, zone, level, side }] \times \text { HtExtWall[level] } \times \text { Num[level }\right] \times \text { NumUnit[level, side }{ }^{*}\right]\right) \\
& =\sum_{\text {level }}\left(\frac{\text { AreaWall[ExtWallID, zone, side] }}{\text { HtExtWall[level] }} \times \mathrm{DF}_{\text {ExtWall }}[\text { zone, level, side] } \times \text { HtExtWall[level] } \times \text { Num[level] }\right. \\
& \left.\times \text { NumUnit[level, side }{ }^{*}\right] \text { ) } \\
& \left.=\text { AreaWall[ExtWallID, zone, side }] \times \sum_{\text {level }}\left(\mathrm{DF}_{\text {ExtWall }}[\text { zone, level, side }] \times \text { Num[level] } \times \text { NumUnit[level, side }{ }^{*}\right]\right) \\
& =\text { AreaWall[ExtWallID, zone, side] } \\
& \times \sum_{\text {level }}\left(\frac{\text { HtExtWall[level, side] }}{\left.\sum_{\text {level }}\left(\text { Num[level] } \times \text { NumUnit[level, side }{ }^{*}\right] \times \text { HtExtWall[level, side] }\right)} \times\right. \text { Num[level] } \\
& \times \text { NumUnit[level, side* }{ }^{*} \text { ) } \\
& =\text { AreaWall[ExtWallID, zone, side] } \times \frac{\left.\sum_{\text {level }}\left(\text { HtExtWall[level, side] } \times \text { Num[level] } \times \text { NumUnit[level, side }{ }^{*}\right]\right)}{\sum_{\text {level }}\left(\text { Num[level] } \times \text { NumUnit[level, side }{ }^{*}\right] \times \text { HtExtWall[level, side]) }} \\
& =\text { AreaWall[ExtWallID, zone, side] }
\end{aligned}
$$

\section{$\underline{\text { For WdWindow in zone }=\mathrm{UNIT}}$}

$$
\begin{aligned}
& \left.\sum_{\text {level }}\left(\frac{\text { WdWindow[windowID, ExtWallID, zone, level, side }]}{\text { WdWindow[windowID] }} \times \text { Num[level] } \times \text { NumUnit[level, side }{ }^{*}\right]\right)
\end{aligned}
$$

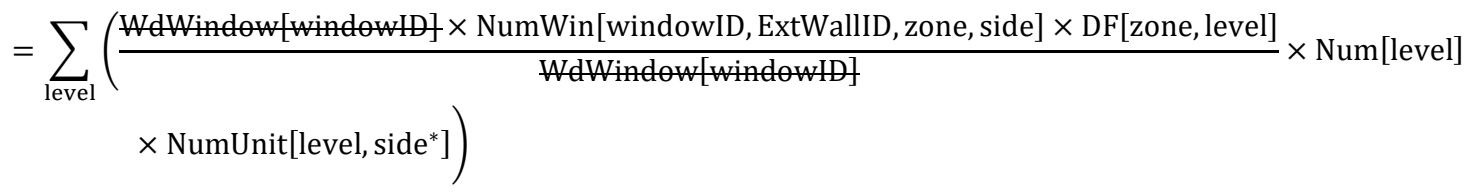

$$
\begin{aligned}
& \left.\left.\left.=\text { NumWin[windowID, ExtWallID, zone, side }] \times \sum_{\text {level }}(\text { DF[zone, level }] \times \text { Num[level }\right] \times \text { NumUnit[level, side* }\right]\right) \\
& =\text { NumWin[windowID, ExtWallID, zone, side] } \\
& \left.\times \sum_{\text {level }}\left(\frac{1}{\left.\left.\sum_{\text {level }}(\text { Num [level }] \times \text { NumUnit[level, side }{ }^{*}\right]\right)} \times \text { Num[level] } \times \text { NumUnit[level, side }{ }^{*}\right]\right) \\
& =\text { NumWin[windowID, ExtWallID, zone, side] } \times \frac{\left.\sum_{\text {level }}\left(\text { Num[level] } \times \text { NumUnit[level, side }{ }^{*}\right]\right)}{\left.\sum_{\text {level }}(\text { Num[level] } \times \text { NumUnit[level,side } *]\right)} \\
& =\text { NumWin[windowID, ExtWallID, zone, side] }
\end{aligned}
$$

\section{B.4. WINDOW U-VALUE AND SHGC}

Uvalue $_{\text {window }}=$ Uvalue $_{\text {glass }} *\left(1-\frac{\text { Area }_{\text {frame }}}{\text { Area }_{\text {window }}}\right)+$ Uvalue $_{\text {frame }} *\left(\frac{\text { Area }_{\text {frame }}}{\text { Area }_{\text {window }}}\right)$ 
$\mathrm{SHGC}_{\text {window }}=\mathrm{SHGC}_{\text {glass }} *\left(1-\frac{\text { Area }_{\text {frame }}}{\text { Area }_{\text {window }}}\right)$

where

Uvalue $_{\text {glass }}$ and $\mathrm{SHGC}_{\text {glass }}$ are obtained from Table B.4.1.

Area $_{\text {window }}=15 \mathrm{sqft}$, assuming $3 \mathrm{ft} \times 5 \mathrm{ft}$ window

Area $_{\text {frame }}=$ Area $_{\text {window }}-\left(3-\frac{2 * \text { Width }_{\text {frame }}}{12}\right) *\left(5-\frac{2 * \text { Width }_{\text {frame }}}{12}\right)$

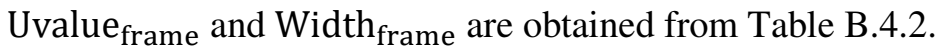

Table B.4.1. Window glass U-value and SHGC (Winkelmann et al. 1993, Window Library, p.126)

\begin{tabular}{|c|c|c|c|c|}
\hline Glass assembly & Glass type & $\begin{array}{c}\text { Reference DOE-2 glass } \\
\text { type code }\end{array}$ & Uvalue $_{\text {glass }}$ & SHGC $_{\text {glass }}$ \\
\hline \multirow[t]{4}{*}{ Single Pane } & Clear & 1001 & 1.09 & 0.81 \\
\hline & Tinted & 1201 & 1.09 & 0.61 \\
\hline & Low-e, Low Solar & 1602 & 0.75 & 0.72 \\
\hline & Low-e High Solar & 1602 & 0.75 & 0.72 \\
\hline \multirow[t]{4}{*}{ Double Pane } & Clear & 2001 & 0.49 & 0.76 \\
\hline & Tinted & 2201 & 0.49 & 0.62 \\
\hline & Low-e, Low Solar & 2631 & 0.32 & 0.6 \\
\hline & Low-e High Solar & 2611 & 0.35 & 0.73 \\
\hline \multirow[t]{4}{*}{ Double Pane, Gas Fill } & Clear & 2002 & 0.46 & 0.76 \\
\hline & Tinted & 2202 & 0.46 & 0.62 \\
\hline & Low-e, Low Solar & 2632 & 0.26 & 0.59 \\
\hline & Low-e High Solar & 2612 & 0.30 & 0.74 \\
\hline \multirow[t]{4}{*}{ Triple Pane } & Clear & 3002 & 0.32 & 0.68 \\
\hline & Tinted & arbitrary & 0.32 & 0.52 \\
\hline & Low-e, Low Solar & 3622 & 0.17 & 0.47 \\
\hline & Low-e High Solar & 3602 & 0.23 & 0.58 \\
\hline \multirow[t]{4}{*}{ Triple Pane, Gas Fill } & Clear & 3003 & 0.29 & 0.68 \\
\hline & Tinted & arbitrary & 0.29 & 0.52 \\
\hline & Low-e, Low Solar & 3623 & 0.14 & 0.47 \\
\hline & Low-e High Solar & 3603 & 0.19 & 0.58 \\
\hline
\end{tabular}

Table B.4.2. Window frame width and U-value (Winkelmann et al. 1993, p. 13)

\begin{tabular}{|l|c|c|}
\hline \multicolumn{1}{|c|}{ Frame material } & Uvalue $_{\text {frame }}$ & Width $_{\text {frame }}$ (inch) \\
\hline Metal Frame & 1.90 & 2.25 \\
Metal Frame w/ Thermal Break & 1.00 & 2.25 \\
Wood Frame & 0.40 & 2.75 \\
Vinyl Frame & 0.30 & 2.75 \\
\hline
\end{tabular}




\section{B.5. SLOPE AND COEFFICIENTS FOR R-VALUE MODIFIER TO ACCOUNT FOR STORM DOORS AND WINDOWS}

Table B.5.1. Window R-value without and with a storm window (Gettings 2003, pp. 2.2 - 3)

\begin{tabular}{|l|c|c|c|}
\hline \multirow{2}{*}{ Window type } & \multicolumn{2}{|c|}{ Window R-Value (includes both interior and exterior film resistances) } \\
\cline { 2 - 4 } & No storm & Metal storm & Wood or vinyl storm \\
\hline Single Pane, Wood Vinyl Frame & 1.19 & 1.55 & 2.08 \\
Double Pane, Wood Vinyl Frame & 1.89 & 2.25 & 2.78 \\
Single Pane, Improved Metal Frame & 0.97 & 1.33 & 1.86 \\
Double Pane, Improved Metal Frame & 1.45 & 1.81 & 2.34 \\
Single Pane, Metal Frame & 0.8 & 1.16 & 1.69 \\
Double Pane, Metal Frame & 1.09 & 1.45 & 1.98 \\
\hline
\end{tabular}

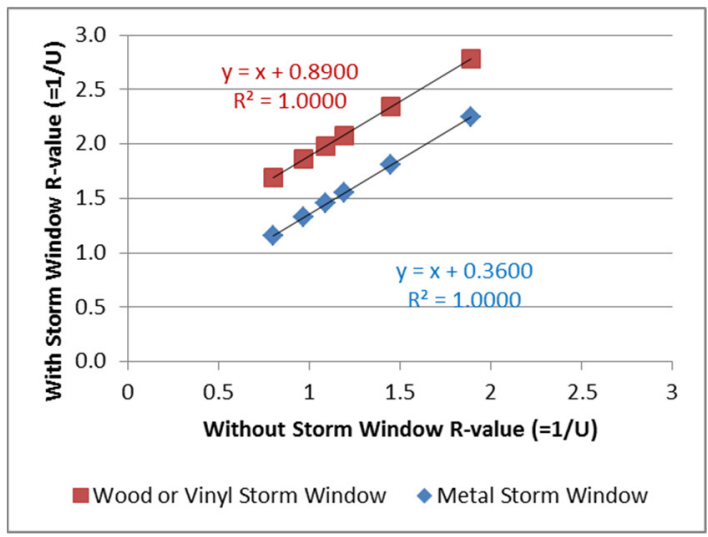

Figure B.5.1. Curve-fit for window R-value with a storm window.

Table B.5.2. Window transmittance without and with a storm window (Window transmittance from Gettings 2003, p. 2.2 - 3)

\begin{tabular}{|c|c|c|c|}
\hline \multirow{2}{*}{ Glazing type } & \multicolumn{2}{|c|}{ Window transmittance } & \multirow{2}{*}{$\begin{array}{c}\text { Calculated } \\
\text { SHGC multiplier }\end{array}$} \\
\hline & \begin{tabular}{|l|} 
Without storm \\
\end{tabular} & With storm & \\
\hline & 0.884 & & 0.895 \\
\hline Double Pane & 0.789 & 0.714 & 0.905 \\
\hline
\end{tabular}

Table B.5.3. Door U-value without and with a storm door (door U-value from ASHRAE 2001, Table 6, p. 25.13)

\begin{tabular}{|l|c|c|c|c|c|c|c|c|}
\hline \multicolumn{1}{|c|}{ Door type } & \multirow{2}{*}{$\begin{array}{c}\text { Nominal } \\
\text { thickness } \\
\text { (in.) }\end{array}$} & \multirow{2}{*}{$\begin{array}{c}\text { Glass } \\
\text { type }\end{array}$} & & \multicolumn{3}{|c|}{ U-value } & \multicolumn{3}{c|}{ Calculated R-value (=1/U-value) } \\
\cline { 5 - 9 } & & No storm & Wood storm & Metal storm & No storm & $\begin{array}{c}\text { Wood } \\
\text { storm }\end{array}$ & $\begin{array}{c}\text { Metal } \\
\text { storm }\end{array}$ \\
\hline Wood, Hollow Core & $1-3 / 8$ & None & 0.47 & 0.3 & 0.32 & 2.13 & 3.33 & 3.13 \\
Wood, Hollow Core & $1-3 / 4$ & None & 0.46 & 0.29 & 0.32 & 2.17 & 3.45 & 3.13 \\
Wood, Solid Core & $1-3 / 8$ & None & 0.39 & 0.26 & 0.28 & 2.56 & 3.85 & 3.57 \\
Wood, Solid Core & $2-1 / 4$ & None & 0.27 & 0.2 & 0.21 & 3.70 & 5.00 & 4.76 \\
Wood, 7/16" Panel & 1.375 & None & 0.57 & 0.33 & 0.37 & 1.75 & 3.03 & 2.70 \\
Wood, 7/16" Panel & $1-3 / 4$ & None & 0.54 & 0.32 & 0.36 & 1.85 & 3.13 & 2.78 \\
Wood, 1-1/8" Panel & $1-3 / 4$ & None & 0.39 & 0.26 & 0.28 & 2.56 & 3.85 & 3.57 \\
\hline
\end{tabular}




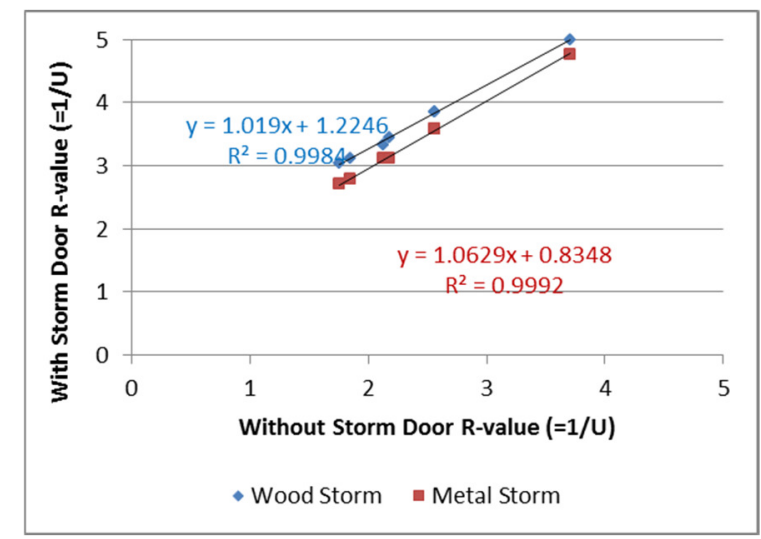

Figure B.5.2. Curve-fit for door R-value with a storm door.

\section{B.6. EQUIVALENT RE AND EF FOR WATER HEATER TANK INSULATION AND PIPE INSULATION}

Given:

EF, Energy Factor

RE, Recovery Efficiency

$\mathrm{P}_{\text {on }}$, Capacity

TankSize,

$\mathrm{R}_{\text {tank }}$, Original tank insulation

$\mathrm{R}_{\text {added }}$, $\mathrm{R}$ value of tank wrap

$t_{\text {pipeinsulation }}$, Thickness of pipe insulation

$\mathrm{L}_{\text {pipeinsulation }}$, Length of pipe insulated

Assume that $\mathrm{R}_{\text {added: }}$

- $\quad$ reduces tank conductance from $U_{\text {tank }}\left(=\frac{1}{R_{\text {tank }}+0.66}\right)$ to $U^{\prime}{ }_{\text {tank }}\left(=\frac{1}{R_{\text {tank }}+R_{\text {added }}+0.66}\right)$

Assume that tank wrap and pipe insulation

- reduce standby energy loss coefficient from $U A$ to $U^{\prime} A$,

- increase energy factor from $\mathrm{EF}$ to $\mathrm{EF}^{\prime}$, and

- increase recovery efficiency from RE to $\mathrm{RE}^{\prime}$

Consider:

Standby energy loss

$$
\begin{aligned}
& =\text { energy loss from tank surface }+ \text { pipe energy losses }+ \text { other energy losses } \\
& =\frac{\text { heat loss from tank surface }}{\text { energy factor }}+\text { pipe energy losses }+ \text { other energy losses }
\end{aligned}
$$

That is:

$$
\mathrm{UA} \Delta \mathrm{T}=\frac{\mathrm{U}_{\operatorname{tank}} \mathrm{A} \Delta \mathrm{T}}{\mathrm{EF}}+\mathrm{Q}_{\text {pipe }}+\text { other losses }
$$




$$
\begin{gathered}
\mathrm{U}^{\prime} \mathrm{A} \Delta \mathrm{T}=\frac{\mathrm{U}_{\text {tank }}^{\prime} \mathrm{A} \Delta \mathrm{T}}{\mathrm{EF}^{\prime}}+\mathrm{Q}_{\text {pipe }}^{\prime}+\text { other losses } \\
\text { where } \Delta \mathrm{T}=\left(\mathrm{T}_{\text {tank }}-\mathrm{T}_{\mathrm{amb}}\right)
\end{gathered}
$$

Subtracting [2]from [1],

$$
\begin{aligned}
& \left(\mathrm{U}-\mathrm{U}^{\prime}\right) \mathrm{A} \Delta \mathrm{T}=\left(\frac{\mathrm{U}_{\text {tank }}}{\mathrm{EF}}-\frac{\mathrm{U}_{\text {tank }}^{\prime}}{E F^{\prime}}\right) \mathrm{A} \Delta \mathrm{T}+\Delta \mathrm{Q}_{\text {pipe }} \\
& \Rightarrow\left(\mathrm{U}-\mathrm{U}^{\prime}\right) \mathrm{A} \Delta \mathrm{T} \approx \frac{\left(\mathrm{U}_{\text {tank }}-\mathrm{U}_{\text {tank }}^{\prime}\right)}{\mathrm{EF}} \mathrm{A} \Delta \mathrm{T}+\Delta \mathrm{Q}_{\text {pipe }} \\
& \Rightarrow \mathrm{U}^{\prime} \approx \mathrm{U}-\frac{\left(\mathrm{U}_{\text {tank }}-\mathrm{U}_{\text {tank }}^{\prime}\right)}{\mathrm{EF}}-\frac{\Delta \mathrm{Q}_{\text {pipe }}}{\mathrm{A} \Delta \mathrm{T}}
\end{aligned}
$$

From WHAM model for hot water energy use,

$$
\begin{aligned}
& Q_{\text {in }}=\frac{V \rho C_{p}\left(T_{\text {tank }}-T_{\text {in }}\right)}{R E}\left[1-\frac{U A \Delta T}{P_{\text {on }}}\right]+24 U A \Delta T \\
& Q^{\prime}{ }_{\text {in }}=\frac{V \rho C_{p}\left(T_{\text {tank }}-T_{\text {in }}\right)}{R E^{\prime}}\left[1-\frac{U^{\prime} A \Delta T}{P_{\text {on }}}\right]+24 \mathrm{U}^{\prime} A \Delta T
\end{aligned}
$$

NOTE: The tank wrap and/or pipe insulation reduces losses during $24 \mathrm{~h}$ (draw as well as no draw) periods, and energy use to heat water (excluding losses) during hot water draw remain unaffected. That is, the first term in equations [4] and [5] are equal. That is,

$$
\begin{aligned}
& \frac{V_{\rho} C_{p}\left(T_{\text {tank }}-T_{\text {in }}\right)}{R E}\left[1-\frac{U A \Delta T}{P_{o n}}\right]=\frac{V_{\rho} C_{p}\left(T_{\text {tank }}-T_{\text {in }}\right)}{R E^{\prime}}\left[1-\frac{U^{\prime} A \Delta T}{P_{o n}}\right] \\
& \Rightarrow R E^{\prime}=R E \cdot\left[\frac{1-\frac{U^{\prime} A \Delta T}{P_{\text {on }}}}{1-\frac{U A \Delta T}{P_{\text {on }}}}\right]=R E \cdot\left[1+\frac{\left(U-U^{\prime}\right) \frac{A \Delta T}{P_{\text {on }}}}{1-\frac{U A \Delta T}{P_{\text {on }}}}\right]=R E \cdot\left[1+\frac{\left(U-U^{\prime}\right) A \Delta T}{P_{\text {on }}-U A \Delta T}\right]
\end{aligned}
$$

Substituting $\left(U-U^{\prime}\right) A \Delta T$ from [3a]:

$$
\mathbf{R E}^{\prime} \approx \mathbf{R E} \cdot\left[\mathbf{1}+\frac{\Delta \mathbf{Q}_{\text {wrap }}+\Delta \mathbf{Q}_{\text {pipe }}}{\mathbf{P}_{\text {on }}-\mathbf{U A} \Delta \mathbf{T}}\right]
$$

From WHAM model for standby energy loss coefficient,

$$
\begin{aligned}
& \mathrm{U}^{\prime} \mathrm{A}=\frac{\frac{1}{\mathrm{EF}^{\prime}}-\frac{1}{\mathrm{RE}^{\prime}}}{67.5\left(\frac{24}{41094}-\frac{1}{\mathrm{RE}^{\prime} \cdot \mathrm{P}_{\mathrm{on}}}\right)} \\
& \Rightarrow \mathrm{EF}^{\prime}=\frac{1}{\frac{1}{\mathrm{RE}^{\prime}}+67.5 \mathrm{U}^{\prime} \mathrm{A}\left(\frac{24}{41094}-\frac{1}{\mathrm{RE}^{\prime} \cdot \mathrm{P}_{\mathrm{on}}}\right)}
\end{aligned}
$$


Energy savings from water heater tank Insulation and pipe insulation measures can be calculated by subtracting term [5] from term [4] and considering that the first term in [4] and [5] are equal. That is,

Energy savings $=Q_{\text {in }}-Q_{\text {in }}^{\prime}=24\left(U-U^{\prime}\right) A \Delta T$

$$
\approx 24\left[\frac{\left(\mathbf{U}_{\text {tank }}-\mathbf{U}_{\text {tank }}^{\prime}\right) \mathbf{A} \Delta \mathbf{T}}{\mathbf{E F}}+\Delta \mathbf{Q}_{\text {pipe }}\right](\text { Btu/day })
$$

\section{B.7. INFILTRATION ACH AS A FUNCTION OF CFM50}

From the power law relationship (ASHRAE 2013a, Chapter 16, Eq. (40)),

$\mathrm{Q}=\mathrm{c}(\Delta \mathrm{p})^{\mathrm{n}}$

where

$$
\begin{aligned}
& \mathrm{Q}=\text { airflow through opening, } \mathrm{cfm} \\
& \mathrm{c}=\text { flow coefficient, } \mathrm{cfm} /(\mathrm{in} . \text { of water })^{\mathrm{n}} \\
& \mathrm{n}=\text { pressure exponent, } 0.65
\end{aligned}
$$

At reference pressure $\Delta \mathrm{p}_{\mathrm{r}}=0.016$ in. of water (or $4 \mathrm{~Pa}$ ),

$$
\mathrm{Q}_{\mathrm{r}\left(\Delta \mathrm{p}_{\mathrm{r}}=4 \mathrm{~Pa}\right)}=\mathrm{c}(0.016)^{0.65}
$$

At pressure $\Delta \mathrm{p}=0.2$ in. of water (or $50 \mathrm{~Pa}$ ),

$$
\begin{aligned}
& Q_{50 \mathrm{~Pa}}=c(0.2)^{0.65} \\
& \Rightarrow \mathrm{Q}_{\mathrm{r}\left(\Delta \mathrm{p}_{\mathrm{r}}=4 \mathrm{~Pa}\right)}=Q_{50 \mathrm{~Pa}}\left(\frac{0.016}{0.2}\right)^{0.65}=0.194 \mathrm{Q}_{50 \mathrm{~Pa}}
\end{aligned}
$$

From ASHRAE (2013a), Chapter 16, Eq. (41),

$$
A_{L}=0.186 Q_{r} \frac{\sqrt{\rho / 2 \Delta p_{r}}}{C_{D}}
$$

where

$$
\begin{aligned}
& \mathrm{A}_{\mathrm{L}}=\text { equivalent or effective leakage area, } \mathrm{in}^{2} \\
& \mathrm{Q}_{\mathrm{r}}=\text { predicted airflow rate at } \Delta \mathrm{p}_{\mathrm{r}}, 0.194 \mathrm{Q}_{50 \mathrm{~Pa}} \mathrm{cfm} \\
& \rho=\text { air density, } 0.075 \mathrm{lb} / \mathrm{b}_{\mathrm{m}} / \mathrm{ft}^{2} \\
\Delta \mathrm{p}_{\mathrm{r}}=\text { reference pressure difference, } 0.016 \text { in. of water } & \\
& \mathrm{C}_{\mathrm{D}}=\text { dischange coefficient, } 1 \\
& 0.186=\text { unit conversion factor } \\
\Rightarrow \mathrm{A}_{\mathrm{L}}= & 0.186 * 0.194 * \mathrm{Q}_{50 \mathrm{~Pa}} * \frac{\sqrt{0.075 / 2 \times 0.016}}{1}=0.055 * \mathrm{Q}_{50 \mathrm{~Pa}}
\end{aligned}
$$

From ASHRAE Standard 62.2-2013 (ASHRAE 2013b), Eq. (4.4),

$$
\mathrm{NL}=1000 \frac{\mathrm{ELA}}{\mathrm{A}_{\text {floor }}}\left[\frac{\mathrm{H}}{\mathrm{H}_{\mathrm{r}}}\right]^{\mathrm{z}},
$$


where

$\mathrm{NL}=$ normalized leakge

$\mathrm{ELA}=$ effective leakage area, $\mathrm{ft}^{2}$

$\mathrm{A}_{\text {floor }}=$ floor area of residence, $\mathrm{ft}^{2}$

$\mathrm{H}=$ vertical distance between the lowest and highest above grade points within the pressure boundary, $\mathrm{ft}$

$\mathrm{H}_{\mathrm{r}}=$ reference height, $8.2 \mathrm{ft}$

$\mathrm{z}=0.4$

Substituting ELA $=\frac{\mathrm{A}_{\mathrm{L}}}{144}=\frac{0.055 * \mathrm{Q}_{50 \mathrm{~Pa}}}{144} \mathrm{ft}^{2}$ and other values,

$$
\mathrm{NL}=1000 \frac{\frac{0.055 * \mathrm{Q}_{50 \mathrm{~Pa}}}{144}}{\mathrm{~A}_{\text {floor }}}\left[\frac{\mathrm{H}}{8.2}\right]^{0.4}
$$

From ASHRAE Standard 62.2-2013 (ASHRAE 2013b), Eq. (4.4a),

$$
\mathrm{Q}_{\text {inf }}=\frac{\mathrm{NL} * \mathrm{wsf} * \mathrm{~A}_{\text {floor }}}{7.3}
$$

where

$$
\begin{aligned}
& \mathrm{Q}_{\text {inf }}=\text { effective annual average infiltration rate, } \mathrm{cfm} \\
& \mathrm{NL}=\text { normalized leakge } \\
& \mathrm{wsf}=\text { weather and shielding factor, from Normative Appendix B of ASHRAE } \\
& \quad \text { Standard 62.2-2013 (ASHRAE 2013b) } \\
& \mathrm{A}_{\text {floor }}=\text { floor area of residence, } \mathrm{ft}^{2}
\end{aligned}
$$

Here $\mathrm{NL} \times$ wsf represents $\mathrm{ACH}$ or infiltration air changes per hour.

This is consistent with ASHRAE Standard 136-1993 (R2006) (ASHRAE 2006), Section 4.2:

$$
\begin{aligned}
& A_{I}=L_{n} \times W \\
& \text { where } \\
& \qquad \begin{array}{l}
A_{I}=\text { Infiltration in air changes per hour } \\
L_{n}=\text { normalized leakage } \\
W=\text { weather factor }
\end{array}
\end{aligned}
$$

Thus,

$$
\text { ACH }=\text { NL } \cdot \text { wSf }=1000 \frac{\frac{0.055}{144} Q_{50 P a}}{A_{\text {floor }}}\left[\frac{H}{8.2}\right]^{0.4} w s f
$$

